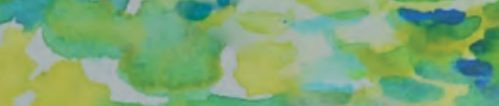

$4 x=0$

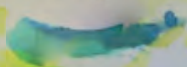

$+$

\title{
Geographies of fear
}

Exploring the transboundary nature of conservation and conflict among the Democratic Republic of the Congo, Rwanda and Uganda

$\because \because \frac{0+\infty}{2}+\infty 0^{+\infty}$

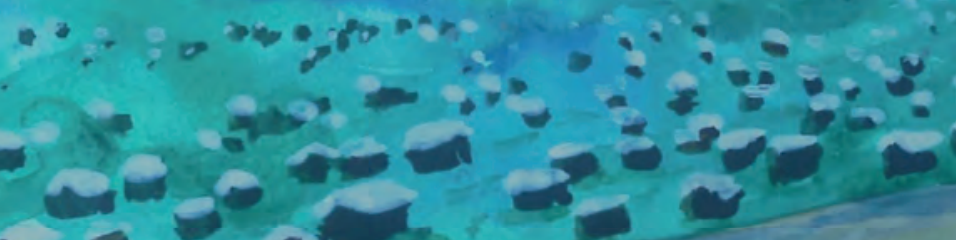

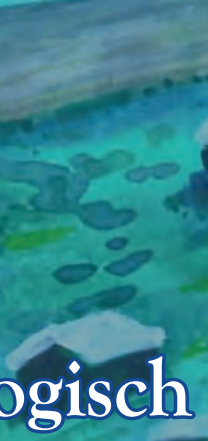

Lisa Trogisch 


\section{Propositions}

1. The intended transboundary protected area straddling the Democratic Republic of the Congo, Rwanda and Uganda is perceived as a threat to national integrity, sovereignty and economic interests.

(this thesis)

2. Nature conservation in the Virunga borderland shared among the Democratic Republic of the Congo, Rwanda and Uganda is shaped by emotio-spatial memories of warfare. (this thesis)

3. Greater attention to emotions as a relatively neglected motive for human behaviour can advance research across a range of social science fields.

4. The commercialization of security is an important aspect of tourism in post-conflict settings.

5. Empathy reveals people's needs and means of finding pathways for survival.

6. Critical awareness in and on white Western fieldwork in Africa contributes to dismantle colonial legacies in academic knowledge production.

7. Serendipity serves research and life throughout all peaks and troughs.

Propositions belonging to the thesis, entitled:

Geographies of fear - exploring the transboundary nature of conservation and conflict among the Democratic Republic of the Congo, Rwanda and Uganda

Lisa Trogisch

Wageningen, 4 October 2021 



\section{Geographies of fear}

Exploring the transboundary nature of conservation and conflict

among

the Democratic Republic of the Congo, Rwanda and Uganda

Lisa Trogisch 


\section{Thesis committee}

\section{Promotor}

Prof. Dr Bram Büscher

Professor of Sociology of Development and Change

Wageningen University \& Research

\section{Co-promotors}

Dr Robert Fletcher

Associate Professor, Sociology of Development and Change

Wageningen University \& Research

Dr Lotje de Vries

Assistant Professor, Sociology of Development and Change

Wageningen University \& Research

\section{Committee members}

Associate Professor Dr Wilber Manyisa Ahebwa, University of Kampala, Uganda

Professor Dr An Ansoms, University of Louvain, Belgium

Associate Professor Dr Elizabeth Lunstrum, Boise State University, United States of America

Professor Dr Rene van der Duim, Wageningen University \& Research, the Netherlands

This research was conducted under the auspices of the Wageningen School of Social Sciences. 


\section{Geographies of fear}

Exploring the transboundary nature of conservation and conflict

among

the Democratic Republic of the Congo, Rwanda and Uganda

\section{Lisa Trogisch}

Thesis

submitted in fulfilment of the requirements for the degree of doctor at Wageningen University by the authority of the Rector Magnificus, Prof. Dr A.P.J. Mol, in the presence of the

Thesis Committee appointed by the Academic Board to be defended in public on Monday, 4 October 2021 at 4 p.m. in the Aula. 


\section{Lisa Trogisch}

Geographies of fear - exploring the transboundary nature of conservation and conflict among the Democratic Republic of the Congo, Rwanda and Uganda

180 pages.

PhD thesis, Wageningen University, Wageningen, the Netherlands (2021)

With references, with summaries in English

ISBN: $\quad 978-94-6395-967-4$

DOI: $\quad$ https://doi.org/10.18174/553302 


\section{CONTENTS}

List of figures and pictures

Acknowledgements II

$\begin{array}{lll}\text { Chapter I Introduction } & 1\end{array}$

Marking the territory 3

Preceding explorations $\quad 5$

Research objective and questions $\quad 8$

Uncharted territories $\quad 11$

Theoretical framework $\quad 12$

Relevance for science and society 20

Methodology 21

Outline of the chapters $\quad 30$

Chapter II Fortress tourism - exploring dynamics of tourism, security 35 and peace around the intended transboundary Virunga Conservation Area

Introduction $\quad 37$

Peace as security through the militarisation for tourism? 40

Historical context of the Virungas - which 'conflict' should 43 be brought to peace?

Discussion of selling security in conservation and tourism $\quad 44$

Local perceptions of 'peace' through tourism $\quad 54$

Conclusion $\quad 56$

Chapter III Geographies of fear - the everyday (geo)politics of 'green' 61 violence and militarization in the intended transboundary Virunga Conservation Area

Introduction 63

Grounding on fear $\quad 65$

$\begin{array}{ll}\text { The history of an idea } & 67\end{array}$

A historically constructed 'geography of fear' 70

'Green' militarization against 'the Other' $\quad 74$

An insight from 'the Other' side $\quad 78$

A scapegoat to justify 'green' violence $\quad 79$ 
Conclusion $\quad 82$

Chapter IV Navigating fearscapes - women's coping strategies with(in) 85

the conservation-conflict nexus

Introduction $\quad 87$

Interdisciplinary encounters: fear, 'scapes' and coping $\quad 89$

A recent history of the Virunga area $\quad 91$

Methods of visual ethnography $\quad 93$

Coping with(in) the fearscape $\quad 94$

Pauline's strategy: bartering $\quad 95$

Mama Sifa's strategy: performativity 100

$\begin{array}{ll}\text { Conclusion } & 111\end{array}$

$\begin{array}{lll}\text { Chapter V Towards an emotional ethnography - engaging with } & 109\end{array}$

reciprocal fears in violent environments

Introduction $\quad 111$

$\begin{array}{ll}\text { Violence and fear in the conservation-conflict context - } & 114\end{array}$

towards an 'emotional ethnography'

Empathizing fears

Reciprocal fears 120

Hidden, systemic fears 122

Spatial fears 124

Efficacious fears 126

$\begin{array}{ll}\text { Conclusion } & 129\end{array}$

$\begin{array}{lll}\text { Chapter VI Discussion and conclusion } & 131\end{array}$

Introduction 133

Emotional, geographical, political - ecology 135

Towards an emotional ethnography 139

Of social, political and ecological relevance $\quad 140$

On fears of whiteness 143

Bibliography $\quad 146$

$\begin{array}{ll}\text { Summary } & 165\end{array}$

$\begin{array}{ll}\text { Funding statement } & 168\end{array}$ 


\section{LIST OF FIGURES \& PICTURES}

Cover The Virunga volcanoes viewed from the Democratic Republic L. Trogisch of the Congo

1.1 Muhabura $(4.127 \mathrm{~m})$ - one of the eight Virunga volcanoes L. Trogisch 1 between Uganda and Rwanda

1.2 Cartographic map of the Virungas shared by the Democratic A. Leroy 4 Republic of the Congo, Rwanda and Uganda

1.3 The Virungas viewed from Uganda L. Trogisch 5

1.4 Covering TBPA failure with a rhetoric of good intentions $\quad$ D. Roher 22

1.5 Research base at the border of Volcanoes National Park L. Trogisch 24

1.6 Getting close to those of whom we are critical D. Roher 26

2.1 A blackback turning his back to his observers $\quad$ L. Trogisch 35

2.2 Transforming Uganda into an outstanding eco-tourism $\quad$ L. Trogisch 44 destination

2.3 Military monitoring of mountain gorilla $\quad$ L. Trogisch 47

2.4 In Rwanda there is a soldier on every block $\quad$ D. Roher $\quad 50$

3.1 Merging with the grass: rangers on a break during patrol $\quad$ L. Trogisch 61

3.2 Park ranger on duty $\quad$ D. Roher 74

3.3 AK-47 for animals and Congolese $\quad$ D. Roher 76

3.4 Ready to 'go slumming' - football shirt and military uniform $\quad$ L. Trogisch 80

3.5 Park rangers finding and triggering an animal trap $\quad$ L. Trogisch 82

4.1 A woman presenting an image of herself $\quad$ D. Roher 85

4.2 Open charcoal sack $\quad$ Pauline 96

4.3 Charcoal sacks $\quad$ Pauline 96

$\begin{array}{lll}4.4 & \text { Selling piles of charcoal } & \text { Pauline }\end{array}$

4.5 Plastic bowls of charcoal in the village $\quad$ Pauline 98

4.6 Pauline L. Trogisch 99

4.7 Child with booklet $\quad$ Mama Sifa 100

4.8 Child in Kitenge Mama Sifa 101

4.9 Child on the pathway $\quad$ Mama Sifa 102

4.10 Crying child in a blur Mama Sifa 103

4.11 Mama Sifa $\quad$ L. Trogisch 105

5.1 A girl holding a white barbie $\quad$ D. Roher 109

5.2 The Rwandan lady carrying her potatoes $\quad$ D. Roher 124

5.3 Bringing a hessian sack D. Roher 125

5.4 Streaming down $\quad$ D. Roher 125

6.1 Cutting a pathway through the Virungas $\quad$ D. Roher 131 


\section{Acknowledgements}

A PhD becomes so deeply intertwined with your own biography, that a part of yourself will always stay and feel with the place and the people you have spent years with, from near and far. I am writing these words when the news reached that Nyiragongo erupted, one of the eight Virunga volcanoes situated in the Eastern Democratic Republic of the Congo. I see the place in my mind's eye where I spent such a formative time of my life with its people. I am writing in a moment of disbelief that many of these people will have irretrievably lost the little they had. I am writing in a moment of anger about an absurd disparity in the world that one place and its people can be struck by so many bitter facets of fate - or what one can deem a natural calamity along with decades of suffering from man-made mischief. I am writing in a moment of impuissance watching pictures of this destruction from a safe place far away, and asking myself about my privilege what little I can I do with that in this moment.

This thesis is not for feelings of disbelief, anger, impuissance or guilt of privilege as they do not help healing or changing the tragedies and injustices that occurred. Instead, it is for the people who have suffered, and those who continue to survive - for their strength, hope and courage that can make a difference in the future. It should serve to always remind myself, and at best - if so others as well, of gratitude for what we have, and that our own, smaller and bigger, privileges give us the ability to share and choose to treat this world, this moment, the people crossing our paths with care and kindness.

The people who crossed my own path made the last four years worthwhile and worth living. First of all, I want to thank my triple-team of supervision who accompanied me through all these years and shared the difficulties and happiness of a $\mathrm{PhD}$ journey with me. Three different personalities with three different opinions may sound intimidating, yet for me proved to be the best support I could wish for - as if having three superpowers.

Bram Büscher who encouraged and inspired me from the very beginning onwards to think, and think critically, and think further and think again while always believing in my ability to think that far.

Robert Fletcher whose brilliant mind shone light on everything I questioned in the right moment, always being there when least expected and most needed.

Lotje de Vries without whom I would not have been able to finish this PhD like I have done. Her care, encouragement and professional advice are beyond any expectations a $\mathrm{PhD}$ and a friend could hope for.

In the lions' den of Wageningen, I was lucky to be embedded among the chair groups of Sociology of Development and Change, Rural Sociology and Health and Society and meet their wide range of inspirational, smart people. I particularly want to thank Gemma van der Haar, Michiel Köhne, Elisabet Rasch and Anke de Vrieze. Outside of the den, I am specifically grateful to have met Peter Tamas who provoked many of my thoughts in sometimes radical but always caring ways. The Cultural Geography chair group became in some regards a leading example and I enjoyed the companionship of many of their members, in particular to mention is Arjaan Pellis. I further want to express my appreciation to Sanne Hannink and Mariëlle Takes, as well as Meta Bakker, Coby Aanhaanen-van Duijn and Aicha Rakraky-el Makoui who guided me through the existential 
challenges of $\mathrm{PhD}$ administration. The time in Wageningen would have been cold and empty without the light-filling moments with Britt Broekhaus. In deepest appreciation I want to thank Yvette Buist sharing her beautiful soul with me and Julia van Middelaar who is always there, always shining, always taking care of me when I forgot myself. Further, I am grateful to have met Anne Leroy - her encouragement and her mapping skills can be found on these pages.

These years of research and fieldwork would not have been possible without a full doctoral scholarship from the Studienstiftung des Deutschen Volkes. This also enabled me to have a lovely home thanks to the generosity of Marian de Wit and Onno Knol, as well as Matthias Weichelt.

It is sad that I cannot express my gratitude to some of the most important people shaping my fieldwork as the need for their anonymization or pseudonymization in the given context surpasses my wish to explicitly thank them. They deserve the main part of these acknowledgements and even - and especially - without their names they shall be seen and read between all lines. Without their trust, support, knowledge, and protection this thesis would be void of content. Alongside the silent names, some can and need to be written down filling the various places of my journey with meaning:

Sally sharing her house, her singing and her kindness with me.

Derek giving me a home, a family and a sense of belonging.

Rebecca Besant and Search for Common Ground helping me to understand 'slowly by slowly'.

The people from the Karisoke Research Centre, Dian Fossey Fund International and the Gorilla Doctors, specifically Sarah who made me a friend, and Winnie, her dogs and her warming soups when me and my low moral came down from the mountains.

Loes, Celine and Julia creating the most wonderful moments for me by pulling me out of the field and the work of fieldwork.

The people from Mgahinga whose patience, hospitality and kind-heartedness I have never encountered elsewhere in the world.

Daniel Roher who once upon a time found me bedridden with Malaria in Uganda and ever since made us companions and research assistants. His beautiful mind, photography and drawings figure prominently throughout this thesis.

Tom Reid whose curious questions and loving support gave me perspective and perseverance.

Pat and his colleagues sharing everything they could with me including their own safety.

The women of North Kivu allowing me a glimpse into their dignity and strength.

Sabine Schmitt making me feel so at home that life in Goma was joy in spite of violence.

Marius Mardare who held me together when I was falling apart nonetheless.

Zachary Norman reminding me of light in some very dark hours.

Katy Robjant contributing decisively to that light as well as my understanding of the everyday lives in the Eastern DRC.

I thank my legs - and Tonnie Dirks who taught me how to use them - that carried me up and down the mountains and through uncountable runs for inspiration and sanity.

Thank you. 
I am very grateful for the junior researcher stipend from the Wageningen School of Social Sciences that allowed me to find the needed emotional and physical distance after fieldwork at the University of Sydney in Australia. The exchange and discussions with scholars of the Sydney Environment Institute and people outside of the academic bubble deeply influenced my thinking and writing in truly multidisciplinary ways.

Astrida Neimanis and the amazing women around her who took me in and taught me how not to follow the mainstream of spectacular words.

Thom van Dooren and his calm, inspiring questions and suggestions giving me the courage to follow fear instead.

Michelle St. Anne who is simply admirable, provocatively encouraging, stirring, giving, always, everywhere.

Elia who is too kind to be human.

Virginia showing me what art and laughter can mean.

My co-workers in Alfalfa House and the Polyphony singers creating warm places of happiness.

Vidit Mathur whose letters and company are an unconditional source of joy and shift my world perspectives continuously.

Thank you.

Being on the move in between many different places over four long years is only possible with the support of the people who root us by caring and loving and making us who we are. I am born under a lucky star and into a fabulous family who ensured that I would never feel alone or doubt that everything happens for a good reason.

My mum Birgit Trogisch and my brother Niklas - above all, I thank you, for being so different, so special and for being my safe space.

My two families Haeger and Weise with all their candour, loving me wherever I was. In particular, this thesis is devoted to their two strong women:

Marlis Haeger who deserves a whole book for herself and without whom I would not have been born into this world; and

Helga Weise who is a like the grandmother everyone wishes to have, with her care and cake being beyond words. I hope that something of you will live on in me.

Anka Zimmer and her kind commitment, tirelessly saving and putting pieces back together - I hope that I can pay it forward.

Maud Guettler who magically pushes everything into the right place.

Ramona Walter who showed me how kindness can disarm all negative thoughts, stereotypes and pain - sadly you will never know but this thesis seeks to carry some of your wisdom further.

Christoph Engel who began to accompany me with white paws on the last stretch of this path that will lead to somewhere beautifully unknown.

Finally, I have no words for my deep gratitude for having Beate Schiedewitz and Noah Wiepking in my life. Throughout all these years, you have not missed a single day to express your love and belief in me.

Thank you. 

Chapter I

\author{
Introduction
}

< Fig. 1.1 "Muhabura (4.127 m) - one of the eight Virunga volcanoes between Uganda and Rwanda" 


\section{Marking the territory}

This thesis is the outcome of five years of research including fifteen months of fieldwork in and around the contiguous forest spreading across the Virunga volcanoes in the borderland of the Democratic Republic of the Congo (DRC), Rwanda and Uganda.

The region is world-renowned for two particular characteristics. First, the borderland is scarred by a brutal colonial history and longstanding intra- and interstate warfare among the three states. In power struggles between 1890 to 1916 the colonizers of Belgium, Germany and Great Britain connected the peaks of the Virunga volcano chain with pencil and ruler on a cartographic map dividing people and forest via political borders into the DRC, Rwanda and Uganda (Mamdani 1996; Newbury 1998). Until today, decades of regional conflicts put the contiguous forest straddling the volcanoes at the heart of the warfare, offering concealed refugee routes and hide-outs, military bases and passages for armed interventions across borders. Given this geostrategic meaning of the borderland, this thesis considers the era of upsurging violence experienced by the inhabitants of the region since 1990 an important component of the analysis. Beginning with the Rwandan civil war that cumulated into the genocide in 1994, the following Congo Wars and ongoing transboundary violent conflicts strongly shaped, and continue to shape, the landscape and its people.

Secondly, the contiguous forest holds unique Afromontane biodiversity providing the last habitat for the endangered mountain gorilla ${ }^{1}$ that is split up by the political borders into three conservation areas known today under the names of Mikeno sector of Virunga National Park (PNVi) in the DRC, Volcanoes National Park (VNP) in Rwanda and Mgahinga Gorilla National Park (MGNP) in Uganda (Fig. 1.2). Managed by the countries' respective protected area authorities, the Institut Congolais pour la Conservation de la Nature (ICCN), the Rwanda Development Board (RDB), ${ }^{2}$ and the Uganda Wildlife Authority (UWA), the three National Parks offer mountain gorilla tracking as one of the most expensive wildlife tourism attractions in the world.

To ensure the conservation of the shared ecosystem in spite of its division among the three states and embedment in persistent conflict, the International Gorilla Conservation Programme (IGCP), a conservation NGO founded by the African Wildlife Foundation (AWF), Fauna and Flora International (FFI) and the World Wide Fund for Nature (WWF), initiated joint park ranger patrols as well as monitoring and training programmes for conservation staff from ICCN, RDB (then ORTPN) and UWA in 1991 (IGCP 2010a). This effort laid the groundwork for the idea to transform the three National Parks into a Transboundary Protected Area (TBPA). TBPAs are collaboratively managed conservation sites that straddle the political borders of at least two countries (IUCN 2020). Promoted as 'peace parks' in sub-Saharan Africa, international development organisations support TBPAs as an environmental peacebuilding initiative intended to encourage collaboration between conflicting states leading to economic development, sustainable conservation and ultimately regional peace (Ali 2007; Barquet et al. 2014; Hanks 2003; UNEP 2009).

\footnotetext{
${ }^{1}$ Besides a small, separated forest part in Uganda's Bwindi Impenetrable National Park.

${ }^{2}$ The protected area authority of Rwanda has been renamed from Office Rwandais du Tourisme et des Parcs Nationaux (ORTPN) to Rwanda Development Board (RDB) as part of the change in official language from French to English in 2009.
} 
With this intention - and funding by the government of the Netherlands - IGCP sought to institutionalize the informal arrangement among park rangers from the three countries into an official TBPA framework managed by an intergovernmental body, the Greater Virunga Transboundary Collaboration (GVTC). In 2015, GVTC together with the respective ministries of the DRC, Rwanda and Uganda, signed the Greater Virunga Transboundary Collaboration Treaty on Wildlife Conservation and Tourism Development, thereby committing to "[...] building trust, understanding and cooperation among wildlife authorities, nongovernmental organisations, users and other stakeholders to achieve sustainable conservation and thereby contribute to peace" (GVTC 2015: 6). Based on the assumption that violent conflict correlates with a lack of economic development (Collier and Hoeffler 2000), the treaty states that a TBPA would simultaneously contribute to both 'peace' - understood in a negative sense as the 'absence of violent conflict' and conservation, through the financial revenues from particularly mountain gorilla tourism (GVTC 2015). In addition to these contributions to the national economy of each state, the theory was that tourism would appease local communities who have been evicted from the forest areas in the establishments of the National Parks through revenue-sharing and employment opportunities, thereby creating 'development' - and its equation with 'peace' - on the local level. While the planned TBPA comprises in total seven National Parks and one wildlife reserve across the three countries, the mountain gorilla habitat around the Virunga volcanoes constitutes the only tri-border region and key tourism attraction branded as the transboundary Virunga Conservation Area. Since this title is not commonly used, I refer to the border-straddling forest area as it is called by locals: 'the Virungas'.
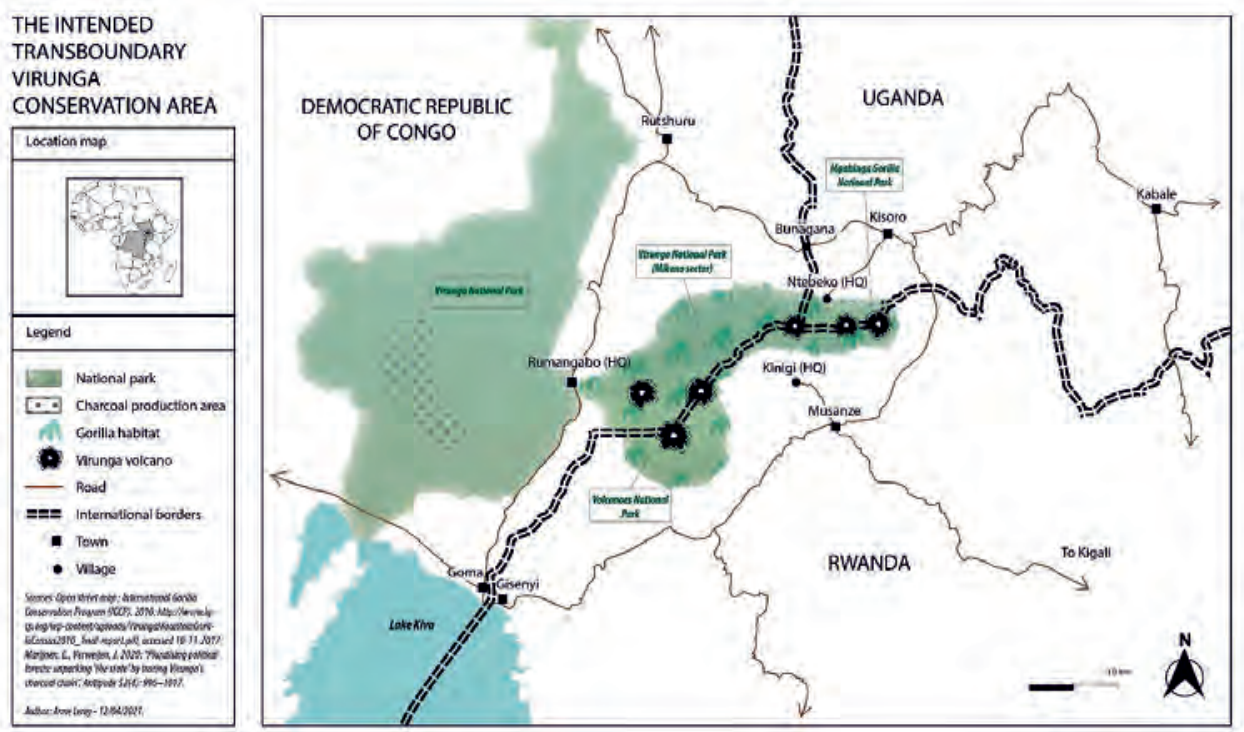

Fig. 1.2 "Cartographic map of the Virungas shared by the DRC, Rwanda and Uganda" 


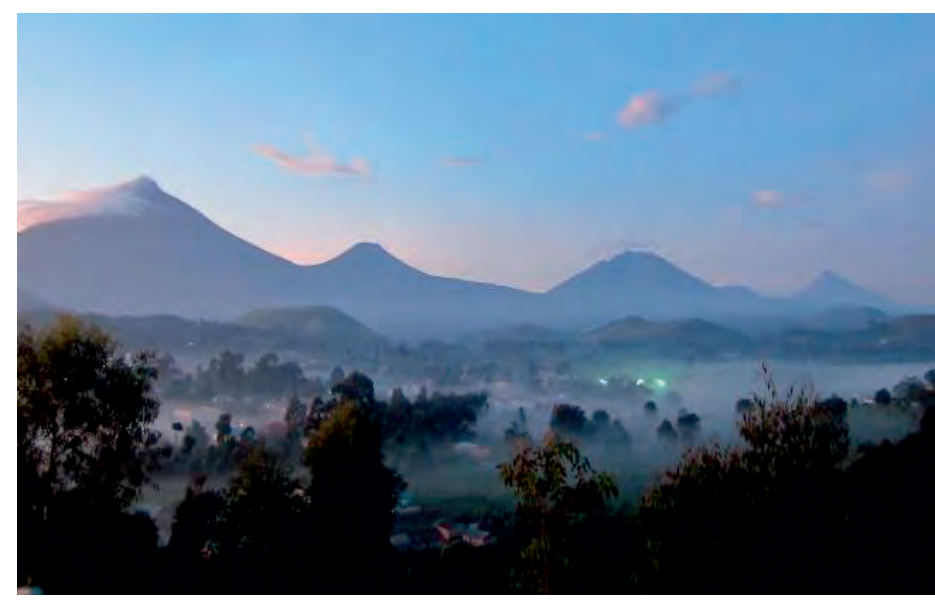

Fig. 1.3 "The Virungas viewed from Uganda"

Various sources present the TBPA efforts as a 'success story' evidenced by the increase of the mountain gorilla population from about 250 individuals in the 1980 s to more than 1000 individuals counted in the census in 2018 (Dian Fossey Fund 2018; Max Planck Gesellschaft 2018; UNEP 2018). As this 'success' solely presents one ecological reality of an ostensibly unified geography, it does not account for the multiple, complex realities of the various people perceiving and performing different yet interconnected geographies that compose the borderland. To explore these realities of the Virungas, this thesis starts from the premise of human geography that the creation and organization of geographies - spaces, places, landscapes, natures - are the condition for and the consequence of human agency, awareness and action (Cloke et al. 1991, Gregory et al. 2009, Tuan 1976, 1979). The intended TBPA in the Virungas exemplifies a specific form of spatial organization confining and dividing a biophysical landscape topographically as well as institutionally that shapes and is shaped by the interactions between people and space creating multiple - social, political and economic - geographies. Particularly inspired by the work on emotional interactions constituting people and geographies (Tuan 1979), my research engages with perceptions and performances understood as the active creation of personally appraised realities (Pennisi and Falzone 2020: 10), moulded, interrelated and separated by the emotion of fear. I followed and studied fear as the emotional response to the multitude of perceived threats that informed all aspects of everyday life stemming from the coalescence of conservation and conflict in the Virungas.

\section{Preceding explorations}

I first found a stark contrast between the compelling TBPA imaginary of a boundless nature overturning colonial delineation of arbitrary borders and violent conflicts versus the everyday realities of fear 'on the ground' when I came to stay with the people living at the border to Mgahinga Gorilla National Park in Uganda for my Master thesis in 2015. My Ugandan host community exemplified the existential fears related to conservation practices that a wide range of studies on the region discussed in reference to conceptualization of structural violence in conflict 
scholarship (i.e. Galtung 1969, 1990). These forms of violence include the eviction and dispossession of local people in the creation of National Parks (Anderson et al. 2012), marginal revenue-sharing from tourism profits (Sandbrook 2010; Ahebwa et al. 2012), a lack of alternative employment opportunities from conservation and tourism (Adams and Infield 2003) and lifethreatening limitations of (agro-)economic policies for a predominantly subsistence-dependent agricultural society (Ansoms 2009; Ansoms and Hilhorst 2014). Other studies highlighted direct acts of violence related to conservation in the region, such as the murder of mountain gorillas (UNESCO 2007) and tourists (Maekawa et al. 2016), frequent targeted killings of park rangers in the DRC (Refisch and Jensen 2016) as well as physical violence against communities by protected area authorities (Marijnen and Verweijen 2016). These findings pointed me to the interrelation between fear and different forms of violence related to conservation that contradicted the TBPA imaginary.

With the objective to explore how the TBPA efforts, and explicitly its promoted tourism measures, affect and interact with these various forms of inter- and intrastate violence, I embarked on my doctoral research in 2017. In preparation for my fieldwork, the political ecology literature seemed to offer the conceptual and theoretical guidance for studying this paradox between peacepromoting TBPA efforts juxtaposed by what Büscher and Ramutsindela (2016: 10) label 'green violence' to describe different forms of structural, discursive and physical violence embodied in coercive conservation policies and practices. To gain a more nuanced understanding of what 'violence' entails for different people in relation to the intended TBPA in the Virungas, my twelve months of doctoral fieldwork concentrated on the park-adjacent communities since they comprise the greatest part of the population evicted from the National Park areas and thus deemed as the main beneficiaries from tourism (GVTC 2015; UNWTO 2015).

Throughout my fieldwork in 2018, two major empirical insights crystallized that were particularly puzzling. The first insight comprised my first-hand observations of how the Greater Virunga Transboundary Collaboration (GVTC) became gradually undermined by the three national governments and their representatives until GVTC faced financial liquidation. I witnessed how agreements signed in the treaty were violated by policymakers and political authorities and how numerous planned manifestations of respective projects established under GVTC were dropped, phased out or never begun. Particularly startling was that state representatives attended workshops, meetings and conferences organized by GVTC and paid lip services to TBPA planning and projects, but ignored or opposed such commitments via contradicting statements, policies and practices on the next day. Exemplarily was Rwanda's unannounced raise of mountain gorilla tourism fees from 750 USD to 1500 USD overnight breaching the agreements on "harmonis[ing] visitor charges for common tourism products and visitor handling services standards" (GVTC 2015: 11) and divesting GVTC any political mandate and authority. 'Transboundary conservation' - in the imaginary of the concept - appeared merely as a form of branding to attract international conservation funding and tourism investments, yet actually putting it into practice was secondary, if not irrelevant, for nation-state politics.

Further underlining this political segregation among the three states, I observed high levels of militarization in and around the three National Parks that effected a geographical 
separation along political borders and clearly contradicted the transboundary vision. This militarization was tangible in barracks and patrol outposts along the stone wall and trenches surrounding VNP of Rwanda and MGNP of Uganda separating forest and communal land, and in the fortress-like headquarters and electric fences around Mikeno sector of PNVi in the DRC. It was also visible in the military uniforms and armament of park rangers who are trained as paramilitaries in close cooperation with the three national armies. Joint patrols between park rangers from ICCN, RDB and UWA was a thing of the past. This political and militaristic segregation highlighted the dominant influence of historical and ongoing regional conflicts informing conservation practices in and among the three countries. The geographical separation further illustrated the absence of the 'transboundary Virunga Conservation Area' as a jointly managed, unified geography and highlighted the three very different conservation-conflict contexts of the three National Parks.

Hence, the first puzzle that I seek to address in this thesis is how and why the official TBPA agreements and GVTC's practical efforts were undermined by the three governments. This is of particular importance for critical conservation studies as well as policymakers and practitioners in the sectors of conservation, tourism and conflict to gain comprehensive understandings on challenges and pitfalls of TBPA projects in conflict-affected regions in order to inform alleviating strategies or suitable location-specific alternatives that can be applied beyond the sub-Saharan African context.

In addition to these contradictory observations on the transnational level, the second empirical insight that particularly stirred me was an intense atmosphere of suspicion, mistrust and fear that shaped all aspects of everyday life on the local level. On the one hand, I encountered a multitude of collective, existential fears experienced by different members from park-adjacent communities directly related to the National Parks on each side. These fears emanated from denied access to basic resources within the parks, from animals exiting the park and destroying harvests, from a lack of compensation for these livelihood challenges from tourism, from conservation authorities and tourism stakeholders taking away people's home- and farmland, as well as from harsh, sometimes violent, punishment by park rangers when people enter the forest unauthorized. On the other hand, I found various fears that reached far beyond the conservation context rather constituting an overarching societal condition in my three field sites. Fear coloured people's attitude towards the contiguous forest as well as towards both their international and local neighbours. Fear was perceptible in my encounters with state representatives in the application process for research permits, in conversations and activities with GVTC and conservation (I)NGOs and the parastatal protected area authorities. Fear informed planned interviews, unplanned encounters and day-to-day interactions with diverse people in their diverse (overlapping) roles as farmers, day labourers, tourist guides, hospitality workers, hotel owners and park rangers, amongst other professions. Although fear was context-dependent, differing between the Eastern DRC, characterized by an ostensibly absent government and active, open conflicts between various armed groups, and the so-called 'post-conflict' societies under the rule of two very different authoritarian regimes in Rwanda and Uganda, the emotion was nonetheless omnipresent. 
Moreover, fear inhibited freedom of speech and movement that rendered probing concerning topics related to 'violence' inappropriate and impossible resulting in further silence, mistrust and suspicion. When following Galtung's common typology distinguishing among direct, structural and cultural violence (ibid. 1969, 1990), direct forms of violence were mostly hidden from the public (and particularly the white researcher's) eye and were too sensitive to be addressed in interviews. Researching structural or cultural forms of violence was - by definition, given their systemic, invisible, 'anonymous', 'abstract' and temporally indefinite features extremely difficult (Gregory and Pred 2007; Laurie and Shaw 2018; Springer and Le Billion 2016). While fear then could be interpreted as a form of structural or cultural violence in its own right, I found that the multitude of fears encompassed more meanings than being a systemic feature, but rather a creation and creator of violence, a meaning behind silences and behind discourses, an obstacle and an incentive for movement, permeating and interrelating transnational dynamics and individual livelihoods. In this light, applying a conceptualisation of violence would limit understandings of the various fears and their implications for the people living and working with(in) the conservation-conflict context.

Therefore, the second puzzle I illuminate in this thesis is how people's various fears shape and are shaped by the conservation-conflict dynamics in the Virungas. This affords two scientific and socio-political merits. First, an analytical angle of fear allows to approximate - yet, not reducing the analysis to - violence that can generate nuanced understandings of inter-relational, discursive, embodied and psychological effects on and of conservation-conflict dynamics beyond categorisations in direct, structural and cultural forms of violence. Secondly, listening to people's fears can indicate their personal understandings of different threats (not necessarily limited to violence), their concomitant needs and their individual coping strategies that can inform practical solutions for mitigating these threats in conservation-conflict contexts.

To address these two puzzles, my research merges their underlying empirical insights in order to explore the interrelation between fear and the undermining of the TBPA attempts between the DRC, Rwanda and Uganda. In the Virungas, people's fears illustrated a coalescence of conservation- and conflict-related threats, affecting how people perceive, react, respond to and (re)create multiple geographies that I therefore conceptualize as geographies of fear. Fear hence became the compass for my navigation throughout the research journey, informing the research objective, questions and methods.

\section{Research objective and questions}

The research objective of this thesis is to explore the multi-scalar entanglements of fear that inform people's perceptions and performances of the multiple - social, political and economic geographies that shape and are shaped by the conservation-conflict dynamics in the Virungas. Therefore, my overall research question is:

How is fear employed, experienced, and responded to in the conservation-conflict dynamics of the intended Virunga Conservation Area among the DRC, Rwanda and Uganda? 
The subsequent four sub-questions constitute the structure of the thesis following a logic of scaling down the levels of analyses from the transnational to the national to the local to the individual scale. Given the three highly diverse contexts of Mikeno sector of Virunga National Park in the DRC, Volcanoes National Park in Rwanda and Mgahinga Gorilla National Park in Uganda (fig. 1.2), the sub-questions cover different aspects of fear in the regional conservationconflict dynamics, yet the chapters provide location-specific answers and hence pay more or less attention to certain countries, respectively.

In order to shed light on how the geo-economic tourism rationale promoted in the TBPA treaty affect the conservation-conflict dynamics between the three states on the transnational level, the first sub-question became:

What is the role of tourism in the intended transboundary conservation and collaboration efforts between the DRC, Rwanda and Uganda?

In addressing this question, chapter II discusses how state economic interests informed national solo efforts of instrumentalizing mountain gorilla tourism that fuelled segregation and militarization among the three countries. While not directly related to the overarching research question, this chapter already establishes a link to the emotional dimension of fear by exploring the interrelations between fear and tourism to conflict-affected regions. On the one hand, mountain gorilla tourism exemplified the emotional manipulation for commercial and political purposes selling touristic security as freedom from fear (Hochschild 1983; Urry 1994). On the other hand, this form of high-end security tourism augments socio-economic inequalities that point to the existential fears of residents living around the three National Parks (chapter IV and V). In this regard, the promotion of 'peace tourism' to TBPAs in conflict-affected contexts like the Virungas exemplifies a geo-economic dimension of fear in commercialising feelings of security that has not yet been analysed in the critical conservation literature.

To explore the political geography that informs the segregation and militarization among the three National Parks, I engage with the discursive instrumentalization of fear as a political tool in national conservation practices. Therefore, my second sub-question constitutes a bridge between the transnational and the local scale by focussing on park rangers as parastatal conservation authorities holding overlapping roles and identities as both national state actors and local community members. Given that park rangers were once enacting an informal transboundary conservation collaboration, I examine how park rangers now experience and make sense of their enactment of the militarization and segregation dynamics between the three National Parks that undermine the formalised attempt of the TBPA. Hence, the second question became:

How does fear inform parastatal conservation actors' perceptions and performances of national conservation policies and practices undermining the intended transboundary Virunga Conservation Area?

This question is answered in chapter III, which demonstrates how fear discourses circulating amongst park rangers' function to mobilise and justify enclosure, militarization and segregation 
of the three National Parks. Park rangers' perceptions and navigations of the Virungas depicted their personal geographies of fear that inspired the title of this thesis as I realized fear's pivotal role in the conservation-conflict dynamics. My emotio-spatial analysis further illustrates the dominant legacy of the regional conflict history that inscribed fear in the geographies of the Virungas informing the gazettements of the National Parks as well as local people's memories and movements today. Chapter III also examines the politics of fear practiced by the governments of Rwanda and Uganda portraying a response to nation-state fears seeing the TBPA as a threat to their national sovereignty and territorial integrity. Accounting for these fears provides an explanation for why Rwanda and Uganda undermine the formalised TBPA attempts by GVTC.

My insights into park rangers' fears and their political instrumentalization underlined my empirical observations of fear shaping the social geography of the people of the borderland. In order to gain a better understanding of their perceptions and performances of this fear as a societal condition interacting with the conservation-conflict dynamics in the region, the third sub-questions further 'scales down' from an analysis of international tourism and national conservation practices to the local level of people living and working in and around the three National Parks and became:

How do different non-state actors living and working with(in) the intended transboundary Virunga Conservation Area experience and respond to fears emanating from the conservation-conflict context in the Virungas?

This question cuts through all four chapters, illustrating the overlapping roles of different people and their variety of strategies to cope with their fears in the conservation-conflict context. Instead of Scott's theory on everyday resistance against conservation commonly applied in political ecology studies, analysing people's coping strategies from a vantage point of understanding their fears allowed to account for the compliances and collaborations unfolding with conservation areas and actors. Chapter II discusses coping strategies of local tourism stakeholders in response to international high-end tourism operators. Chapter III depicts how park rangers in their role as community members try to mitigate their fears through scapegoating to justify violent conservation practices and still participate in community life. Chapter IV focuses on coping strategies by Congolese women facing their fears related to the active violent conflict and Virunga National Park in the DRC. This chapter emphasizes that an analytical differentiation of 'local communities', in particular along gendered lines, is crucial to understand the various impacts of fear on inequalities, struggles and survival in conservation-conflict contexts. Chapter V engages with coping strategies of different Rwandan community members living adjacent to Volcanoes National Park who commute daily to Uganda in search for wage labour to escape from diminishing farmland and the state politics of fear and oppression.

Throughout my fieldwork and its aftermath, I realized that my personal experiences of situations filled with fear compelled me to critically reflect on my own situatedness in this conservation- 
conflict context. Most critical conservation and conflict studies focus on fear felt by the researcher or by the people in the field, yet no accounts have brought these two foci together to explore the effects of researchers' presence inducing fear for the people in the field. In order to address this individual scale of fear that informed my personal perceptions and interpretations, a final subquestion imposed itself on me:

What empirical, methodological and theoretical insights arise from the reciprocal entanglements of fear between the researcher and the 'researched' (places, people) in the conservation-conflict context?

Through a critically reflection on the reciprocity of fear, I developed a methodological and theoretical contribution to conservation-conflict studies that I refer to as a practice of 'emotional ethnography' (chapter V). In addition, discussing how I - in my role as a white, Western researcher - was seen and treated as a source of fear elucidated the colonial legacy I found attached to my fieldwork. In relation to the TBPA attempts, the fieldwork experiences presented in chapter $\mathrm{V}$ show that both the intended TBPA as well as Western research in this conflictaffected region of sub-Saharan Africa were perceived and treated as foreign, neo-colonial, threatening and ultimately undesired interferences. This realization raises further questions about the decolonialization of academia more generally that is beyond the scope of this thesis yet will inform my future research.

\section{Uncharted territories}

In engaging with the above questions, certain limitations - territories that could not be explored in this thesis - need to be addressed from the outset in order to demonstrate in the following how my conceptual framework developed specifically geared to the demarcated boundaries of my research.

First, while I have spent a significant amount of my fieldwork with non-humans, in particular with mountain gorillas, they do not figure prominently in this thesis as an emotional exploration of their fears would have required a different scientific training from my side. Yet they have an all-encompassing presence throughout all chapters since they give the Virungas its meaning as a unique and therefore highly protected biodiversity hotspot informing all aspects of the human lives in the borderland. Others have accounted for their important significance with much more comprehensive understanding in important studies on Bwindi Impenetrable National Park in Uganda that engage with mountain gorillas' multiple, inter-relational roles as actors shaping and shaped by conservation, tourism and landscape (van der Duim et al. 2014; Ampumuza and Driessen 2020).

Secondly, I took up the challenge of studying the human emotion of fear aware of the difficulty that "emotions are never simply surface phenomena, they are never easy to define or demarcate, and they are not easily observed or mapped although they inform every aspect of our lives" (Bondi et al. 2005: 1). While emotional research accounts are subject to interpretation and their culturally and linguistically specific expressions are difficult to accurately represent (Derrida 2001), I demonstrate how my empirical insights depict a commonality of fear patterns, their entanglements and spatial attachments across the three different field sites. An analytical angle on fear is hence not aiming to generalize, over-simplify or judge on the emotional inner worlds 
of diverse people in and around the Virungas, but is instead a way of organizing, interrelating and presenting my findings of fear's prominent role in the conservation-conflict context.

Thirdly, political turmoil due to the long-term delay of presidential elections, increasingly frequent, unpredictable outbreaks of violence, attacks and kidnappings, and the outbreak of the Ebola epidemic created a highly volatile security situation in the Eastern DRC throughout 2018. In addition, the kidnapping of two British tourists on the way to Virunga National Park in May 2018 resulted in the closure of the National Park for external visitors. These conditions constituted major restrictions for my planned fieldwork and methodology, especially given the life-threatening implications for the Congolese people who worked with me and myself, augmented by my appearance as a white Western woman. Acknowledging these restrictions in the DRC underlines that my findings are determined by the different possibilities of access in the three divergent field sites, yet also highlighting the creative methodological adaptations these restrictions sparked (see under Methodology and chapter III ,IV, V).

Considering these safety concerns, this thesis reveals no names of villages and people since the anonymization of all informants demands specific responsibility given the three field sites being characterized by state surveillance, intimidations, imprisonments, killings, raids, violence and ongoing inter- and intrastate warfare where suspicion and mistrust are basic codes of conduct for survival.

With acknowledging the demarcated boundaries of this thesis, I will illustrate in the following how I generated a novel conceptual approach to analyse the multi-scalar entanglements of fear informing the conservation-conflict contexts by bringing political ecology into dialogue with emotional geographies and critical geopolitics.

\section{Theoretical framework}

In order to demonstrate the development of my conceptual framework for examining the geographies of fear in the Virungas, I first depict how I brought studies on violence and nature conservation from political ecology into dialogue with theories on fear from critical geopolitics aiding to analyse the interdependencies between transnational dynamics and everyday lives (Pain and Smith 2008). Adding the emotio-spatial dimension of fear into the analysis of these interdependencies, I thereupon show how concepts from emotional geographies subserved my theoretical framework allowing to account for the reciprocal influences between geographies and emotional experiences informing people's mental and behavioural (re)actions (Bondi et al. 2005; Davidson and Milligan 2007; Tuan 1979). To elicit these mental and behavioural mechanisms triggered by fear, I weave studies on fear from a wide range of Psychology, Criminology, Security, Military and Conflict studies into the exploration of people's different perceptions and performances constituting the multiple geographies in the Virungas.

For theoretical guidance I consulted an extensive body of literature on the relationship between violent conflict and nature conservation. In this process, studies in the field of political ecology were particularly enlightening. In the Anglophone academy of the 1970s, the intellectual roots of political ecology emerged in seeking to deconstruct dominant neo-Malthusian explanations of overpopulation and resource scarcity understood to lead to famine, environmental degradation 
and violent conflict (see e.g. Hardin's Tragedy of the Commons 1968; Meadows et al. 1972 The Limits to Growth). Primarily substantiated by empirical, ethnographic fieldwork methods, early scholars of political ecology sought to generate alternative understandings for these phenomena by illuminating their socio-economic, political and colonial root causes (Peet and Watts 1996; Perreault et al. 2015).

Ever since, a diverse body of work on human-environment interactions associated with the field of political ecology has challenged deterministic understandings of violence and conflict in relation to natural environments. In the anthology Violent Environments, Peluso and Watts present different conceptualizations of violence in relation to nature and resources that need to be explored as a "site-specific phenomenon rooted in local histories and social relations yet connected to larger processes of material transformations and power relations" (2001: 5). Almost 20 years later, a burgeoning scholarship within political ecology builds on this concept of 'violent environments' to highlight the entanglements between violent and militaristic conservation practices of Protected Areas embedded in and contributing to "violent conflicts or larger geographies of protracted violence, civil and colonial wars, and political violence" (Marijnen et al. 2021: 1; further see e.g. Lombard and Tubiana 2020; Minarchek 2020; Titeca et al. 2020). These studies on Protected Areas situated in areas of violent conflict exemplify the alarming increase in "green militarization" (Lunstrum 2014) - the adaption of militaristic methods, tactics and equipment for the protection of flora and fauna - that has been widely documented in recent years (Adams 2019; Bocajero and Ojeda 2016; Duffy 2014; Massé 2018; Mushonga and Matose 2020).

Expanding on the concept of green militarization, Büscher and Ramutsindela (2016) propose 'green' violence as entailing material, social, discursive and other forms of violence deployed for conservation ends, including spatial enclosure and militarization. Few studies, however, have addressed these problematic developments in the context of TBPAs. Specifically in the context of sub-Saharan Africa, proponents praise TBPAs as 'peace parks' that contribute to collaboration between conflicting states, leading to economic development, sustainable conservation and ultimately regional 'peace' (Ali 2007; Barquet et al. 2014; Hanks 2003). TBPAs are thus intended to address violent conflict through nature conservation. Since nature and wildlife sites are preferred spaces for travel, one intended strategy of TBPAs to achieve these compelling objectives is tourism. In the assumption that violent conflict correlates with a lack of development (Collier and Hoeffler 2000), conservation investments and tourism revenues are said, in theory, to lead to economic growth trickling down to create welfare on the local level that will end violent conflict in low-income countries. There is a growing body of literature illustrating and criticizing this ostensibly causal relationship between tourism and 'peace' (D'Amore 2009; Kelly 2006; UNWTO 2016) and pointing out the potential of tourism financing nature conservation in conflict areas (Alluri 2009; Milburn 2012).

Yet, the undifferentiated utilization of the concept of negative 'peace' simplified as 'the absence of violence' within these studies lacks a nuanced definition of the ambiguous concept of 'violence' and hence appears unable to establish contextualised and location-specific mitigation measures through conservation and tourism. In addition, the pitfalls of tourism for peace more generally have been subject to substantial scholarly analysis (Blanchard and Higgins-Desbiolles, 2013; Kelly 2006; Pizam 1996). Yet, the few scholars engaging with tourism to Protected Areas 
in conflict contexts either focus on the negative impact of warfare in reducing economic revenues for conservation (Baral and Heinen 2006; de Merode et al. 2007) or on tourists' concerns and travel choices (Grosspietsch 2006). Others have specifically discussed the prospects and problems of mountain gorilla tourism yet mostly focussing on Uganda's Bwindi Impenetrable National Park (Ahebwa et al. 2012; Muresherwa et al. 2020; van der Duim et al. 2014), or Rwanda (Grosspietsch 2006; Maekawa et al. 2013; Spenceley et al. 2010).

Complementing those discussions on tourism, an increasing number of critical conservation scholars scrutinize increasing levels of violence and militarization in and around (transboundary) protected areas that contradict the asserted associations with peacebuilding more generally (Büscher and Ramutsindela 2016; Fairhead 2015; Ybarra and Kelly 2016). Yet, there was no empirical research conducted on the TBPA-tourism paradigm as a peacebuilding and conservation strategy. Chapter II of this thesis seeks to fill this void by gaining an understanding of how people living and working with(in) the intended Virunga transboundary protected area perceive the TBPA-tourism impacts. As my findings illuminate the absence of the promoted TBPA and collaborative tourism practices in light of the conflict-affected context, new questions are raised about the blurring lines of different forms and ambiguous understandings of violence that cannot clearly be attributed to conservation practices or the inter-and intrastate warfare per se.

To give sharper contours to these blurring lines, the multitudinous concepts of violence need further discussion. Most understandings of, for example, 'green' (Büscher and Ramutsindela 2016), 'slow' (Nixon 2011), indirect (Tyner and Inwood 2014) and direct (Verweijen 2020) violence in relation to political ecologies rest on Conflict Studies and in particular on Galtung's differentiation among direct, structural and cultural violence (ibid. 1969; 1990). While direct violence is commonly understood as "the intentional use of physical force or power" (WHO 2002: 4), Galtung described structural violence as incorporated in the societal structure, reflected in unequal distribution of resources, space constraints or the denial of access and movement (Galtung 1969: 171). Cultural violence defined as forms of "exploitation and/or repression [perceived] as normal and natural, or into seeing them ...[as] 'right' or at least not 'wrong"” (Galtung 1990: 291) has since been studied to map 'geographies of violence' to reveal systemic inequalities that can be invisible, 'anonymous', 'abstract' and temporally indefinite (Gregory and Pred 2007; Laurie and Shaw 2018; Springer and Le Billion 2016).

Informed by these conceptualizations, studies by Political Ecologists have criticized the structural violence behind an economic functionality of tourism to conservation areas as exemplifying the profit-maximizing logic of the capitalist system feeding into exploitative practices in form of natural and cultural commodification with detrimental effects on local populations (Brockington et al. 2010; Büscher and Fletcher 2017). Specifically engaging with the conservation contexts in the DRC, Rwanda and Uganda, other Political Ecologists applied these definitions of violence to call out the direct acts of violence such as beating, rape, imprisonment as well as eviction and dispossession executed by conservation actors against local communities (Cavanagh and Benjaminsen 2014; Clay 2019; Marijnen 2018; Verweijen 2020).

While this political ecology approach to violence is helpful to make sense of the critical conservation aspects and their inherent power hierarchies, I found limited explanatory studies of 
the diverse, yet sometimes overlapping roles of the people ultimately shaping their perceptions and performances of violence that I encountered in the conservation-conflict context in the Virungas. In particular, my work with park rangers showed how violence is understood, experienced and enacted by "those of whom we are critical" (Massé 2017: 3) such as conservation authorities, which is rarely examined in studies associated with political ecology (with the notable exceptions of Lombard 2016 and Massé 2017). In addition, my research revealed the pivotal role of the emotion of fear in moulding different understandings and enactments of violence, neither solely attributable to conservation practices nor to violent conflict, which I could also not make sense of via the political ecology literature. While a few scholars in political ecology account for emotions in their analyses of resource struggles, power hierarchies, and environmental conflicts (see Nyantakyi-Frimpong 2021; Sultana 2015), there have been no studies on the impact of fear on violence and militarization related to conservation.

My research seeks to address these gaps by approximating the link between conservation and violence from an analytical angle of fear informed by critical geopolitics and emotional geographies allowing to account for the interrelations between different people, conservation policies and practices and the wider conflict-affected context.

To contribute to and advance the political ecology literature on violence, tourism and transboundary conservation in conflict-affected settings, I found a complementary theoretical approach in critical geopolitics that emerged from a combination of feminist scholarship with security studies, International Relations and political geography. Scholars from critical geopolitics challenge conventional geopolitical approaches that tend to reduce political violence and power struggles to contestation between dominant nation-states on the global scale (Dalby 1994; Hyndman 2007). By contrast, critical geopolitics seeks to generate a "more geographical geopolitics that disaggregates rather than homogenizes actors, and by implication, localizes rather than globalizes analysis and explanation" (Ó Tuathail 2010: 257). Exemplified in the edited volume Fear: Critical Geopolitics and Everyday Life, Pain and Smith propose to "collapse the geopolitical and everyday as separate spheres of life" by bringing out these dynamics' interdependencies and dismantling the hierarchy between them in scientific analyses (Pain and Smith 2008: xv). In relation to transboundary conflict-conservation contexts, geopolitics can be understood as the politics that shape and are shaped by transregional geographical features including discursive constructions of social, political and economic geographies. The establishment of TBPAs is an inherently geopolitical process given their border-crossing geography characterized by complex (geo)political dynamics, a multitude of interests between state and non-state actors and transnational agreements that are informed by international development, conservation and peacebuilding trends. Entangled with this geopolitical process, Pain and Smith define the 'everyday' as the "feelings, experiences, practices and actions of people outside the realm of formal politics" (Pain and Smith 2008: 2). This framework connecting the transnational dynamics of geopolitics with local perceptions and experiences 'on the ground' appeared illuminating for my multi-scalar exploration of the transboundary conservation-conflict context in the Virungas. 
In the introduction of the book, Pain and Smith propose "to examine geopolitical events through the prism of the emotional landscapes of everyday life" (ibid. 2008: xv). By pointing to people's 'emotional landscape' as the vital link between the geopolitical and the everyday, the anthology directed me to the field of emotional geographies. Scholars from emotional geographies emphasize this 'inter-relatedness' between actors, emotions and landscapes that shapes both social relations and political processes (Anderson and Smith 2001, Bondi et al. 2005; Davidson and Milligan 2004; Pile 2009; Tuan 1978). In this approach, 'emotion' functions as a concept comprising the different strands of analyses concerning moods, affects, feelings and atmospheres to capture the multiple ways of how (human) beings perceive and perform geographies. As Ahmed summarized, this scholarship seeks to explore what emotions do, and to a lesser degree what they are (Ahmed 2004: 4).

Originating in Lefebvre's work on the reciprocal interaction of emotions and spaces (ibid. 1974), emotional geographies discusses "the extent to which the human world is constructed and lived through the emotions" (Anderson and Smith 2001: 7). Further drawing on anthropological work since the 1980s (see e.g. Lutz and Abu-Lughod 1990; Rosaldo 1980; Scheper-Hughes 1995), emotional geographies concentrates on the interpretation and expression of emotions to gain insights into social, political and economic aspects of studied spaces, places and landscapes. Emotions 'cling' to particular places, engrained, embodied and passed on over generations, depicting the emotional relationship between people and landscapes.

Emotional geographies further offers analytical interpretations concerning the entanglements between the emotion of fear, people and landscapes in particular. This interrelation is based on conclusions in Evolutionary Psychology that animals show 'spatial patterns of risk perception' that ultimately structure their ecosystem into go- and no-go-areas referred to as their 'landscape of fear' (Gaynor et al. 2019). Since similar physiological responses to certain spaces have been found in humans, Tuan analysed fear-induced human behaviour in relation to landscapes in his pioneering work titled Landscapes of Fear that "refers both to psychological states and to tangible environments" (1979: 6). On the one hand, this emotiospatial approach aided my attempts to map the inter-relatedness between political, economic, ecological and social geographies informing the conservation-conflict dynamics in the Virungas. On the other hand, this approach offered me an entry point to analyse the multiple manifestations, conditions and consequences of fear I encountered during fieldwork. Merging insights from critical geopolitics and emotional geographies thus opened up a new perspective on violence in the conservation-conflict nexus, namely through the lens of fear.

My understanding of fear in the conservation-conflict context developed further through an engagement with a wide range of literature across disciplines including Psychology, Criminology, Security, Military and Conflict studies and Geography.

In Social Psychology, fear is generally understood as an emotion evoked in relation to someone or something deemed a threat regardless of whether the impending danger is real or imagined. ${ }^{3}$ In situations of reputed danger, fear signifies the reptilian complex within the human brain to release the stress hormone cortisol. Cortisol functions as an innate survival mechanism

\footnotetext{
${ }^{3}$ https://www.dictionary.com/fear, accessed 27-7-2019.
} 
that prepares the body to fight or flee (LoBue et al. 2019). In fight mode, fear thus functions to cognitively justify the use of violence for protective purposes (Kekes 2013). Hence, fear can be an emotional response to violence, while violence can be a physical response to fear, in defence or as a pre-emptive attack against a perceived threat. This function of fear lowering the threshold to commit or support acts of violence has been widely used within military tactics as "a tool of war that works through the minds" (Watson 1978: 534). Understanding fear can help to understand the motivation of people resorting to violence, for example in fear of disobeying orders (as I demonstrate in chapter III) or in existential fears of subsistence informing the criminalized, 'illegal' activities within the protected park areas such as hunting or logging (analysed in chapter IV). An analytical focus on fear allows for a less hierarchical, more inclusive account of how violence is perceived and performed by different actors moving in and around protected areas that can dismantle victim-perpetrator depictions in conflict contexts.

When the life-threatening situation has passed, cortisol levels in the body generally decrease. Yet it was found that people who experience ongoing violence, warfare or 'daily stressors' in form of harmful socio-structural and material conditions (Miller and Rasmussen 2010: 7), can encounter permanent perceptions of threat resulting in chronically elevated cortisol levels (Martz 2010). This effect depicts how fear can give a time-transcending quality to the study of violence. Fear can persist when violence has faded. Longstanding exposure to threat can lead to an embodiment of fear with far-reaching, epigenetic consequences, storing trauma in the body of succeeding generations who continue to sense, suffer and react under those fear-induced stress levels (Kwapis and Wood 2014).

Conflict scholars draw attention to this pervasive presence of fear permeating and forging people's everyday lives into a 'culture of fear' in so called 'post-conflict' contexts (Fujii 2014; Green 1994; Wood 2006). Acknowledging and analyzing a culture of fear can illuminate the 'neither peace, nor war' situation within and between countries that are categorized misleadingly as 'post-conflict' by international organizations based on the cessation of open inter- and intrastate warfare. My attribution of the status as 'conflict-affected' to the Virunga borderland is a way of accounting for the ubiquity of fear from past and ongoing - often concealed - forms of violent conflict scarring the region. In a similar manner, Green (1994) depicted the deceptive concept of 'post-conflict situations' applied to Guatemala by demonstrating how fear became a way of life engrained within society and shaping the mental and topographical geographies of its inhabitants.

To account for these mental and spatial manifestations of fear, geographer Tulumello (2017) proposed the term 'fearscapes' to critically analyse the politics of fear behind the organization of landscapes and people. Fearscapes feature four characteristics: "enclosure", erecting spaces of exclusion/seclusion; "barrier", creating the infrastructure of the fearscape; "post-public space", established through privatisation and fortification of public space; and "control", as the politics of surveillance (ibid. 2017: 4). His approach aids in revealing governmental practices of power and control that can be similarly observed in the conservation context, for example in the enclosure and conversion process of natural environments into protected areas as a form of "fortress conservation" (Brockington 2002; Kelly 2015). 
Spatial enclosure of landscapes is often accompanied by violent and militaristic measures. In this regards, politics of fear are related to Max Weber's political theory of the nation-state holding a monopoly on legitimized violence to establish a social order (ibid. 1919 [1992]). The threat of violence determines access to spaces, power and resources (Robin 2004). Yet, this threat of violence can be radiated directly from the state or from an external danger constructed as a distinguished 'Other' through fear discourses (Mountz 2009). Piotr Cap elaborated in his book The Language of Fear on how "policy legitimization is characterized by the discursive construction of fear, which involves recognition of a gathering external threat and mobilization of the home group to approve the use of preemptive measures" (2017: 81). He understood fear constructions as discourses generated by 'powerful voices' including public communication, state-infused political narratives as well as non-governmental, media and institutional discourses (Cap 2016: 1).

Placing emphasis on the most powerful of these voices coming from governmental authorities, scholars from critical geopolitics specifically highlight the 'politics of fear' describing the instrumentalization of geopolitical threats through fear discourses to legitimize statesanctioned violence in the name of national security (Cowen and Gilbert 2008; Huysmans 2006; Hyndman 2007). Exemplary of such fear discourses was the 'war on terror' rhetoric used by the U.S. Bush administration from 2001 onwards, establishing fear-inducing links between a people as 'terrorists' and a geography as an 'axes of evil' to evoke popular support for the military invasion of Iraq (Gregory and Pred 2007; Robin 2004; Sparke 2007). Similar geopolitical fear discourses that discursively link the 'war on terror' with conservation have been identified as a political tool of governments to justify increasingly violent and militaristic conservation practices (Duffy 2016). Others again have depicted that conservation authorities utilize such fear discourses to criminalise and punish people who enter Protected Areas unauthorized, for example by branding 'poachersas-terrorists' (Pennaz et al. 2018).

In this regard, some political ecology scholars coined the concept of 'green security' to demonstrate how 'globalised fears' are used for national security and state territorialization purposes under the cover of nature conservation in order to justify exceptional violent and military protection (Lunstrum and Ybarra 2018; Ybarra and Kelly 2016). Since "[v]iolence cannot be understood without understanding the discursive concepts that justify it for the actors" (Mathys 2017: 467), I contend that thorough examination of governmental - as well as public fear discourses can illuminate the various understandings, perceptions and performances of violence by diverse people in their interacting and overlapping roles and thus serves to decompartmentalize victim-perpetrator distinctions.

Merging analytical approaches on fear discourses from political ecology with critical geopolitics can thus account for the various social, political and economic interests behind violence and militarization from the transnational to the local scale in a transboundary conservation-conflict context. Moreover, a critical geopolitics-informed approach examines the manifestations of geopolitics in people's everyday perceptions and performances in this context to ground the analyses of violence, militarization and transnational conservation efforts on the local scale.

While an analysis of fear as a discourse can illuminate people's individual, group-inspired or stateled sense-makings of violence, listening to people's personal fears can yield insights into different, 
also non-violent behaviours that respond to and recreate the multiple geographies in the conservation-conflict context. In order to engage with people's behavioural responses to conservation policies and practices, many critical conservation scholars apply James Scott's (1985, 1990) concept of 'everyday resistance' (Matose 2014; Poudel 2019; Verweijen 2018). Informed by early Peasant Studies, 'everyday resistance' describes people's oppositional behaviour against domination and oppression to analyse how mostly rural people challenge political authorities and powerful decision-makers (Robbins 2012: 62). Based on numerous studies showing that current conservation practices fail to sufficiently include or benefit members of rural communities (Acranez et al. 2007; Bocajero and Ojeda 2016; Minarchek 2020), the resistance concept serves to analyse local people's behaviours directed against conservation authorities and areas. The identified 'resistances' vary from hidden acts such as dissimulating continued livelihood practices within National Parks (Poudel 2019) to physically attacking conservation staff (Matose 2014). Verweijen describes the "civilian resistance repertoires" in light of an eroded social fabric around Virunga National Park in the Eastern DRC as "the aim to reduce future threats and enlarging future opportunities" (2018: 297). Resistance as a mitigating behaviour to 'future threats' entails the preceding emotional reaction of fear, yet the role of fear informing people's behaviours has yet not been accounted for in the critical conservation literature.

To explore people's various (re)actions in and on the conservation-conflict context, an examination of their fears brought me to the psychology literature on coping. Coping strategies are attempts to control a situation - a chronic condition, a setting, a context, a landscape through "altering the environment, changing the meaning of the situation, and/or managing one's emotions and behaviours" (Lazarus and Folkman 2010: 170). Based on Selye's "general adaptation syndrome" (1976), coping describes the ability of individuals to develop emotional, cognitive and action-oriented strategies for reducing or eliminating perceived threats, and thus lowering chronic feelings of fear in conflict-affected settings (Johnson and Chronister 2010). While resistance is directed against a target, coping unfolds with someone or something. Hence, the resistance-focussed analyses foreclose opportunities to see the "tactic agency" (Utas 2005) within proactive shifts among resistance, compliance and collaboration developed in people's search of viable livelihoods with conservation actors and areas. Tactic agency describes people's everyday interactions with, navigations around, counteracts and adaptations to, as well as utilizations of conflict-affected contexts in particular (Tripp 2015; Utas 2005; Yadav 2020). In this sense, coping implies tactic agency based on fear's positive qualities as a 'constructive strategy' inspiring 'creative thinking' and empowering people to lift themselves out of paralysing, chronic conditions of fear (Humphrey 2013: 289). While not intending to disregard people's experiences of violence and life-threatening livelihood struggles that can result in overwhelming, paralyzing fear and long-lasting trauma, this thesis seeks to emphasize people's agency as the often-untold acts of self-determination, self-representation and active engagement with(in) conservationconflict contexts. By moving beyond resistance, my research contributes to the critical conservation literature by accounting for the different fears of different people (including the researcher) that inform various individual coping strategies shaping and being shaped by the multiple geographies of the Virungas (chapter II, III, IV, V). 
Ultimately, my theoretical framework brings analytical insights from political ecology into dialogue with concepts from critical geopolitics and emotional geographies to analyse how the multi-scalar influences of fear interconnect the social, political and economic geographies in conservation-conflict contexts. This enables the thesis to make key arguments in relation to the role of fear in TBPA efforts, in the high-end tourism paradigm, in the instrumentalization of 'green' violence and militarization of conservation, and in informing individual coping strategies in everyday life (and fieldwork).

\section{Relevance for science and society}

Through this innovative theoretical framework, I wish to contribute to the conceptual deepening of emotional engagements in political ecology research. I do so by introducing fear as a concept of analysis that can benefit understandings of human-nature relations, and in particular concerning the persistence of violence, militarization and warfare in relation to conservation areas beyond the sub-Saharan context. Analysing and accounting for different fears can further inform practical recommendations for policymakers and practitioners in the sectors of tourism and conservation, particularly related to TBPA projects in conflict-affected regions, in developing mitigating, location-specific strategies to accommodate fears that block successful collaboration attempts.

In addition, by analysing the interrelation between violence and fear, this thesis is a first attempt to generate new understandings of the rise of violent and militarized measures in the conservation context more generally. My approach offers a different perspective on violence, namely through an alyses of the multiple meanings of fear that discloses socio-cultural, geographical, historical, economic and political interrelations in the conservation-conflict context. In light of increasingly violent and militaristic conservation practices, attention to the fears of park rangers in particular can reveal the hidden (geo)politics behind the legitimization of such practices. In this sense, I advocate grounding critical discussions of conservation practices in the emotional realities of those who feel and enact these practices in their everyday lives, in order to include their voices in efforts to create alternative and non-violent pathways for conservation in the future.

Moreover, engaging in a sensitive and empathetic way with the different, overlapping roles of people and their different fears indicates their individual needs in conservation-conflict contexts that would enable new perspectives for development, peacebuilding and conservation projects and programmes. In this regards, a focus on individual coping strategies enables an identification of people's own developed solutions for livelihood challenges related to conservation and conflict. This could inform forthright, local bottom-up approaches in contrast to top-down impositions by policymakers, practitioners and foreign stakeholders in tourism, conservation and development sectors. 


\section{Methods and adaptations}

"If we think of geographical knowledge as constituted through a range of embodied practices - traveling, seeing, collecting, recording, mapping, and narrating - the subject of fieldwork becomes difficult to escape. The field in this sense is not just 'there'; it is always in the process of being constructed, through both physical movement - passage through a country - and other sorts of cultural work in other places. It is produced locally by the spatial practices of fieldwork, and discursively through texts and images." (Driver 2001: 12-13)

My 'field' of the borderland comprising three geographical sides and sights was constructed by my physical movements in which I became literally 'transboundary' myself. Following the road network surrounding the Virunga volcanoes, I moved in circles across the borders of the DRC, Rwanda and Uganda. Circulating around the Virungas was a spatial and mental experience throughout my iterative research journey: every re-arrival at the same point forced me to reflect on and shift my course, both methodologically and theoretically. As I elaborate in chapter $\mathrm{V}$, my border crossings allowed me to change places and perspectives to reflect on things from a spatial and emotional distance and as such became the decisive experience for my methodology, interpretation and analyses during and after fieldwork.

I began fieldwork in January 2018 with the process of obtaining the required research affiliations for permit and visa applications in Rwanda's capital Kigali and subsequently the other two countries. I had chosen Rwanda as a first field site because the secretariat of the Greater Virunga Transboundary Collaboration (GVTC) and one of their contracted cooperation partners the INGO Search for Common Grounds (SFCG) were located in the capital city. These organisations kindly offered to become my affiliating institutions for the transboundary research project in the DRC, Rwanda and Uganda. Research clearance was granted by Rwanda's Ministry of Education (MINEDUC) through the Directorate of Science, Technology and Research and the Rwandan Development Board (RDB) in charge of tourism and conservation in Rwanda. In Uganda, the National Council for Science and Technology and their Research Ethics Committee provided ethical clearance and validated the research permit from the Uganda Wildife Authority as my affiliated institution. In the DRC, the Ministry of Higher Education allowed research to be carried out in affiliation with GVTC and the Bureau d'Informations, Formations, Echanges et Recherches pour le Dévelopment (BIFERD) as my local sponsor. These research permits enabled me to get a researchrelated Green Card allowing me to travel freely across the borders between the DRC, Rwanda and Uganda.

With this freedom of movement, I began to establish contacts and bases in my three chosen research sites: in the village of $Z$, located in the district adjacent to the park entrance to Volcanoes National Park with its RDB headquarters in Rwanda; in my former host community in $\mathrm{K}$, in manageable distance to the headquarters of UWA and the main entrance to Mgahinga Gorilla National Park in Uganda; and in Goma, the regional capital in vicinity to the village of Rumangabo, where the ICCN headquarters and the entrance to Mikeno sector of Virunga National Park in the Eastern DRC is located. These sites were also chosen as they promised access to park-adjacent communities comprising the greatest part of the population living in the area 
for several decades and who had experienced the gazettements of the National Parks, and/or worked in tourism or conservation (GVTC 2015). In total, I conducted three months of fieldwork during my Master thesis in 2015 that laid the foundations for twelve months of fieldwork for the $\mathrm{PhD}$ from January 2018 to December 2018.

During the research application process in 2018, I commuted between Kigali and Musanze in Rwanda to get to know the GVTC and conduct interviews with the Congolese, Rwandan and Ugandan representatives that worked for the trilateral institution in charge establishing the TBPA. My fieldwork hence began with methods of 'collaborative event ethnography' (Brosius and Campbell 2010) by taking part in meetings, workshops and conferences in Kigali and Musanze organized by GVTC where I was introduced to the main authorities of the parastatal conservation agencies of RDB (Rwanda) and UWA (Uganda). The absence of representatives from the Congolese conservation authority ICCN already provided a decisive insight into the problematic relationship between the three states in the beginning of my fieldwork. In the final months of my fieldwork, one particularly incisive event was the United Nations conference on "Peace and Security in the Great Lakes Region" in November 2018 for which I was spontaneously asked to keep notes and write the summarizing report. From that moment in time, the Government of the Netherlands stopped funding GVTC and the three governments did not follow up on their agreement to continue the financing of the TBPA efforts, yet the peacebuilding-through-transboundary-conservation rhetoric was predominant, and depicted a certain absurdity (fig. 1.4).

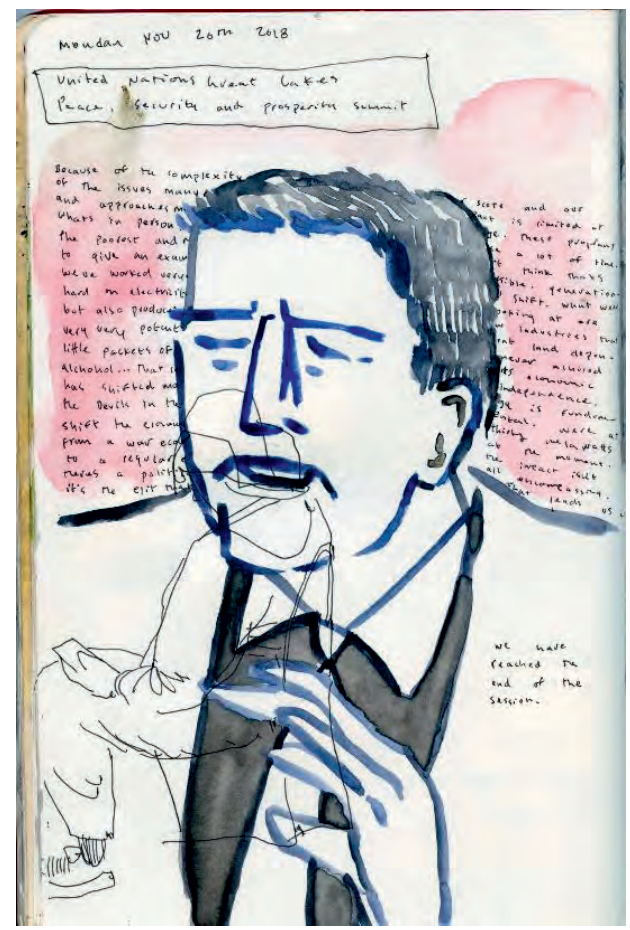

Fig. 1.4 "Covering TBPA failure with a rhetoric of good intentions" 
Overall, participating in events allowed for initial observations, interactions, conversations and interviews with of a variety of stakeholders related to GVTC that were insightful and enhanced my general understanding of the efforts to institutionalise the TBPA on a transnational level, yet these impressions do not figure prominently in this thesis.

GVTC also linked me to various (inter)national partner organisations that were charged with conservation-related projects and baseline studies for the TBPA funded by the Netherlands Initiative for Capacity Development in Higher Education (NICHE). One of these organisations was Search for Common Grounds (SFCG) in collaboration with the Vrije Universiteit Amsterdam conducting a 'conflict mapping and needs assessment' of 'local communities' and 'park managements' in the DRC, Rwanda and Uganda to provide 'transboundary conflict resolutions' (unpublished SFCG report 2018). Since this objective was in line with my initial research topic on promoted 'peace' through TBPA efforts, SFCG agreed to take me on board so I could gain insights into their work and evaluations for several weeks. The final report of this assessment presented commonplace statements of 'park-versus-people' conflicts generalizing 'local communities' living in vicinity of the National Parks in all three countries. This homogenization and the repetitive narratives evident in different interviews of the report fitted into the promotion of the TBPA that would provide easy fixes to the presented conflicts. While this experience deeply irritated me, it underlined the necessity of my planned ethnographic fieldwork methods in order to gain a deeper understanding of what is going on 'on the ground'.

My qualitative research design was based on an inductive approach to develop an understanding of what was going 'on the ground' and accordingly adjusting my research questions and methods based on initial experience. This iterative process was further determined by the restrictions of accessibility and security that were compromised by the highly different political contexts of each country (as I elaborate in chapters III, IV and V). In the following I will briefly outline my methodological adaptation process since certain planned ethnographic methods such as oral history, audio recordings and videos appeared to be unimaginable, and even dangerous for the people I worked with as well as myself, requiring at times draining, at times inspiring and innovative methodological adaptations.

Like van Maanen, I imagined that "fieldwork usually means living with and living like those who are studied" (ibid. 2010: 2). In this attempt, my first field base was a tent surrounded by potato fields and small houses belonging to Kinigi directly at the border of Volcanoes National Park (VNP) in Rwanda (fig.1.5). Adapting to and experiencing the extreme living and working conditions of people around VNP was challenging and telling. Situated at approximately 2400 meters above sea level, the surroundings were covered in permanent fog from the forest in the shadows of the volcano chain. Fog was also a suitable metaphor for the three months I spent trying hard to see something: informal conversations as well as planned interviews with most diverse people of different gender and age holding professions as farmers and agricultural day labourers, hospitality and other tourism-related workers or employees at the RDB headquarters presented similarly repetitive narratives to the ones I have found in the SFCG report. Or - often - my questions were met with silence. 


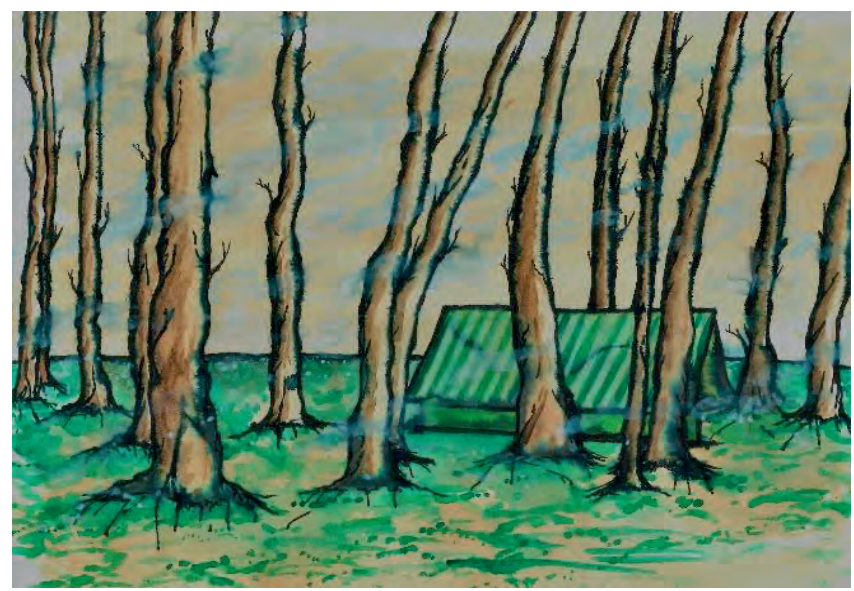

Fig. 1.5 "Research base at the border of Volcanoes National Park, Rwanda"

Before fieldwork, I had read about common characteristics of (post-)conflict societies where people's fear to speak lead them to repeat state-induced narratives or to "purposeful concealment and misinformation" (van der Haar et. al. 2013: 26). Particularly given Rwanda's recent postgenocide history, previous researchers in the area described the silences in response to high suspicion and the sensitivity of topics related to violence (Fujii 2010; Wood 2006). Yet, experiencing a lack of 'research access' day to day resulted in an affective drain and strong feeling of self-doubt blocking any creative thinking to adapt. In this moment I followed two scenarios. First, I did what many researchers during fieldwork do and have done and would seldom dare to acknowledge: I withdrew from the field in an isolating, self-destructive way fuelling feelings of incompetence and unworthiness. Secondly, and potentially equally harmfully, I was convinced that I just needed to 'try harder' in the belief that if the data is 'not good', it must be my mistake in not doing enough, in speaking to the wrong people, or in being in the wrong space at the wrong time. This narrative replaying in my head was reinforced by the fact that research deemed 'successful' seldomly acknowledges any "negative" emotions during fieldwork. In both scenarios, it is the up-crawling fear can either paralyze, make us flee or make us fight. I feared failure and I was also afraid of doing something harmful for the people when I realized that the people fear me. Those kinds of inner emotional turmoil are seldomly found in fieldwork accounts, leaving young researchers caught by surprise when mixed up in them. This thesis is also an attempt to change this (chapter V).

The breakthrough came when I decided to travel across the border to Uganda. In Uganda, my long-standing research connections and friendships with the local group "Q" allowed me to live on their ground close to the entrance of Mgahinga Gorilla National Park. My position as a known researcher and an adopted member of the community brought me the Rufumbira ${ }^{4}$ nickname gahuzamiryango ("she who connects people") that helped to establish needed mutual trust and access to key informants via snowball sampling with other local stakeholders ranging

\footnotetext{
${ }^{4}$ Rufumbira is spoken in Uganda, yet very similar to Kinyarwanda spoken in Rwanda and common in North Kivu of the DRC, signifying the linguistic connection of the people living in the borderland region.
} 
from owners and employees of the park-adjacent tourism facilities, tour and ranger guides to a wide range of community members with different occupations not directly engaged in tourism or conservation practices. In addition to the regained confidence, I was able to gain a new perspective and infuse my planned fieldwork methods with three specific adaptions.

\section{Participatory ethnography}

The first methodological advancement to overcome the limitations in interviews with parkadjacently living community members was my application at the headquarters of RDB in Rwanda and UWA in Uganda to accompany park rangers in their daily life and work tasks. Through this 'participatory ethnographic approach' (deWalt and deWalt 2002) I sought to get an understanding of park rangers' perceptions and performances of conservation policies and practices. Massé described this active form of participant observation in his research with a South African conservation agency "as a way of getting close to or attaining a certain degree of proximity with those of whom we are critical [that] can be important for gaining a comprehensive understanding of the micropolitics and quotidian dynamics of violence, security practices, and related institutions" (Masse 2017: 3). This certain granted proximity allowed me to take part in anti-poaching and routine patrols, tourist guiding and daily gorilla monitoring, as well as living with rangers in different patrol outposts along the borders of the forest. Partaking in conservation work and life was an extreme physical and mental challenge. The gendered implications of the park ranger profession augmented this fact, exemplified when I was asked by the park authorities if I am not afraid to stay with all these men, alone and remotely, and anyway: 'women cannot do that work'. Patrols and monitoring usually started around $6 \mathrm{a} . \mathrm{m}$. in the morning and could take up to twelve hours cutting through the forest and up the volcano slopes, thus covering an altitude range between 2400 up 3200 metres above sea level. During rain season, heavy rain, extreme cold and permanent mist made the tough work even more strenuous. In addition to these physical challenges, I found it mentally particularly difficult when a patrol identified tracks of unauthorized park activities heralding some sort of silent 'hunt' to catch the people within the forest 'in flagrante delicto'. The tension during these moments was extreme and I am grateful I never witnessed a collision between park rangers and park 'intruders', only the destruction of numerous wooden snares and traps laid for hunting wild animals.

In this way, I got an understanding of the extreme working conditions and in particular the inherent dilemma of park rangers in their roles as state representatives and community members at the same time (chapter III). I also learned about the dense military deployment within the contiguous forest of the Virungas and the close collaboration between the national armies and conservation actors. To complement the conversations and observations with park rangers during these activities, I conducted semi-structured individual and focus group interviews with their superiors holding positions as park wardens and in park management. Participatory research with conservation authorities gave me decisive insights into the everyday discourses informing conservation policies and practices in Rwanda and Uganda (chapter III). 


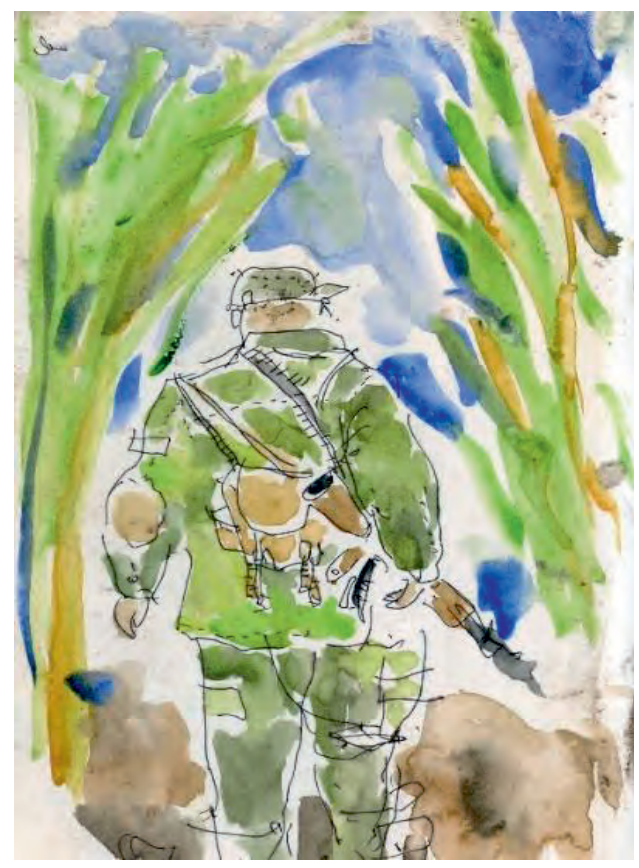

Fig. 1.6 "Getting close to those of whom we are critical"

This participatory approach could not be applied in the DRC. Throughout 2018 the continuously delayed presidential elections by the ceding president Kabila led to increasing violent unrest in the city of Goma and a plethora of armed actors claimed authority to fill the approaching power vacuum. Due to the outbreak of Ebola and the kidnapping of two tourists on the way to Virunga National Park in May 2018, the park closed for external visitors, including researchers. Through personal contacts I was allowed to join an armed convoy to the Rumangabo headquarters within PNVi and stay with the park management and the ICCN rangers for several days. This allowed me to conduct a range of observations and interviews with the Congolese conservation authorities of PNVi, yet all other information were gained in interviews at the ICCN offices in Goma.

\section{Visual ethnography}

The previously described political situation in the Eastern DRC in 2018 inspired my second methodological adaptation informed by a visual ethnography approach. In order to overcome the restricted access and with the aim to mitigate the bias my appearance as a white, Western women evoked, I made use of participant photography to gain insight into the socio-spatial relations of people in their everyday lives. Also referred to as 'photovoice', this constitutes "a visual method in which research participants are encouraged to visually document their social landscapes through photography and reflect on their photos to produce personal narratives" (Allen 2012: 443). In total, I distributed 45 disposable cameras and diaries via local research partners to literate volunteers in different villages adjacent to the three National Parks of the DRC, Rwanda and 
Uganda. In line with my open, inductive approach, the photographers were asked to make one picture of their day-to-day experiences and to write a diary entry about what this photo means to them.

In this regard, an ethical and moral collaboration with the paramount objective of protecting my voluntary participants was crucial given the politically sensitive, conflict-affected context of the borderland region. All volunteers were comprehensively informed about the study, have been given the choice of withdrawal at any time, were remunerated for their work and received their photos. Only photographs and verbal accounts that participants have explicitly consented to use for the thesis are presented. While chapter IV only represents a small sample of this photovoice method in the DRC context, the photos from all three countries decisively informed my sense-making throughout the interpretation process after my return. The meanings and interpretations conveyed by representatives of different groups from the park-adjacent societies showed their various livelihood struggles and coping strategies that illuminated my overall understandings of the conservation-conflict context in the Virungas.

\section{Emotional ethnography}

The third methodological adaptation developed throughout my fieldwork to ultimately constitute a "self-transforming experience [...] that underlies all understanding of social life" (van Maanen 2010: 2). Particularly my own experiences of extreme fear (amongst other intense emotions) informed my conceptual notions of the fear around me. This might have been partially because fear tainted my gaze, but more importantly because I made myself vulnerable to connect and empathize with the people around me.

Since ethnographic fieldwork methods serve "the attempt to understand another life world using the self - as much of it as possible - as the instrument of knowing" (Ortner 2006: 42), my 'self' is the research instrument that observes, converses and navigates guided by my subjective perceptions and interpretations (see also de Vries 2012). Particularly the expressions of emotions are subject to an individual and socialized linguistic framing (Derrida, 2001). As the official and widely spoken language in Uganda is English, I did not need a translator for conversations and interviews. Rwanda posed a more difficult context since the government officially changed the national language from French, still negatively associated with the former Hutu government and the Belgium colonizers, to English in 2008. For that reason, particularly farmers, day labourers but also park rangers who learned French where afraid to use it, yet could not speak English and thus resorted to the commonly spoken dialect of Kinyarwanda. My own Kinyarwanda was good enough for conversations, yet not for elaborated interviews where I got support from different translators. Kinyarwanda is commonly spoken in the borderland of the Virungas with certain variations in the DRC and in Uganda. In the area surrounding Mikeno sector of Virunga National Park in the DRC, I conducted most interviews in French, which is widely spoken by Congolese people in North Kivu, often in combination with Kinyarwanda and Kiswahili and various other local dialects. My notion of 'fear' is hence also a subjective interpretation of people's expressions in comparison with my own experiences during fieldwork.

In acknowledging this subjectivity of my interpretations, the recognition and tracking of "meta-data" (Fujii 2010) improved the collection of information in the given restricted 
circumstances. The acknowledgement of potentially fictional stories, rumours, inventions, denials or silences as categorized by Fujii (2010) as data in themselves provide a vital source for understanding. In following Fujii's suggestion to pay systematic attention to 'meta-data', all silences and repetitive narratives bore meaning in the given political context, the time and space of the conversation, and for and with me as a foreign researcher. It thus became secondary whether the content of people's reiterated memories, stories, rumours, anecdotes might have been 'true' or 'false' or merely invented for my presence as a researcher and a $\mathrm{w}^{3}$ (white, Western woman). In this regard, following this 'meta-data' became a practice of honouring what people say - sometimes fragmented, invented, repetitive and contradicted by their behaviour complemented by my own experiences and observations. It all made sense when fear becomes a natural way of being in conflict-affected setting under authoritarian regimes. The result is a snapshot of a moment in time conveyed in selected exemplary stories throughout the four chapters.

In chapter $\mathrm{V}$, I elaborate on this basic understanding of my fieldwork methods in suggesting a move towards a practice of 'emotional ethnography' in critical conservation studies in political ecology and as well as the wider discipline of Human Geography. Telling the stories we have encountered during fieldwork is a scientific tool to structure and grasp how complex realities and emotions play a decisive role for our own and the listener's - reader's - understanding, aiding to (make) sense (of) our experience.

\section{Artwork}

In advocating acknowledgement and accounting for personal emotional experiences in research, I want to spend some words on the artworks illustrating this thesis that were a method in its own right. Artworks are "artefacts produced by people as part of their situated and embodied experience" (Ingram 2009: 262). To convey their findings to the outer world (through meaningful analyses and interpretation), researchers first need to engage with their own inner world formed by these experiences. Drawings can help in this two-way process of introspection and expression. They have the ability to show ourselves and other what we otherwise could not see or understand, and can offer a different perspective on things, translating observations we have made within or around us that are hard to grasp or explain in words. As Taussig reflects on his drawings in ethnographic fieldwork notebooks, the act of making drawings "is at once intimate and personal yet bears the obligation to make something that exceeds the personal [...] like a three-way conversation is going on between the drawer, the thing drawn, and the hypothetical viewers" (2009: 265). Throughout this thesis the artwork drawn by the film maker Daniel Roher during his visiting research assistance to my fieldwork in November 2018 and my own drawings throughout my twelve months of fieldwork convey what we felt and saw, while at the same time also starting a conversation with the reader/spectator to evoke their own thoughts, feelings and sense-makings. In addition, this thesis is illustrated by photography made by camera diary participants, Daniel Roher and myself to offer another perspective on my research. The drawings further serve to abstract faces and places that cannot be depicted on the photos to ensure the anonymization and protection of the people who engaged with me. An overview of the thought- 
inspiring titles of the drawings and photography as well as the respective artist can be found in the list of figures (i).

\section{Primary data and triangulation}

Using a two-journal design (Kumar 2011: 140), the artwork was embedded in my reflective journal kept to foster self-awareness concerning how my presence influenced the situation, interaction with and responses to and by informants. The other journal recorded my findings in extensive, descriptive fieldwork notes. In total, I have conducted over 75 semi-structured interviews with protected area authorities, 36 with representatives of (international) conservation NGOs working in the three field sites and 47 with people directly working for the tourism sector to gain an overarching understanding of conservation and tourism management in the VCA generally. In addition, with permission from local authorities, my partaking in daily life as well as in conservation and tourism-related activities surrounding the three National Parks afforded insights into day-to-day events and conversations, which were then substantiated by semistructured interviews with local community members not working for the National Parks directly. Given the fluid transitions from small talk to conservations to open interviews, I stopped counting these often decisively more informative, yet 'informal' talks in the course of my fieldwork. Particularly insightful were conversations with park rangers while being on patrols together that I would 'record' by actively taking mental notes and writing them down later. This form of primary data collection was triangulated by iterative "member-checking": discussing the accuracy of findings with participants (Creswell and Plano Clark 2011: 211). In addition, I tried to organize multiple conversations and interviews to reassure people about my trustworthiness and my intentions (Fujii 2010). However, while I was always upfront about my role as a researcher underlined by my request to take notes in and after conversations, this form of 'informal' interviewing requires a discussion of ethical considerations and informed consent.

\section{Ethical considerations and dilemmas}

Although I forthrightly explained my academic intentions to people, the conflict-affected context in the three field sites made any formalised consent agreements impossible. To afford anonymity and confidentiality, I coded my data writing in my mother tongue German and changed the names of people and places to alleviate unintended negative repercussions. Yet, as I elaborate on in chapter $\mathrm{V}$, formal interviews and even informal conversation were often corrupted by people's suspicion, mistrust and fear, which were partially related to decades of warfare and surveillance and partially to my appearance as a $\mathrm{W}^{3}$ - a white, Western ${ }^{5}$ woman - that carried strong colonial legacies. These experiences raised uncomfortable questions, and other fears, in me: In how far does my foreign, Western research in countries of sub-Saharan Africa perpetuate colonial and/or imperial legacies of scientific exploitations of flora, fauna and people? And further exacerbating this Western academic dilemma in conflict-affected settings as pointed out by Bourgois (1990): What do I as a foreign researcher have 'meaningful to offer' for the people that I engage with and rely on while I can just leave these settings and the people at any time? How meaningful is

\footnotetext{
${ }^{5}$ „Shorthand to designate Europe and regions where populations largely originate from Europe as a result of European Imperialism” (Marchais et al. 2020: 390)
} 
appreciation and acknowledgment of the hard work and high risks my research partners and interlocutors took for me?

While searching for answers to these questions will inform my research in the future, one way of trying to account for these inherent dilemmas now is to pay respect to the people who made my research possible by sharing my findings with them "in culturally appropriate ways and in a language that can be understood" (Smith 1999: 15). In addition - and in the awareness that this stance might be my personal indulgence system - I hold on to my moral principles of mindfulness towards the people who shared with me by giving back or paying forward. This principle yielded a range of non-academic collaborations and projects in my three field sites that I will carry on and that hopefully maintain my gratitude into the future.

\section{Outline of the chapters}

All chapters of this thesis explore how fear influences and interrelates the social, political, and economic geographies constituting the conservation-conflict context of the Virungas. Therefore, each chapter serves to examine the interlinkages between geopolitical processes and everyday practices across four scales of analyses: from transnational dynamics in relation to tourism to national conservation practices that inform local livelihoods and ultimately also influence the individual, including the researcher. The golden thread weaving those scales of analyses together is the emotion of fear in its multiple, instrumental roles and meanings. At the same time, the outline depicts the process of my own conceptual - theoretical and methodological - research journey increasingly incorporating approaches on fear from critical geopolitics and emotional geographies into a political ecology perspective.

Chapter II challenges the relationship between 'peace' and tourism promoted as an incentive for and benefit of establishing the Virungas as a TBPA. This chapter is based on the article with the same title co-written with Robert Fletcher that was published in the Journal of Sustainable Tourism. The chapter exemplifies the geo-economic interests of parastatal conservation practices in the commercialisation of security to accommodate international tourists' fears of the region commonly associated with the genocide and decades of violent conflict in medial accounts of the global North. At the same time, national tourism and conservation stakeholders utilize these fears by constructing threat narratives to defame the neighbouring tourism destinations in order to sell their own provision of security as a luxurious product. We argue that revenue generated from gorilla tourism finances the militarisation of conservation actors, areas and national borders in the name of providing security for tourists, while functioning as a geopolitical strategy to make the National Parks a military bulwark against the neighbouring countries. The economic competition and political segregation among the three states undermines collaboration and trust among national conservation authorities and tourism actors and thereby contradicts the promoted 'peace tourism' narrative in the TBPA treaty. For these reasons, we suggest the term 'fortress tourism' - instead of 'peace tourism' - with exclusionary and marginalizing impact on local communities around the three National Parks.

Chapter III demonstrates how and why dynamics of 'green' violence, militarization and segregation of the three National Parks undermine the peace-promoting, transboundary 
conservation attempts of GVTC between the DRC, Rwanda and Uganda. This chapter published as an article in Geoforum - is inspired by frameworks from emotional geographies and critical geopolitics that illuminate geopolitical interests by examining how state-led fear discourses are perceived and enacted in the everyday realities of individuals. Based on my participatory fieldwork spending life and work time with park rangers in Rwanda and Uganda, I analyse the instrumental role of fear discourses informing park rangers' enactment and justification of violent and militaristic conservation measures revealing the entanglement between everyday conservation practices and (geo-)politics in the historically conflict-affected region. Rangers' perceptions reflected a discursively constructed 'geography of fear' that informed my overall understanding of the conservation-conflict nexus in the Virungas and the title of this dissertation. This microlevel analysis of fear narratives offers an innovative theoretical contribution to critical conservation studies pursuing a deeper understanding of how and why 'green' militarization and violence are worldwide on the rise and undermine TBPA attempts.

Since park rangers hold overlapping roles and identities as state representatives and local community members simultaneously, this chapter represents a bridging element between transnational TBPA agreements by the national governments and the impact of such high-level politics on everyday livelihoods in and around the National Parks. In this regard, I advocate for a methodological adaptation in critical conservation studies to engage with and include the voices of 'those whom we are critical of' who feel and perform violent practices in their day-to-day duties to inspire alternative, non-violent conservation pathways in the future.

Chapter IV focuses on women and their coping strategies with(in) Virunga National Park in the Eastern DRC. By pointing to the gendered impact of fear from persistent insecurities from conservation and conflict dynamics in the Virungas this chapter further dismantles the homogeneity of 'local communities' living adjacent to the three National Parks. Based on an article, currently under revision for second resubmission to Gender, Place and Culture, this chapter brings a feminist emotional geographies approach into discussions with conservation and conflict studies. This chapter presents an insight into my methodological adaptation of visual ethnography, explicitly the use of 'photovoice', due to insecurity in the volatile political context of the Virungas. Analysing the photo diaries and narratives of two women from two villages adjacent to Virunga National Park in the DRC exemplifies their attempts to make sense of the fears generated by conservation and conflict in the region in order to develop emotional and behavioral coping responses. Staying with the fear, women of the Virungas like Pauline and Mama Sifa actively appropriate the fearscape, making fear work for them, through re-naming her own fears, alleviating their gruelling mental impact and creating room for manoeuvre. Going beyond a dominant focus on 'everyday resistance' against enclosed conservation spaces and violent conservation practices, I argue that this fear-induced coping allows to account for the compliances and collaborations unfolding with landscape and actors, that afford the women a sense of integrity, agency and ownership of their bodies and minds.

Chapter V presents my methodological and conceptual development process discussing the reciprocal dynamics of fear between the researcher and the 'researched' in the conflictconservation nexus. Although a wide range of political ecology studies conduct ethnographic fieldwork in conflict-affected settings, there is little critical reflection on the emotional impacts of 
these research practices on researcher and interlocutors. I demonstrate how my own fear stirred up by encounters with open violence, societal exclusion, surveillance and direct intimidation pointed me to systemic features of fear induced by historical legacies and governmental regulations in the park-adjacent societies. These personal experiences of fear were entangled with my position and status as a white, Western researcher eliciting a source of fear for the people I lived and worked with that shaped my data collection, analysis and interpretation during and after fieldwork. In light of these dynamics, I argue that emotional reflexivity of one's own and other people's fears during fieldwork can improve studies within political ecology and beyond in three ways. First, it enables methodological creativity, promoting a problem-solving attitude helping fieldworkers to make more empathetic, sensitive and ethical decisions in the field. Secondly, it generates theoretical insights into often invisible, systemic features of structural violence, power and oppression in the conservation-conflict context. Thirdly, it fosters critical awareness and opens room for dialogue concerning the colonial legacies inherent in foreign-led fieldwork practices in sub-Saharan Africa. I suggest calling this practice of observing emotions, using them as a compass to navigate the field and incorporating the observations that are coloured by these emotions into our knowledge production an 'emotional ethnography'.

Chapter VI provides the conclusion to the thesis by synthesizing the findings of my fieldwork and analyses in line with my research objective set out in chapter I. Advocating for a more emotional political ecology, I first present how my innovative theoretical framework on geographies of fear drawing on critical geopolitics and emotional geographies can contribute to and advance critical conservation studies of political ecology. Thereupon, I demonstrate how a methodological advancement towards a practice of 'emotional ethnography' could advance empathetic, ethically considerate and critically reflective practices of knowledge production in white Western research, in critical conservation and wider human geography studies.

Ultimately, I discuss the social and political relevance of fear research in providing alternative understandings of violence, tourism, conservation practices and TBPA efforts in conflict-affected borderlands offering a range of practical recommendations. In addition, I depict my practical suggestion for an academic institutionalization of emotional engagement to create healthier researchers and research environments in the social sciences beyond the publication realm. Finally, I draw attention to the colonial legacies inherent in foreign-led fieldwork practices in postcolonial societies of sub-Saharan Africa in the aim to contribute to ongoing efforts of advancing the decolonization of academic knowledge production. I contend that forthright emotional engagement aids to address uncomfortable questions of inherent research asymmetries and inspire alternative visions for a future of more empathetic and humble scientific practices. 
Introduction 


\section{Chapter II}

Fortress tourism - exploring dynamics of tourism, security and peace around the intended transboundary Virunga Conservation Area

This chapter has been published as:

Trogisch, L. and Fletcher, R. 2020: "Fortress tourism: exploring dynamics of tourism, security and peace around the Virunga transboundary conservation area", Journal of Sustainable Tourism, ahead-of-print, 1-21.

Content has been slightly edited, in particular "we" was changed to "I", to make the chapter fit into the rest of the thesis.

< Fig. 2.1 "A blackback turning his back to his observers" 


\section{Introduction}

Before the Corona pandemic abruptly halted international travel in 2020, tourism was the fastest growing industry in the world and thus increasingly promoted as 'peace tourism': a key strategy for peacebuilding in conflict-affected regions (UNWTO 2016, WTTC 2016). Given that natural sites, and particularly those containing charismatic wildlife, are popular travel destinations, the United Nations World Tourism Organisation (UNWTO) advocates tourism promotion within protected areas as a substantial opportunity for low-income countries to achieve a "triple win" combining sustainable economic development, nature conservation and peacebuilding (UNDP 2012: 2). Within this broader promotion, one proposed but deeply contested modality to pursue this triple win is the creation of Transboundary Protected Areas (TBPA). Since TBPAs straddle the borders of at least two countries, they also became praised under the compelling name of "Peace Parks" to encourage cooperation among states characterized by historical and/or current conflict. Proponents argue that the mutual interest to generate revenue from nature-based tourism within the parks incentivizes states to collaborate over conservation of the flora and fauna they share (Ali 2007; Hanks 2003). In this respect, TBPAs have been incorporated into broader environmental peacebuilding initiatives by the United Nations positing a relationship between overpopulation and exploitation of natural environments in stimulating violent conflict in lowincome countries (UNEP 2009, 2016). This "recognition that environmental issues can contribute to violent conflict underscores [TBPAs'] potential significance as pathways for cooperation, transformation and the consolidation of peace in war-torn societies" (UNEP 2009: 5). 'Peace parks' thus offer the potential to harness 'peace tourism' as a market-based, businessoriented solution to these challenges (D'Amore 2009).

The prospects and pitfalls of peace tourism more generally have been subject to substantial scholarly analysis and discussion (see e.g. Blanchard and Higgins-Desbiolles 2013; Kelly 2006; Pizam 1996). Yet research concerning promotion of tourism for peace within TBPAs in conflictaffected regions remains scarce. The few scholars engaging with tourism in protected areas in conflict contexts either focus on the negative impact of warfare in reduced economic revenues for conservation (Baral and Heinen 2006; de Merode et al. 2007) or on tourists' concerns and travel choices (see e.g. Alluri 2009), but rarely on socio-economic and political impacts of 'peace tourism' on local stakeholders in relation to this particular mode of conservation. This paper aims to fill this gap by analysing the role of tourism within a TBPA in relation to its triple-win framing as a simultaneous sustainable development, conservation and peacebuilding strategy.

I focus on the intended transboundary Virunga Conservation Area (VCA) composed of Virunga National Park (PNVi) in the DRC, Volcanoes National Park (VNP) in Rwanda and Mgahinga Gorilla National Park (MGNP) in Uganda. VCA is an ideal case to interrogate the peace tourism narrative for two main reasons. First, the Virungas are the last remaining habitat of endangered mountain gorillas and are therefore deemed both a biodiversity hotspot by conservationists and a 'unique selling proposition' for one of the most expensive wildlife tourism attractions in the world. Secondly, VCA is situated within the Great Lakes Region, an area infamously described as the epicentre of "Africa's World War" (Prunier 2011) due to its history of intra- and interstate warfare including the Rwandan genocide and its aftermath characterized by persistent violent conflict in the DRC. Since 2007, the Dutch government has financed the intergovernmental 
Greater Virunga Transboundary Collaboration (GVTC) to institutionalise transboundary conservation within VCA on the model of a 'Peace Park'. One focus of the trilateral GVTC Secretariat is to bring together protected area authorities, governmental representatives, researchers and conservation non-governmental organizations (NGOs) to promote gorilla tourism as a peacebuilding strategy founded in socio-economic and political cooperation among the three countries.

Yet the promising official agreements among the DR Congo, Rwanda and Uganda are contradicted by the prevalence of various kinds of violence, from reported killings of mountain gorillas (Jenkins 2008) to tourists (Maekawa et al. 2013) to park rangers (Marijnen and Verweijen 2016). Other forms of violence, ranging from social exclusion to imprisonment and murder of civilians living adjacent to the TBPA, are also frequent but rarely documented by mass media, official reports or academic researchers. Despite these highly problematic developments, there has been no research on the effects of 'peace tourism' inspired measures within the Virungas in relation to this violence. In bringing together current debates over 'peace tourism' with critical conservation studies, this paper contributes to both discussions by offering a pioneering analysis of the role of tourism in peacebuilding efforts within TBPAs in conflict-affected regions.

In relation to these issues, I argue that the transboundary collaboration efforts centred on gorilla tourism development have paradoxically spurred increased economic competition among the three states that has in turn precipitated political distancing as well as militarisation within the three National Parks constituting the VCA. Focusing mainly on the relationship between the DRC and Rwanda, my analysis demonstrates how gorilla tourism has merged with the selling of 'security' as a luxury, high-end tourism product in its own right. The revenue generated from these endeavours finances the militarisation of conservation actors, areas and national borders, thereby functioning as a geopolitical strategy to make the National Parks a military bulwark against the neighbouring countries. The resultant segregation among the three states undermines collaboration and trust among national conservation authorities and tourism actors and thereby contradicts the promoted 'peace tourism' narrative in the TBPA treaty. Hence, 'gorilla tourism for peace' seems to remain largely an appealing piece of rhetoric that attracts international funding for gorilla conservation, private investments into tourism-related businesses and tourists that is used to finance military expenditures in the name of securitising the great apes and their visitors.

After a brief description of my methods, I situate the study within the debate on 'peace tourism' intersecting with critical conservation studies. Thereafter, I explore the functional role of gorilla tourism in peacebuilding and collaboration efforts within the VCA by focussing specifically on narratives and practices used by different governmental and non-governmental conservation actors in Rwanda and the DRC on national and transnational levels. I then shift the attention to the local context to analyse the perceived impacts of gorilla tourism on 'peace' for local tourism stakeholders as well as people not directly involved in tourism living adjacent to the VCA. I conclude by advocating more critical engagement with the concealed pitfalls of highend wildlife tourism in conflict-affected regions packaged within the 'Peace Parks' brand, particularly as we continue to struggle with the ongoing fallout of the COVID-19 pandemic. 


\section{Methods}

This paper draws on twelve months of qualitative field research in communities adjacent to the the three National Parks that constitute the mountain gorilla habitat in the Virungas conducted by the first author from January to December 2018. These communities were chosen since they comprise the greatest part of the population evicted from the Parks and therefore are viewed as the main stakeholders to benefit from tourism interventions (GVTC 2015; UNWTO 2015). Long-standing exploratory research within the area by the first author since 2015 provided the needed trust for beginning the formal participatory research period within the park-adjacent villages of Kinigi (Rwanda) and Ntebeko (Uganda) as well as access to key informants. Proceeding from these personal connections, snowball sampling enabled data collection with other local stakeholders ranging from owners and employees of the park-adjacent tourism facilities, tour and ranger guides as well as community members not directly engaged in tourism or conservation practices. With permission of local chiefs and park authorities, partaking in daily life as well as conservation and tourism related activities within the National Parks afforded the researcher insights into day-to-day events and conversations, which were then substantiated with 60 semistructured interviews.

Due to the volatile political situation, the outbreak of Ebola and unpredictable violence and kidnappings in the region of the Congolese park in 2018, participatory methods with local communities in the Eastern Congo were restricted to an interactive collaboration with a Congolese NGO in the regional capital of Goma, which enabled 28 open and semi-structured interviews during field trips to seven park-adjacent villages. In this regard, I want to emphasize that all informants are anonymized to honour and protect those who agreed to participate despite the danger that the ongoing interregional conflict, mistrust and surveillance present for them. Additional participant observation was conducted with park authorities from the Institut Congolais pour la Conservation de la Nature (ICCN), the Rwandan Development Board (RDB) and the Ugandan Wildlife Authority (UWA) during overnight stays at the park's headquarters and patrol outposts, during which the researcher accompanied anti-poaching patrols, gorilla monitoring and touristic activities within the parks.

These insights concerning location-specific dynamics were complemented by 12 focus group interviews followed up by 75 semi-structured interviews with protected area authorities, 36 with representatives of (international) conservation NGOs working in the conservation-tourism sector and 47 with people directly working for the tourism sector to gain an overarching understanding of conservation and tourism management in the VCA generally. ${ }^{6}$ In addition, frequent attendance of GVTC workshops, meetings and conferences throughout the year provided insight into discussions of 'peace tourism' among representatives of national research institutions, security services, government officials, the GVTC and the United Nations international development and peacebuilding initiatives in the Great Lakes Region.

The results of these interactive methods were recorded with extensive fieldwork notes in a two-journal design, one holding descriptive field notes and the other used for reflective notes

\footnotetext{
${ }^{6}$ For protective purposes I anonymized participating organisations if they not explicitly expressed their will to be mentioned by name.
} 
in order to foster self-awareness concerning how the researcher's presence influenced the situation, interaction with and responses by informants. This primary data collection was triangulated by iterative "member-checking" discussing the accuracy of findings with participants (Creswell and Plano Clark 2011: 211) and a comprehensive review of policy briefs, treaties and reports discussing transboundary peace, tourism and conservation as well as popular media representations of the Virungas. My analysis of these various data sources employed a grounded theory approach (Strauss and Corbin 1997) in pursuit of a holistic understanding of the complex interrelations among different actors on multiple scales. This analysis relied on an iterative process of inductive pattern building from specific data points rather than formal content analysis in line with the qualitative, experiential focus of the overarching project.

\section{Peace as security through the militarisation for tourism?}

Since the establishment of Waterton-Glacier International Peace Park in 1932 to symbolize peace and friendship between the United States and Canada, the number of Transboundary Protected Areas (TBPA) in the model of "Parks for Peace" has increased steadily throughout the world (Sandwith et al. 2001; IUCN 2020). Based on the assumption that environmental problems correlate with violent conflicts (see e.g. Ali 2007), proponents argue that transboundary conservation offers a solution to these conflicts "to promote and strengthen peace and cooperation between neighboring countries [...] as a prerequisite for sustainable economic development and foreign investment" (Hanks 2003: 136). In particular, scholars and practitioners focused on environmental governance promote TBPAs as an environmental peacebuilding strategy in its own right (UNEP 2009).

In light of persistent environmental problems and social conflicts around conservation areas worldwide, the compelling concept of TBPAs has been questioned by a growing body of critics in the past decades. Some argue that TBPAs produce new conflicting interests among a multitude of actors as conservation strategies are aligned to the profit-maximising logic of capitalism (see e.g. Duffy 2006). Fairhead (2005) pointed specifically to the creation of TBPAs as a covert tactic of neo-colonial governance by industrialised states to ensure the exploitation of resource-rich environments in sub-Sahara Africa. Büscher and Ratmusindela (2015) call attention to the increasingly violent methods that contradict the promoted intentions of 'Peace Parks' within the Great Limpopo Transfrontier Park. They refer to the wider debate in the critical conservation literature that scrutinizes the militarisation of all types of protected areas and actors (Duffy et al. 2019; Lunstrum 2014, Ybarra 2016) and the entanglement between violent and militaristic conservation practices and political violence, conflict or warfare within the larger surroundings (see e.g. Lombard and Tubiana 2020; Minarchek 2020). Others point to conservation violence and its destructive consequences for local residents (Bocajero and Ojeda 2016; Büscher and Fletcher 2017; Duffy 2014). Specifically in the enclosure of protected areas, the forceful eviction, dispossession and exclusion of local residents from their means of survival, traditions and beliefs continues to be problematized in reference to the persistence of "fortress conservation" as a central environmental protection strategy (Brockington 2002; Neumann 2004; Pemunta 2019). 
As one response to this increasing critique, international development institutions have praised 'eco-tourism' as a new panacea to fund conservation and simultaneously benefit communities in low-income countries in proximity to protected areas (Honey and Gilpin 2009). The 'peace parks' narrative expanded this notion of eco-tourism into a triple-win scenario by promoting TBPAs as tourism destinations that can support both environments and people through the economic prosperity generated from tourism revenues that will ultimately also contribute to regional cooperation and peace (see e.g. Hanks 2003; Mearns 2012). While tourism was already promoted as a "passport to peace" in $1967,{ }^{7}$ it gained increasing attention as a peacebuilding approach after the "Amman Declaration on Peace through Tourism" was formally adopted by the UN in 2000 (UNWTO 2016). In 1988, D'Amore proposed 'peace tourism' as 'the world's first global peace industry' in founding the International Institute for Peace through Tourism (IIPT 2017). In outlining its approach, IIPT refers to traditional conflict studies defining 'negative' peace as the absence of the 'direct use of physical force' (WHO 2002) and 'positive' peace as the absence of 'structural' violence reflected in the unequal socio-economic and political organization of society (Galtung 1969, 1996). In relation to this distinction, IIPT and other 'peace tourism' proponents stress tourism's potential not only to reduce direct violence but also to enhance positive peace indicators, in particular intercultural understanding, ecological sustainability and human welfare through "attitudes, institutions and structures that create and sustain peaceful societies" (IEP 2017: 4; see also Haessly 2010).

Based on the widespread assumption that violent conflict correlates with a lack of development (Collier and Hoeffler 2000; Nassani et al. 2017), the ostensible 'virtuous cycle' of peace tourism to TBPAs in particular is aligned with the conservative neoliberal paradigm asserting that economic growth contributes to the Gross Domestic Product (GDP) of a nation state, which ultimately 'trickles down' to create development amongst the local population (Williamson 1989). In consequence it is argued that citizens depending on the tourism industry for their well-being have an incentive to remain or become peaceful to help create a positive image of their country and attract more tourists (Haessly 2010). Tourism's contribution to economic growth is thus seen as key to a form of development within low-income societies that will bring 'liberal peace' after the Western model: expanding free markets, democracy, human rights and the rule of law (Doyle 2005; Levy and Hawkins 2010). An extensive literature emphasizes this putative causal relationship between tourism and peace (e.g. Kelly 2006; D'Amore 2009, Honey and Gilpin 2009) and even stresses the potential for tourism to create a global 'culture of peace' (Moufakkir and Kelly 2010). By contrast, a growing body of critical tourism scholarship problematizes this posited relationship between tourism and peace (Litvin 1998) as well as the focus on economic growth through neoliberal market engagement underlying this peace rhetoric (Blanchard and Higgins-Desbiolles 2013).

Discussion of the potential for tourism to facilitate peacebuilding in conflict areas is nowadays complemented by attention to "human security". The UNWTO asserted in 1996 that "the success or failure of a tourism destination depends on being able to provide a safe and secure environment for visitors" (UNWTO 1996). While the United Nations has more generally

\footnotetext{
${ }^{7}$ United Nations declaration 1967 of the International Tourist Year under the slogan "Tourism: Passport to Peace"
} 
depicted 'human security' as an outcome of expanding military investments by the state (Haq 1999), a significant shift to increased militarisation for ensuring security of 'the tourist' occurred in the aftermath of the 11 September 2001 attacks in the United States, after which terrorism was declared a global threat influencing travel advisories (Hall et al. 2004). While tourism scholars have thereby increasingly incorporated 'human security' into the debate concerning tourism's peace-generating potential (e.g. Blanchard and Higgins-Desbiolles 2013), a few have also pointed to the consequent problematic entanglement between the 'securitisation of travel' and the military-industrial complex in inventing counter-terror measures to protect wealthy consumers (Lisle 2016). In the same vein, Weaver shows that tourism strategies become increasingly militarized to serve the tourists' demand for 'security' leading to a normalization of military presence in tourist destinations, and thereby in the everyday reality of local people (2011, p. 674). Scholars have also highlighted the separation between locals and tourists through enclosed facilities and services in "enclave tourism" practiced in all-inclusive resorts in particularly remote areas (Mbaiwa 2005; Nunkoo and Ramkissoon 2016). My study builds on all of this previous research to analyse "fortress tourism" (Fletcher 2011) as a particular dynamic in which militarization is used to securitize tourism activities in (post-)conflict areas outside of enclave resorts.

Within critical conservation research, the relationship between tourism, peace and security in the context of conflict-affected conservation areas has been touched on in broader debates on violence within peace parks but has not yet been systematically investigated. While some conservation literature on tourism in conflict-affected contexts asserts tourism's potential to finance nature conservation in such areas (Joras et al. 2011; Hanks 2003), others have questioned whether tourism's propensity to commodify natural and cultural 'products' may instead augment violence and conflicts among people (Brockington et al. 2010; Büscher and Fletcher 2017), as well as among states in competing to attract more visitors within the global tourism market (Tripp 2010). In addition, the eviction and dispossession of communities in the establishment of protected areas (Andersson et al. 2013), the lack of compensation and employment opportunities often attending these displacements (Adams and Infield 2003) and the marginal revenue-sharing from tourism benefits such initiatives frequently entail (Sandbrook 2010) speak to the presence of problematic, conflict-aggregating effects of tourism in conservation areas on the micro level.

Building on these initial explorations, the following analysis brings together discussions of peace tourism, peace parks, and the militarization of conservation to pursue a novel investigation of the implications of tourism as a peacebuilding strategy via a case study of the VCA. While the endangered mountain gorilla became the face of commercial tourism and led to increased international attention to the region, the impact on increased socio-economic development and peacefulness are expected to vary greatly among the DRC, Rwanda and Uganda. While acknowledging the undeniable ecological violence of stress, diseases and habitat destruction from tourism on mountain gorillas (Robbins 2014) that problematizes the environmental component of 'peace tourism' narratives, I focus here on the socio-economic and political consequences for human stakeholders related to tourism. I argue that gorilla tracking became a form of 'fortress tourism' that sells a provision of security to wealthy visitors that simultaneously funds the military 
build-up of national borders within the three National Parks of the VCA, while excluding local residents. I begin by briefly outlining the historical context within which the regional tourism efforts originated.

\section{Historical context of the Virungas - which 'conflict' should be brought to peace?}

In violent quarrels over colonial boundaries between German East Africa and Belgium in 1902, two mountain gorillas shot by Robert von Beringe brought the great apes to the attention of Western scientists who assigned them their zoological name (gorilla gorilla beringei). In 1925, the Belgium king Albert I established Parc National Albert in the Eastern DR Congo. This space continues to constitute the main area of Virunga National Park (PNVi) today but previously incorporated Rwandan and Ugandan parts of the Virunga volcano chain to protect the broader mountain gorilla habitat. With independence attained by the DRC (then Zaire) ${ }^{8}$ in 1960 and Rwanda and Uganda in 1962, management of the forests became separated into independent state-owned entities that gained international prominence through Dian Fossey's work in Rwanda from 1967-1985. PNVi in Zaire became a popular tourist destination in the economically vibrant first years of Mobutu Seso Seko's dictatorship (1969-1997). Inspired by neoliberal Structural Adjustment Programmes introduced by the World Bank and other international financial institutions (IFIs), Western conservationists promoted mountain gorilla tourism as an 'incentive' for the Rwandan government to commit to conservation beginning in 1979 (Vedder and Weber 1990; Nielsen and Spenceley 2010).

With regional conflict placing the Virungas at centre stage of the warfare in the 1990s, conservation and tourism came to an abrupt halt (Kanyamibwa 1998). Supported by the Ugandan government of Yoweri Museveni, the rebel group Rwandan Patriotic Front (RPF) under nowpresident Paul Kagame began to fight the Hutu regime invading Rwanda from Mgahinga forest through Volcanoes National Park (African Rights 1998). The following years of Rwandan civil war cumulated in the genocide in 1994. Justified as a conservation measure, the Ugandan government declared Mgahinga forest a National Park, precipitating eviction of the local population and prohibition of any entrance to the gazetted area to erect a buffer zone between Uganda and Rwanda. Acknowledging the devastating impact of the genocide on the conservation area, PNVi was declared as 'UNESCO World Heritage site in danger' in 1994.

The aftermath of the genocide led to an estimated 1.2 million refugees into Zaire with the largest camps around PNVi (UNHCR 2000). Factions of the former Rwandan army and the Interahamwe ${ }^{9}$ that executed the genocide re-established a military stronghold in PNVi forming the Forces démocratiques de libération du Rwanda (FDLR) in 2000. This armed group is held responsible for crimes against humanity and continued violent attacks both within Eastern Congo and in Rwanda via Volcanoes National Park (USNCC 2009). Concerted counterstrike of Rwandan and Ugandan backed military to eliminate associated Rwandan Hutu refugees in the region of Eastern DRC have officially been labelled the two Congo Wars (1996-1997; 1998-2003). However, humanitarian organisations report ongoing interference by armed groups supported by the

\footnotetext{
${ }^{8}$ The Democratic Republic of Congo was named 'Republic of Zaire' from 1971-1997.

${ }^{9}$ The Interahamwe is a paramilitary organization formed under Rwanda's former president Juvénal Habyarimana who played a central role in the atrocities before and during the Rwandan genocide in 1994 (Gourevitch 1998).
} 
Rwandan and Ugandan governments, who are suspected to incite insecurity and chaos in Eastern Congo to facilitate the exploitation and trafficking of natural resources (HRW 2005; Lopez et al. 2017; UNEP-MONUSCO-OSESG 2015; UNSC 2000, 2003). While conservation and tourism activities of PNVi have been revamped under a public-private partnership between ICCN and the Virunga Foundation with international funding since 2008, the park and its surrounding population are affected by the violent activities of more than approximately 140 armed groups within Eastern Congo (HRW 2019).

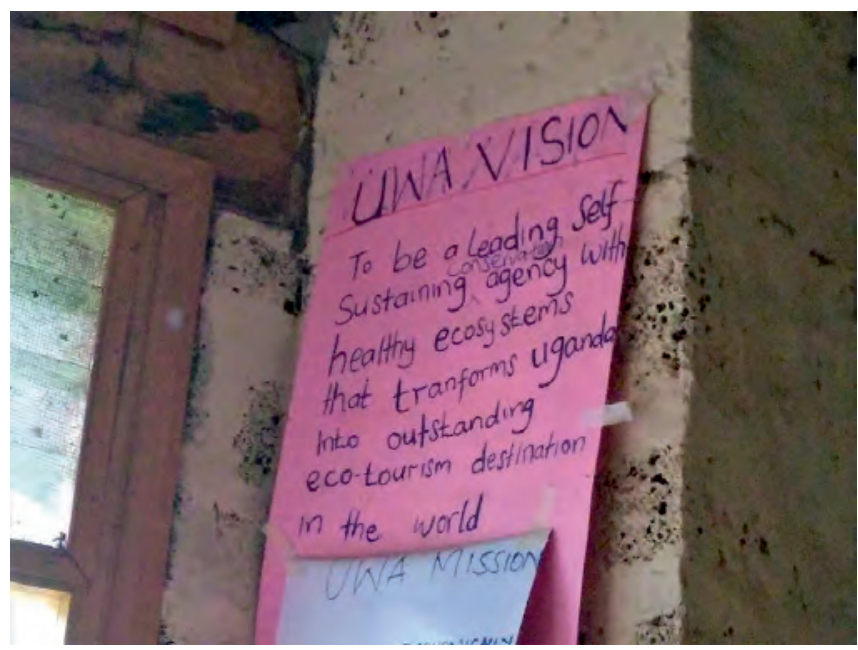

Fig. 2.2 "Transforming Uganda into an outstanding eco-tourism destination"

\section{Peace and security - through conservation and tourism?}

Considering these complex entanglements and power struggles in the conflictual history between the DRC, Rwanda and Uganda, international peacebuilding and conservation actors stressed the unifying qualities of joint conservation and tourism measures to establish collaboration, understanding and trust between the three states during the United Nations Great Lakes conference for "Peace and security in Greater Virunga Landscape: silencing the guns" in $2018 .{ }^{10}$ A representative of the GVTC asked:

„Can we create a peace haven in the Greater Virunga Landscape by collaborating over transboundary resources, including mountain gorillas, for benefitting all three countries?"

What sounded like a committed agenda to work towards generating peace through gorilla conservation together was, in fact, an appeal to establish a partners coalition for the institutional sustainability of GVTC, to replace the in political and financial support withdrawn by the Dutch government following their termination of funding at the end of 2018. In the first formal Memorandum of Understanding in 2004, the three Protected Area authorities and respective Ministries of the DRC, Rwanda and Uganda agreed to "build trust, understanding and

\footnotetext{
${ }^{10}$ Personal statements by Ramasamy Jayakumar, Head of Natural Sciences Sector, UNESCO, and Gabor Beszterczey, Senior Program Officer, O/SESG during United Nations Great Lakes conference, November 26, 2018.
} 
cooperation among wildlife authorities, nongovernmental organisations, users and other stakeholders to achieve sustainable conservation and thereby contribute to peace" (GVTC 2006 [2015]: 6). The treaty emphasized specifically the role of 'gorilla eco-tourism' comprising over $80 \%$ of all visitors in the three countries to achieve the objectives in the same spirit as the 'peace through tourism' vision of IIPT. Moreover, governmental officials of each country declared that they would take over the financing of GVTC as a coordinating institution for the concerted efforts (GVTC 2006 [2015]: 31).

In stark contrast to these written agreements and lip service proclamations, however, all transboundary meetings and projects by GVTC have expired, incapacitating the institution due to its liquidation at the time of writing (November 2020). Witnessing the preceding developments in 2018, the questions arose for us what impact the 'peace tourism' rhetoric has on the region and for the Virunga Conservation Area? What are the practices and outcomes of implementing 'peace tourism' propositions in each country and in how far do they lead to more peaceful relations between the three states? And how do tourism-related state and non-state actors, conservation organisations as well as people living around the parks without direct involvement in gorilla tourism, perceive and experience the impact of tourism on 'peace'?

\section{Transboundary gorillas offer no comparative advantage}

Mountain gorilla tracking appears to be an ideal 'product' to advocate for the benefits of tourism for peace in the relationship between the DRC, Rwanda and Uganda. The most evident commonality between neoliberal development policies promoted by the UNWTO and World Bank and 'peace tourism' aspects of the GVTC treaties is the primary focus on gorilla tourism as a foreign exchange earner to stimulate economic growth in each country. In pursuit of this revenue, the protected area authorities and governmental representatives of DR Congo, Rwanda and Uganda agreed to "[d]evelop a regional tourism plan that covers infrastructure development, marketing, visitor services and allows coordinated movement of tourists in the region" (GVTC 2006 [2015]: 11). The mountain gorilla attraction indeed made tourism the most important export earner of both Uganda (contributing 7.7\% to GDP in 2018) and Rwanda (14.9\% to GDP in 2018). Yet in interviews with representatives of the main gorilla conservation NGOs in the region, many expressed concern about the deterioration of political and economic relations between the DR Congo, Rwanda and Uganda and the negative impact of this on transboundary conservation efforts. As a representative of the International Gorilla Conservation Programme (IGCP), a long-standing transnational conservation NGO, highlighted:

"We started to talk to all of them [park authorities] to create relationships between Rwanda, Uganda and the DRC on the conservation level at least, while the governments had a tense relationship. We organized joint trainings and patrols between park officials and rangers from ORTPN, ${ }^{11}$ UWA and ICCN since 1991. We were allowed to ignore the borders. But with GVTC everything became political and conservation NGOs have less to say. Now rangers cannot share conservation data or walk together across the borders anymore."

Another IGCP employee made the explicit link between increasing conflict and tourism:

\footnotetext{
${ }^{11}$ Rwanda's conservation authority has been renamed from Office Rwandais du Tourisme et des Parcs Nationaux (ORTPN) to Rwandan Development Board in 2009.
} 
"In my opinion, I think tourism has negative effects on the relations between Rwanda, Uganda and the DRC because of increased competition over attracting tourists and in many cases it becomes more politicized. Gorillas are a golden asset and now each government wants to have an advantage over the other."

Based on Ricardo's (1817) well-rehearsed economic model of comparative advantage, international development organizations argue that due to lack of industrial capacity and/or 'valuable natural resources' to extract, many developing countries hold their only 'unique selling proposition' in the nature and wildlife they harbor, which they can vend as a competitive tourism product on the world market (UNEP 2009). Since the forest habitat of mountain gorillas is split between the DR Congo, Rwanda and Uganda, the three states embrace the same 'natural asset' in selling gorilla tracking as a high-end activity to international tourists. Hence, mountain gorillas framed as 'consumer products' confer no comparative advantage - no 'unique product' - to any one of the three countries involved in this activity. Due to the need to compete to attract the biggest share of the limited supply of visitors and tourism-related investors, therefore, the three countries are each encouraged to develop new consumer products to differentiate themselves from one another. As a result, GVTC's attempts to homogenize gorilla tourism across the VCA and share both costs and benefits regionally produced the opposite effect of increased political segregation and militarization of borders between the DRC, Rwanda and Uganda rather than the increased collaboration over management of the shared ecosystem the initiative envisioned. In the next section I analyse the different strategies each country developed to maintain sovereignty and create a 'unique', competitive product to showcase on the global tourism market.

\section{Regional dynamics triggered by Rwanda's gorilla price increase}

Gorilla tracking in all three National Parks comprising the VCA includes a guided hike with a military escort through dense forest at 2,200 to 4,300 metres altitude to visit one of the habituated gorilla families for one hour of observation on site. The extreme variation between prices for gorilla tracking - from 350 USD in the DR Congo to 650 USD in Uganda to initially 750 USD in Rwanda - creates the impression that the three countries offer highly differentiated touristic experiences. This image is reproduced by park rangers of RDB who are trained to promote the 'uniqueness' of Rwanda's mountain gorillas compared to the Ugandan and Congolese specimens. Despite the fact that mountain gorillas move freely across political borders in direct accordance with the aims of the transboundary conservation approach, the rangers persistently emphasized the unique Rwandan identity and superiority of 'their' apes. In a focus group interview with park rangers at a patrol outpost, one ranger expressed:

"Uganda has less [sic] gorillas and they are not cute. Look at our new gorilla babies in Agashya, ${ }^{12}$ they have much, much fur and look so cute."

Another ranger added:

"Tourists cannot see the gorillas in Congo because they hide from the war. When gorillas have fear they are not funny."

These statements represent a common sentiment among RDB rangers that the Congolese and Ugandan gorilla families are 'less': 'less visible', 'less funny', 'less cute'.

\footnotetext{
${ }^{12}$ Mountain gorillas are distinguished by their families with assigned names.
} 
In this context, GVTC presented its first substantial transboundary achievement in the "transfrontier gorilla tourism" agreement by declaring that when a gorilla group crosses borders from the country in which it has been habituated, the revenues generated from tracking this family has to be shared equally between the two countries (GVTC 2006 : 13). In response, every day from 6 in the morning to 6 at night, park rangers and their assistant trackers are assigned to locate each habituated gorilla family and follow them closely throughout the day until they build their nests to go to sleep in the evening, in order to ensure the animals do not leave the national park area. By taking part in monitoring patrols I witnessed these 'safeguarding' measures that are conducted similarly in Rwanda and Uganda (fig.2.3), enabled by the small sizes of VNP $\left(160 \mathrm{~km}^{2}\right)$ and MGNP $\left(33,9 \mathrm{~km}^{2}\right)$ compared to PNVi in the DRC $\left(7769 \mathrm{~km}^{2}\right)$. In contrast to the national commitments under GVTC, these measures exemplify the unwillingness by each state to collaborate over transnational revenue-sharing with respect to border-crossing gorillas.

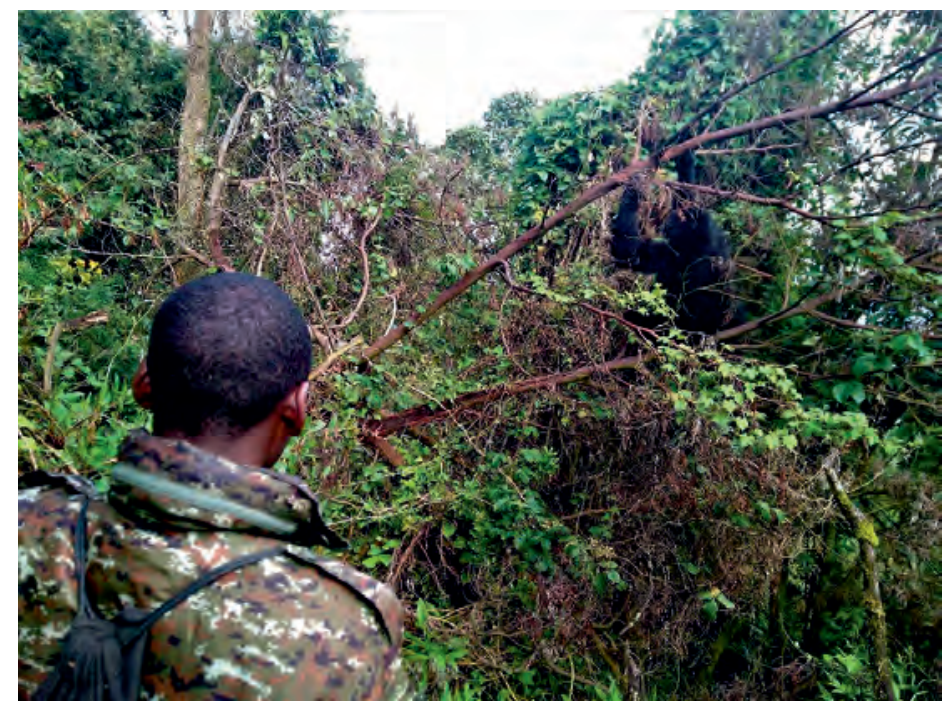

Fig. 2.3 "Military monitoring of mountain gorilla"

As a second proposition to overcome regional differences in the 'gorilla tourism product', the three states added to the transboundary strategic plan in 2015 the intention to "[h]armonise visitor charges for common tourism products and visitor handling services standards" (GVTC 2015: 11). Hence, RDB rangers and tourism operators claimed to be taken by surprise when Rwanda doubled its gorilla tracking fees to 1500 USD overnight on May 11, 2017 (personal interviews, Musanze, Goma, Kigali, 2018). The Chief Executive Officer of RDB, Claire Akamanzi, officially justified the unprecedented price spike on grounds of ecological sustainability as intended to decrease the number of tourists (and associated impact) without decreasing the foreign exchange Rwanda needs to finance development projects and "empower 
communities living near the park" ${ }^{13}$ In response, an employee of a regional gorilla conservation organisations complained:

"The Rwandan government is always doing what it wants. We monitor and work with the gorilla

families for four decades but we would not be consulted for any conservation-related advices."

In a meeting with the trilateral secretariat of GVTC, one representative admitted feeling subverted:

"We were not informed about the price increase. We did not get an official letter or call after the decision. We heard the information on public news."

The unilateral price change made a strong statement against the promoted transboundary collaboration and undermined any political mandate and authority the GVTC retained at that point. Rwanda's official explanation of the price increase was intended to please conservationists, international donors and further serves as part of Rwanda's image campaign to overcome persistent associations with the genocide in 1994 (Grosspietsch 2006). The tourism management literature accordingly advices, "developing countries must constantly [...] protect their image and maintain their position in the global tourism arena" (Avraham and Ketter 2016: 3) by 'selling' their destination that faces "stereotypes of high risk, hostility and underdevelopment" (ibid. 2016: 110). This dominant conceit of the Western tourism literature already points to the imbalance of the global tourism market that is intended to please Western consumer demands.

Since gorilla tracking was initiated again in 1999, a growing group of Rwandan scholars has praised the Rwandan government for adapting to this 'world standard of tourism' to rapidly reestablish the devastated national image and economy creating 'wealth and peace in post-conflict Rwanda' (Maekawa et al. 2013; Spencer and Rurangwa 2012). The World Bank reinforces this perception in framing Rwanda as the "African success story" pointing to the peace-generating link between mountain gorilla conservation and economic development as a key component of this success (Nielsen and Spenceley 2010).

\section{Selling security}

Tourism exemplifies the capitalist principles of permanent (re-)invention of 'new' consumer goods for offer to the global market. Rwanda's gorilla tracking fee increase was intended to promote a novel, unique tourism product for the country combining the endangered gorillas with high-end security. It is this singular combination that underlines Rwanda's success in ostensibly providing a 'peace haven' for the great apes in the conflict-affected region. Moreover, since tourist arrivals are highly dependent on the stability and security of a destination region (Neumayer 2004), globally fanned fears of terrorism led to new tourism marketing strategies offering 'security' for purchase more widely (Sönmez 1998). Rwanda's strategy falls right in line with this approach. In accordance with Hochschild's argument that the 'management of emotions' became an 'instrument' of the capitalist system to invent new products turning 'feeling into a commodity' for sale (Hochschild 1983 [2012], p. 186), Rwanda promotes an inimitable gorilla tourism experience combined with a luxurious feeling of security for the tourist in the otherwise "war-

\footnotetext{
${ }^{13}$ The EastAfrican $10^{\text {th }}$ May 2017: Rwanda targets wealthy tourists with new gorilla permit fees, Wednesday May 10 2017; https://www.independent.co.uk/travel/news-and-advice/rwanda-gorilla-encounter-fees-doubled-ugandaa7727821.html
} 
torn' region (World Bank 2013). Since the commercialisation of security is a fruitful strategy to overcome the distorted international crisis narratives surrounding African countries in general, the Rwandan government devotes a significant part of its marketing campaigns as well as national expenditures to the security sector. As the official website of VNP presents:

"Today the people of Rwanda are living in a very stable and peaceful country as the RPF ${ }^{14}$ have continued to ensure the safety of all Rwandan borders to ensure that there are no external attacks from any rebel group that might be formed in one of the neighboring countries. The internal security within the country is also very tight with forces always moving around communities to ensure that all the citizens are safe." (VNP 2018)

In this respect, Rwanda's 'unique selling proposition' in the tourism sector has never been solely the mountain gorilla but rather this combined with the "African success story" that seemingly transformed the country "from a land of zombies and misery to become an economic model on the African continent" (VNP 2020). Given the importance of this differential framing for capturing tourism revenue, increasing the GVTC's interference within national policies and practices as part of its transboundary peace efforts appear to pose a particular threat to Rwanda's specific tourism asset. Hence, Rwanda's increase of gorilla tracking fees was partially a political measure to reclaim sovereignty and re-create a unique tourism product. Presenting Rwanda as "more developed", "more progressive" and a "safe haven" (African Wildlife Fund 2020) relative to its neighbours further justifies the high price as a necessary investment to provide security and high standards for visitors and investors. A Rwandan tour operator explained in the same spirit:

"Rwanda has no natural resources, the only thing we have is our security that attracts foreigners: investors and tourists. That is why our government invests everything into security. [...] I get concerned if I don't see a soldier somewhere."

\section{Tourist 'security' to justify militarisation}

This quote underscores how official promotion of Rwanda's tourism seems to be aligned to the security demands of the tourism sector to militarize the destination (Weaver 2011). Yet Rwanda's government rather appears to make use of the normalised militarization for tourism in Rwanda's everyday reality in a reverse manner. In order to keep the current power structures under the authoritarian regime of Paul Kagame unchallenged, the deployment of military, security services and surveillance infiltrates and controls every space within the country's borders, regardless of the presence of tourists. The official explanation of focussing security on high-end tourism generates an internationally accepted and even appreciated legitimization of militarising Rwanda in the name of tourists' safety. More generally, tourism scholars have found a strong positive correlation between military expenditures and tourism growth, thus recommending states to create 'security' through the militarisation of tourism destinations. Such prescriptions offer states further legitimization to devote larger shares of the fiscal base to military expenditure and attract international funding and supply for the national armament (Nassani et al. 2017).

\footnotetext{
${ }^{14}$ Rwandan Patriotic Front (explanation by the authors)
} 


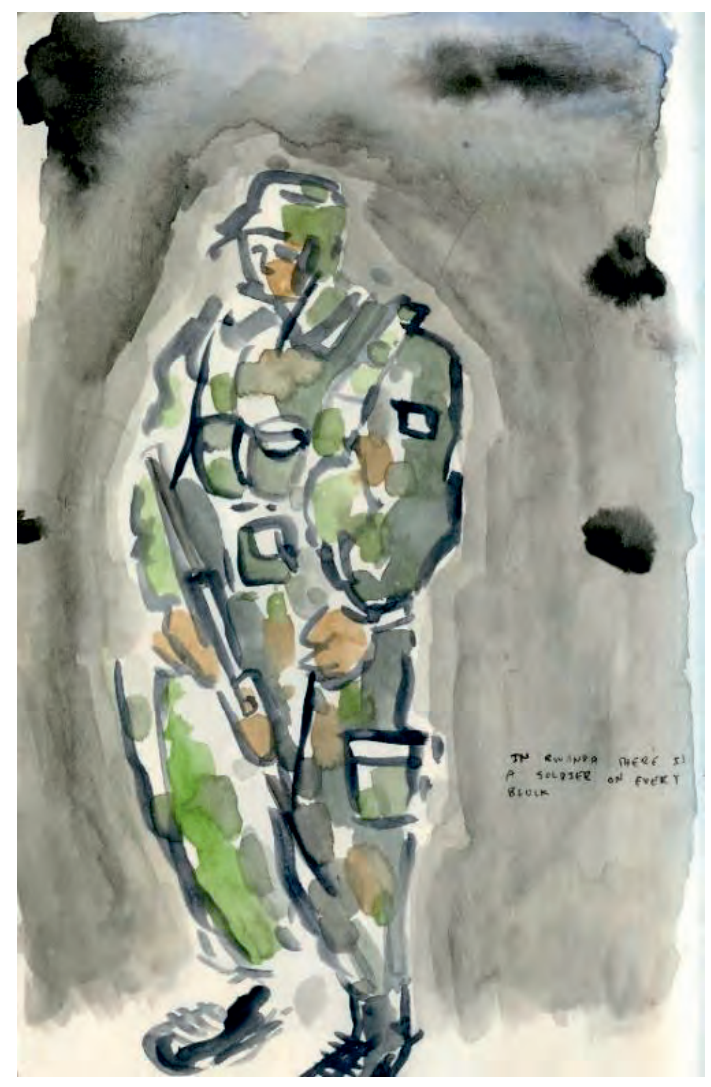

Fig. 2.4 "In Rwanda there is a soldier on every block"

While international and national media commonly portrays Rwanda as an island of security in the conflict-ridden region, the frequent violent skirmishes between armed forces from the DRC and the Rwandan military within Volcanoes National Park on Rwandan territory are for the most part successfully concealed by Rwandan censorship of the media, under the imperative not to scare away potential tourists. On 4 October 2019 an exceptionally violent incident reached the international media, when militias entered Rwanda though VNP and killed 14 people in the adjacent communities of Kinigi district where the National Park headquarters are located. The British travel advice service stated in the same moment that "the Government of Rwanda reports that the area is now secure following the deployment of additional security forces and tourism services continue to operate as normal in the Park" ${ }^{15}$.

After the end of the genocide, the Rwandan government established a dense network of the national military, the Rwanda Defence Force ${ }^{16}$, in and around VNP, to protect the national borders with the DRC from expected and actual attacks by fighters from the deposed former Hutu government and nowadays its remnants within the armed group of the FDLR. With the

\footnotetext{
${ }^{15}$ https://www.gov.uk/foreign-travel-advice/rwanda/safety-and-security, accessed 27-2-2020.

${ }^{16}$ The Rwandan Defence Force was formerly known by the name Rwandan Patriotic Army created by the military division of the former rebel group of the Rwandan Patriotic Front.
} 
reintroduction of tourism in 1999, the paramilitary training and armament of park rangers added another militarised set of actors to the park and the national borders. In the name of conservation, the 'green' militarisation (Lunstrum 2014) of the area is justified to the international public and visitors through two main narratives. First, the training and armament of rangers is justified as necessary for the protection of mountain gorillas against 'poachers'. The 'law enforcement' warden of VNP explained this in the following way:

"The biggest problem of the park are poachers, those Historically Marginalized People ${ }^{17}$ who are addicted to hunting. First, we have routine patrols every day inside park to protect the animals. They report on illegal park activities. Second, we get information from the communities that there is a poacher who enters the park. We respond with an ambush patrol."

However, while partaking in patrols close to the Congolese border, park rangers explained that would-be 'poachers' are too poor to afford the fire weapons they would need to present a substantial threat to the animals or to rangers themselves. The leading ranger of the patrol further explained:

"The forest is steep and has too many trees, that is why poachers can only use bamboo traps to catch small duikers. ${ }^{18}$ But it is our duty to destroy all traps because a gorilla can step into it and get injured."

This conviction that local hunters could not use firearms in the dense forest on the steep volcano slopes calls into question whether militarization of park patrols for protection of wildlife is either effective or necessary.

The second narrative deployed by protected area authorities and ranger guides from RDB to justify militarization to gorilla tourists is that the military joining every tracking group is needed to protect visitors from wild buffalos. In contrast to the rifles carried by park rangers, RPF soldiers wear bullet-proof security vests and heavy arms, join tourist groups just before entering the National Park and leave again just after the group leaves the forest again to not compromise the welcoming atmosphere of the park headquarters. Yet even on routine patrols with rangers far away from any tourist activity, up to ten armed soldiers would join the armed RDB staff as well, calling into question explanations of their necessity for 'protection from buffalo'.

\section{The Virunga National Park strategy - embracing security through militarization} Rwanda's price spike resulted in an increase of tourism flows from Rwanda to the DRC and Uganda. In 2018, Volcanoes National Park stated that they lost an estimated 60\% of gorilla tourists to Uganda (VNP 2020). In 2018, interviews with Rwandan tourism stakeholders and protected area authorities were increasingly coloured by derogatory anecdotes and a hostile attitude towards the neighbouring gorilla destinations. In particular, depictions of 'the Congo' as a place of barbarity, violence and war came through in conversations with park rangers, tourism workers and local residents throughout both Rwanda and Uganda (first author, forthcoming). Western media, international organisations and international travel advisories contribute to

\footnotetext{
${ }^{17}$ After 1994, Rwanda invented the problematic label "Historically Marginalized People" (HMPs) to refer to the indigenous Batwa population to avoid categorisation into ethnicities.

${ }^{18}$ Duikers are a type of small antelope.
} 
undifferentiated and distorted narratives of crisis throughout the Eastern DR Congo (see e.g. Autesserre 2012).

In contrast to Rwanda's reputation as the "most secure African country", ${ }^{19}$ the Eastern Congo stands on the opposite end of the safety spectrum as the "world's deadliest spot" ${ }^{20}$ and Western governments advice against all travel to Eastern Congo. ${ }^{21}$ In an effort to transform this image from curse to blessing, marketing strategies implemented by the new management of PNVi comprising a public-private partnership between ICCN and the British charity Virunga Foundation established in 2008. This strategy aims to embrace the DRC's negative image in describing "the fight to save one of the world's most dangerous parks" (National Geographic 2016). Funding by the Howard Buffet Foundation and the European Union enabled large-scale projects "to foster peace and prosperity through the responsible economic development of natural resources" (PNVi 2PNV020). A central aspect of this economic plan is PNVi's own peace tourism model. As a PNVi staff member explained in an interview:

"GVTC extracts money from our investors to finance projects that are completely inappropriate for the Congo. These people [from GVTC] have no understanding of our situation, they just give money to "Water4Virungas'22 and wonder that it disappears and nothing happens."

This statement reflects a common perception among PNVi staff and rangers that external institutions such as GVTC lack an understanding of the Congolese context and of PNVi as characterized by both severe corruption and extraordinary security requirements.

Consequently, PNVi representatives rarely attended transboundary meetings organized by GVTC in 2018, resulting in growing resentment on the part of protected area authorities from RDB and UWA, as exemplified in focus group interviews:

"De Merode 23 does not want to listen to other people. To be fair, he faces incredible challenges that most, not even Congolese, could manage. But he thinks he is a better leader and this arrogance makes him work on an island."

Such claims to autonomous sovereignty by conservation authorities have prompted researchers to argue that PNVi's adoption of securitization and militarization measures in the name of conservation that can be equated with the governance strategy under Belgium colonial rule to create 'a state within the state' (Marijnen 2018: 2).

In interviews, the PNVi park management in the park headquarters in Rumangabo (DRC) gave two official reasons for their withdrawal from participation under GVTC. First, permanent intimidation and blackmailing by Congolese state authorities and armed groups would not allow managers to spend time and money on GVTC efforts that have no political

\footnotetext{
${ }^{19}$ Most travel advisors for Rwanda quote the Gallup report 2017 ranking Rwanda as second safest country in Africa, as leading example the Lonely Planet: https://www.lonelyplanet.com/rwanda/safety, accessed 18-42020.

${ }^{20} \mathrm{https} / / /$ www.brookings.edu/opinions/democratic-republic-of-congo-worlds-deadliest-spot/, accessed 18-4-2020.

${ }^{21}$ https://www.gov.uk/foreign-travel-advice/democratic-republic-of-the-congo/safety-and-security, accessed 18-42020

${ }^{22}$ The funding by GVTC was based on "the overall objective of Water4Virunga [...] of contributing to the regional stability through an improved human security and inclusive growth" (GVTC n.d.). Yet, the embezzlement of project funds and power struggles between different stakeholders on the Congolese side has torpedoed any implementation on Congolese ground - in contrast to the compelling depictions of success on W4V official website (https://www.water4virungas.org/).

${ }^{23}$ The Belgium Emmanuel de Merode is PNVi's park director since 2008.
} 
mandate to create any positive change. Second, the ongoing exploitation of the Eastern Congo's natural resources by Rwanda would render any collaboration merely superficial window-dressing. These explanations point to a history of mistrust and anger against Rwanda's overt interventions and backing of armed militias in the Eastern DRC, as exemplified by this statement from one ICCN employee:

"Please stress when you go back to your country that it is Rwanda that keeps the insecurity in Eastern Congo. Rwanda controls our mines, our trade, our roads, our borders. Kagame has its own control even in the Congolese military. Our instability is created by Rwanda, they take advantage of our weakness. Rwanda has an interest to maintain the instability in North Kivu. For their own benefits."

Parallel to Rwanda's self-portrayal as an island of security in sub-Sahara Africa, PNVi's park managers espouse negative narratives about the Eastern Congo in claiming to offer visitors a contrasting safe experience with military escorts in the dangerous environment. In the same vein, tour operators advertise PNVi for adventurous travellers as a reasonably safe, unique experience in "the heart of instability" on the internet. ${ }^{24}$ In an interview, a Rwandan tour guide who presented himself as a the founder of a transboundary tourism agency aligned to Virunga's transnational travel sphere, emphasized a kind of 'dark touristic' interest in the Congo:

"These people would pay anything just to set one foot on Congolese soil to say they have been in the war zone."

In this respect, the kidnapping of tourists on the road between Goma and the park headquarters in Rumangabo in May 2018 was unprecedented in the park's history and caused a major shock to the park and tourism stakeholders within the DRC. In contrast to the frequent kidnappings of local people living in proximity to the park barely gaining media attention, the abduction of two British visitors attracted international publicity leading to the closure of all tourism activities in and around PNVi until February 2019. The incident further undermined the relationship between Congolese and Rwandan park authorities and brought all diplomatic discussions concerning transboundary conservation measures under GVTC to a halt. In reaction to Rwanda's sudden price increase, ICCN staff accused Rwanda of having initiated the kidnappings out of jealously that Rwanda would lose its tourists to PNVi. In a focus group interview, one employee of PNVi's tourist lodge at the park's headquarters in Rumangabo stated this clearly:

"Rwanda needed to stop it [tourism], to get more tourists. We know all the armed groups in and around the park, they have never kidnapped tourists."

Investigations from the United Nations mission United Nations Organization Stabilization Mission in the Democratic Republic of the Congo (MONUSCO) corroborated other sources in explaining that the kidnappers were probably linked to the FDLR in response to the latest law enforcement activities of PNVI's park management entailing confiscation of large amounts of illegal charcoal from several FDLR cartels.

To respond to the panic of international tourism operators and Western travel advisories that discouraged any travel into the Eastern Congo, PNVi's management hired security service operators and risk analysts from France and the United States to restructure the National Park's whole security system, creating an electronic-fenced, highly protected stronghold out of the park's

\footnotetext{
${ }^{24}$ https://www.virungaparkcongo.com/information/safety-virunga-safe/, accessed 27-2-2020.
} 
headquarters and the patrol outposts. While the park management stated that they cannot establish a Virunga specific army, the paramilitary training, equipment and salary of the 700 ICCN rangers extends the resources of the regular Congolese army, Forces Armées de la Republique Democratique du Congo (FARDC). As an attempt to overcome a history of violent collision between park rangers and military personnel in the past and to strengthen the regional security in the future, PNVi re-established joint patrols of park rangers and Congolese soldiers, called Corps Protection Parque de Naturel (CorPPN), in the aftermath of the kidnapping incident. Furthermore, an arrangement with the MONUSCO was made to safeguard the road from Goma to Rumangabo.

Based on the new security protocol, the park management promoted security for travellers, including warning that safety in relation to transport, accommodation and tourism activities in and around the park can only be guaranteed when provided by PNVi park authorities themselves. The access to a special visa for the DRC that can only be issued via Virunga National Park and the monopoly on military security asserted as a necessary tourism service undermines any potential for local tourism operators who are not able to compete with the 'security standards' demanded by international tourism operators and Western governments' travel advice. A number of Congolese tour operators and driver guides confirmed this; as one succinctly summarized:

"The park is de Merode's private business. He does not want to share."

When discussing this perceived exclusion with the PNVi management, an employee explained in response:

"There is a political agenda behind all the negative rumours about the park. The Congolese government is blackmailing us because they cannot exploit the oil in Virunga: 'If you want to protect the park, pay us the revenue!' If not, they attack. We have the responsibility that our staff and visitors are safe, we cannot delegate that task to externals."

This statement points to the complex entanglement of conservation practices with the violent conflict and warfare in the Eastern Congo that informed establishment of the tourism industry for decades. These measures aimed towards reopening the park for tourism illustrate how the understanding of 'peace' in tourism became increasingly linked to the concept of human security, yet the 'humans' deserving of (military) protection within this context appears to be primarily the tourists rather than local citizens. In the context of PNVi in the Eastern Congo and VNP in Rwandan, 'security' seems to be a luxurious privilege for the humans in transit through, not the humans actually inhabiting the destination region. Military escorts, fenced park headquarters and tourism lodges as well as the gazetted, patrolled borders of the National Park create strong boundaries between visitors and locals rather than the intercultural understanding proposed by 'peace tourism' visions.

\section{Local perceptions of 'peace' through tourism}

UNWTO proposes that local communities adjacent to protected areas should receive the greatest benefits from tourism as they comprise the greatest part of the population evicted in the establishment of National Parks and further need an incentive to support conservation efforts (UNWTO 2015: 22). In this spirit, the GVTC treaty between the three states emphasized 
"revenue-sharing schemes from tourism revenues with local communities to establish positive attitudes towards tourism and the TBPA" (GVTC 2006 [2015]: 13). Yet, the 'peace tourism' agenda does not consider the violence done to local people and environments by tourists, private businesses and the nation states as among the biggest tourism providers. National reports still identify the highest poverty levels in all three countries in direct vicinity to the National Parks (Bush et al. 2010; Kalulu et al. 2016, Kujirakwinja et al. 2010; Twinamatsiko et al. 2014). In addition, and partly in consequence of this rampant poverty, illegal park activities such as logging and hunting in Rwanda $^{25}$ and the DRC, and charcoal production and fishing in PNVi specifically, persist (Marijnen and Verweijen 2016; Sabuhoro et al. 2020). In response, park managers have introduced stricter law enforcement measures by conservation staff, from imprisonment to the legalization of shoot-on-sight in Uganda and the DR Congo. Studies concerning local perceptions of gorilla tourism confirmed my interviews with park-adjacently living community members in all three countries reflecting the persistent conflict between park staff and local residents who complain about the loss of their harvests to animals exiting the park, the inequitable distribution of revenues, and labor exploitation by tourism businesses (Adams and Infield 2003; Nkurunungi and Ampumuza 2013; Munanura et al. 2016). In this regards the promotion of national revenue-sharing models appears to be largely a marketing strategy to appeal to tourists' conscience, enabling them to 'offset' their luxurious consumer footprint by offering them the conviction that their presence and money are serving "help ending poverty" (PNVi 2020), "empower local communities" (VNP 2020) and "contribute to improving the livelihoods of households in frontline villages" (UWA 2020). GVTC's transboundary strategic plan further asserts that

[t]he tourism industry creates employment opportunities in both urban and rural areas, thereby reducing pressure on wildlife resources. At the current level of tourism, the available facilities, especially for the up market visitor seem to be adequate in some areas. Focus is therefore required for the lower market visitor in these places. (GVTC 2006 [2015]: 10-11)

In direct opposition to this mandate to improve the 'lower-end' market, however, Rwanda's 2017 increase of gorilla tracking fees led to a drastic decrease in the numbers of tourist arrivals with devastating impacts on small-scale tourism businesses including hostels and smaller hotels, local tour guides and restaurants. In order to keep the flow of tourism's foreign exchange for the Rwandan government, Rwanda implemented a range of new tourism rules and regulations to homogenise the tourism landscape around Volcanoes National Park to make it "one of the world's most remarkable luxury ecotourism destinations" (RDB 2020). Consequently, high-end hotels and services became the face of Rwanda's tourism marketing strategy to attract the wealthiest tourists and celebrities. Five-star hotel projects thus began to mushroom around VNP in 2018, offering helicopter flights to overcome the inaccessibility of stony dirt roads up the volcano slopes.

In the course of 2018, in reaction to this shift, I witnessed the closure of numerous tourist accommodations. While many smaller facilities simply lost out from the lack of international

\footnotetext{
${ }^{25}$ Georgia Tech Center for GIS and the Dian Fossey Gorilla Fund International 2018: 'Poaching in Rwanda's Volcanoes National Park', http://hub.arcgis.com/datasets/6a9e68db05704b119adb5fc3e4708291, accessed 17-1. 2020 .
} 
tourist arrivals, one particular narrative circulated around the main tourist areas of VNP, as a hostel owner described:

"The big hotels complain to the government of Rwanda that they see no guests anymore and demand to shut us down. Now the government makes up new law every day, to bring licenses and documents that cost a lot of money. We cannot speak to the government and we cannot pay. We obey the law and shut down."

Many other small tourism businesses similarly claimed that the Rwandan government invented arbitrary policies demanding unfulfillable requirements to ostensibly improve business standards. For example, one day in 2018 an official note sent to local guesthouses that remained in business commanded them to provide a marquise covering the front 'porch' of each house or face prohibition of any tourism services until further notice. After three weeks, the resulting closure cut any possible profit leading to bankruptcy for most owners. In this politically legitimized way the government squeezed remaining competitors for the high-end tourism facilities out of the market.

The promises made by the public-private partnership managing PNVi to "deliver large-scale opportunities for the local community by reducing poverty rates, stabilizing security, and strengthening local infrastructure" (PNVi 2020) leave many local people living in the vicinity feeling disappointment and rage. In focus group interviews in park-adjacent villages, many expressed their resentment against PNVi personified in the park director de Merode. Despite implementation of two hydroelectric power plants and numerous community development projects funded largely by the Buffet Foundation, many local communities complained that they are not and have never been included in the benefits from these projects, particularly pointing at the electric wires running through their village to the city of Goma, without an electric connection to their houses (Trogisch, forthcoming). Moreover, they explained how they mostly suffer from the persistent insecurity around PNVi, a situation that appears exceptionally unjust to them when large military convoys safeguard a few tourists in and out of the park. One local chief summarized this view:

"The park is for the communities, ICCN just manages it. But ICCN takes the crops and the land from our communities, so they [community members] turn against the park. Now the park is for white people and there is no peace between the park and the communities."

\section{Conclusion}

This paper contributes to ongoing debates concerning the role of 'peace tourism' initiatives in the politics and lived realities around transboundary protected areas in conflict-affected settings through a case study of the Virunga Conservation Area. While the VCA is a single case study embedded in the complex historical context peculiar to the DR Congo, Rwanda and Uganda, it serves to problematize dynamics of 'peace tourism' rhetoric and practice more generally that will hopefully inspire future interdisciplinary research at the intersection of tourism, conservation and conflict studies.

In particular, this paper questioned the dominant conceptualizations of 'peace through tourism' in the context of transboundary protected areas drawing on neoliberal, macro-economic 
development theories. Protagonists of so-called peace parks suggest that augmenting the fiscal base of the national economy will improve the well-being of citizens as well as collaboration between governments in management of the shared ecosystem. In the case of the VCA, however, my analysis has demonstrated that intergovernmental 'peace tourism' propositions under the umbrella institutions GVTC have instead led to increased competition, mistrust and mutual 'defaming' among the DRC, Rwanda and Uganda to assert sovereignty and capture the lion's share of gorilla tourism revenue. In this context, the historical warfare between the three countries provides an opportunity to maintain and exacerbate accusations and threat discourses legitimizing militarization within the National Parks comprising the VCA.

Simultaneously, the national park authorities exploit this same militarization as an indicator of the 'security' that is sold to tourists as a luxurious (and lucrative) product in paradoxical combination with the opportunity to encounter endangered mountain gorilla. In a circular logic, these tourism revenues are used to justify and finance the militarisation of national and park borders to ultimately create a military bulwark against the neighbouring states under the cover of providing security for tourists. My framing of this dynamic as 'fortress tourism' points to the contradictions that the 'peace tourism' label conceals in safeguarding wealthy visitors using military means that simultaneously exclude and alienate local residents. This provision of 'human security' for tourists thus underscores the structural violence and inequality local inhabitants experience in not being considered as 'human' and therefore barely profiting from the expanding infrastructure projects, risk assessments and security measures implemented around them. In this way, the association of peace with 'human security' promised within peace parks discourse becomes yet another consumer product for the people who can afford to pay for this 'peacefulness'. These dynamics suggest that the improvement of park-to-people relationships the peace park concept intended to facilitate reverses in the case of the Virungas as local people instead experience an increase in inequality and sense of abandonment by conservation, state and international agents due to the provision of security itself.

Ultimately, 'peace tourism' in the VCA thus seems to remain a largely rhetorical strategy intended to please international conservation and development donors and international tourists so as to secure funding for other stakeholders and projects having little or nothing to do with environmental peacebuilding itself. This contradiction between tourism's ostensive 'peace dividend' and the different forms of violence it actually generates within the context of transboundary conservation efforts poses the question of what kind of 'peace' can actually be generated through this type of tourism, and for whom? Who defines what this 'peace' means and entails?

To address these questions became even more urgent since the COVID-19 pandemic drastically impacted the international travel industry, in the process accentuating the highly volatile entanglement between tourism and conservation in relation to both local people's livelihoods and biodiversity protection (Fletcher et al. 2020). In VCA, dependency on gorilla tourism led to closure of the three National Parks, leaving local tourism stakeholders without business and diminishing the park's revenue-sharing with local communities even further. This has aggravated an already tense situation as further militaristic securitization of the protected 
areas confronts a growing number of people who enter the parks unauthorized in pursuit of basic resources for survival as other livelihood options recede. Yet COVID-19 also presents a moment of global uncertainty that could offer potential for new aspirations and innovations to alter these long-standing patterns of inequality entrenched by the flawed concept of tourism as a panacea for peace, conservation and economic development. This moment demands engaged, critical and constructive scholarship and activism to pursue transformative change, in the contexts of conservation, tourism and beyond. 
Fortress tourism 



\section{Chapter III}

Geographies of fear - the everyday (geo)politics of 'green' violence and militarization in the intended transboundary Virunga Conservation Area

This chapter has been published as:

Trogisch, L. 2021: “Geographies of fear - the everyday (geo)politics of 'green' violence and militarization in the intended transboundary Virunga Conservation Area"

Geoforum 122: 92-102.

Content has been slightly edited to make the chapter fit into the rest of the thesis.

< Fig. 3.1 "Merging with the grass: rangers on a break during a twelve-hour patrol" 


\section{Introduction}

Although critical scholars have contested violent practices undertaken in the name of conservation for decades (Neumann 1998; Peluso and Watts 2001; Shiva 1990), an alarming increase in "green militarization" (Lunstrum 2014) - the adaption of militaristic methods, tactics and equipment for protection of flora and fauna - has been widely documented in recent years (Adams 2019; Bocajero and Ojeda 2016; Duffy 2014). Expanding on this concept, Büscher and Ramutsindela (2015) outline a continuum of forms of 'green' violence including but not limited to militaristic measures deployed in the specific context of Transboundary Protected Areas (TBPA). TBPAs are conservation sites that straddle the political borders of at least two countries (IUCN 2020). Promoted as 'peace parks' in Sub-Sahara Africa, they have been praised as contributing to encourage collaboration between (formerly) conflicting states, leading to economic development, sustainable conservation and ultimately regional peace (Ali 2007; Barquet et al. 2014; Hanks 2003). While increasing violence and militarization in and around TBPAs contradict this asserted association with peacebuilding, few studies have addressed these problematic developments in the specific context of peace parks (a notable exception being Büscher and Ramutsindela 2015). This article thus pursues a deeper understanding of how and why 'green' militarization and violence unfold within these spaces and thus undermine the cooperation and peace intended to manifest between countries who entered a transnational TBPA agreement?

To fill this research gap, this paper explores the case of the intended transboundary Virunga Conservation Area, composed by Virunga National Park (PNVi) in the Democratic Republic of the Congo (DRC), Volcanoes National Park (VNP) in Rwanda, and Mgahinga Gorilla National Park (MGNP) in Uganda. Since TBPAs are border-crossing geographical spaces characterized by complex political dynamics and a multitude of interests between state and non-state actors, they require transnational agreements that are often informed by international development, conservation and peacebuilding trends (see e.g. UNEP 2009). They are thus inherently geopolitical.

Within the Virungas, efforts to institutionalise cooperation among the DRC, Rwanda and Uganda on the TBPA model by the intergovernmental organisation Greater Virunga Transboundary Collaboration (GVTC) are undermined by segregation and militarization of the three National Parks as well as their respective rangers. Stories of frequent violent and lethal skirmishes between different armed groups within the contiguous forest and across state boundaries also contradict the regional peace aspirations expressed in the TBPA agreements. Further, militaristic measures undertaken in the name of conservation are jurisdictionally and discursively 'normalized' by the national governments of both Rwanda and Uganda, yet are reiterated and performed through the local and felt in the everyday experiences of conservation staff and park-adjacent communities alike. In order to shed light on this link between (trans)national dynamics and local realities within the context of TBPAs, I focus on the experiences and perceptions of of park rangers from the Rwanda Development Board (RDB) at VNP and the Uganda Wildlife Authority (UWA) at MGNP. To develop my analysis of these dynamics, I offer a novel conceptual approach to exploring 'green' conservation violence inspired by frameworks from emotional geographies and critical geopolitics 
focused on the analysis of fear, understood as a discursively constructed experience. Scholars from emotional geographies emphasize the circular relationship between emotions and landscapes that shapes both social relations and political processes (Anderson and Smith 2001, Davidson and Milligan 2004; Tuan 1978). Meanwhile, the subjective experience of emotions that informs individual behaviour in relation to certain spaces has been explored in the critical geopolitics literature. Critical geopolitics challenge conventional geopolitical scholarship that tends to reduce political struggles to contestation between dominant nation-states on the world stage. In contrast, work in critical geopolitics emphasizes analysis of personal, emotional experiences that can illuminate the reciprocal interrelation between (geo)political state discourses and their enactment by individuals in their everyday lives (Hyndman 2007; Pain and Smith 2008). Placing emphasis on individual emotions, some scholars specifically highlight the instrumentalization of fear by governmental discourses wherein geopolitical threat narratives are promoted to legitimize statesanctioned violence in the name of national security (Cowen and Gilbert 2008; Huysmans 2006). Inspired by this approach, I propose to ground the analysis of 'green' violence within transnational conservation efforts on the local scale in order to illuminate how fear is experienced and negotiated by actors charged with carrying out state-mandated conservation directives.

My aim is to examine how militarized and violent dynamics reveal the entanglement between conservation and (geo-)politics by analysing the emotional repercussions of these developments in park rangers' narratives about their day-to-day work. Trained and deployed as parastatal conservation actors by their respective governments, rangers' perceptions revealed patterns of fear that inform their enactment of and ostensible compliance with these dynamics. Based on rangers' narratives depicting the transboundary forest as a 'geography of fear', I argue that their fears function to legitimize 'green' violence, militarization and segregation of the National Parks, thereby serving underlying (geo-)political interests of sovereignty and integrity for the respective governments. Analysing fear discourses within conservation practices can thus aid in deconstructing the interlinkage among 'green' violence, militarization and concealed (geo)political interests in TBPA development. Moreover, previous studies concerning the perceptions of fear have yielded deeper understanding of individuals' and groups' willingness to commit violence that have helped to inform better targeted interventions (see e.g. Agnew 2001). Thus, understanding rangers' fears in the context of conservation enforcement can help to explain why different forms of 'green' violence persist and hence inspire pathways for pursuit of non-violent alternatives.

After a brief description of ethnographic methods used in this research, I explain how integration and synthesis of literature from critical geopolitics and emotional geographies on fear can advance the debate on 'green' violence and militarization in the context of (transboundary) conservation. I then outline the historical context of the Virunga region before turning to the analysis of three dominant fear narratives and their underlying governmental interests that inform rangers' everyday realities. Based on this discussion, I argue that rangers' perception of a 'geography of fear' ultimately serves to legitimize militarization of the Virungas in the name of conservation, thereby undermining the transboundary collaboration efforts. In conclusion, I reiterate how the 
analysis of fear discourses can benefit critical conservation studies by highlighting the concealed geopolitics in everyday conservation work on the ground.

\section{Methods}

This paper draws on twelve months of ethnographic fieldwork in 2018 conducted in and around the three National Parks that are envisioned to constitute the transboundary Virunga Conservation Area. Taking a participatory research approach, I spent a significant amount of life and work time with park rangers from RDB in Rwanda and from UWA in Uganda, partaking in tourist guiding, gorilla monitoring, and anti-poaching patrols as well as living with rangers in different patrol outposts (permanent posts away from the park headquarters). To complement conversations and observation conducted during this time, I held semi-structured individual and focus group interviews with local community members, park rangers and their superiors holding positions as park wardens and in park management. Due to security restrictions, interaction with rangers in the DRC was limited to a granted stay at the Rumangabo headquarters within PNVi and interviews in Goma, the regional capital of North Kivu. Triangulation of data from these various sources was reinforced by interviewing transboundary conservation actors from GVTC and different regional (I)NGOs in all three countries, as well as by reviewing secondary literature from previous academic research, policy documents, national and international media releases and reports from international organisations.

As the perception and expression of emotions is subject to a specific socialized linguistic framing (Derrida 2001), my focus on the expression of 'fear' is a subjective interpretation of local experiences. By 'fear,' I thus refer to narrated phrases in the commonly spoken language Kinyarwanda, ${ }^{26}$ where to "be feared" (gutinywa) and "be fearful" (gingimiranya / ubwoba) hold similar contextual meanings and overlap with the same expressions in both English and French. In line with van Maanen's (2011: 2) emphasis of the interpretive act of fieldwork, my ethnographic methods aim to make sense of narratives constructed of recounted memories, stories, rumours and anecdotes of ranger's social world. Therefore, it is less important whether the content of these stories is 'true' or 'false' or merely invented for my presence as a researcher and $\mathrm{a} \mathrm{w}^{3}$ (white, Western woman). Yet these limitations as well as the anonymization of all informants demand specific acknowledgement in a region of high surveillance shaped by historical and ongoing inter- and intrastate warfare where suspicion and mistrust are basic codes of conduct for survival.

\section{Grounding on fear: 'green' violence, militarization and transnational conservation efforts}

The creation of a transboundary protected area, defined as "a clearly defined geographical space that consists of protected areas that are ecologically connected across one or more international boundaries" (IUCN 2020), entails substantial political negotiation between the involved governments and (international) non-governmental conservation actors and organisations. While

\footnotetext{
${ }^{26}$ While Kinyarwanda is the name for the national language of Rwanda, people living in the borderlands of the DRC and Uganda speak the same language with marginal differences.
} 
conservation scholars have critically examined the underlying political interests of the multitude of stakeholders involved in the production of TBPAs (see e.g. Büscher 2013; Fairhead 2005), the instrumental role of fear informing these interests has not been taken into account so far.

Yet fear and its functionalities have been examined by a plethora of disciplines ranging from evolutionary biology, psychology, criminology, security and military studies, traditional and critical geopolitics to wider social sciences for centuries. The emotion of fear is generally defined as "a distressing emotion aroused by impending danger, evil or pain, whether the threat is real or imagined". ${ }^{27}$ In situations of perceived danger, the reptilian complex within the human brain is understood to release hormones for fight-or-flight responses that cognitively justify the use of violence for protective purposes and survival (Meloy 2006; Siever 2008). Hence, fear can be an emotional response to violence, while violence can be a physical response to fear, in defence or as a pre-emptive attack against a perceived threat.

Evolutionary psychologists have identified a spatial dimension in triggering fear. It was found that animals show 'spatial patterns of risk perception' that ultimately structure their ecosystem into go- and no-go-areas referred to as their 'landscape of fear' (Gaynor et al. 2019). Since similar physiological responses to certain spaces or places have also been found in humans, Tuan (1979) adapted the concept of 'landscapes of fear' for analysis of human behaviour. Based on Lefebvre's argument that emotions and spaces interact reciprocally (ibid. 1974), he laid the foundation for emotional geographies in the social sciences that "refers both to psychological states and to tangible environments" (Tuan 1979: 6). Building on this, Tulumello (2015) proposed to critically analyse the politics of fear behind the production of spaces revealing governmental processes of violence, power and control - a dynamic that can be similarly observed in the production of TBPAs.

In order to shed light on the politicized interrelation between fear and these constructed geographical spaces, I also draw on research in critical geopolitics. Scholars from this discipline have focused attention on the geopolitical interests behind the instrumentalization of fear that is used to legitimize armament, violence and military interventions by states against a declared threat (Dalby 1994; Girard 1979; Hyndman 2007). These threats are often informed by 'Othering' practices aiming to create a national identity distinguished from constructions of an external danger developed through fear discourses (Mountz 2009). Research concerning the neurophysiological functionality of fear suggests that this perception of the dangerous 'Other' lowers the threshold to commit or support acts of violence that has been widely used within military tactics since records of war began (see e.g Homer's 'Ilias' ca. $8^{\text {th }}$ century BC). Fear has thus been identified as 'a tool of war that works through the minds' (Watson 1978: 534). A prominent example can be found in 'war on terror' discourses under the U.S. Bush administration from 2001 onwards, showing how fear-inducing labels such as 'terrorists' were created and disseminated as propaganda to evoke popular support for the military invasion of Iraq (see e.g. Gregory and Pred 2007; Robin 2004; Sparke 2007).

Similar to these geopolitical war tactics, critical conservation scholars have scrutinized how governments justify the increasingly violent and militaristic practices employed for the

\footnotetext{
${ }^{27}$ https://www.dictionary.com/fear, accessed 27-7-2019.
} 
protection of flora and fauna through geopolitical discourses by linking conservation with the 'war on terror' (Duffy 2016). The themed issue on 'green security' previously published in this journal highlights how those kinds of "globalised fear frameworks" discursively connect national security with protected areas framed as in need of exceptional violent and military protection (Ybarra and Kelly 2016: 171). In here study of militarisation within the Maya forest in Guatemala, for instance, Ybarra demonstrates how "successful security strategies use imaginaries of existential threats to justify violence" (2016: 195). Thus, violence can be enabled by threat narratives that criminalise people who enter protected areas unauthorized, for example by branding 'poachersas-terrorists' (Pennaz et al. 2018) or 'rogues for elimination' (Fairhead et al. 2012). I refer to the concept of 'green' violence in the context of TBPAs entailing an amplitude of material and nonmaterial characteristics, including spatial enclosure and militarization of the protected areas as well as the implementation of discursive and physical forms of violence by conservation actors (Büscher and Ramutsindela 2015: 10).

Yet thus far, this line of analysis has not focused on the use and consequences of fear as a tactic in 'green' conservation violence. In order to generate a deeper understanding of the paradox behind increasing violent and militaristic practices in the context of supposedly peacegenerating TBPAs, this paper thus seeks to illuminate the interrelation between (geo-)political interests and the implementation of 'green' violence by analysing individual fear narratives of park rangers in their day-to-day conservation work. Training attention on the local level allows one to account for the specific emotional experiences embedded in particular cultural, historical contexts and present conditions (Berger and Luckmann 1966; Harré et al. 1986; Wouters 1989).

Since the expression of personal emotions can reflect underlying motivations for people's behaviour (Bordieu and Wacquant 1992), my focus on individual, emotional experiences and narratives of park rangers may help to explain their ostensible commitment to and/or compliance with the enactment of different forms of 'green' violence. Previous studies from critical geopolitics suggest that fear narratives in the everyday can reflect how governmental discourses construct social realities pointing to the political interests behind the production of violence (Pain and Smith 2008: 3). Hence, analysis of park rangers' fear narratives can offer a bridge between violence and militarization in the name of conservation on the ground, on the one hand, and its implications for national policies and practices in relation to the transboundary conservation efforts on the transnational level, on the other. To apply this analytical framework to the Virungas, I begin with a brief presentation of the historical context of the conservation sites in the DRC, Rwanda and Uganda.

\section{The history of an idea - a transboundary Virunga Conservation Area?}

The intended transboundary protected area straddling the Virunga volcanoes appears to be an exemplary case for the intensification of militarisation in conservation enforcement, which is popularly legitimized on two main grounds. First, the contiguous forest constitutes the last habitat of endangered mountain gorillas (besides a small, separated forest parcel in Uganda's Bwindi Impenetrable National Park). It is thus deemed a biodiversity hotspot by conservationists as well as a 'unique selling proposition' for one of the most expensive wildlife tourism attractions in the world (Trogisch and Fletcher 2020). Secondly, the TBPA is situated in the Great Lakes Region - 
infamously labelled the site of "Africa's World War" (Prunier 2011) - which is historically scarred by brutal colonial legacies and long-standing intra- and interstate warfare.

The historical entanglements among the DRC, Rwanda and Uganda point to the decisive geopolitical role of the Virungas in these armed conflicts and enable a deeper understanding of fear discourses that accelerate dynamics of segregation and militarisation among the three National Parks today. Long before colonialization, transnational interactions across the Virunga volcano chain have been characterized by territorial combats as well as intermarriages, settling, trading, labour and migration mobilities (Hochleithner 2017; Nzabandora 2006). The common language of Kinyarwanda spoken by locals settled around the volcanoes testifies to the centuryold mobility and interconnection among communities in the region. In the colonial power struggles between 1890 to 1916, however, Germany, Belgium and Great Britain drew the borders for the Democratic Republic of the Congo, Rwanda and Uganda, respectively, by connecting the peaks of the Virunga volcano chain with a ruler on the map (Mamdami 1996, Mathys 2017; Newbury 1998).

As a result of the Western 'discovery' of the mountain gorilla in colonial expeditions in 1902, international conservationists became another powerful usurping actor in contestations over the area. Manifested in the gazettement of the forest around the Virunga volcanoes as part of Albert National Park in 1925, Belgium colonial rulers established one of the first National Parks on the African continent encompassing in total roughly $8000 \mathrm{~km}^{2}$. After independence of the DR Congo in 1960 and Rwanda and Uganda in 1962, the forest was managed by the separate state entities and fluctuated in size due to fights between clearance for commercial and subsistence activities and conservation enforcement. The strict protection of mountain gorillas became prevalent due to international fame and funding garnered through Dian Fossey's research from 1967 until 1985 that subsequently led to an influx of international tourists.

Thus, for the past 100 years, colonial powers and international conservation organisations have staged the borderland forest surrounding the Virunga volcanoes as a 'space of exception' for mountain gorilla conservation requiring eviction of local inhabitants and military protection of the enclosed area (de Bont 2017; Marijnen 2018). As part of the colonial legacy, international threat discourses portending the looming destruction of forest and great apes by local people informed 'green' militarization practices based on harsh conservation laws (Ashaba 2020). Their enforcement is managed by the three nations' respective protected area authorities: the Institut Congolais pour la Conservation de la Nature (ICCN), the Rwanda Development Board (RDB), ${ }^{28}$ and the Uganda Wildlife Authority (UWA).

In contrast to the parastatal management of RDB and UWA, ICCN entered a public-private partnership with the British NGO Virunga Foundation in 2008 which changed the organisational structure, financing and management of Virunga National Park in the DRC significantly (Marijnen 2017). As a result, this article focuses mainly on park rangers of RDB and UWA. Similar in their hierarchical organisation, both institutions are subordinated to the government, headed by one chief park warden and four to five wardens as well as administrative park management staff who supervise, instruct and manage the rangers in the domains of tourism, security, community

\footnotetext{
${ }^{28}$ The protected area authority of Rwanda has been renamed from Office Rwandais $d u$ Tourisme et des Parcs Nationaux (ORTPN) to RDB as part of the change in official language from French to English in 2009.
} 
relations and finance. While wardens in Uganda live at the headquarters of MGNP situated at the main entrance to the park, VNP wardens have residences in the next city or the capital Kigali.

Park rangers living at the headquarters or barracks at the outposts of VNP and MGNP carry out three main tasks on a daily base: monitoring of wildlife, patrols as deterrence and in response or in search of illegal park activities, and tourist guiding. In Uganda, UWA mainly deploys rangers to MGNP who not originate from the park-adjacent communities or the region to reduce social ties and clientelism. In contrast, RDB rangers at VNP mostly come from the surrounding communities and visit their families regularly. While there is a significant difference in terms of gender distribution within RDB and UWA, ${ }^{29}$ I anonymize all quotes to avoid a gendered interpretation of the presented fear narratives as these differences did not appear as an important aspect of the present analysis.

In 1991, the International Gorilla Conservation Programme (IGCP), a transnational conservation NGO founded by the African Wildlife Foundation (AWF), Fauna and Flora International (FFI) and the World Wide Fund for Nature (WWF), initiated joint ranger patrols as well as monitoring and training programmes for conservation staff from ICCN, RDB (then ORTPN) and UWA 'to ensure effective management of the shared ecosystem' (IGCP, 2010a). These first efforts to establish a transboundary protected area (TBPA) for the conservation of mountain gorillas were in line with international development and conservation organisations promoting the triple-win effects of TBPAs intended to bring economic development, conservation collaboration and ultimately regional peace (UNEP 2009). In this effort, funded by the Government of the Netherlands, the three national protected area authorities signed the first Memorandum of Understanding to transform the informal arrangement between rangers into an intergovernmental institution titled Greater Virunga Transboundary Collaboration (GVTC) in 2004. In the official treaty two years later, the respective ministries of the DRC, Rwanda and Uganda agreed to commit to "building trust, understanding and cooperation among wildlife authorities, nongovernmental organisations, users and other stakeholders to achieve sustainable conservation and thereby contribute to peace" (GVTC 2006 [2015]: 6).

However, these formal attempts of establishing the Virungas as a TBPA in the model of a 'peace park' have proven difficult to operationalize, being opposed by nationalist attitudes, mutual hostile perceptions and accusations of the 'other' side by people living and working with(in) the different National Parks. This mental segregation was expressed in stories about periodic border skirmishes between different armed groups and the military from the DRC, Rwanda and Uganda carried out within or through the forest, yet official statements and media reports would only sporadically confirm those incidents, partially due to strict censorship by the government of Rwanda and Uganda (see e.g. BBC 2018; International Crisis Group 2020; Reuter 2018, 2020). Political killings of mountain gorillas (UNESCO 2007; UWA 2020), tourists (Maekawa et al. 2016) as well as frequent targeted killings of park rangers from ICCN (Virunga 2020) also contravene the 'official' peace intentions in the ministerial agreements on the national

\footnotetext{
${ }^{29}$ In 2018, VNP engaged 135 rangers of which only six were women who carried out administrative and less strenuous guiding tasks. In contrast, around $30 \%$ of all rangers at MGNP were woman, including one of the four wardens who carries out the same tasks as her male counterparts.
} 
scale. Moreover, the transboundary conservation collaboration between the three governments and protected area authorities have decreased drastically, underscored by the diminishing support for GVTC requests, propositions and meetings. National solo efforts from the unexpected price increase for gorilla tourism by Rwanda in 2018, increasing border controls and closures and the militarization of the three National Parks undermine the agreements of the GVTC treaty and undermine any political authority of the trilateral organisation. One decisive example for this segregation is the unannounced increase of mountain gorilla tracking fees by the Rwandan government in 2018, which had tremendous impact on tourism dynamics and concomitant conservation challenges for the DRC and Uganda (Trogisch and Fletcher 2020). After termination of Dutch funding in 2018, GVTC had to face liquidation as the three states have not acted upon their official lip services to secure the financing (as of February 2021). The 'transboundary Virunga Conservation Area' thus remains a label without spatial or practical manifestations.

Spending time with park rangers in their everyday life throughout 2018 shifted my attention to the lived realities of these segregation processes on the ground. The last joint patrol along the borders of the DRC between RDB and UWA with ICCN was recorded in 2003; meanwhile RDB and UWA continued along the Rwandan-Ugandan frontier until 2016. While patrols along and across borders together were frequently remembered by rangers from ICCN, RDB and UWA as friendly meetings for sharing information, monitoring data and lunches, the perception of their neighbours was subsequently coloured by suspicion, hostility and fear (personal interviews, 2018). These fear-induced narratives of rangers illustrate the mental and spatial segregation between the three states in the local conservation context that highlight the stark contrast with the intergovernmental 'peace park' rhetoric in the GVTC agreements.

Moreover, rangers enact and become the core of 'green' militarization as their training and daily conservation work expanded significantly to para-military and intelligence tasks. While scholars have critically analysed the discursive techniques of legitimizing militarization of Virunga National Park (Marijnen and Verweijen 2016) and its interrelation with ongoing violent conflicts in the Eastern DRC (Vikanza 2001), my major focus is on narratives of rangers from Uganda and Rwanda and the specific role the perception of 'the Congo' plays in the segregation, militarization and violence. To generate a better understanding of these dynamics, in the following section I examine how three state-cultivated fear narratives construct RDB and UWA rangers' understanding and performance in their everyday reality.

\section{A historically constructed 'geography of fear'}

The first narrative circulated amongst the park rangers in Rwanda and Uganda presents the Virungas as a 'geography of fear' based on legacies of insecurity from the historical warfare inside the transboundary forest justifying strict conservation measures of enclosure and military protection. As Pain (2009) argues, 'geographies of fear' are made of personal perceptions of spaces regardless whether the triggered emotions rely on factual experiences of threat or on their imagination. In Rwanda and Uganda, rangers' narratives illustrate how their spatial perception 
of the Virunga volcanoes depict such a 'geography of fear' informed by factual and fictive memories of the Rwandan civil war in 1990 that culminated in the genocide in 1994.

While navigating through the parks for their daily patrols, rangers from MGNP and VNP showed 'spatial patterns of risk perception' that map a landscape into go- and no-go-zones (Gaynor et al. 2019). No-go-zones pointed to spaces of 'death' and 'danger' ${ }^{30}$ inside the forest that rangers on both sides recalled as memories of their 'personal experiences' 24 years after the end of the Rwandan war. These detected zones informed their paths in avoiding certain hill tops, valleys and natural volcanic caves that they referred to as rebel hide-outs or execution spaces as well as mass graves from the war (personal interviews, 2018). In interviews, some rangers specifically demarcated these dangerous sites in sketching maps to illustrate the topographical knowledge required for their day-to-day conservation tasks in the Virungas. These verbal and visual illustrations show how rangers picture the forest as a 'geography of fear' based on memorized and reiterated 'experiences' of violence and threats in the past.

Yet these narrated 'experiences' were seldomly consistent with the personal timeline of ranger's deployment or their age. ${ }^{31}$ As Fujii (2010) pointed out, invented stories, rumours and silences are frequently part of local testimonies in political sensitive contexts and can indicate suspicion towards external actors, and researchers in particular. However, "their value might lie in the meaning with which the narrator endows the events or moments," reflecting "the speaker's state of mind, aspirations, and desires" (Fujii 2010: 234). At first, I assumed that especially young rangers' aspirations behind telling these stories of violence and killings were to impress by depicting how they confront the fearsome dangers of their work. Over time, however, I found resemblance between rangers' 'fictive' fear narratives and dominant threat discourses circulated amongst their respective superiors in the park management and in the media. Other studies have found that governments gain popular support by drawing on historical legacies and previous events to reinforce narratives of insecurity that mobilize and instrumentalize previous fears within the population (Sparke 2007: 341). In the following I explore such a historical, geopolitical dimensions behind fear discourses used to legitimize the enclosure and 'green' militarization of MGNP in Uganda and VNP in Rwanda from 1990 onwards.

\section{Enclosure of Mgahinga Gorilla National Park, Uganda}

In the guise of exclusive conservation enforcement, the Ugandan government under Yoweri Museveni initiated the enclosure of Mgahinga forest to create an undisturbed, invisible and wellprotected hide-out for the rebel army Rwandan Patriotic Front (RPF) to support their attack against the government of president Juvénal Habyarimana in Rwanda (UN 2010; Epstein 2017). Therefore, the gazettement of Mgahinga to a National Park category II mandated the eviction of 2400 people from their former homelands within the fenced area ${ }^{32}$ briefly after the beginning of the Rwandan civil war on the $1^{\text {st }}$ October 1990. With international funding from various conservation agencies, the park headquarters, three permanent patrol outposts and a girdling stone wall were erected on the forest frontier in the following years, officially declared to 'protect'

\footnotetext{
${ }^{30}$ In Rwanda, rangers referred to specific sites with the Kinyarwanda word 'urupfu' (death). In Uganda, rangers used the English terms 'death' and 'danger' interchangeably to demarcate a site they would avoid.

${ }^{31}$ Some older rangers indeed presaged traumatizing personal experiences but would not elaborate on those.

32 According to the categorization by IUCN (2020).
} 
adjacent residents from wildlife exiting the forest (Blomley 2003). These material manifestations made Mgahinga forest literally a 'fortress' (Brockington 2002) in the name of mountain gorilla conservation (Butynski and Kalina 1993).

Yet testimonies of local residents are in line with official reports maintaining that the government of Uganda utilized this enclosure to shield their strategic and military support for the RPF from witnesses. A resident from Mgahinga emphasized that this timing of the National Park creation and the begin of the Rwandan civil war was no coincidence:

"Everybody knew who sat inside the forest because the rebels from Rwanda told us how to hide from the bombs. We were so stupid, we did not know what bombs are, so we climbed on trees to see better.

The government closed the park, so we could not see."

As this quote exemplifies, many locals recall their first-hand experiences of the deployment of the Tutsi-dominated RPF led by today's president Paul Kagame and the warfare with Rwanda unfolding within the forest. From 1991 to the genocide in Rwanda in 1994, Mgahinga Gorilla National Park became a military base, refuge and battleground supported by Ugandan president Yoweri Museveni that forged an alliance between the two governments in subsequent years. While rangers' sense-making of the enclosure was aligned with the official conservation purpose, their perception of dangerous places inside the transboundary Virunga forest points to their mental spatialization of the area in reference to this historical warfare. Thus, memories and imaginaries of the Virunga forest as a 'geography of fear' were reproduced and strengthened how rangers understand and legitimize the enclosure and militarized enforcement of MGNP then as now.

\section{Enclosure of Volcanoes National Park, Rwanda}

The 'geography of fear' perceived by rangers from the Rwandan side of the Virungas illustrates how the historical enclosure and militarization of VNP is entangled simultaneously with international conservation demands and Rwanda's geopolitical interests. From 1990 onwards, VNP and its adjacent hinterland became the main theatre of war between the RPF invading from MGNP and the Rwandan military under Habyarimana. As the VNP headquarters and outposts were abandoned, the park was used as a resource base and battleground between the warring parties. Subsequently, the forest became an atrocious execution space and graveyard during the genocide in Rwanda in 1994. In its aftermath, VNP provided one of the main routes for refugees fleeing into neighbouring Zaire including the Habyarimana government and its military organizations, among them the interahamwe who is held responsible for perpetration of the genocide. $^{33}$

While younger rangers pointed out historical places of urupfu ["death"], park rangers who have been on duty during this period and survived did not speak about their experiences or shifted the conversation to Rwanda's present conservation successes. Similarly to those stories and silences, other studies on (pre-)genocide memories found that many Rwandans either 'choose collective amnesia' (Buckley-Zistel 2006: 133) or align their stories to strong state-led discourses (Nymeth Brehm and Fox 2016: 121). One of the most compelling of those discourses focuses on Rwanda's conservation achievements to create popular support for the gazettement and

\footnotetext{
33 'Interahamwe' translates from Kinyarwanda to 'those who fight/work together'.
} 
militarization of the National Park. With an estimated funding of over six million USD by international conservation organisations, aid agencies and NGOs (Milner-Gulland and Mace 1998: 304), the new Rwandan government re-established VNP under the pretext of reclaiming mountain gorilla habitat in 1996. Similar to MGNP, VNP became a strictly enclosed 'fortress' surrounded by partial stone wall constructions, trenches and nine permanent patrol outposts for rangers in addition to numerous military bases along and within the park. This strict enclosure assuaged the fears of primatologists accusing Rwanda of reducing the mountain gorilla population to the brink of extinction and hence resulted in unabated international investments.

Yet, more importantly, VNP also served the new Tutsi-dominated Rwandan government under Kagame to erect a military bulwark against Zaire in fear of revenge from the expelled but largely intact former Hutu government, with related military parts of the interahamwe reinvigorating within and around Virunga National Park (PNVi). Meanwhile, the enclosure of VNP enabled the Kagame government to send armed groups through the safe, concealed passage of the Virunga forest into Eastern Zaire to carry out pre-emptive strikes against the expelled former regime. With military support from its Ugandan ally, these counterinsurgencies were intended to exterminate suspected Hutu living in refugee camps, surrounding villages and within PNVi. In response to Rwanda's interventions, Mobutu Sese Seko, then president of Zaire, mobilized ethnic hatred against Zairian residents considered to be Tutsi, defined as 'Kinyarwandaspeakers' or 'Rwandophones,' who were accused of supporting Kagame's Tutsi-dominated regime (Mathys 2017: 469). In consecutive years of warfare, officially accounted for as the 'two Congo Wars' (1996-1997; 1998-2003), approximately two million people have been killed (UNHCHR and OHCHR 2010). In this aftermath of the genocide in Rwanda, the mutual exclusion and killing orders along the Hutu-Tutsi dichotomy by the Rwandan and Zairian (later Congolese) governments resulted in wide-spread atrocities and new waves of refugees in both directions across the borders (Okosun and Kibiswa 2013).

Besides this geostrategic utilisation of VNP's enclosure, park rangers were assigned a significant role in Kagame's counterinsurgencies that evidenced the blurring lines between conservation and military tasks. Under Mobutu's command to exclude the Tutsi-related population from Zaire, public resentment increased leading to intimidation, violence and killings of community members with an associated Tutsi heritage, including ICCN rangers.

As a result of this first Congo war, ${ }^{34}$ some rangers with this attributed Tutsi ethnicity fled in fear of their lives to Rwanda. During the 'second Congo war' from 1998 to 2003, the Rwandan government made use of these rangers' precarious situation and topographical knowledge of the Congolese side of the forest to recruit them to detect Hutu hide-outs within PNVi, in exchange for jobs, asylum, and - in case of accused Hutu-affiliation - amnesty (personal interviews, 2018). As an example representative of a number of testimonies, a former ICCN ranger described the command to lead the Rwandan army through PNVi into the Eastern Congo as follows:

"Nobody knew when we would start to guide the soldiers, because nobody should know what we do and where we go. Not even I did know. After the genocide everybody was a spy. I just showed the

\footnotetext{
${ }^{34}$ The DRC was named Zaire under Mobutu Sese Seko in 1962. After the coup by the Alliance of Democratic Forces for the Liberation of Congo-Zaire (AFDL) aided by the Rwandan and Ugandan government overthrowing Mobutu, Zaire was renamed to the Democratic Republic of the Congo in 1998.
} 
places in the forest where they [Hutu refugees, authors' note] hide. I put down the GPS coordinates and then they [Rwandan soldiers, authors' note] would - you know. There was nothing left."

The mutually incited fears along ethnic lines by the Rwandan and the Zairian/Congolese government served to exploit park rangers for military, cross-border interventions through the enclosed forest. As became evident in collaboration workshops organised by GVTC in 2018, these historical fears continue to inform feelings of mistrust, suspicion and hostility between Rwandan and Congolese rangers. Such fears offer one explanation for why park rangers increasingly oppose the former transboundary collaboration with their neighbouring conservation counterparts, compounding governmental withdrawal of support for the Virunga Conservation Area project in the model of a TBPA.

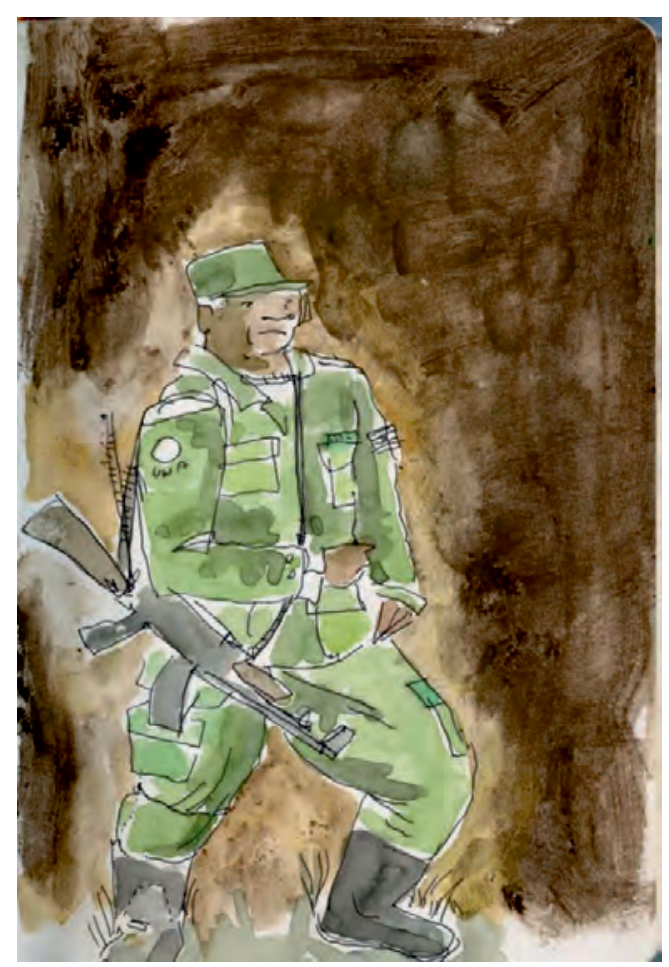

Fig. 3.2 "Park ranger on duty"

\section{'Green' militarization against 'the Other'}

The second narrative serving to legitimize 'green' militarization of the National Parks and their rangers in Rwanda and Uganda demonstrates how the politics of fear unfold in 'Othering' discourses against an external enemy symbolized in a generalized image of 'the Congo'. As Mountz states, the geographical aspects of these 'Othering' processes "rely heavily on spatial metaphors to locate and place identities and difference in the landscape" (2009: 332). Since the metaphor of the Virungas as a 'geography of fear' was fuelled by the historical war alliance 
assimilating Rwanda and Uganda in the aftermath of $1994,{ }^{35}$ narratives of rangers from RDB and UWA still located the source of their fears in 'the Congo'. In the course of my fieldwork in 2018, rangers were eager to share stories from loudly declared hostilities to tacit, subtle but no less angstridden anecdotes about the chaos, insecurity and the barbaric behaviours of Congolese people on 'the other' side of the park.

Yet most Rwandan and Ugandan rangers admitted they have never experienced an incident with a Congolese, had never stepped on Congolese soil or even spoken with a Congolese person. Their fear narratives point to a public 'Othering' discourse constructing a unifying national identity of park rangers as state agents distinguished from the DRC. 'Othering' functions as a discursive tactic to legitimize violence declared as measures for security against an external enemy (Mountz 2009: 328). Militarization of the National Parks was hence rationalized as a security measure against the enemy labelled 'the Congo', a generalizing title to merge landscape, inhabitants, the government and armed groups situated in the DRC into a threat to national territory, wildlife and tourists. This 'Othering' of the DRC is substantiated by rangers' reiteration of two specific violent incidents presented in the media that impacted gorilla conservation and tourism efforts of Rwanda and Uganda.

\section{Rwandan enmity against 'the Congo'}

The incident in Rwanda refers to the deadly attacks by "several thousand interahamwe" against civilians in 1997 that disrupted the just re-opened tourism and conservation activities at VNP (East 1999: 74). Since this incident, president Kagame continuously attributed cross-border attacks against Rwanda to the Democratic Forces for the Liberation of Rwanda (FDLR), one of the most dominant armed groups in the Eastern Congo that emerged from the interahamwe, remnants of the former Hutu government and its supporters (see e.g. The New Times 2018). Further alleging that the Congolese government prevents extradition as well as supporting the militias for decades, governmental discourses established a clear link between threats to Rwanda's national security and 'the Congo' as a territorial and political entity. In addition, media sources incriminate the Congolese army, Les Forces armées de la République démocratique du Congo (FARDC), who are accused of transgressing the territorial boundaries and challenging Rwandan border integrity (BBC 2018; Reuters 2018; The New Times 2012).

RDB rangers would consistently agree with this state-led fear discourse that frames 'the Congo' as the enemy of Rwanda by providing a sanctuary for the 'genocide perpetrators' and support for the 'Hutu rebels' within PNVi (focus group interview, 2018). This rhetoric underscores how fear discourses are linked to the imagined space of the Eastern DRC serving as an imperative for the militarization of VNP. While stories about violent attacks and killings between different armed groups on the Rwandan side of the forest frequently occurred during fieldwork in 2018, all questions about these skirmishes posed to RDB rangers on site were commonly dismissed with the words: "On ne sait pas..." ["We don't know"] or with vague reference to rumours. When asked about their fears of getting involved and physically harmed in these

\footnotetext{
${ }^{35}$ The relationship between Rwanda and Uganda deteriorated significantly since the severe warfare between Rwandan and Ugandan forces on Congolese territory during the Second Congo War (BBC 2000) and political accusations and economic trading barriers in the past years (Reuters 2019).
} 
skirmishes during patrols along the Congolese border, rangers predominantly restated their general fear of meeting 'a Congolese' anywhere who would kill them for being a Rwandophone, and thus - assumedly - a Tutsi. This prejudicial fear points to the historical legacy of ethnic mobilisation that fuelled the 'Othering' and alienation of rangers from ICCN and RDB, further undermining the envisioned transboundary collaboration. From this perspective, rangers expressed their firm belief in the necessity of their military education, armament and conjoined movement with the national army to protect tourist, gorillas and Rwanda's national borders against 'the Other', namely 'the Congo'.

At the same time, Rwandan rangers similarly voiced their feelings of security within Rwanda due to their countries' military capabilities. One ranger expressed the sense of protection in the day-to-day patrols with the phrase "chaque arbre, un soldat" ["Each tree, one soldier"]. The statement refers to the high density of soldiers from the Rwandan Defence Force (RDF) deployed within VNP and its surroundings that I witnessed first-hand on daily patrols. As soon as we were invisible from the public after passing trench and stone wall to enter the park, four to ten wellequipped soldiers with bulletproof vests and machine-guns would join the group of three rangers armed with rifles. These conjoined activities point to the double function of VNP's 'green' militarization that serves to merge the increasingly popular conservation paradigm of militarized environmental protection with Rwanda's security concerns by establishing a military bulwark against the DRC.

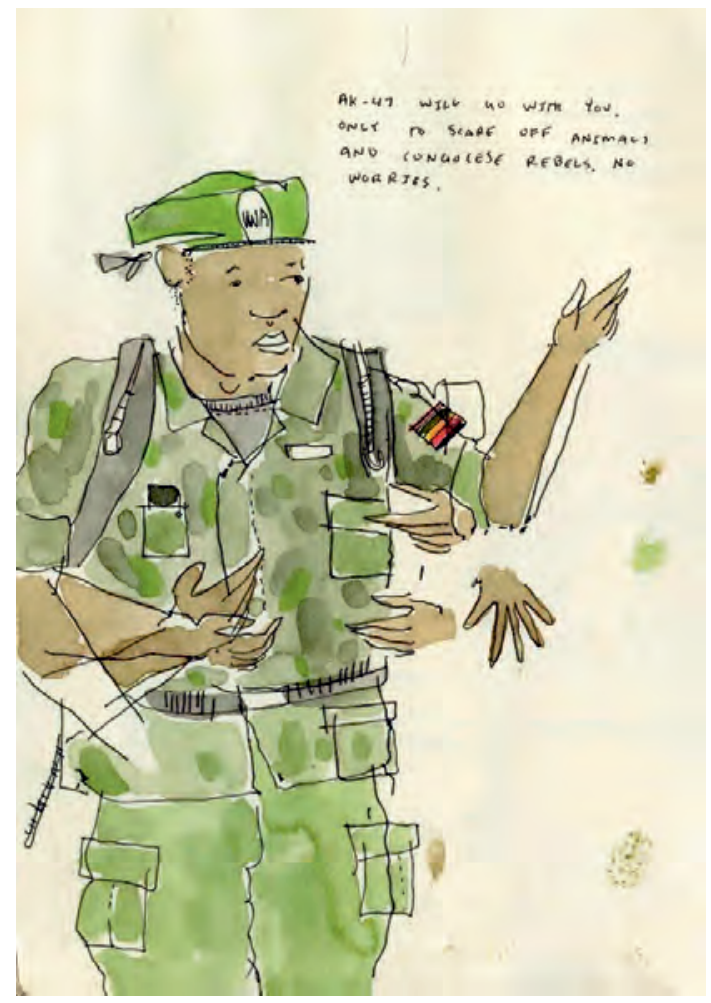

Fig. 3.3 "AK-47 for animals and Congolese" 


\section{Ugandan enmity against 'the Congo'}

The incident fuelling 'Othering' amongst UWA rangers in MGNP refers to a supposedly Hutuaffiliated militia killing of eight tourists and four park rangers on the borderland between the DRC and MGNP's neighbouring Bwindi Impenetrable National Park (BINP) in Uganda in 1999. The militias declared the attack revenge for the ongoing military interventions into the DRC by conjoined forces of Rwanda and Uganda and their international support by the US and UK in the context of the second Congo War (HRW 1999). Since the incident led to the complete halt of tourism, Uganda's most important export sector, the government of Uganda interpreted the attack inside the National Park as a political tactic to harm the national economy (BBC 1999). In response, discourses amongst park rangers and wardens linked threats to the safety, sovereignty and economic prosperity of Uganda with the 'insecurity' emanating from the Eastern Congo.

In focus group discussions, many UWA rangers reproduced this threat discourse, further referring to the national and international media presentation about the killing of tourists in BINP as 'the jungle massacre' and 'a horrific act of slaughter' (The Independent 1999; BBC 1999). Despite official investigations concluding that the armed group belonged to 'Rwandan Hutu rebels' who sought revenge for the Ugandan backing of the Tutsi-dominated Kagame government and the supporting governments of USA and UK (HRW 1999), rangers recounted the killings as evidence for, as one condensed it, "the barbarity and lawlessness of the Congo". This depiction dehumanized Congolese people and generalised them into a vague, impersonal object - 'the Congo' - that needs to separated and kept out of Uganda.

This 'Othering' discourse led to a mental segregation between Congolese and Ugandan rangers, on the one hand, while further manifesting the spatial segregation of the transboundary protected area, on the other. Underpinning their perception of the Virungas as a 'geography of fear', UWA rangers repeatedly pointed out the invisible borders to the DRC within the forest that demarcated no-go-zones for them. One UWA ranger explained why it was vital to identify these invisible borderlines within the forest: "We just move along here with GPS. That tells you: stop, now you are close to Congo. When you get there, they jail you. [...] They mistake you for a rebel." Numerous fear-related stories about the consequences of accidently stepping on Congolese soil were shared between rangers and informed the movement of the patrols in MGNP on a daily basis, underlining the impossibility of joint conservation practices between the two states.

Several insurgencies in other border-adjacent National Parks in Uganda led the Museveni government to discursively link conservation tasks with national security duties (Ashaba 2020: 8), resulting in the introduction of 'under-cover' military personnel from the Uganda People's Defence Force (UPDF) into ranger staff since the 2000s. Their 'under-cover' status refers to their being indistinguishable for tourists, as the soldiers live together with rangers and perform the same conservation tasks including tourist guidance, gorilla monitoring and patrols. While this military-conservation partnership in Uganda has historical roots informed by (post-)colonial legacies and the gradual militarization of society under the Museveni regime since 1986 (Ashaba 2020), fear discourses directed against 'the Congo' served UWA rangers at MGNP to make sense of their four to six month paramilitary training, the establishment of UWA's own intelligence unit and the state-mandated collaboration with the UPDF. 
Due to their similar uniforms, rangers frequently raised their fears of being mistaken for the military when patrolling in proximity to the Congolese border, as one ranger expressed in the following way: "Those people [Congolese] don't ask, they flush you out [kill] before they look." Such fears further fuelled rangers' sense of 'need' for military training and UPDF support while the armies' mandate to enforce national security simultaneously mobilized rangers' sense of national responsibility for protecting park and borders against 'the Other'. This discursive framing of 'the Congo' as a threat simultaneously to national security and conservation evidences the functionality of fear in mobilizing ranger's physiological reaction of a fight-response. Thus, fear narratives circulating amongst rangers served to increase their acceptance of and commitment to violent responses as a form of defence of both self and nation. The construction of enmity against the DRC hence substantiated mental and spatial segregation between rangers from ICCN, RDB and UWA on the ground, enabled the military build-up of the parks and rendering transboundary collaboration among the park authorities impossible.

\section{An insight from 'the Other' side}

In the course of 2018, I witnessed that ICCN rangers have been largely absent from the trinational GVTC workshop that were mostly taking place in Rwanda. GVTC representatives as well as staff from RDB and UWA accused the PNVi management of being unwilling to cooperate since it receives international funding from a wide range of donors through its public-private partnership with the British NGO Virunga Foundation and is therefore not dependent on or interested in the benefits of transnational collaboration (see also Hsaio 2018). In contrast to these allegations, Congolese park rangers and park management personnel explained, in interviews at the PNVi headquarters in Rumangabo and their two offices in Goma, North Kivu, that they reject sitting together at one table with Rwandans or Ugandans for several reasons. Firstly, a common narrative amongst PNVi staff depicted the two neighbours as the cause of prevalent insecurity in Eastern Congo by perpetuating militia activities, illegal resource extractions and violence affecting the conservation efforts of PNVi. While accusations were also directed against the Congolese government for supporting and orchestrating (foreign) militia activities at the expense of conservation efforts, one managerial officer emphasized that primarily the absence of governance, law and order in North Kivu has been exploited by Rwanda in the past decade. ICCN rangers also expressed their grievance concerning the killing of more than $200 \mathrm{PNVi}$ rangers in the past ten years seen as a consequence of this incited insecurity in the aftermath of the genocide in Rwanda.

Secondly, facing the threat of violent collisions with armed groups in their daily conservation duties, ICCN rangers and staff from the PNVi Air Wing blamed the governments of Rwanda and Uganda for financing and supporting a wide range of militias operating within PNVi, such as the Ugandan Allied Democratic Forces (ADF) and remnants of the Mouvement 23 rebellion. Despite the complex, constantly changing landscape of armed actors, international reports on the control areas of armed groups reinforce these statements about the militia presences (see e.g. International Alert 2010; Kivu Security Tracker 2021; OHCHR 2020).

Thirdly, staff from the PNVi management related that they hold the government of Rwanda indirectly responsible for the destruction of PNVi through illegal park activities practiced 
by the FDLR. Since the FDLR consist mostly of former Rwandan Hutu who established their stronghold after the genocide in Rwanda within the Congolese side of the forest, PNVi staff accused the Kagame regime of lacking political will for amnesty and repatriation of the militias. In addition, some members of the PNVi management expressed their resentment against the ongoing military interference by Rwanda in North Kivu (confirmed in reports by UNSC 2020; Kivu Security Tracker 2020), perceived as geostrategic interventions to maintain insecurity and chaos in Eastern Congo in order to facilitate the illegal exploitation and trafficking of valuable resources such as coltan, gold and timber. While these accusations have been supported by a number of international organisations, reports also point to the illicit exploitation networks of multinational companies in collaboration with the Congolese government and the Congolese army FARDC (International Alert 2010; Global Witness 2018; Reuters 2012; UNEP, MONUSCO and OSESG 2015; UNSC 2020). Official exports alongside smuggling of minerals in concession with Congolese officials pass through and significantly contribute to the economy of Rwanda (tin, tantalum, cobalt) and Uganda (gold) (see e.g. Epstein 2017; Vogel and Raeymaekers 2016).

Overall, the perceptions of PNVi staff reinforce Ugandan and Rwandan blame narratives of 'the Congo' and shed light on the complex entanglements between state and non-state actors from the three countries in their geo-economic interests, the ongoing involvement of Uganda and Rwanda in the Eastern DRC and in prevalent violent conflict in the PNVi surroundings. In contrast to these formal and informal transboundary collaborations over resource extraction and supply chains, narratives of Congolese, Rwandan and Ugandan rangers underline persistent segregation in the ostensible conservation collaboration that render transboundary conservation policies and practices void of substance.

\section{A scapegoat to justify 'green' violence}

The third narrative unfolds in a scapegoating practice accusing 'the Congo' of 'poaching' activities within VNP and MGNP that allows rangers to rationalize the command for increasingly violent conservation measures against people entering the park illegally. Through scapegoating, a person or a group attributes blame for a problem to an external group in order to persecute and punish the supposed cause (Girard 1979). Since the strict enclosure of MGNP and VNP, park authorities stated that the major problem in their conservation efforts is the increase in illegal park activities due to persistently high levels of poverty in park-adjacent communities who depend on basic resources from the park (Bush et al. 2010). These activities comprise the collection of water, bamboo or honey, logging as well as hunting small animals, an act that is referred to as 'poaching' in conservation law (CGIS/DFGI 2018). However, studies have found that 'poaching' in VNP and MGNP is mostly carried out by unarmed local residents with self-built snares hunting for means of subsistence (Sabuhoro et al. 2020).

Nevertheless, Rwanda and Uganda expanded the law enforcement duties of rangers where punishments for 'poaching' range from public exposure and humiliation to imprisonment against people who illegally enter the National Park. While shoot-on-sight policies are not formally implemented in the conservation law and I found no evidence for such measures in Rwanda, Ugandan President Museveni declared them acceptable and imputable. During my fieldwork in 
2018, I witnessed the killing of a hunter caught in MGNP and the concealment of the incident as well as the lack of criminal prosecution of the ranger responsible. Other forms of punishment I observed include the killing of hunters' dogs (justified as 'destruction of their poaching weapon'), confiscation or destruction of food resources, assault and public naming and shaming in front of family, children and the community. Carrying out these forms of 'green' violence against people violating conservation law is predicated on rangers' commitment to and/or compliance with national law enforcement policies and practices.

Given the permanent deployment of rangers in the headquarters or outposts in Uganda and Rwanda, many developed friendly relationships with local community members in spending their free time together. While some rangers preferred to stay in their barracks and avoiding contact with people from the park-adjacent communities, many others made a lot of effort to 'go slumming'. When taking me along, rangers explained that - in order to enjoy these social pleasures and be accepted by civilians - they must not look like military and cannot talk about their work in public. They changed their uniforms to civilian clothes, going to the local bar or public-viewings for international football matches or actively participating in community activities, such as church meetings or playing team sports together. Nevertheless, most admitted that they suffer from their duty to violently punish local people who entered the park illegally and the social exclusion they experience as a consequence (personal interviews, 2018).

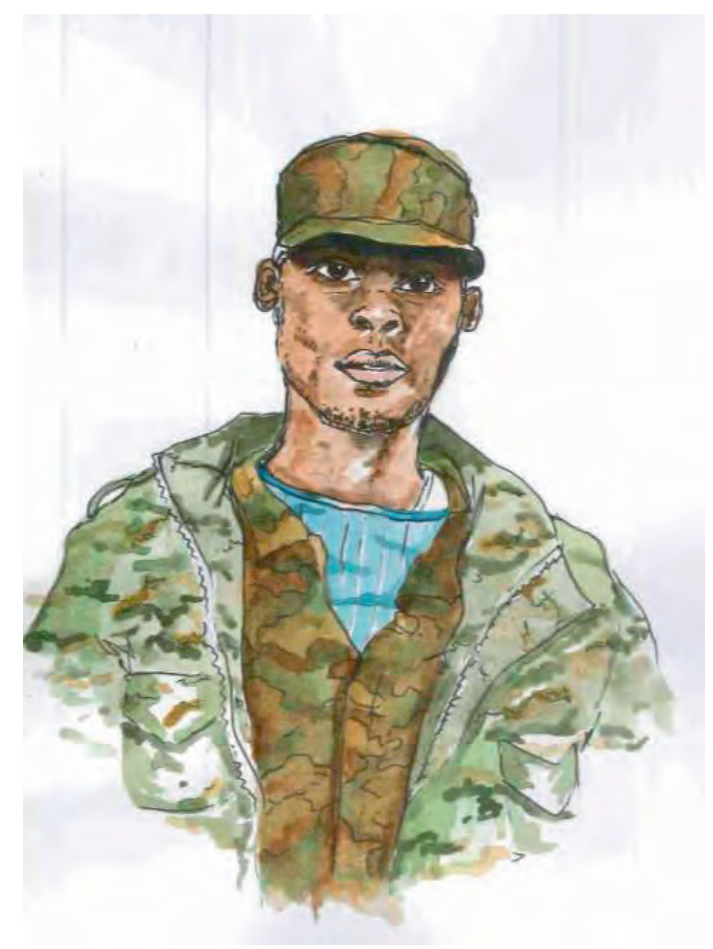

Fig. 3.4 "Ready to 'go slumming' - football shirt and military uniform" 
As Mathys asserts, "Violence cannot be understood without understanding the discursive concepts that justify it for the actors" (2017: 467). Scapegoating appeared to help rangers resolve the personal cognitive dissonance consequent to enacting violent commands against community members they interact with privately. On anti-poaching patrols with rangers, I found that they utilized 'the Congo' as a scapegoat for 'poaching' activities that helped them to legitimize the need for these violent measures. Regardless of the reality that most law enforcement practices are carried out against people from their own communities, rangers' fear-induced stories about the barbarity of 'the Congo' served to conjure what Girard (1979) calls a 'surrogate victim' to distance their own communities from illegal park activities. Thus, rangers externalised the blame and could redirect the required aggression for violence onto this 'Other', impersonal 'Congo'. This scapegoating strategy further helped rangers to maintain their "perceived personal moral value by minimizing feelings of guilt over one's responsibility for a negative outcome" (Rothschild et al. 2012:1148), namely the act of punishing.

This discursive link between 'the Congo' and the environmental destruction of 'poaching' activities was further strengthened by narratives from park rangers' superiors justifying violent conservation measures. The chief park warden of MGNP exemplified how 'the Congo' is blamed for 'poaching' within the Ugandan side of the forest:

"What makes the harder situation here is the transboundary nature of the park. Now we are not talking about poaching from the communities here, but we are talking about poaching from the insurgent forces from Congo. This poaching by these forces that move in and out 'cause they must survive [...]. They are eating animals, they are cutting for shelter, they are cutting for wood, all those stories to survive."

In addition, the security warden of VNP attributed poaching activities within the Rwandan part to the incapability of Congolese ranger patrols while simultaneously criticizing the transboundary nature of the forest that enables trespassing:

"The political situation in the Congo affects the security of the whole region [...] because for example the Mikeno sector [PNVi, DRC] is not well patrolled, which leads to increased transboundary poaching. Poachers find it very easy to cross the border from DRC side and get involved in poaching activities in areas along the border and many times cross borders to poach in Rwanda and Uganda." Since "scapegoating...enables a group to convert an anxiety into a fear, thus legitimising hostile utterances and actions against bodies 'out-of-place'” (Haldrup et al. 2009: 42), park wardens' perceptions reinforce the fear of 'the Congo' amongst rangers, further legitimizing use of 'green' violence for conservation law enforcement.

This scapegoating practice of creating an external threat to the nation-state is a common military tactic, reducing potential barriers to carrying out violence by individuals (Watson 1978). Rangers of VNP and MGNP are mobilized by this scapegoating that makes 'the Congo' the external threat for the protection of flora and fauna that ultimately legitimizes the use of violence in defence of the national park and borders. Consequentially, rangers' attitude to collaborate with their counterparts across the borders have deteriorated and undermined the institutionalised transboundary collaborative efforts made by GVTC. Ultimately, by denying GVTC any authority over their National Parks' management, the governments of Uganda and 
Rwanda retain a state monopoly on violence through their parastatal conservation authorities that contradict the transnational peacebuilding intentions of a TBPA.
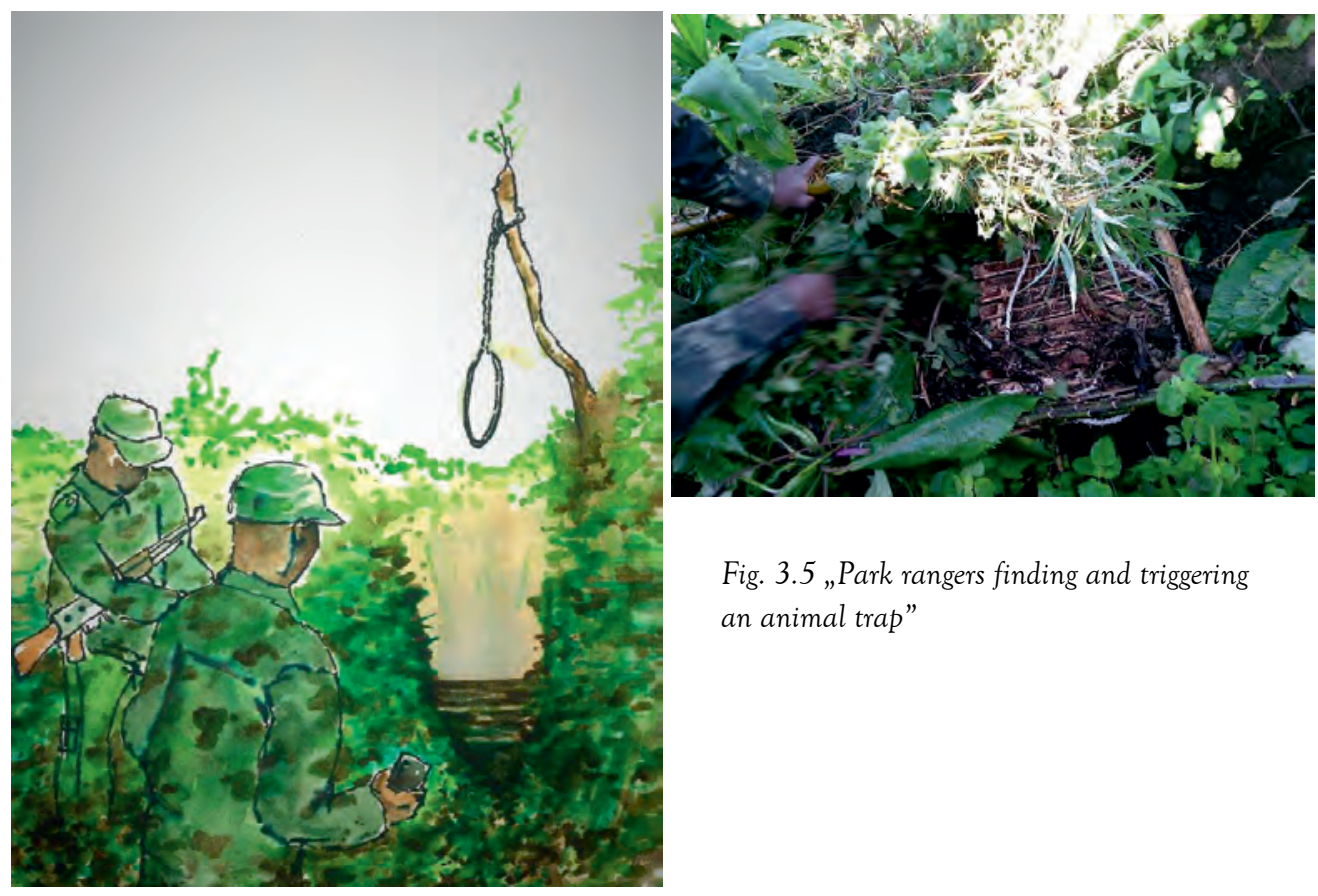

Fig. 3.5 „Park rangers finding and triggering an animal trap"

\section{Conclusion}

This paper has examined how fear functions to legitimize modes of 'green' violence, militarization and segregation of the three National Parks that were intended to form the transboundary Virunga Conservation Area between the Democratic Republic of Congo, Rwanda and Uganda. Since statecultivated discourses in the form of public rhetoric and media accounts inform everyday realities on the local scale, I explored three fear narratives common among park rangers in Uganda and Rwanda that depict perceptions of a 'geography of fear', practices of 'Othering,' and scapegoating, respectively. These interrelated narratives shed light on rangers' understanding, enactment and sense-making of their militaristic and violent conservation duties, mobilizing their sense of responsibility and necessity to protect both national park and borders. The resultant mental and spatial segregation between the three National Parks undermines attempts to foster transboundary collaboration to institutionalize the Greater Virunga Transboundary Collaboration. In this regard, I argue that analyzing the link between fear discourses and 'green' militarization practices on the local level illuminates the complex and concealed entanglements between conservation and (geo)political interests on the transnational scale. In the Virunga context, agents of the Ugandan and Rwandan states instrumentalize rangers' fears to justify the militarization of the borderland under the guise of mountain gorilla conservation to stage the transboundary forest as a military buffer zone and bulwark to 'the Congo' deemed to serve cross-border military interventions in the context of the genocide in Rwanda and its aftermath. 
The study has also demonstrated that an interdisciplinary approach combining critical geopolitics and emotional geographies can advance debates on transboundary conservation dynamics by introducing the analysis of fear discourses and their geopolitical instrumentalization to generate a deeper understanding of why 'green' violence and militarisation unfold and persist in many parts of the world. Building on this analysis, I suggest that more nuanced research concerning the role of emotions beyond fear in contemporary conservation efforts could benefit the critical conservation literature in general. Therefore, I advocate grounding critical discussions of conservation practices in the emotional realities of those who feel and enact these practices in their everyday lives, in order to include their voices in efforts to create alternative and non-violent pathways for conservation in the future. 

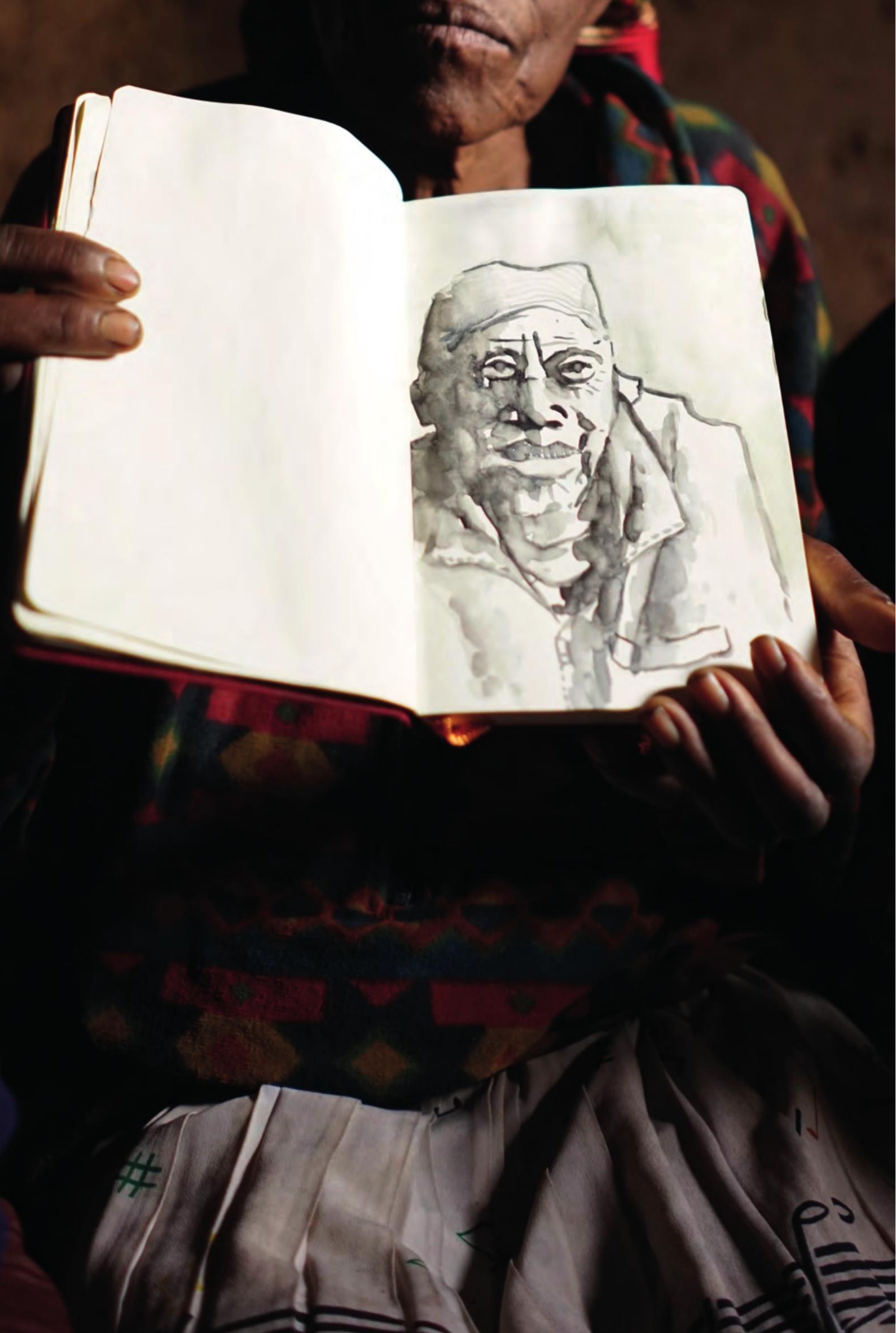


\section{Chapter IV}

Navigating fearscapes

- women's coping strategies with(in) the conservation-conflict nexus

This chapter is under revision for second resubmission as:

Trogisch, L.: "Navigating fearscapes - women's coping strategies with(in) the conservation conflict nexus", Gender, Place and Culture.

Content has been slightly edited to make the chapter fit into the rest of the thesis.

< Fig. 4.1 "A woman presenting an image of herself" 


\section{Introduction}

The blackmailing letter must have passed through many hands, as it was tattered, seemingly having been folded and unfolded numerous times before Mama Sifa handed it to me. "You cannot show it to anybody", she made clear. The handwriting was difficult to decipher but a sketch indicated where the mother should place the amount of 6000 USD and, with a little cross, where her son would then be released - alive, if she would deliver the ransom in the designated timeframe. Puzzled about the simultaneous trust and mistrust in me this overture signalled, I asked: "But if no one will see it, how can anyone believe it and help?" Mama Sifa answered: "Everybody who came to help made things worse. If you show this letter to anybody, the kidnappers will know we gave it to you and they will kill us." I did not understand: "Why will the kidnappers know that I have gotten the letter from you?" Mama Sifa responded in a hushed tone: "Because the kidnappers are amongst us."

During my fieldwork around Virunga National Park $\left(\mathrm{PNVi}^{36}\right.$ in the province of North Kivu, the Democratic Republic of the Congo (DRC), this kind of conversation repeated itself over and over. The threats Mama Sifa and many other women referred to throughout the year of 2018 differed, but they were always there or lurking in close proximity, seemingly unpredictable in terms of when they would appear. Initially, I wondered what these threat stories were supposed to signify until I got to see and sense the perpetuating condition of fear that decades of ongoing violence and warfare instilled in the people of the Eastern Congo. Davidson and Milligan called this phenomenon the "emotio-spatial hermeneutic: emotions are understandable - 'sensible' only in the context of particular places" and "[l]ikewise, place must be felt to make sense" (ibid. 2004: 524).

Scholars working at the intersection of feminist and emotional geographies assert that paying attention to fear enables us to understand the mental and topographical landscape as experienced by different inhabitants (see e.g. Bondi et al. 2007; Pain and Smith 2008; Sharp 2009). Moreover, since fear functions as an embodied survival mechanism, it provides insight into emotional and behavioural coping responses aimed to alleviate perceived, impending danger. Hence, fear works like an inbuilt compass to navigate a landscape thick with factual and fictive threats - what I call, after Tulumello (2017), a fearscape. If, as Green argues, this pervasive, invisible, and often silent presence of fear in conflict-affected areas determines "the way of life" for its occupants (ibid. 1994:227), surprisingly few geographers have examined how people respond in and to these fears in order to mentally, physically and emotionally survive.

In this article, I therefore seek to contribute to an emerging literature on the anthropology of fear (Boscoboinik and Horáková 2014) by bringing a gendered, emotio-spatial dimension into discussion concerning the relationship between conservation and conflict. A wide range of critical studies show that current conservation practices fail to sufficiently include or benefit, and instead often mistreat, members of local communities, leading to (violent) conflict between parks and people (Acranez et al. 2007; Bocajero and Ojeda 2016; Minarchek 2020). Focussing specifically on PNVi, Hochleithner (2017) documents different forms of "peasant resistance" embodied in

\footnotetext{
${ }^{36}$ Original name in French: Parc National des Virunga (PNVi), thus I will refer to PNVi or "Virunga".
} 
customary land claims against PNVi's conservation practices, while Marijnen and Verweijen (2018) depict how increasingly militarized conservation measures fuel forms of "counterinsurgency as resistance" by community members. This common reference to Scott's "everyday forms of resistance" (Scott 1985, 1990) framework tends to homogenize "people", not accounting for the diversities regarding age, ethnicity, and gender within park-adjacent communities. It further concentrates on behaviour directed against nature conservation practices and hence inhibits us from seeing the opportunities, compliances and collaborations unfolding within and because of conservation areas and practices. To go beyond this dominant focus on resistance, I introduce a feminist geography approach into critical conservation studies to examine the decisively gendered impact of fear informing women's coping strategies with both landscape and actors.

The history of fear in Eastern Congo runs deep and is interwoven with the particular features of a landscape scarred by violent oppression and exploitation by the Belgium colonizers from 1908 to 1960. In North Kivu, this included King Albert's conservation efforts in establishing Albert National Park in 1925 (renamed to Virunga National Park in 1969), evicting the local population to fence off the flora and fauna of Africa's largest rain forest spreading across the Virunga volcanoes into Rwanda and Uganda. As the volcanoes constitute the habitat of endangered mountain gorillas, conservationists have ever since become a powerful stakeholder in the violent conflicts over the landscape.

This article concerns the era of upsurging violence experienced by the women with whom I worked, specifically after the genocide in Rwanda in 1994, that put PNVi and its surrounding communities at the heart of warfare. My research did not intend to focus specifically on women. While men equally face fears, albeit less often expressed in further fear of stigmatisation by others (see e.g. Ammann and Staudacher 2020), it was the men who directed me to the women asking me to listen to their stories because, as one local chief stated: "They are the ones who suffer from the park." This statement refers to the predominantly gendered division of household tasks in the rural area around $\mathrm{PNVi}$, with women primarily performing the duties of getting firewood or charcoal, water and resources for cooking and washing. Given a lack of alternatives, a majority of women enter the National Park every day for those basic necessities, exposing them to encounters with park rangers and other armed groups operating within the forest. In fact, particularly women from the adjacent villages reported that they have experienced harassment, physical and sexualised violence, rape, imprisonment and being shot at by park rangers, who are in charge of enforcing the boundaries of PNVi based on its status as a UNESCO World Heritage Site and a category II Protected Area. ${ }^{37}$

Therefore, a gendered analysis accounts for the socio-cultural context in North Kivu and can offer nuanced insights into survival strategies in the conservation-conflict nexus. Examining the relationship between fear and coping affords identification of women's own prioritized needs as potential solutions for livelihood struggles. It hence contributes to fill a noteworthy gap in current research concerning more diverse, inclusive and locally created strategies to reduce the

\footnotetext{
${ }^{37}$ Protected Area category II prohibits any access and resource use within the park, apart from scientific research and tourism (IUCN 2020).
} 
conflict between conservation areas and people more generally. Moreover, by placing special emphasis on women's perceptions of fear and their multitudinous self-created coping strategies, I follow Utas' call for "a far more complex understanding of women's experience in African and other wars than prevailing depictions that deduce from women's accounts of victimization that they have no agency" (2005: 409). Definitions of women's agency are debated across disciplines, for example in how far modes of female behavior can transcend and transform structures and relationships in traditional, patriarchal and/or religious societies (Kooks and Harel-Shalev 2020), or gendered identities (Ahmed 2020). In this article, I refer to agency as women's practices in their everyday lives by interacting with, navigating around, counteracting, adapting to and making use of violent societal structures within a conflict-affected social space (see e.g. Tripp 2015; Yadav 2020). While women's daily agency can have powerful manifestations in silent forms to deal with persistent insecurities (Ammann 2020; Fujii 2010; Parpart and Parashwar 2019), this article focuses on the women's voluntary articulation through their 'photovoice' (Wang 1999). While not meaning to disregard women's experiences of hardship, cruelty and structural terror that can result in overwhelming, paralyzing fear and long-lasting trauma, I seek to emphasize women's agency as the often untold acts of self-determination, self-representation and active engagement with(in) the fearscape.

In the following, I first introduce a feminist emotional geographies approach into discussions concerning the relationship between conservation and conflict studies to explore the concept of coping with fear. Afterwards, I give a brief insight into the history of Virunga National Park to thereupon elaborate on my methodology and the visual ethnographic elements in adaptation to the volatile conflict context. Then I turn to the narratives of two women in particular demonstrating how their fears inform their survival strategies with(in) the conservationconflict dynamics. In concluding, I advocate listening to people's fears can advance our understanding of their own prioritized needs in relation to the political and economic interests behind the creation and maintenance of fear in conflict-affected settings that can inform pathways to mitigate people's livelihood struggles.

\section{Interdisciplinary encounters: fear, 'scapes' and coping}

In the past two decades, the study of fear has received growing interest across disciplines, yet few geographers have accounted for the significance of fear in motivating human coping behavior to survive in spatial contexts of violent conflict and war. As one exception, Taussig (1992) argues that modes of domination, terror and inequality metaphorically and literally transform society as a whole into a 'nervous system'. His essays obscurely refer to the sympathetic nervous system that in threatful situations induces the emotion of fear through releasing the stress hormone cortisol within the brain. Cortisol functions as an innate survival mechanism that prepares the body to fight or flee (LoBue et al. 2019). When the life-threatening situation has passed, cortisol generally decreases.

However, people who experience ongoing violence, warfare or, what Miller and Rasmussen (2010: 7) call 'daily stressors' in the form of harmful socio-structural and material conditions, can encounter permanent perceptions of threat resulting in chronically elevated cortisol levels (Martz 2010). Such longstanding exposure to threat can lead to an embodiment of 
fear with far-reaching, epigenetic consequences, effectively storing trauma in the body of successive generations who continue to sense, suffer and react under those fear-induced stress levels (see e.g. Kwapis and Wood 2014). Green (1994) drew attention to this pervasive presence of fear permeating and forging people's everyday lives in conflict-affected regions. While policies, economies and societies at large shift along what Richards calls the "peace-war-peace continuum" (2005:13), Green depicts how fear remains engrained within societies in ostensibly post-conflict situations, thus shaping the mental and topographical landscape for its inhabitants. In order to account for this spatial dimension of emotions, conflict studies took up Appadurai's suggested “scape” suffix, exemplarily in Nordstrom's “warscapes” (1997), focusing on how landscapes scarred by violence and warfare interact with people's livelihoods (see e.g. Bourgois 2001).

While these scholars commonly mention the ubiquity of fear within warscapes, they rarely examine how this emotional dimension influences the development of diverse and gendered livelihood strategies. To address this neglected issue, my analysis is inspired by Verweijen's (2020) argument that studies on direct and indirect (Tyner and Inwood 2014), structural (Galtung 1969), "slow" (Nixon 2011) or "green" violence (Büscher and Ratmusindela 2016) alike tend to disregard the specific social, psychological, emotional and physiological circumstances and micro-dynamic processes that constitute spaces and actions. For this reason, I suggest shifting the analytical angle onto fear that persists and shapes landscapes even after direct violence and warfare may have faded, and which consequently informs people's (and especially women's) navigation within and through these spaces.

As an overarching framework, therefore, I build on work in emotional geographies to examine how spaces forge the experience of emotions, and how, in turn, emotions mold these spaces by informing people's everyday navigation routes throughout landscapes (Davidson and Milligan 2004; Koskela 1997; Mehta 1999; Pain and Smith 2008). I refer to landscapes that continuously trigger the emotion of fear as "fearscapes". The term originates from behavioral biology to describe "a variable landscape of predation risk" that influence animal movements in avoiding certain spaces of threat from predators (Olsoy et al. 2015). Similarities to the human sphere were first highlighted by geographers such as Tuan (1979) exploring how the human imagination creates "landscapes of fear" in association with threats of famine, diseases, authoritarian terror or individual dark thoughts. Tulumello (2017) invoked the "fearscape" concept specifically to develop a taxonomy for urban fearscapes according to four categories: "enclosure" creating spaces of exclusion/seclusion; "barrier" implying the infrastructure of the fearscape; "post-public space" established through privatisation and fortification of public space; and "control", namely the politics of surveillance (ibid. 2017:4).

These urban fearscape characteristics exhibit categorical similarities to the conversion of natural environments into National Parks as a specific form of protected area (PA). Political geographers brought attention to problematic measures applied in this conversion process as a form of "fortress conservation" (Brockington 2002; Kelly 2015), "based on the belief that biodiversity protection is best achieved by creating protected areas where ecosystems can function in isolation from human disturbance" ${ }^{38}$ This conversion commonly entails framing and treating

\footnotetext{
${ }^{38}$ Sage Encyclopedia of Environment and Society 2020, https://sk.sagepub.com/reference/environment/n432.xml?term=fortress\%20conservation, accessed 16-6-2020.
} 
local communities as "threats" to nature in order to evict, dispossess and punish inhabitants (Ybarra 2012), justify violent and militarized measures to "protect" conservation sites (Lunstrum 2014; Massé 2018) and fight a discursive and physical "war for biodiversity" (Duffy 2014). Other critical conservation scholars focus on local peoples' "resistance" to these violent measures (Holmes 2007), varying from hidden acts such as dissimulating continued livelihood practices within National Parks (Poudel 2019) or physically attacking conservation staff (Matose 2014).

Complicating this "park versus people" debate, recent work building on the concept of "violent environments" (Peluso and Watts 2001) points to the entanglement between conservation practices and wider dynamics of warfare within a given region, blurring boundaries between conservationists, 'civilians' and diverse armed actors in their overlapping roles and claims for power, or at least survival (Marijnen et al. 2021). In this context, a sole focus on resistance to conservation risks compartmentalizing into "good" (legitimate) versus "bad" (illegitimate) actors and behaviors that reinforce dichotomous victim-perpetrator relationships. Thus, it forecloses opportunities to see the "tactic agency" (Utas 2005) within proactive shifts between resistance, compliance and collaboration developed in search of viable livelihoods with conservation.

To overcome these limitations, I ground my analysis of female livelihood strategies on the understanding that fear informs mental and behavioural responses towards survival in the form of coping strategies. While resistance is directed against a target, coping unfolds with someone or something. Lazarus and Folkman (1984) define coping as "an action, a series of actions, or a thought process used in meeting a stressful or unpleasant situation or in modifying one's reaction to such a situation". ${ }^{39}$ Based on Selye's "general adaptation syndrome" (1976), coping describes the ability of individuals to develop emotional, cognitive and action-oriented strategies for reducing or eliminating perceived threats, and thus lowering chronic feelings of fear in violent and (post-)conflict settings (Johnson and Chronister 2010). Coping entails the "choice of action" aligned to the personally appraised reality (Haan 1977: 80) and and hence accounts for ownership and empowerment. In this article, I seek to shed light on the fear-induced coping strategies of two women in particular, in their attempts of appropriating Virunga's fearscape that both constrains and enables their efforts to maintain livelihoods amidst ongoing violence.

\section{A recent history of the Virunga area}

After the end of the genocide in Rwanda in 1994 more than two million people fled into Zaire, ${ }^{40}$ including the former Hutu government of Rwanda and its military wing interahamwe responsible for carrying out the genocide. These old governmental forces reinvigorated their power within Congolese refugee camps to stage attacks against Tutsi-affiliated peoples, in particular the Banyamulenge, within Zaire and across the border against the new Tutsi-dominated government of Rwanda. From 1996, this new Rwandan government with support by Uganda, responded with military invasions into Eastern Congo in order to eradicate the expatriated opponents and assumed supporters, in the process also displacing, humiliating and killing millions of Congolese

\footnotetext{
${ }^{39}$ American Psychological Association. 2020: Dictionary of Psychology, https://dictionary.apa.org/coping-strategy, accessed 17-7-2020.

${ }^{40}$ From 1971-1997, then president Mobutu Seso Seko renamed the DRC to Zaire.
} 
(Mathys 2017). Those Congolese who survived count the following, internationally declared 'two Congo Wars' (1996-1997; 1998-2003) as six waves of an ongoing war. Divergent sources show how this war continues to be directly or indirectly initiated by Rwanda and Uganda to maintain instability facilitating their exploitation and trafficking of mineral resources from the DRC (Lopez et al. 2017; UNEP, MONUSCO and OSESG 2015). The instability, combined with a weak and in North Kivu largely absent - Congolese government, created a power vacuum filled by more than 140 local and foreign armed groups. Many of those groups use Virunga as a passage, hideout and resource base while committing major atrocities against the population (Kivu Security Tracker 2020).

Fearing irretrievable biodiversity loss from these militia activities within the park, PNVi further militarized its conservation efforts when the state-owned conservation authority Institut Congolais pour la Conservation de la Nature (ICCN) entered a public-private partnership with the British NGO Virunga Foundation in 2008. The new park management under the Belgian Emmanuel de Merode attained international fame and funding from private donors including the Howard Buffet Foundation and the European Union, amongst others. Thereupon, PNVi stated on their official website that they plan to "deliver large-scale opportunities for the local community by reducing poverty rates, stabilizing security, and strengthening local infrastructure" (Virunga 2020). These ambitions raised the hopes and expectations of local communities to get their share of the National Park in the form of economic benefits and improved regional security.

In 2018, ten years of disenchantment, during which Virunga's conservation-asdevelopment efforts have not lived up to these hopes, have left an imprint on local attitudes towards the park and its managers. Many Congolese women in North Kivu perceived PNVi as a self-enriching, neo-colonial project of Belgium that is only created for wealthy tourists while stealing agricultural land that local residents would need for subsistence. Despite Virunga's implementation of two hydroelectric power plants, the park management states that only roughly 5000 of the four million people living in proximity to the park benefit from their projects (Virunga 2020). Above all, women stressed repeatedly how they suffer from persistent insecurity coming from PNVi. Facing threats to their livelihoods from the multitude of armed actors around and within the forest and a state providing neither protection nor law enforcement, the situation appears exceptionally unjust to residents when PNVi's paramilitary convoys pass through their village safeguarding a few tourists in and out of the park. Despite deployment of the largest United Nations peacekeeping mission in the world, those who stayed not only feel left out of Virunga's conservation "success" in monetary and security terms, but also see the park as one more threat worsening their hardship. The threats caused by PNVi include taking away their farmland through park expansions, animals exiting the park and destroying harvest, denial of access to basic resources within the park, and harsh, often violent, punishment by ICCN rangers when entering the area unauthorized. These recent historical developments reflect how violence, militarization and warfare coalesced conservation practices and the wider, complex dynamics of the regional conflict into a fearscape. 


\section{Methods of visual ethnography}

Due to the volatile security situation in 2018, my fieldwork base was in Goma, the regional capital of North Kivu. From March to December 2018, my Congolese research partner Pat and I conducted research trips to five villages adjacent to Mikeno sector, which is the highly securitized part of PNVi that constitutes the habitat of mountain gorillas blending into the forest of Rwanda. ${ }^{41}$ My research partner Pat is a Congolese man who holds the status of a 'mzee', ${ }^{42}$ respected for his advanced age and longstanding advocacy work in his native home area in the park-adjacent villages in North Kivu. He became my advisor, protector and translator after a common friend from Uganda introduced us and thereby established the needed, mutual trust. We conducted semi-structured and focus group interviews with local chiefs, governmental officials, security personnel, park rangers, farmers, local cooperatives and so called "groupes de solidarité". We repeated visits to one specific women's group who lived in Pat's native village in proximity to the borders of PNVi.

In 2018, political turmoil due to long-term delay of presidential elections and increasingly frequent, unpredictable outbreaks of violence, attacks and kidnappings impeded regular access. In addition, the Ebola epidemic spread to North Kivu in May 2018 leading to a withdrawal of many foreigners working in the region. This had threatening consequences for Pat's and my own safety due to my visibility as one of the few white people leaving Goma and therefore an easy target for raids. My presence as a white Western woman and researcher also had a decisive impact on the women's responses - a bias I will discuss further below.

To mitigate those barriers, Pat's social embedment in the park-adjacent district enabled us to make use of participatory photography techniques in combination with written diaries and reflective, individual interviews. Participant photography - also referred to as 'photovoice' constitutes "a visual method in which research participants are encouraged to visually document their social landscapes through photography and reflect on their photos to produce personal narratives" (Allen 2012: 443; see further Wang 1999). In the paramount objective of protecting our voluntary participants, we ran several information meetings about my research project as well as the risks, responsibilities and choice of withdrawal at any time when utilizing the cameras. Pat distributed 15 disposable cameras and diaries to literate volunteers in three different parkbordering villages. Maintaining an open, inductive approach, the photographers were asked to make one picture per day of their everyday experiences and to write a diary entry about the photo and what it meant to them. All participants were renumerated for their work and received their photos. Only photographs and verbal accounts that participants haven chosen themselves and explicitly consented to use for the research project are presented in this article. ${ }^{43}$

This visual ethnographic approach allowed the participants to represent how they saw and sensed their everyday lifeworld without the unavoidable impact of my presence. The photos and texts further assisted my understanding of what is meaningful to them but equally important, what they wanted me to see. In addition to my own observations, we complemented the photo diaries with semi-structured interviews. In the following, I focus on two women from two different

\footnotetext{
${ }^{41}$ For the protection of all participants, all names and explicit locations are pseudonyms or kept anonymous.

${ }^{42}$ The Kiswahili word 'mzee' is a title of respect for an elder person due to age, authority or experience.

${ }^{43}$ Participants hold copyright over their images. Their work is not further displayed in any public or private form.
} 
villages who have been willing to take photos, write and speak to me throughout 2018. The stories of Pauline and Mama Sifa give an insightful, idiographic - yet widely-shared - account of women's livelihoods adjacent to PNVi.

In total 52 pictures, complemented by diary entries and personal narratives, pointed to the women's fears generated by different threats to their livelihoods and their individual responses for survival. Given the subjective nature of emotions, identifying fear is a point of personal sensing and linguistic interpretation. Yet I have chosen to focus on fear as it appeared to be more than an emotion, but a deep, underlying condition that informed other feelings of disappointment, resentment, anger, despair, apathy and sadness in the livelihoods of women around Virunga.

\section{Coping with(in) the fearscape}

Pat and I followed the single road from Goma north until we turned onto dusty side roads flanked by huts with UN tarpaulins and iron sheets as roofs. At the end was a stone house, painted with slogans by the NGO who donated the building as a community hall for village meetings. Mama Sifa, the leader of the self-organised "groupe de solidarite" for women from the surrounding villages, welcomed Pat at the door and guided us into the dark, windowless room. Inside, 16 women, between 19 and 52 years of age, were already seated in a circle on plastic chairs.

The women seemed calm and unimpressed when we met that first time in March 2018. They saw waves of violence come and go - and they saw that nothing changed in their situation. The high number of kidnappings of Congolese, many of them of children, as well as the violence, lootings and attacks by different armed actors, including the Congolese army Forces Armées de la République Démocratique du Congo (FARDC), had become so "ordinary" for them, yet remained mostly unnoticed by the international media. The earnest serenity and dignity of the women in Mama Sifa's group was admirable, yet alarming considering what Taussig describes as a "numbing and apparent acceptance" (1992:11) provoked by a permanent state of insecurity.

During the introduction round, Mama Sifa enjoined every member of the group to tell their personal story. Many women appeared timid or reluctant to speak, gazing towards the floor when they briefly answered Pat's and my questions. In the awareness of the bias my appearance created, I sensed an unwillingness to speak to or in front of me, yet another 'white Western researcher' (who are often associated with an exploitative, violent, colonial legacy in the Congolese and conservation context in particular (see e.g. Marchais et al. 2020) asking them questions, reminding me of the phenomenon Mwambari (2019) calls "research fatigue". More even than fatigue, the women later on expressed their resentment about being interviewed. They had been disappointed so many times before that these meetings with white researchers delivered no benefits for them. They witnessed how foreign NGO workers offered humanitarian assistance ranging from material goods to counselling services, and have been coming and going in waves like the warfare, yet similarly have not brought any long-lasting change to their hardship. I respected their silences as an expression of their agency to draw their own boundaries, potentially indicating what Fujii described as "admonishments to the researcher to respect certain topics as 'off limits"” as well as choosing to "deny [...] researchers access to the data they seek" (2010: 238239). 
It was due to Pat's status, longstanding advocacy work in the villages and his friendship with Mama Sifa that some of the women eventually opened up. Pat explained before each interview that our research project and our visits were temporary and we could promise any positive change in the long run. That somehow validated the women's disappointed assumption about my appearance and my own discomfort asking in how far anthropology here can really be an agent of social change (cf. Schepher-Hughes 1992: 28)? By devoting this article to these women, I hope to give back - or pay forward - by making another step towards change by raising attention and acknowledgement that seeks to inspire our own agency as academics, practitioners and activists.

\section{Pauline's strategy: bartering}

Unlike most young women in the region, Pauline, 24, had finished primary six because her mother found education important and saved to pay the 25 USD annual school fees. Pauline started her first year just after schools re-opened in the short moment of stalemate when the end of the first Congo War in May 1997 brought hope for a return to "normal life" in Eastern Zaire. ${ }^{44}$ In August 1998, this short glimpse of hope was destroyed when the governments of Rwanda and Uganda disagreed with DRC's new president Laurent-Desiré Kabila. Thereafter, they recruited mostly as ethnic Tutsi identified Banyamulenge from Eastern Congo to form the rebel movement Rally for Congolese Democracy heralding the Second Congo War in North Kivu.

During the five years that followed, Pauline's teacher continued lessons at his home, irregularly but sufficient for her to develop her spoken French. Later this turned out to be a decisive asset for Pauline, as it enabled her to hide the Kinyarwanda that was spoken at home. Despite the fact that Kinyarwanda is widely known through trading and kinship in the surrounding regions of the Virunga volcanoes in the DRC, Rwanda and Uganda alike, the Congolese government used this linguistic demarcation as a discursive war tactic to identify, assault, expel and kill the "Rwandophones" (Mathys 2017). As a result, many Congolese of North Kivu developed strong resentments against Kinyarwanda-speakers, who were accused of being affiliated with and supportive of the Rwandan invaders. In the course of the successive wars that were instrumentalised along ethnic lines, a multitude of armed groups mushroomed within North Kivu, directly and indirectly supported by the Rwandan and Ugandan governments, in opposition to those forces or shifting in between them. ${ }^{45}$

In 2018, Pauline lived with her own four children in her childhood village on the border to Rwanda and Virunga National Park. She had been told by her mother that her family once had a plot of fertile land. The park took this away, leaving the family without the opportunity to cultivate food and hence with no other choice than going into the park unauthorized to find some basic resources to survive. Being born into this "natural" order of things, Pauline neither questioned the given structure of conservation's domination over the landscape, nor her right to navigate around those policies and practices. Her sense of being an original and thus rightful owner of what is now park land informed Pauline's personal justification of going into the forest

\footnotetext{
${ }^{44}$ In course of 1997, the dictatorship of Mobutu Seso Seko was overthrown by Rwandan forces with their Congolese allies. The country was renamed to the Democratic Republic of the Congo.

${ }^{45}$ For a comprehensive historical overview see e.g. Lemarchand (2012) and Stearns (2012).
} 
to extract resources that would effectively be hers. Other women expressed similar attitudes recalling one specific moment in 2016 when the park expanded its borders "again". Park rangers pushed them off their crop fields, confiscating their harvested potatoes and erecting sign posts saying "ICCN Parc National des Virunga - limite du parc" to demarcate the new conservationclaimed territory. They promised to give the affected villagers compensation for the land taken. However, people never received anything apart from 1000 saplings which they were supposed to plant as a new demarcation line to separate the conservation area from their remaining farmland. Pauline showed me the rotten saplings that were lying at the same spot where they were dumped by the ICCN truck. "Can we eat those trees?", she commented concerning the saplings' lack of value in making up for the loss of food harvest.

Pauline feared the rangers ever since she observed how they changed when ICCN entered the public-private partnership in 2008 and gained international funding. She remembered that the rangers suddenly got good boots, good weapons and a lot of money. These new features came into place when Virunga's new park director de Merode invested great effort into eradicating clientelism and corruption among rangers, militias and local communities. Giving rangers a regionally extraordinary monthly salary of 250 USD, amongst other employment benefits, the ICCN head warden confirmed to me, caused reported cases of ranger bribery and collaboration with armed groups and civilians to decrease. Nowadays, a cohort of about 700 mostly young rangers, trained and equipped as paramilitary, carry out foot patrols along and within the park's borders. These new rangers are the "Virunga's army" that Pauline feared. Some women still try to go back to their former fields to plant seedlings, but this army always comes back and rips out the crops, beats them up and threatens to take them to the prison at the park's headquarters in Rumangabo. Some women, Pauline said, were taken there and never returned, leaving their children orphans. Despite these threats of punishment when entering the park, Pauline emphasized: "I have to go into the forest every day - for the survival of my children. The poverty is big and there are no jobs. We are going as robbers, but women have no choice." She mostly collects firewood and water for cooking, sometimes also some special plants her mother taught her about that she applies as medicine. In addition to these basic resources, Pauline enters the park to earn some income by working in the makala [charcoal] business. In her camera diary she devoted every photo to makala, documenting the importance of charcoal that is used as a cooking fuel by the majority of households surrounding PNVi (UNEP 2015).

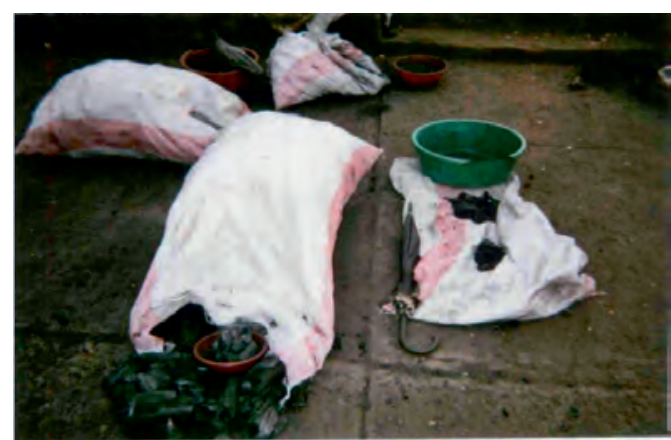

Fig. 4.2 Pauline's photo diary - "Open charcoal sack"

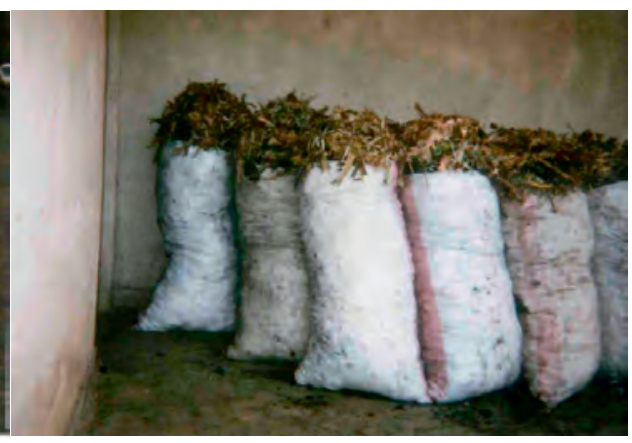

Fig. 4.3 Pauline's photo diary - "Charcoal sacks" 
Produced by slow burning trees into carbonized pieces, the charcoal industry is one of the main drivers of deforestation of Virunga's rainforest. PNVi's official website states that "millions of dollars' worth of illegally trafficked charcoal [...] are extracted from the Park each year by members of armed militias" (Virunga 2020). Yet, the photos of Pauline show that not only militias but also girls and women of all age groups are engaged in this business. While men are mostly in charge of the burning process, women cut and bind trees, carry heavy sacks of makala on their backs to bring them to markets or transporting trucks, or sell charcoal on the sides of the street. The charcoal made from high-density wood within the park has a much higher quality and thus a higher price, as Pauline wrote: "You come with one sack of full (char)coal costing 10 USD whereas a half sack of (char)coal from Virunga park costs 10 USD. [...] The charcoal from the park is heavy and of good quality." Rather than selling full bags of makala, Pauline prefers to sell in piles of small pieces measured in a bowl for 200 Congolese Franc [roughly 0,10 USD]. Selling in small bowls "goes fast because many of the clients are vulnerable". By also referring to herself and other women as "the vulnerables" she stressed that she cannot think of tomorrow in the struggle for surviving from day to day.

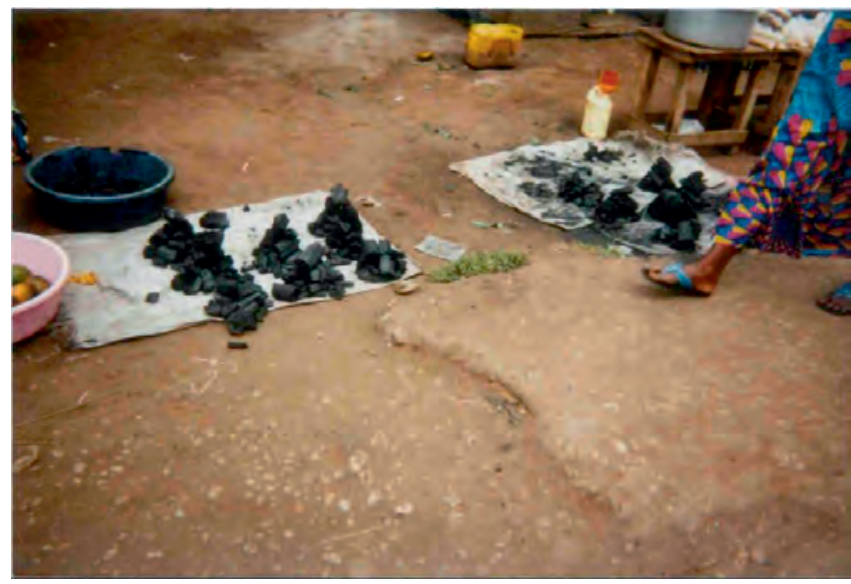

Fig. 4.4 Pauline's photo diary - "Selling piles of charcoal"

The majority of the charcoal business in North Kivu is part of an illegal cartel run by the Forces démocratiques de libération du Rwanda (FDLR), one of the biggest rebel groups in North Kivu that emerged from the former Hutu-dominated Rwandan government and its military wings in 2000. The FDLR organizes a network of alliances with public authorities, businesses, the police, the Congolese army, security personnel and community members to produce charcoal within PNVi, transporting it to and selling 90\% of it in Goma (UNEP 2015). Studies on the illegal charcoal chain from Virunga state that the FDLR commits major atrocities and human rights violations, animal poaching and trafficking, forced labour and sexual slavery "accelerat[ing] cycles of insecurity, poverty, fear, and environmental destruction” (Enough Project 2016: 2).

In contrast to the common assertion that the FDLR recruits locals by coercion for illegal charcoal activities, Pauline emphasized her 'choice of action' by stressing that she works in the charcoal business and with the militias. Blurring common distinctions between victims and 
perpetrators, other studies of North Kivu similarly point to the solidarization and "contentious co-production" of locals with armed groups (Marijnen and Verweijen 2020: 997). Pauline justified her decision with the persistent insecurity surrounding her:

"If we would be safe, we could go everywhere and do something. For example, my man could buy a moto and use it as taxi from [...] to [...]. But on this road is attack every day, so moto taxis stopped [operating]. Or when a bandit loots all my harvest of cassava and maize. I ask myself: what am I doing on this earth? I work with the rebels because they are robbers too. I have nothing to lose."

"Working with the rebels" hence became Pauline's coping strategy to address two stressors simultaneously: food and physical insecurity. Other studies underline the benefits of this liaison for survival that Pauline expressed, as similar complicity with powerful armed groups can provide a degree of protection from lootings, property destruction and violent attacks (Iñiguez de Heredia 2017; Vlassenroot and van Acker 2001). Given the plethora of armed and "predatory" actors in the region (Kankwenda 2005), Pauline's complicity with the FDLR underlines what Utas described as the possibility that women work voluntarily with rebel groups as an "proactive effort to protect self and families" (Utas 2005: 409). Moreover, by categorizing herself and the militias as "robbers" of the park's resources, Pauline expressed a sense of similarity and symbiosis with the militias. Conservation law makes them appear as equals, since they are both criminalized and punished as illegitimate intruders of the park. In addition to this socio-economic bonding over PNVi in uniting enemy and "marketplace", being on good terms with the FDLR functions as a point of access into the park and safeguarding out of it again, hence protection from ranger patrols and other armed actors within the forest.

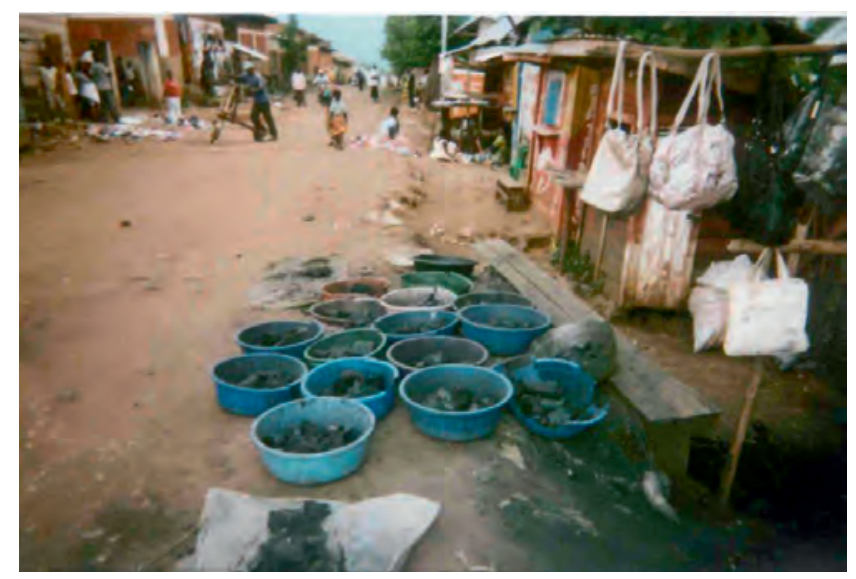

Fig. 4.5 Pauline's photo diary - "Plastic bowls of charcoal in the village"

Nevertheless, Pauline also feared the FDLR who use the park as a resource base and hide-out. When Pat asked about her relationship with the militias, she fell silent and carefully closed the door to make sure nobody would overhear our conversation. Women who interact with rebel groups, voluntarily or forced, are often stigmatized within the communities since those interactions indicate a "collaboration with the enemy" and often involve sexual and violent acts. A psycho-counselling study in 2018 found the highest instances of rape and abduction of women 
as soldiers or sex slaves in the bordering villages to PNVi's Mikeno sector (Robjant et al. 2019). Pauline knows about women who have been raped in her village but she stressed that "these stories remain the secret of the victims". Importantly, Pauline's further explanations clarified that the label "victim" does not preclude agency for her. Pauline was not herself a „victim“ of rape, she was a "troc" ["barterer"]. She explained her trading agreements with the unknown, different actors she might encounter on her way in and out of the park in a professional manner to us: "In the park there are bandits, rebels, FARDC and rangers. If we meet, we [women] sell what we have. And we have nothing but a body."

Pauline never referred to any women specifically but always used the plural "we" when she spoke about women's collaboration with armed actors, as if she wanted to change all women's fear of being raped by depicting it instead as a work-trade relationship. Besides, by expressing her own experiences as a collective situation, she was able to depersonalize the sexual abuse. This rephrasing offered her a form of mental protection, maintaining her dignity and agency to be in charge of her decisions and her body. Being unable to leave the fearscape, threat avoidance proves elusive for Pauline. Yet coping with her fears by changing her personal narrative helped her to alleviate the threat and horror of sexual violence. Facing the lawlessness and unlikelihood of any prosecution by a largely absent government, she adapted to North Kivu's own rules of power and dependencies on those kinds of personal relationship to participate in the second economy, an "economy of survival".

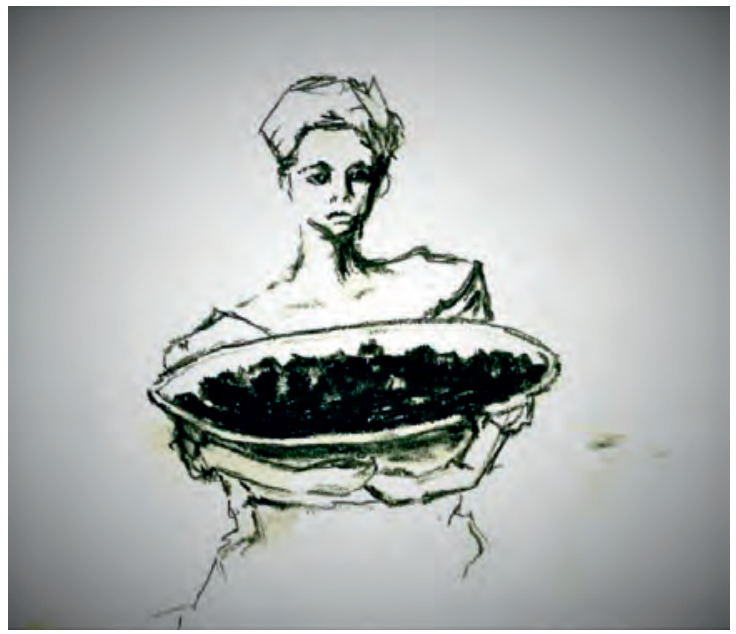

Fig. 4.6 "Pauline"

Pauline's example illustrates one particular physical and emotional coping strategy shared by many women whose fear of not being able to feed their family outpaced their fear of the multitude of armed actors and the consequences an encounter with them could entail. To mitigate the heavy impact on mental and physical health and potential stigmatisation, she changed the victimfocussing narrative of "being raped" or "being exposed to (sexualized) violence" into a narrative of agency by instead speaking of "trading" and "selling her body". She thus found opportunities 
to circumvent the constraints of the fearscape by proactively interacting with its features to provide for her children's survival.

\section{Mama Sifa's strategy: performativity}

Born in 1966, Mama Sifa praised the old days of Zaire's independence under Mobutu Seso Seko when she could safely walk the four kilometres down the road to her school and had realistic aspirations of going to university one day. Her diary entries, written in neat handwriting in a table with dates and locations, relate that the children of today are not able to have this experience of going to school and thus have no hope for any improvement of this tough life.

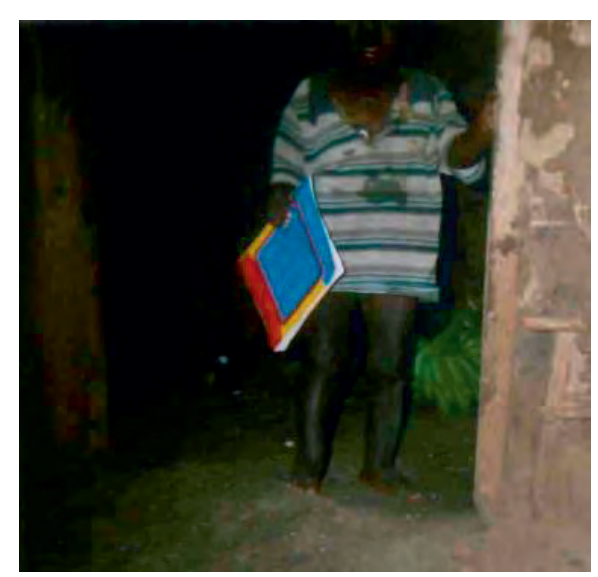

Fig. 4.7 Mama Sifa's photo diary - "Child with booklet"

She expressed her concerns that these "children without a future" have no other choice than joining an armed group:"Born and bred in war, what else do they know? Killing is a joke to them." Mama Sifa had nine children, two of whom died from gastrointestinal diseases, while the other seven survived the never-ending war. She was proud of this - her - achievement of protecting them. All her photos were devoted to children in the neighbourhood carrying out different types of labour such as selling beans or maize, carrying goods, or cleaning in order to support their families. These duties and the financial inability of affording school fees are only two reasons why children are not in school. More importantly, Mama Sifa emphasized, a mothers' biggest fear is that her child would get abducted by "the bandits" on the way to school.

She observed that cases of child kidnapping for ransom increased drastically after Virunga stopped its tourism in May 2018, as a consequence of the abduction of two British tourists on the road to PNVi. Before, the fixed hours when tourist convoys were going to the park and back to Goma generated windows of spatial security along the road for everyone. Now, women cannot send their children to go to school or to fetch water anymore. "The next water source is 40 kilometres away from the village, but the road to Goma is dangerous," she says, "the only salvation is the rain - when the water comes to us, because we cannot go to the water." The closest water access would be inside the park consisting of high altitude wetland, wells, and small streams, yet the forest bears similar risks as the road. 


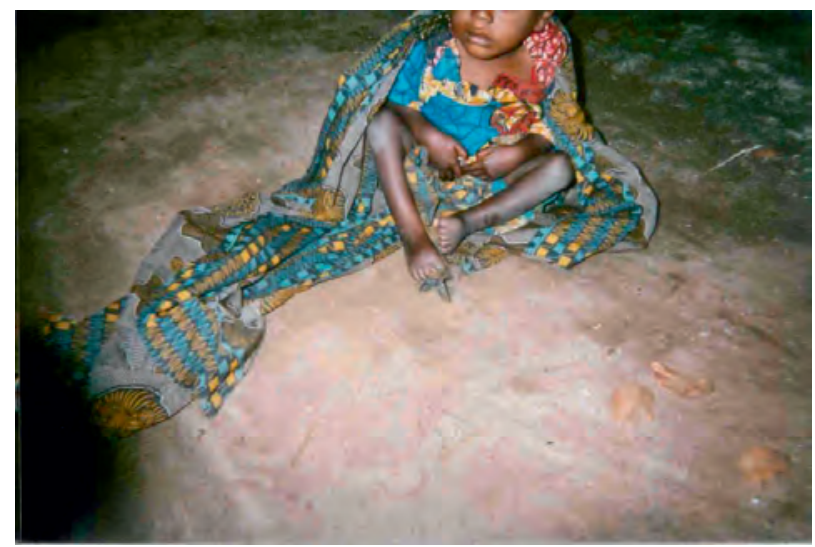

Fig. 4.8 Mama Sifa's photo diary - "Child in Kitenge"

Many women ascribed the threat of kidnapping and other encounters of unpredictable violence to the vague term "the bandits". Similarly, Mama Sifa's statement that "the kidnappers are amongst us" referred to community members, and hence everybody in their multiple, overlapping roles crossing categorisations as "civilian", "kidnapper", "robber", "rebel”, "army soldier", "FARDC” or "neighbour". "Bandits" reduced finger-pointing in a context where everybody could be blamed, but also seemed to alleviate the terror of this violence to "just" an act of banditry. In addition, Mama Sifa justified the increase of "bandits" since Virunga closed its tourism and mainly men lost their income opportunities, directly and indirectly linked to PNVi. When Pat and I visited the porter association in North Kivu consisting of 256 men only, they expressed their desperation since they cannot accompany tourists on gorilla tracking and volcano hiking activities within PNVi. A cooperative of men carving gorilla statues for tourists were afraid of what will happen if PNVi never opens again because without the foreigners who were brought to them by tour guides they have no market. Other male-dominated jobs working with or for PNVi such as drivers, tourist operators, guides and employees of the three Virunga lodges also stopped. It was these men Mama Sifa pointed to when she explained to us: "These men have a lot of desperation. They fear to not be able to provide for their families. That is the reason why men go into kidnapping business, because ransom brings quick money." When tomorrow is uncertain, "quick money” - similar to Pauline's logic to selling small charcoal piles - is the only valuable currency for survival, keeping the second economy in motion.

One day in October 2018, Pat and I arrived at the village after some time had passed without us visiting. I greeted Mama Sifa, asking in an honest but not (re)searching manner: "Good morning, Mama. How have you been the last weeks?" Her response came quick: "Aye, aye. Last week bandits came and looted many houses. They killed the grandma and raped the 13-year old girl." I was taken by surprise and unsure what to say, but Mama Sifa continued: "The bandits used pangas [machetes]..." imitating the slashing movements with the arm, bending her body. "I founded the association for raped women. We are all volunteers", she finished. Later I realized that her timing was not a coincidence. It was just one week after Dr. Denis Mukwege received the Nobel peace prize for 
founding the Panzi Hospital in South Kivu treating women who have experienced sexual violence. When asking Mama Sifa, she confirmed that she heard this news on the radio, eliciting pride that her country was awarded. In founding her own association, she expressed her desire to be part of this "success" given the morbid paradox of many rape cases in North Kivu that attract international attention and aid. ${ }^{46}$

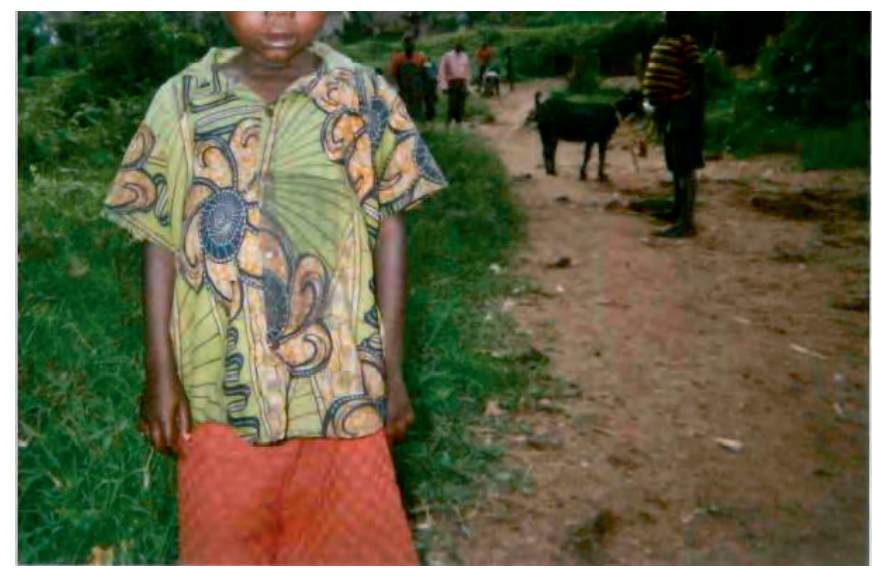

Fig. 4.9 Mama Sifa's photo diary - "Child on the pathway"

As Utas witnessed similar coping strategies with violence in post-conflict Liberia, "presenting themselves as victims was a means by which women effectively established themselves as 'legitimate recipients' of humanitarian aid" (2005: 409). Mama Sifa was candid concerning how she managed the national and international non-governmental organisations passing through the village to find "an issue", often expressed in buzzwords of NGO jargon, which "they can teach us about", she added ironically. She learned the vocabulary in order to apply for any kind of support depending on what was "in vogue" at the time. From her memory, "rape" has been popular for some time; before it was "child soldiers", "food security", "malnutrition of children", and "demobilisation". In the past 20 years, Mama Sifa has sent people from surrounding villages to workshops, interviews, sensitization and information meetings with different organisations to gain material and financial goods, including the community hall building.

By picking up different, sensation-seeking depictions of "the Congo" in international media and aid industry, Mama Sifa demonstrated her capacity for strategic performance to Pat and me. While it is widely discussed whether performativity can entail a "conscious" application of speech acts (Butler 1990; Derrida 1973), cognitive and behavioral sciences define performativity as a physiological function of the mind to actively enact and influence personally appraised realities (Pennisi and Falzone 2020: 9-10). Mama Sifa's adaptation of a certain terminology in the fearscape context is a coping strategy with what Searle (1972) described as "a functional duality" of the performative speech act: she adopted the linguistic conventions of

\footnotetext{
${ }^{46}$ For a comprehensive, critical discussion about sexualised violence in Eastern Congo see Mertens and Pardy 2016.
} 
NGO jargon that played a major role in the conflict-affected history of her lifeworld; and she actively constituted her own context by attracting this kind of humanitarian assistance to ameliorate the impact of conflict and fear.

Mama Sifa hoped we would spread her words expressing the "suitability" of her case in the assessment of an NGO that would bring attention, financial support, physical presence of foreigners, or, as she said, "at least a soda," which became a common "compensation" for participants given by researchers, journalists and NGO workers alike. Mertens and Pardy similarly describe this strategic behaviour of community members in North Kivu as "local compliance with international dictates" used to "present an image of the DRC they think outsiders want to see" (2016: 16). However, as Pauline's story shows, sexualized violence should not be trivialised as a speech act to attract aid as it constituted a part of women's everyday reality that demanded a strategy for survival. In awareness of the international interest in this and other forms of violence, Mama Sifa demonstrated how she can make women's fears work for them by presenting it to foreigners who bring stuff in exchange for the stories of women's misery.

This performative alignment with humanitarian NGOs further indicates women's feelings of exclusion from the conservation fortress and its benefits. Mama Sifa described her idea of Virunga's headquarters in Rumangabo like "un chateau" sitting enthroned amidst the forest. In a physical sense, fences, guards, watchtowers, international security personnel, armed convoys, track hounds, an air force and the paramilitary ranger staff provide the protection of a fortress from the insecurity and unpredictable violence in North Kivu. ${ }^{47}$ Additionally, the institution Virunga appears to provide social and economic security to those who are "inside": regular wages, international funding, shelter, food and some rule of law, in contrast to the lawlessness that rules its surroundings. The women felt excluded from these protective features, left out of conservation-related development projects and without hope for alternative employment possibilities from PNVi.

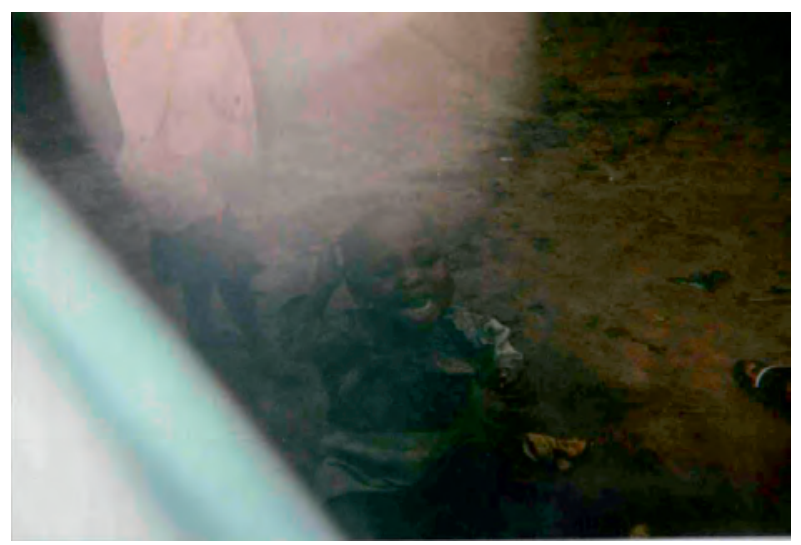

Fig. 4.10 Mama Sifa's photo diary - "Crying child in a blur"

\footnotetext{
${ }^{47}$ It would be misleading to depict PNVi solely as a fortress that radiates fear to its outside(rs) while disregarding the fear of its inside(rs), in particular its rangers who carried many colleagues to the graves, facing the threat of being killed on duty on a daily base.
} 
One day, Mama Sifa responded to my repetitive questions about PNVi's community projects by guiding me around her house to point out the electric wires running through her village to the city of Goma. The electricity line from PNVi's power-plant funded by the Buffet Foundation has not a single cord connection to one of the houses in her village. She told me that PNVi's park director de Merode asked 163 USD for the monthly electricity, a sum nobody could pay. Yet, she had heard that some villages on the other side of the park got access to the lines, asking me: "What is the difference to us?" Many community members referred to de Merode when talking about PNVi to personify the institution, offering a focal point they can direct their anger towards.

In addition to PNVi, many conservation NGOs expressed their intention to make parkadjacent communities the main beneficiaries of conservation and who thus would not have a reason to resort to illegal park activities. Yet, Mama Sifa has not received anything in her lifetime. In an interview with the Congolese community program manager of one of the leading conservation organisations, he complained: "The nature of locals is that they are always demanding. It does not make sense to invest into communities because every achievement will be destroyed again". When asked why he thinks those projects do not persist, he replied angrily that he lost hope in "locals" (not specifying his use of the term, e.g. how he would classify park rangers) who are either "lazy" or "rebels", so "nothing you can work with." In many interviews with PNVi-aligned NGOs, I frequently encountered this negative attitude towards local communities depicting conservationrelated development projects as Sisyphean work: projects that are undermined as soon as they are established. Yet, many of these local NGOs are phantom companies sitting in Goma, purporting to execute community-based projects that only exist on paper and creating websites to attract donations from international organisations such as the World Wildlife Fund. Many of these have never set a foot into the park-adjacent villages, contributing to the women's perception of being left out by Virunga and conservationists more generally.

Facing this exclusion, Mama Sifa's reproduction of humanitarian NGO discourses showed her own coping with the situation giving her some scope of action. In her concern for not being able to protect today's children from fear, violence and a forlorn future, she found a possibility to bring some short-term support and momentary joy when aid workers arrive, talk, and hand out goods. This coping strategy to appropriate the fearscape for her community simultaneously claimed the legitimacy of women's suffering. Further, it gave hope for some physical protection coming with the presence of NGO workers in the village. These moments of perceived security are too short-lived for one to move freely and live an "ordinary" life, but as Mama Sifa expressed, they allow the children to play on the street and give the angst-ridden mind a break. As the group's eldest, Mama Sifa made the women's fears visible bringing them beyond the realm of an individually felt reality to some form of collective recognition. 


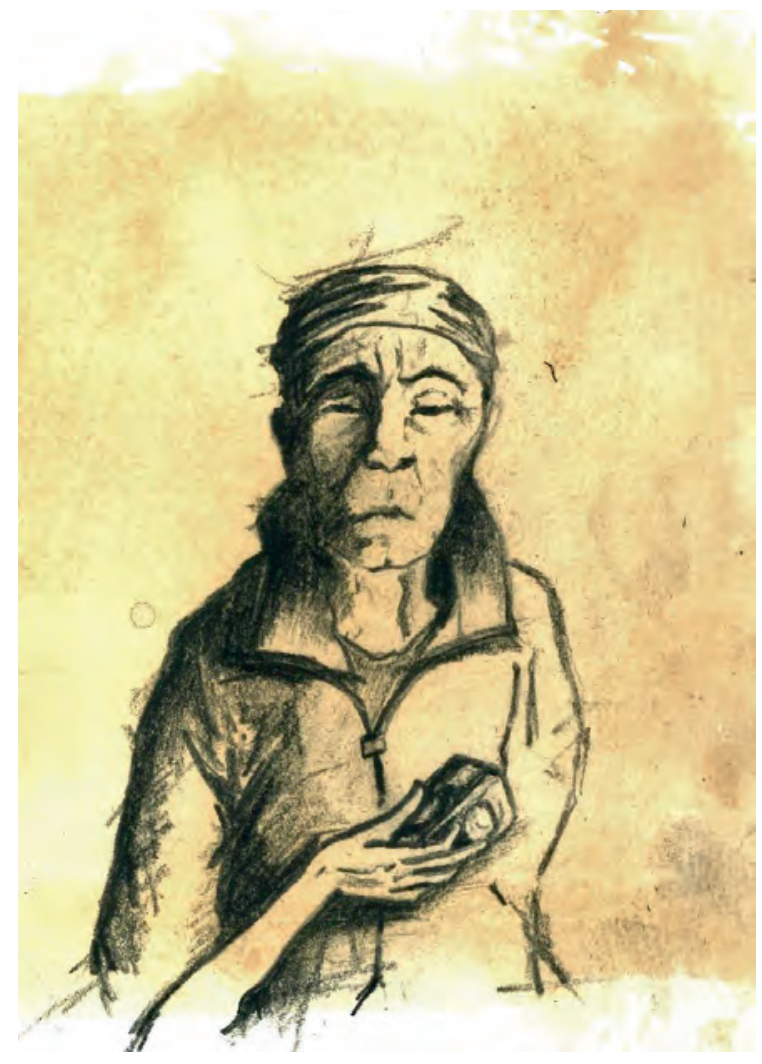

Fig. 4.11 "Mama Sifa"

\section{Conclusion}

At the end of the photo diaries, I asked each woman to make one wish if anything would be possible. The answer was always the same: "peace". Despite the ambiguous meanings of 'peace' in relation to the continuum of violence in conflict-affected spaces like North Kivu, the women living in a permanent state of fear might see their 'peace' as a permanent end of all forms of violence that would allow fear to vanish.

Staying with the fear, women of Virunga like Pauline and Mama Sifa sought to actively appropriate the fearscape, making fear work for them. Through re-naming her own fears, Pauline alleviated their gruelling mental impact and created room for manoeuvre as a "voluntary" participant in the second economy. Through performing internationally acknowledged and spectacularized fears, Mama Sifa attracted "plasters" briefly covering what Mollica (2000) calls the "invisible wounds" of fear. These coping strategies gave the women cognitive and behavioural space to feel a sense of agency, empowerment and self-determination in surviving from day to day.

While conservation efforts add further constraints to women's navigation through the fearscape, the National Park simultaneously offers some enabling features for survival to the adjacent communities. In contrast to the promoted benefits by conservationists, these are barely conservation- and tourism-related job opportunities, but subsistence and economic possibilities 
that residents - civilians, militias, army - make use of within the park. Further, Virunga features as a culprit allowing 'outsiders' to project their fears and anger onto a clearly defined enemy. The disappointment of not gaining from PNVi's promises serves to legitimize women's actions in undermining conservation efforts.

In closing, I want to stress Utas' (2005) important reminder, that certain livelihood strategies in conflict contexts - such as park activities declared as illegal - do not align with our understanding of what is "right" or "wrong", thus it is not for us to judge choices born out of fear for survival. This article has demonstrated that attention to fear puts another complexion on the matter of violence and survival, allowing us to avoid prejudgments and disabling categories. While past and present experiences of violence will continue to haunt women's fearful memories, their coping responses give them a degree of ownership, strength and dignity in this seemingly never-ending war. 


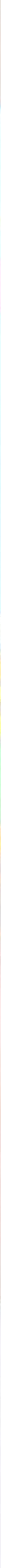




\section{Chapter V}

Towards an emotional ethnography

- engaging with reciprocal fears in violent environments

This chapter is under revision submitted as:

Trogisch, L.: "Towards an emotional ethnography - engaging with reciprocal fears in violent environments," Journal of Political Ecology.

Content has been slightly edited to make the chapter fit into the rest of the thesis.

< Fig. 5.1 "A girl holding a white barbie" 


\section{Introduction}

"How this silence haunts me: you start to shift and silence yourself, you don't dare to ask anymore because you fear the silence that would follow, you fear the suspicion and discomfort that you have sensed so many times from far, distanced and close, dear people alike. You start to doubt what you have read, see and think - is it all just conspiracy? You stop to know what is right and what is wrong - you become paranoid - you hear rumours that might be nothing more than rumours but you start to take them as facts - you drop the 'facts' because you see and read nothing about political prosecution, imprisonment, torture, government-led intimidation and violence....but then someone disappears and people - hush, hush - suggest in their silence that there might be..."

(field notes, Z., Rwanda, $12^{\text {th }}$ March 2018)

This note from my diary written in the third month of my fieldwork depicts my first recognition of the reciprocal dynamics of fear I sensed in the 'field' - my own fear entangled with the fear of potential research informants to talk to me. Silences stemming from people's fear to speak out has been a well-documented characteristic of self-censorship in (post-)conflict societies such as Rwanda (Ansoms 2013a; Fujii 2014; Green 1994; Ingelaere 2010; Jayasuriya 2013; Wood 2006). Yet, I could only achieve a sketchy idea of an imminent 'culture of fear ${ }^{\text {, }}$ through my own experience during twelve months of fieldwork in and around the contiguous forests of the Virunga volcano chain that was intended to become a transboundary conservation area straddling the DR Congo, Rwanda and Uganda. ${ }^{49}$ As this borderland region is scarred by histories of intraand interstate warfare and active, simmering violent conflicts, the Virunga volcanoes gained geostrategic importance for the three countries and hence inform their respective conservation policies and practices used to militarize their international borders transecting the contiguous forest. This amalgamation of conflict and conservation dynamics constitutes a highly sensitive political context affecting all aspects of people' everyday life in the park-adjacent districts of all three countries.

One particular effect of these conservation-conflict dynamics is to provoke a variety of fears informing the behaviours of the different people living in the park-adjacent districts in their most diverse (and sometimes overlapping) roles as farmers, day labourers, tourist guides, hospitality workers, hotel owners or park rangers, amongst other professions. On the one hand, fear often shapes people's perceptions of their neighbouring countries as well as of their immediate neighbours; while on the other hand, fear is also entangled with the conservation areas and actors. While I have engaged with the multitude of fears held by parastatal conservation actors, namely park rangers, elsewhere (Trogisch 2021), this article focuses on the variety of fears expressed by other community members living in vicinity to the three parks. Some of their collective, existential fears explicitly emanate from conservation policies and practices including the denial of access to basic resources within the parks, a lack of benefits from tourism, animals exiting the park and destroying harvests, conservation authorities and tourism stakeholders

\footnotetext{
48 'culture of fear' (Furedi 1997)

49 'Transboundary' here means geographically contiguous, while the three countries sharing the area manage their parts as distinct, state-led National Parks separately. Therefore, I will refer to the contiguous forest area on the Virunga volcano chain as 'the Virungas'.
} 
taking away people's home- and farmland, as well as from harsh, sometimes violent, punishment by park rangers when people enter the forest unauthorized. While these conservation-related fears play an important role in relation to local livelihoods in the park-adjacent districts in the Eastern DRC, Rwanda and Uganda alike, I found that the culture of fear is further informed by the three national political contexts - the active violent conflict combined with an ostensibly absent state in the DRC, and the so called 'post-conflict' context under the authoritarian regimes in Rwanda and Uganda. This culture of fear decisively affected and directed me and my interactions with my research informants.

While a number of scholars account for fear felt by the researcher or their interlocutors (Begley 2013; Green 1994; Rodgers 2007; Taussig 1992), there has hardly been exploration of the reciprocity of fear between fieldworkers and the people encountered 'in the field'. Reciprocity is understood as a "causality being the relation of action and reaction, [...] in which two or more substances interact in such a way that the states of the one are both the cause and effect of the states of the other". ${ }^{50}$ Experiencing this reciprocal interaction between my own fear and other people's fear elicited by my presence gave my research truly an "emotional turn" (Bondi 2005: 2). In exploring the role of emotions in the conservation-conflict nexus, this article demonstrates how the reciprocity of fear can inform innovative methodological adaptations to conflict-affected contexts in critical conservation studies. These adaptations can yield decisive conceptual understandings during and after fieldwork. To develop discussion of these dynamics, I bring political ecology into dialogue with reflections by conflict scholars on the practice of ethnographic research to incorporate emotional reflexivity into fieldwork concerning conservation areas in conflict-affected settings.

Engaging with conservation-related conflicts in particular, a range of political ecologists have scrutinized spatial enclosures, militarization and different forms of violence deployed for the creation and maintenance of protected areas (Büscher and Ramutsindela 2016; Lunstrum 2014; Massé 2018; Ybarra 2016). Particularly TBPAs - biodiversity hotspots straddling the borders of several countries - are often promoted to generate peaceful collaboration in regions that conflict scholars would describe as "conflict zones" characterised by "political polarization, the presence of armed actors, the precarious security of most residents, the general unpredictability of events, and the traumatization through violence of combatants and civilians alike" (Wood 2006: 373). Previous studies in political ecology have challenged the conflictalleviating impacts of TBPAs (Büscher 2013; Duffy 2016; Wolmer 2003). In addition, others have highlighted that increasingly militaristic conservation practices in general can contribute to wider dynamics of inter- and intrastate warfare (Marijnen et al. 2021; Peluso and Watts 2001; Verweijen 2020).

While fieldwork constitutes the pivotal methodological approach for political ecologists in studying conservation practices and related conflicts, there has been little critical reflection on fieldwork experiences in the political ecology literature (Johnson et al. 2020). Despite the

\footnotetext{
${ }^{50}$ Inwood, M.J. 1995: A Hegel dictionary, Oxford: Blackwell Reference.
} 
prevalent focus on conflictual situations and dynamics within the literature on conservation areas in particular, there is also a surprising absence of engagement with conflict studies in terms of reflexive accounts of fieldwork in particular. This missing exchange between critical conservation and conflict studies hinders methodological and conceptual advancement as well as potential sharing of useful advice with future fieldworkers in conflict-conservation settings in order to preemptively mitigate unintended, negative and even traumatizing repercussions for researchers and their interlocutors in these contexts.

In contrast with political ecologists, different scholars conducting research in conflictaffected settings have discussed the difficulties and danger for the researcher during fieldwork for decades (see e.g. Bourgois 1990; Lee 1995; Rodgers 2007; Thomson et al. 2013). Yet, these ethnographic reflections on conflict-affected settings pay little analytical attention to the emotional impact of fear as a natural human reaction accompanying danger. While Taussig (1992) and Green (1994) engaged with fear on the part of both their interlocutors and themselves within their analyses of the violent conditions that structure daily life in their conflict-affected field sites, the reciprocity of fear - in particular the role of researchers' presence fuelling fear for their interlocutors in (post-)conflict contexts - has not been considered.

In addressing this reciprocal dynamic, I argue that emotional awareness of and reflexivity concerning the need for methodological adaptions to one's own and other people's fears during fieldwork can improve studies within political ecology and beyond in three ways. First, it enables innovative methods while helping fieldworkers to make more empathetic and ethical decisions concerning the safety of interlocutors and themselves. Secondly, this methodological adaptation can generate unexpected theoretical insights into often invisible, systemic features of oppression and inequality created through the multiple functionalities of fear in the conservation-conflict context. Thirdly, it fosters critical awareness on the emotional repercussions concerning the colonial legacies inherent in foreign-led fieldwork practices in sub-Sahara Africa. I suggest calling this practice of observing emotions, using them as a compass to navigate the field and incorporating the observations that are coloured by these emotions into our knowledge production, a practice that I term 'emotional ethnography'.

In the following section, I outline and bring together critical conservation studies from a political ecology perspective with literature on emotional reflexivity concerning fieldwork in conflictaffected contexts. Guided by this synthetic conceptual framework, I reflect on my own methodological adaptations in the fieldwork process resulting in undertaking 'emotional ethnography'. Following this, I demonstrate how my own fear stirred up by encounters with open violence, surveillance and direct intimidation pointed me to systemic features of fear induced by warfare, historical legacies and governmental regulations in the communities living adjacent to the National Parks in the DRC, Rwanda and Uganda. In conclusion, I advocate incorporation of emotional reflexivity into fieldwork practices as well as data analysis and interpretation to increase ethical considerations and contribute to critical discussions concerning colonial legacies of research in postcolonial societies. 


\section{Violence and fear in the conservation-conflict context - towards an 'emotional ethnography'}

Critical research concerning nature-society relations has been on the agenda of human geographers and other social scientists for decades. Scrutinizing common assumptions about the relationship between violent conflicts and the environment, Peluso and Watts' pioneering work (2001) collected interdisciplinary studies concerning the question of how simplistic discourses of overpopulation and scarcity are instrumentalised to justify resource extraction, enclosure and militarization of nature creating normalized forms of environmental violence. This inspired a subsequent explosion of work on these themes (see e.g. Duffy 2014; Le Billion 2001; Fairhead 2015; Lunstrum 2014; Marijnen and Verweijen 2016; Ybarra 2016). Building upon this stream of research concerning 'violent environments', Marijnen et al. (2021) highlight the analytical link between political ecology and conflict studies in the context of conservation areas situated within and simultaneously contributing to "violent conflicts or larger geographies of protracted violence, civil- and colonial wars, and political violence" (ibid. 2020: 1). Others have adapted concepts from violence and conflict studies to question conservation policies and practices of "green violence" (Büscher and Ramutsindela 2016), "green militarization” (Lunstrum 2014) and the "war to save biodiversity" (Duffy 2014) in the context of protected areas.

To gain a deeper understanding of how these complex, multi-scalar dynamics in the conflict-affected context of protected areas, fieldwork based on ethnographic methods constitutes the key methodological approach for many political ecologists (e.g. Büscher 2013; Marijnen 2016; Massé 2018; Ybarra and Kelly 2016). Yet, despite conducting fieldwork in often highly politicized conservation-conflict contexts, it is surprising to find few interdisciplinary exchanges on fieldwork methodologies and practices between political ecology and conflict studies (with a notable exception being González-Hidalgo and Zografos 2020). In contrast to political ecologists, however, anthropologist in conflict-affected settings have addressed how the emotional experiences of fieldwork can have extreme impact on their research, themselves and their interlocutors, regardless of whether the study focuses specifically on the continuum of violence or whether violence is an ever-present, underlying condition of the research setting (see e.g. Lee 1995; Rodgers 2007; Wood 2006).

In the past two decades, the literature on ethnographic fieldwork practices has experienced an 'emotional turn', acknowledging the fieldworker as the 'essential research instrument' who is affected by a reciprocal emotional relationship with research participants and the field (Bondi 2005; Coffey 1999; Davidson and Milligan 2004; Rosaldo 1989; Thomson et al. 2013). Based on anthropological work since the 1980s, the interpretation and expression of emotions became increasingly acknowledged as offering decisive insights into social, economic, political, cultural and linguistic aspects of studied realities, as well as the researcher's own moral and ethical responsibilities (see e.g. Lutz and Abu-Lughod 1990; Rosaldo 1980; Scheper-Hughes 1995). As van Maanen argues, these insights into micro-systems of society are made visible by interpreting and representing our own observations and experiences influenced "by the researcher's own emotions in the field" (ibid. 2010: 23). In this sense, fieldwork is intense emotion work (ref. Hochschild 1983). 
While emotional reflexivity concerning fieldwork experiences burgeoned in the anthropology and conflict studies literature, there persists an "overall uneasiness that many political ecologists have in sharing personal experiences in scholarly journals," conveying the impression that emotional accounting in fieldwork is secondary for methodological and conceptual developments (Johnson et al. 2020: 7). Whereas an 'emotional turn' has similarly unfolded in political ecology - with Sultana (2015) coining the term 'emotional political ecology' itself (see also e.g. Escobar 2014; Nightingale 2013; Singh 2013) - thus far it has remained largely on the theoretical level building on feminist scholarship to analyse emotional aspects of resource struggles, power hierarchies, and environmental conflicts. As an exceptional, first methodological discussion from the perspective of emotional political ecology, Nyantakyi-Frimpong (2021) incorporated critical reflexivity concerning emotions to reveal the impact of gendered norms in Ghana during longterm ethnographic fieldwork. This notable exception signals the analytical merit of analysing the link between emotions, violence and power in the conservation-conflict context that has been largely overlooked so far. Since studies related to political ecology increasingly engage with areas scarred by violence and/or conflict via fieldwork, the field could profit from deeper engagement with conflict studies literature discussing the emotional - and as such physical and mental impact of violent exposure and aligned methodological choices during 'dangerous fieldwork' situations that has been passed on for generations (see e.g. Diphoorn 2012; Lee 1995; KovatsBernat 2002; Rodgers 2007).

Curiously, however, this emotion- and conflict-sensitive literature rarely engages with the experience of fear that often accompanies these 'dangers' in the field. In one of the few exceptions, Taussig (1992) examines his personal experiences of fear, panic and terror to illustrate the state-induced internalisation of fear that regulates society in Latin America. In a similar manner, Green (1994) systematically analyses how acknowledging and understanding her own fears in the violent context of Guatemala helped her to gain a better understanding of the women she worked with and the systemic conditions of fear in their daily lives. While these accounts focus on fear felt by the researcher or by the people in the field, no accounts have yet brought these two foci together to explore the effects of researchers' presence inducing fear for the people in the field, particularly within conflict-affected settings.

Psychosocial research characterizes fear as a universal human emotion, yet one that can only be understood when described by those who have experienced it from within specific cultural frames of reference (Baumann 2009: 347; see further Rosaldo 1989). Hence, the meaning of fear is both highly cultural and personal and involves a more or less conscious act of interpretation of a perceived threat. In this interpretative process, fear can become 'limiting' through creating mental and physiological barriers in the form of paralysing, traumatizing, and even depressive thoughts. Equally possible is fear's 'enabling' impact on humans that can inspire an innovative attitude to prepare or mitigate various, threatening outcomes and thus foster personal development and growth (Baumann 2009; Boscoboinik and Horáková 2014; Humphrey 2013; Robin 2004; Stodulka et al. 2019). These latter, positive qualities of fear can serve fieldworkers in conflict-affected contexts in two ways: for ethical and methodological decisionmaking during fieldwork; and for the data analyses and interpretation during and after fieldwork. 
Firstly, the positive quality of fear in fieldwork lies in its methodological merit, grounded in its status as "crucial evolutionary mechanism for individual and social survival" (Boscoboinik and Horáková 2014: 28). As Robin argues, feeling fear enables a "heightened state of experience" as "it quickens our perceptions as no other emotion can, forcing us to see and act in the world in new and interesting ways [...] with a more acute consciousness of our surroundings and ourselves" (2004: 4). These qualities benefit the researcher in conducting fieldwork. Moreover, fear indicates social or physiological needs motivating action to protect us and others and as such "fear incorporates good sense" and offers "strategic answers to particular contexts" (Boscoboinik and Horáková 2014: 24). Given the emotional reciprocity of research relationships, acknowledging our own and other people's fears and reflecting upon them helps us to make decisions concerning what we can, want or need to do in the field. Especially in dealing with difficult, dangerous or unexpected situations in volatile conflict contexts that might require quick, ambiguous judgements, our awareness of fear can enable us to consciously act upon it. Fear can thus be a compass in fieldwork.

Emerging from these methodologically adaptions to fears' reciprocity, the second positive quality of accounting for fear is the theoretical discovery it enables. Feeling the fear of and with the people in violent environments allows empathetic sensing and through this better understanding how structural - systemic, ostensibly invisible - as well as direct forms of violence affect local livelihoods (Galtung 1969). While direct violence is commonly understood as "the intentional use of physical force or power" (WHO 2002: 4), Galtung described structural violence as incorporated into the societal structure, reflected in unequal distribution of resources, space constraints or the denial of access and movement (Galtung 1969: 171). Merging insights from previous conflict studies and personal emotional reflexivity opens up a new perspective on how violence is experienced and responded to in the conservation-conflict nexus, namely through the lens of fear.

Hence, the reciprocal relationship of having fear and being feared contributes to theoretical insights into the multiple meanings of fear in people's day-to-day lives. In this interpretative process, the emotional imprint of fear on the people informs their behaviours such as avoidance, denial or silencing. As such, it can be analysed as 'meta-data,' defined by Fujii as "spoken and unspoken expressions about people's interior thoughts and feelings [that] are as valuable as the testimonies themselves because they indicate how the current social and political landscape is shaping what people might say to a researcher" (2010: 232). The question is how fieldworkers in conflict-affected contexts more generally, and in research within political ecology in particular, can integrate these meta-data and reflexive accounts of fear (and other emotions) in a credible manner into their work without drifting into confessional navel-gazing?

In the following, I engage with this question by depicting my methodological adaptions to the different reciprocal dynamics of fear I encountered in the three highly different field sites in the DRC, Rwanda and Uganda in the course of my long-term fieldwork. First, I discuss how engaging with fear allowed to better understand the coalescence of conservation practices and active conflict in the Eastern DRC. Afterwards, I elaborate on my experiences in Rwanda in two steps. First, I illustrate how the reciprocity of fears between Rwandans and myself shifted my methodology to merge emotional reflexivity with an accidental ethnography approach. Secondly, I show the empirical and conceptual insights from this approach revealing different conditions 
and consequences of fear in the 'post-conflict' context of Rwanda. The last part analyses a farreaching incident of reciprocal fear during my fieldwork in Uganda that ultimately impacted the end of my fieldwork, my research focus and interpretations of the conservation-conflict dynamics around the Virungas.

\section{Methodological adaptations}

This article draws on my experiences I gained during three months of research in Uganda for my Master thesis in 2015 and twelve months of fieldwork for my PhD in 2018. While during this time I was able to live with one community at the entrance of Volcanoes National Park in Rwanda, and with my formerly known community at Mgahinga Gorilla National Park in Uganda, the security situation in the DRC restricted my fieldwork interactions with local communities to frequent research trips to seven villages bordering Virunga National Park (original name in French: Parc National des Virunga - PNVi). My qualitative, inductive approach allowed me to adapt my research questions and methods to the three different regimes and the inter-and intrastate conflict dynamics that informed the local realities around the three National Parks in 2018. Certain ethnographic methods I had planned to use, such as recording, filming, repeated interviewing or oral history, proved to be infeasible, and even harmful for the people I worked with and myself. Generally speaking, the rapidly changing political context required at times draining, at times inspiring, innovative methodological adaptations. While I applied methods of participant observation, visual ethnography as well as open, semi-structured and focus group interviewing with different community members in the DRC, Rwanda and Uganda, in this article I focus specifically on my utilization of an 'accidental ethnography' approach involving the training of "systematic attention to unplanned moments that take place outside an interview" (Fujii 2014: 1). As Trigger et al. (2012) described, these 'unplanned moments' generate particularly strong emotions in the researcher that enable deeper insights into otherwise unnoticed aspects of social life.

Expanding on Fujii and Trigger et al., I suggest a methodological adaptation that I call 'emotional ethnography' that incorporates emotional awareness and reflexivity into our methodological choices as well as our analysis and interpretation of data during and after fieldwork in conflict-affected contexts. Therefore, my analysis includes elements of analytical auto-ethnography understood as a reflexive accounting "of the relationships between self and others and a developed awareness of reciprocal influences between ethnographers, their settings, and informants" (Marchéal 2010: 44-45). This method allows one to include the researchers' subjective emotional experiences into the analyses as important data for knowledge production (Anderson 2006) and to account for even unconsciously defining moments retrospectively (Koot 2016). Through critical reflexive journaling I documented my own emotions as well as my perceptions of people's emotional reactions in 'accidental moments'. Given "the contingency of knowledge claims because of divergent linguistic conceptions, let alone languages and interpretations" (Whatmore 2002: 2), I will examine the two-sided dynamic of fear between my interlocutors and myself in the field in triangulation with a wide range of secondary sources on the political context of the DRC, Rwanda and Uganda. 


\section{Empathizing fears}

Paying attention to the reciprocity of fear between researchers and people living in an active conflict context points to location- and time-specific insecurities in the field and allows to adapt methodologies in an empathetic, namely emotionally sensitive and ethical, manner. Empathetic methods can shed some light on the multiple conditions and consequences of fear affecting local people's understandings of the violence and their needs and navigations within a volatile conservation-conflict environment.

While people living in 'active conflict' contexts experience (the threat of) different forms of violence on a daily base, it was found that National Parks situated in such wider conflict regions can contribute and coalesce with these violent threats (Marijnen et al. 2021). Conducting fieldwork in the surroundings of Virunga National Park (PNVi) in North Kivu of the Eastern DRC requires to take into account the long-standing warfare, shifting alliances of old and emerging armed groups, foreign interventions and a 'weak' and 'dysfunctional' state shaping the social order (Stearns 2013; Vlassenroot 2012). In addition, previous studies on PNVi demonstrate how conservation policies and practices constitute existential threats to local livelihoods through the denied access to basic resources within the park, a disappointment with promised tourism benefits and conservation-related projects, and the enforcement of park borders reducing farmland, as well as imprisonment or violent punishment by park rangers when people enter the forest unauthorized (Marijnen 2018; Verweijen 2020).

In light of these various threats informing my fieldwork context, I found that fear became 'a way of life' (ref. Green 1994) determining people's words and movements in and around PNVi. Amplified by the continuous delay of presidential elections in 2018, I sensed a permanent tension in the atmosphere and its eruptions at frequent, yet unpredictable, intervals of staggering violence. One particularly disturbing incident evidencing this volatile context occurred briefly after my arrival in the regional capital of Goma where I was establishing my network with potential informants and so called 'fixers' - local contacts who know the context and help researchers for access and security. Just before my appointed meeting with my first contact person in Goma, I received the message that he had been killed by unsub. I did not know the man before, yet this shock pointed me to the imminent danger of - lethal - violence for everyone, locals and foreigners, in a context where the ostensible absence of the government created a system of violent rules and lawlessness. A few weeks later, I truly understood and embodied this inherent feeling of fear emanating from this volatile context myself, when I got mugged on a street in Goma in daylight. Being mugged is a twofold violent experience: on the one hand, it contains physical harm to the body carried out by the attackers; on the other hand, it does violence to the mind inducing feelings of paranoia and long-lasting existential fears to personal integrity. I embodied this fear that kept me in a state of alertness, day and night. At the same time, this fear gave me a sense of empathy how many others around me must feel in their daily lives that enhanced my conceptual understanding of the regional conflict dynamics around PNVi.

Moreover, getting a sense of this existential fear for life informed my methodological decisions with heightened caution about the dangers for my informants and myself. In this awareness I sought for a reliable Congolese research partner who was willing to navigate around these dangers with me in order to gain access to the surrounding villages of PNVi. In a society 
scarred by fear, suspicion and mistrust from violent conflict, finding such a person requires a good listening to one's gut feeling and serendipity: a longstanding Ugandan friend introduced me to his Congolese pal Pat who grew up in one of the districts adjacent to PNVi, worked with different local communities in the area and was willing to take on the roles of a research assistant, translator and security advisor. Particularly in regards to this last role, Pat pointed out to me nogo-areas - places of expected, violent threats - when moving in and around Goma, PNVi and the park-adjacent villages, and no-go-topics - sensitive question that could offend or harm - in interviews with different people from different communities. Hence, his fears became my fears. On the one hand, this reciprocal dynamic of fear provided me methodological guidance to - as Baumann (2009) described it - 'prepare' and 'mitigate' threatening outcomes of fieldwork trips such as moving at uncertain, ever-changing and thus elusive times. On the other hand, his fears exemplified the fears of community members living near PNVi that offered me an empirical insight that the threat from conservation practices and policies appear secondary compared to the permanent (threat of) violence radiating from the active, open conflict context in North Kivu. I have elaborated on how these fears of different threats in the conservation-conflict nexus in the DRC affect local people's survival strategies in their daily lives (Trogisch, forthcoming).

Moreover, I further found that PNVi's conservation actors and practices were similarly subordinated to the multitude of unpredictable threats from the active, violent conflict. Exemplarily for this was when during my fieldwork two British tourists were kidnapped on the road to PNVi in May 2018. The incident forced PNVi to close the park for tourists and complicated their own conservation tasks in two ways. Firstly, through the lack of tourism revenues the closure complicated to finance park staff and other conservation-related projects (Virunga 2021). Secondly, the kidnapping led to the withdrawal of foreign humanitarian organisations that used to travel regularly the road way up North from Goma through the park radiating a certain level of security for conservation actors to move relatively freely in these areas. Since the daily conservation tasks in and around the park hence are constantly compromised by sudden changes in the conflict context.

Similarly exacerbating the persistent fears and restricting movements of other local community members, the area experienced an increase of violent attacks by a growing number of different armed groups on villages around PNVi (see e.g. Kivu Security Tracker 2018). These unpredictable attacks demanded a sudden adaptation of my field trips, routes and my overall methodological approach. The absence of foreigners - tourists and staff from international organisations - particularly compromised my planned in-person interviews since Pat and other Congolese informants warned that my white appearance was (more) exceptional and could attract armed ambushes or kidnapping for ransom, bearing high risks for my research partner, my interlocutors and myself. The fear of attracting such an assault was augmented when Pat and I travelled on the road through the park and got stopped at a roadblock one day. A man in a uniform introduced himself as the 'security officer' checking illegal trafficking of charcoal on the road to Goma. When seeing me in the car he calculated aloud to us how much ransom I would bring him while Pat was only 'worth a bullet'. ${ }^{51}$ Although this intimidation could be resolved by

\footnotetext{
51 'vaut une seule balle' (original quote in French translated by the author)
} 
Pat's official mission documents signed by the provincial governor, it exemplified the warnings and the inherent danger for Pat in taking me along, and ultimately the people I interview. This reciprocal dynamic of my own fear being attacked on field trips and simultaneously creating lifethreatening danger for my interlocutors in the field forced and also inspired me to adapt my methodology in creative ways (Humphrey 2013). In order to prioritize the safety of the people willing to work with me and of myself, I designed a new conflict-specific method of visual ethnography distributing disposable cameras and diaries to literate volunteers in park-adjacent villages. This method allowed these representatives of different communities around PNVi to express their perceptions of their daily lives in the conservation-conflict context without the potentially dangerous repercussions (and bias) of my presence.

Given the "importance of lived experiences in shaping theory" (Hume 2007: 148), the impact of my position as a foreign - and specifically, white - researcher needs to be discussed in relation to my privilege to leave at any time to safe and comfortable spaces that stood in stark contrast to the Congolese people I worked with. I have to acknowledge that I could only get a slight sense of the fears of living in an active, violent conflict context while never truly being able to understand the hardships and horrors Congolese people experience(d). The reciprocal interaction of their and my own fears yet enabled me some understanding how everyday fears determine all aspects of life, including conservation practices of PNVi. This empirical insights in combination with the findings of my visual ethnography illustrated that PNVi indeed constitutes another threat to local people's livelihoods in the denied access to the resources and farmland within the National Park, yet the dominant fears in the region of North Kivu emanate from the long-standing interregional warfare in combination with weak Congolese state governance.

Ultimately, empathizing with the fears of ourselves and the people we work with can shed light on the range of potential threats and concomitant prioritized needs of the people in the field, allowing to learn from their navigation patterns in active conflict dynamics, and as such inspire methodological adaptations as well as conceptual insights.

\section{Reciprocal fears}

Different to the active, violent conservation-conflict contexts such as the Eastern DRC, the examination of reciprocal dynamics of fear in declared 'post-conflict' societies such as Rwanda can offer a different perspective on structural forms violence that determine local livelihoods. Brown et al. conceptualized a 'post-conflict' context on the transition continuum from active inter- and intra-state warfare to cessation of direct violence, signing of peace agreements and an establishment of a 'functioning state' accompanied by 'economic recovery' (ibid. 2011: 4). While Rwanda indeed fulfils these political, economic and material indicators, numerous researchers described how Rwandan's expressions of feelings or opinions in the so declared 'post-conflict' society are distorted, aligned to state-led narratives or silenced due to the fear of historical conflictrelated grievances and sanctions by the authoritarian regime (Ansoms 2013a; Fujii 2010; Mathys 2017; Wood 2006).

These fears to speak - and move - freely were evidenced during my fieldwork experiences living with(in) a local community at the border of Rwanda's Volcanoes National Park (VNP). In 
addition to the silences I encountered in planned interviews and unplanned conversations as described in the introductory note, I also listened to all-too-similar narratives about the achievements of Rwanda's government and its successful, community-benefitting conservation strategy by highly diverse community members holding a variety of professions such as hospitality workers, hoteliers, tracker guards, park rangers, farmers, students and shop owners. People's fear to tell different than state-led narratives was confirmed in an interview with the parastatal conservation authority Rwandan Development Board (RDB), who were in charge of my research permit. When I brought up my confusion about these repetitive narratives, the RDB officer responded that I "look for the forest elephant in the trees". His reference to both, the close proverb as well as to the shy, rarely observed elephants living within the park - calling into question whether they actually exist - expressed that people are to 'shy' to speak, and that state-led narratives are the only narratives I would get in interviews. His comment further implied that I am looking for something that might not exist, namely a more differentiated opinion than the official representations of Volcanoes National Park as "a success story for Rwanda's communities and conservation" (AWF 2017).

I only just began to understand these state-aligned narratives and silences of people as a result of an invisible culture of fear when I experienced the sense of permanent state surveillance in Rwanda's 'post-conflict' society myself. During an interview with a public authority in an almost empty restaurant, my interlocutor pointed indirectly to a man sitting at my back a few metres away at another table, whispering that this man is sent by the government to follow me and therefore he could not answer my questions. He further explained that foreign researchers in Rwanda are equated with being 'spies' who either work for the Rwandan government to gain information about potential anti-governmental resentments within the population or for an external organisation against the Rwandan government. Hence any conversation with me would portray the person interviewed as a dissident. His explanation elucidated that people resort to silences or state-led narratives reducing the risk of bringing them into trouble because they feared me.

Regardless of whether this man sitting behind me in the restaurant was indeed keeping me under surveillance or not, the fact that my interlocutor was fearful to speak to me made me aware about the reciprocity of fear that my position as a white Western researcher in the 'postconflict' society of Rwanda brought out. While I was seen and treated as a source of fear, the sheer thought of being followed and observed raised feelings of fear within myself, planting the believe that I was offending against Rwandan law. My own fear of being followed and treated as a potential 'spy' by the Rwandan government was reciprocally interlinked with the fear of my interlocutors in being seen with me. Realizing this reciprocity between people's fear to speak to me and the structural surveillance by state agents evidenced the impossibility of access to information through interviewing methods and hence forced me to shift my methodological approach. As a consequence, by expanding on Fujii's 'accidental ethnography' I devoted systematic attention to unplanned, emotionally charged moments by capturing my own and people's emotional reactions, expressions and behaviours in critical reflective journaling. 


\section{Hidden, systemic fears}

Emotional reflexivity in accidental ethnographic encounters enabled a collection of numerous 'unplanned moments' in observed scenes, contradicting narratives, uncomfortable conversations and distorting encounters with people that shaped my conceptual understanding of the culture of fear around VNP in Rwanda.

One exemplary incident demonstrated how people's fear towards me as a 'spy', and my fear of the - unspecified - people keeping me under surveillance were linked to the politics of fear by the state governing the district adjacent to VNP. One evening I drove with my motorbike from $\mathrm{Z}$. (the biggest town within the district), the 15 kilometres up the single road to my tent at the park borders. It was late, yet a crowd of people were assembled in front of "La Cruche", ${ }^{52}$ a popular local restaurant. The building was dark and all three entrances shut. A note pinned on the door stated: "This premise is closed by the government of Rwanda". A person dressed in a police uniform amongst the people hissed continuous phrases in Kinyarwanda. I asked another bystander if they could explain to me what was going on. They answered that the government closed $\mathrm{La}$ Cruche because it is dirty and the 'police officer' said there are cockroaches ${ }^{53}$ in the facility. They expressed their feeling of betrayal because they had eaten many times at this restaurant. I knew the owner of $\mathrm{La}$ Cruche well and had been sitting in their kitchen chatting with the staff many times. I expressed doubts concerning the provided explanation for the closure as I have never seen the place dirty enough to attract cockroaches, and in any event these insects do not appreciate the cold of the high altitude around VNP.

The next morning, I went to La Cruche again. The owner opened the door, quickly pulled me inside and locked the door behind me. They told me to sit out of sight from the windows. Restlessly standing between me and the windows accentuated their hesitation to speak to me. At the same time, their gesture of pulling me in signified that they wanted to tell something. ${ }^{54}$ The owner began by explaining that if any community member would see me inside the restaurant, the government would close their business forever because 'everybody is the eye of one's neighbour'. On the one hand, these words underlined the fear of being seen and speaking to foreign researchers that my interviewee in the restaurant had similarly pointed out to me. On the other hand, I heard this phrase 'the neighbours' eye' when an RDB park warden elaborated on the strategy to reduce unauthorized activities such as logging and hunting within VNP. Through the 'neighbours' eye' strategy, the warden assigns certain community members to report on all issues, from gossip to overheard plans directed against the conservation law of VNP, in exchange for material benefits and other 'privileges' such as access to jobs. Upon such pieces of information, park rangers are sent to the village to launch pre-emptive interventions against the denigrated 'troublemakers'. The 'neighbours' eye' hence exemplified a measure of the politics of fear applied in a twofold way. On the one hand, it served as a conservation practice to generate fear through the omni-presence of control by conservation authorities that could be represented by 'every

\footnotetext{
${ }^{52}$ Pseudonym - for further protection of the people included in this study, I refer to the pronoun "they" instead of he or she throughout the whole article to make gender and sex unidentifiable.

${ }^{53}$ This is a loaded term in Rwanda, reminding of the denouncement of Tutsi as 'inyenzi' (cockroaches) during the genocide in 1994.

${ }^{54}$ The following conversation was translated from French by the author.
} 
neighbour' within the park-adjacent communities of VNP. On the other hand, the 'neighbours eye' was a general systemic surveillance strategy by the Rwandan government to keep the population in check that further explained the reciprocal dynamics of people's fear towards everyone, including me in my position as a researcher.

Other scholars on Rwanda have pointed to this systemic surveillance through the felt 'presence of an all-embracing state apparatus' (Ingelaere 2016) exacerbating the feelings of fear of the state executed through micro-level militarization by the Rwandan government (Purdeková et al. 2018). Due to ongoing insurgencies from armed militias based in the DRC and further legitimized by conservation and tourism concerns (Trogisch and Fletcher 2020), the density of military, security forces and police in addition to paramilitary park rangers in and around VNP is extremely high, augmenting the general sense of fear of state authorities in the area (see e.g. Harding 2020). Exemplary for the politics of fear through military presence was the influential defamation by a uniformed person speaking to the crowd to kindle mistrust agianst La Cruche I witnessed the night before.

In addition, the owner of $\mathrm{La}$ Cruche depicted that this form of governmental control implied a hierarchical power dimension regulating privileges along ethnic lines within Rwanda's society. When I asked why the government sought to close La Cruche, the owner answered that they do it because of 'jealousy': as long as La Cruche was granting free meals and beverages to the local authorities the government allowed 'someone like them' to run a successful business, but last time the owner requested the local authority to pay for the service and products and thereby lost the governmental 'patronage'. This vague reference to 'someone like them' points to the politically sanctioned pronouncing of ethnic affiliation as Bahutu, Batutsi or Batwa manifested in Rwanda's post-genocide constitution..$^{55}$ Due to fear of recurring violence manipulated along ethnic lines, the Kagame regime prohibited these categorisations as historical inventions of the Belgium colonizers that were instrumentalized for the genocide (see e.g. Mamdani 2001). Despite the fear of speaking out about these perceived inequalities, La Cruche's owner expressed that the closure is part of the politically legitimated defamation of Hutu-led businesses in the prosperous area around VNP that enables a form of 'legal corruption' by the government to favour people with an ethnic Tutsi affiliation. This accusation was in line with other 'accidental' snippets of conversation I overheard amongst community members around VNP that people identified as Tutsi have better access to schools, scholarships, employment opportunities and health care and commonly hold higher positions of authority in business and politics, while the vast majority of Rwanda's rural population are considered as Bahutu.

Ultimately, my own fear of the 'all-embracing state apparatus' gave me an insight into the culture of fear, suspicion and mistrust that shapes the lives and livelihoods of local people in and around VNP. The experience of becoming a source of fear myself further made me realize that my study of conservation dynamics in Rwanda's North are inseparable from the broader governmental politics of fear and silencing that permeate the Rwandan society at large. Conservation policies and practices serve the politics of fear as another public surveillance and security strategy maintaining a hierarchical order within the park-adjacent Rwandan society. Fear reinforces the silences, disables public dissent or oppositional uprising and at the same time

\footnotetext{
${ }^{55}$ The prefix "ba-" refers to the plural indicating a group of people from Hutu, Tutsi and Twa.
} 
covers incidents of 'hidden corruption' that would contradict the state-led narrative of equal opportunities. The culture of fear determining people's reiteration of state-led narratives (or silences) in the park-adjacent communities of VNP largely prohibits honest evaluations of their existential fears exacerbated by conservation policies and practices, and thus forecloses potential targeted interventions to improve their living conditions.

\section{Spatial fears}

In response to my own fears from being under surveillance and paralysed by denied access to information in Rwanda, I moved across the border to the neighbouring community in Uganda's part of the contiguous forest, gazetted as Mgahinga Gorilla National Park (MGNP). This change of field sites and countries also brought a change of perspective to reflect on the culture of fear in Rwanda from a spatial and emotional distance.

One day my Ugandan research partner and I had a surprising accidental encounter with an old lady sitting on the stony path leading up to the border of MGNP (fig.5.2). When approaching to see whether she needed help, she answered to my surprise in Kinyarwanda - the national language of Rwanda - that she had finished her work in N. (Uganda) and was now 'commuting' back to her home in G. (Rwanda). She explained to us that she - like many other Rwandans - looks for causal labour in Uganda every day. Today she found herself to be very lucky because she earned some potatoes and 2000 Ugandan Shilling (approx. 0,55 US Dollars). I tried to lift the heavy sack standing next to her with both hands and failed. When taking the road across the official Rwandan-Ugandan border the distance to G. would amount to approximately 30 kilometres one way, but the old lady pointed to a trail that directly connects the communities around VNP and MGNP via an unofficial border crossing point.

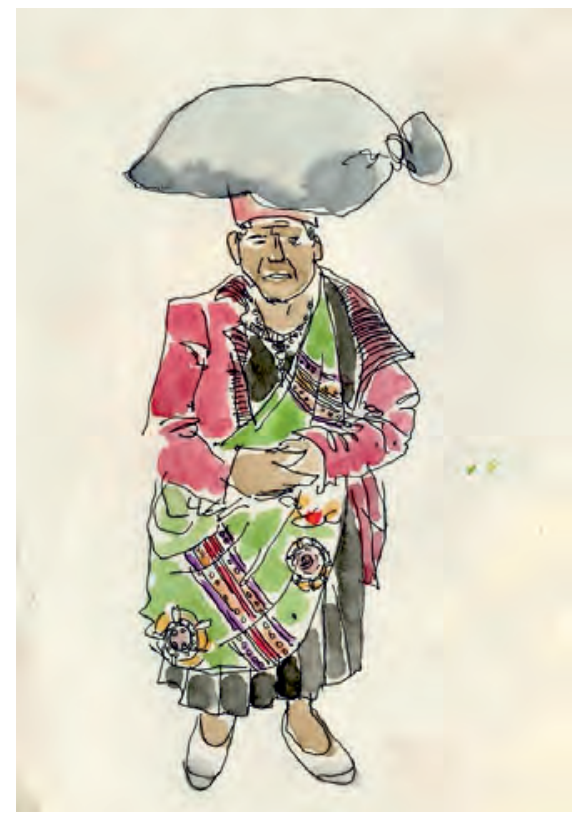

Fig. 5. 2 "The Rwandan lady carrying her potatoes" 
To confirm and explore these border movements, my research partner and I made our way to the unofficial border the old lady had indicated at 5:30 am in the morning. We had not even reached the point where the contiguous forest of MGNP and VNP merge when we saw hundreds of people streaming down the maze of small paths from Rwanda into the Ugandan borderland. I found that while these Rwandans commuting to Uganda on a daily base, their fears not necessarily crossed the political borders but appeared to cling to Rwandan territory. The Rwandans we interviewed on Ugandan soil spoke less fearfully and less in words of the Rwandan regime demonstrating a spatial dimension of fear and people's navigation to escape its restrictions. First came boys and young men, jumping down the stony trails, followed by groups of all age and gender: young girls dressed in colourful Kitenge scarfs, ${ }^{56}$ women with hoes an empty hessian sack wrapped around the handle, older men with stiff hats and baggy trousers (fig. 5.2, 5.3). Many of the 'commuters' we approached expressed their rush to reach the next commercial centre on the Ugandan side to be first in line when someone has a job offer such as assisting in farming activities or - more lucratively - carrying heavy loads of potatoes and other crops. A teenage girl and her younger sister explained to us that they look for a 'Ugandan man' who would marry them because Ugandan men 'have money and many wives'. My Ugandan research partner explained that many Ugandan men pay for sexual services from Rwandan women as the latter are considered particularly beautiful. These sexual interactions are more difficult to identify as prostitution since these women disappear across the border to Rwanda afterwards. Some Ugandan men would indeed take Rwandan women as wives since polygamous households are customary in some traditional families and would afford these women a higher living standard that they could ever achieve in Rwanda.

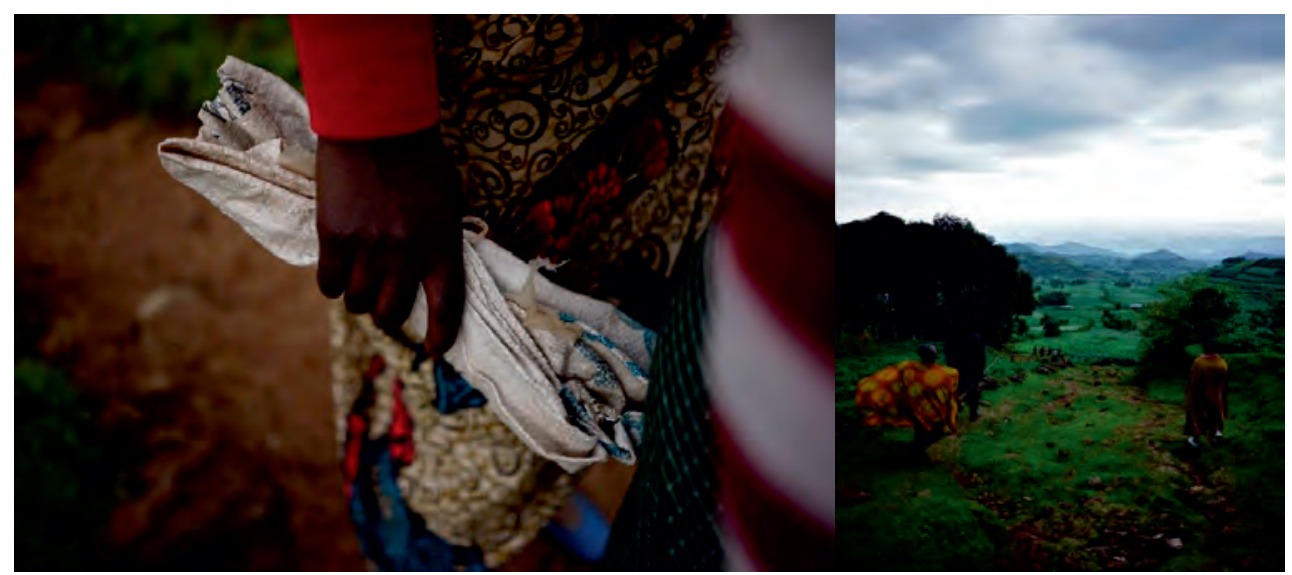

Fig. 5.3 "Bringing a hessian sack"

Fig. 5.4 „Streaming down“

In contrast to official narratives proclaiming community-benefitting conservation achievements from the Rwandan government (see e.g. RDB 2018), the amount of daily 'commuters' and their expressed motivations underline studies about the VNP-adjacent communities characterized by

\footnotetext{
${ }^{56}$ Kitenge is a printed textile commonly worn in many African countries, often for special occasions.
} 
the highest population density and poverty levels in the country facing extreme food insecurity and limited livelihood opportunities (Munanura et al. 2016; Verpoorten 2012). In addition to conservation measures restricting traditional access to natural resources such as firewood, water and game meat, unequal access to non-agricultural jobs in Rwanda's tourism sector and insufficient compensation from tourism revenue-sharing augment this livelihood precarity (Bernhard et al. 2020; Trogisch and Fletcher 2020).

Moreover, during my fieldwork in 2018 I witnessed the announcement of a planned expansion of VNP that would further reduce farm and home land for the park-adjacent communities. ${ }^{57}$ When asking Rwandan 'commuters' in Uganda about this park expansion, many expressed their doubts whether they would be resettled and compensated by the Rwandan government at all. Others indicated that they fear losing the last parcels of farmland used for their own food subsistence, since the government forced many farmers around VNP to grow inedible crops like pyrethrum. Different scholars criticized these state-regulated crop intensification, specialization and market-oriented commercialisation programs for reducing the already limited farmland and exacerbating poverty amongst the more than $80 \%$ small-scale subsistence farmers in the area (Ansoms 2013b; Del Petre et al. 2019).

The sheer amount of daily commuters exemplified the precarity of local livelihoods around VNP. In addition, Rwandans' perceptions of this precarity augmented by state politics shed light on their existential fears that inspired responsive survival strategies. By commuting to Uganda they escape the spatiality of these fears. Similarly, my escape from the reciprocal fear dynamics that limited my research in Rwanda brought me to Uganda. This spatial and emotional distance ultimately enabled an understanding of the culture of fear I encountered in Rwanda's 'post-conflict' society.

\section{Efficacious fears}

A reciprocal interaction of fear can also occur when foreign researchers are seen as a source of threat to national sovereignty and integrity that governmental authorities seek to neutralize through use of fear as a political tool of intimidation. Despite Uganda's authoritarian regime, violent political repression of opponents and media, and presidential election fraught (see e.g. Abonga et al. 2020; Tripp 2010; Reuss 2020), I was accustomed to feel free and safe due to my long-established networks in the Western region adjacent to Mgahinga Gorilla National Park (MGNP). In the last month of my doctoral fieldwork in 2018, however, this feeling of safety dissipated when I was forced into a - from my side 'unplanned' - interrogation by the national intelligence service of Uganda. A person I will call 'the security officer' asked me to enter their car and drove me out of town through an uninhabited area until we reached a fenced, apparently empty complex. The following three hours, the security officer's intimidation tactics triggered strong feelings of fear, panic and terror in me that put a different, lasting complexion on my research focus and my conceptual understandings of the conservation-conflict dynamics after fieldwork.

\footnotetext{
${ }^{57}$ See official announcement African Wildlife Foundation (AWF 2018).
} 
Intimidation is defined as the act "to make timid or fearful, especially to compel or deter by or as if by threats" ${ }^{58}$ Commonly used by state intelligence services in particular to gather information on potential 'threats to the nation', intimidation can be a national security strategy implying "any operation or activity (including use of violence) designed to influence foreign governments, persons, or events in support of the sponsoring government's foreign policy objectives while keeping the sponsoring government's support of the operation a secret" (DCAF 2002: 2). In this spirit, the security officer began their interrogation by showing me a range of close-up photos of corpses, mutilated, with different body parts cut off and their faces covered in blood or with eyes wide open. They asked me if I knew these people who had been killed in the Virunga forests straddling the DRC, Rwanda and Uganda since I have spent the last eleven months in and around the countries' National Parks. Clearly, I did not know the people in the photos, notwithstanding that those dead were barely identifiable anymore. Violent collisions between the Forces armées de la république démocratique du Congo (FARDC), the Rwanda Defence Force (RDF) and armed militias, mostly from the Forces démocratiques de libération $d u$ Rwanda (FDLR), inside the protected area were a 'public secret' (Taussig 1999), yet seldom covered by the censored media that would much less depict the killings.

By sharing information and photos concerning concealed incidents of violence between the three states that I was not supposed to know, the security officer made me an unwanted confidant. Based on this, they clarified their power to imprison me as I now could be deemed as a 'threat to the nation'. As an 'alternative' threat, they pointed out the possibility that I could get into a - in Uganda fairly common - road-related accident during my field trips on boda-bodas (Ugandan motorcycle taxis). Another example of their fear-inducing tactic was to describe my room and my hosts, situated in a remote area on the volcano slopes on the border of MGNP in such great detail that I lost my feeling of safety for the place and the people living there. In hindsight, I would argue that this intimidation was a strategy to 'break' me, probing whether I have gotten any - potentially politically sensitive - information (and informants) during my fieldwork. The method achieved the desired effect of instilling fear in me, leading me to immediately stop my last planned research activities and leaving my hosts in the aftermath of this encounter in order to protect myself and the people who worked with me. In this sense, fear as the effect of political intimidation informed my methodological decision in the field. In addition to this ethically undisputable adjustment of my research to protect my hosts, informants and myself, the incident pointed me to the reasons behind this intimidating interrogation exemplifying a reciprocal dynamic of fear between national governments and foreign researchers who are seen as a source of threat to sovereignty and integrity of the state. Throughout the interrogation, the reasons why I was seen and treated as a threat were highlighted by the security officer's own brought up topics of concern.

Firstly, the security officer suspected me of having gained information during my fieldwork in and around MGNP that Uganda still hosts and protects the rebel group Mouvement du 23 Mars (M23) within the park. According to the UN, after the M23 war in the DRC largely supported by Rwanda from 2012 to 2013, the militias were defeated and surrendered to Uganda's MGNP (UN 2013; UNSC 2014). Yet in 2017, the official surrender of M23 was denounced and

\footnotetext{
${ }^{58}$ https://www.merriam-webster.com/dictionary/intimidate, accessed 20-3-2021.
} 
their military base in MGNP revealed when the same militias, reinvigorated and well-equipped, started fights in the Eastern Congo again (Aljazeera 2017; Reuters 2017). In fact, local community members from the area shared stories and rumours with me in line with these media reports reaffirming that M23 militias are still hiding within MGNP today. Many expressed their fears that the militias could suddenly leave their hide-outs in the park and attack them and their families. The security officer attempted to refute these stories vehemently, highlighting a fear of me in my role as a researcher, and as such a potential threat to reproduce these narratives that could harm Uganda's international reputation as a successful conservation hotspot attracting tourists, international investors and ecologists. As fear inspires political action to alleviate a potential threat to personal or societal integrity and power (Robin 2004), I understood the security officer's intimidation as a governmental effort to protect Uganda's territorial sovereignty, economic interests and international reputation. In addition, the incident illustrated measures of authoritarian control over information and movement in the park-bordering society around MGNP demonstrating how this state control and menacing must affect local community members in their daily lives in fuelling a culture of fear.

Secondly, throughout the three hours of interrogation the security officer did not hide their contempt of 'mzungus', 59 especially of white researchers, who come to 'what they call Third World' to 'sniff around' and 'think they know what is best'. Particularly shocking for me was that the security officer's perspective stood in stark contrast to my - what I thought to be comprehensive "reconnaissance of the field situation" (Lee 1995: 73) in Uganda, as ostensibly welcoming and supporting foreign research. As the security officer accused me of being sent from a 'Western'60 country with 'neo-colonial intentions', their understanding of white, Western research was to undermine Uganda's sovereignty and integrity with the complacency of telling lies about the country in their 'First world'. Feeding into my experiences in the DRC and Rwanda where I was perceived as a source of fear, the security officer's attitude underlined that my appearance as a white Western researcher was not welcome and carried a strong colonial association. This colonial legacy is particularly present in the conservation-conflict context of the Virungas where a history of violent colonial oppression and exploitation by dominant European countries is entangled with white conservationists such as Dian Fossey enclosing flora and fauna along with condemnation and mistreatment of local inhabitants of the region. The reciprocity of fears I experienced was also a product of this negatively connoted amalgamation of 'colonial', 'conservation' and 'conflict' with 'white', 'Western' and 'research'. This realization further raises questions for me concerning 'Western' fieldwork practices that are beyond the scope of this article but will direct my own research in the future.

Finally, this experience in my last month of fieldwork augmented my understanding about how the politics of fear can demand silence by creating the fear to speak out, that I have first encountered in the beginning of my fieldwork as described in the introductory note of this article. While the protection of hosts, research assistants and informants through anonymisation and indecipherable descriptions of events requires particular diligence in politically sensitive conflict

\footnotetext{
${ }^{59}$ Commonly used in East Africa and other regions for 'white person'.

${ }^{60}$ „Shorthand to designate Europe and regions where populations largely originate from Europe as a result of European Imperialism" (Marchaies et al. 2020: 390)
} 
regions, writing about the politics of fear is a way to speak up against enforced silences and the culture of fear that permeates people's lives. Moreover, by writing about the reciprocal dynamics of fear and their underlying, constitutive politics I hope to encourage other researchers to sense, acknowledge and reflect on emotionally charged and potentially harmful interactions in the field that can advance ethical - and increasingly decolonial - fieldwork practices.

\section{Conclusion}

This article has demonstrated how systematic attention to emotionally defining moments during fieldwork can influence and inspire data collection, analysis and interpretation in conflictconservation contexts. In particular, I have explored how accounting for the reciprocal dynamics of fear between me in my position as a researcher and the people with whom I lived and worked informed my methodological adaptations to fieldwork in the conflict-sensitive setting. Throughout my twelve months of research with communities living adjacent to the intended transboundary Virunga conservation area between the DRC, Rwanda and Uganda, my several methodological adaptations comprised the merging of emotional reflexivity with accidental ethnography, implementation of visual ethnographic elements, the shift of my research locations across borders to gain new perspectives with physical and emotional distance, and finally the halt of all research activities to protect interlocutors and myself. These methodological adjustments enabled decisive empirical and conceptual insights into the causes and consequences of the various fears that inform local people's perceptions of and navigations around the threats from conservation practices and the wider violent conflict dynamics. In the Eastern DRC, I saw fear emanating from the active conflict context combined with an ostensibly absent state that also subordinates conservation policies and practices of Virunga National Park. In Rwanda, I experienced fear as a cultural phenomenon induced by state politics of surveillance and unequal advantages that also informs conservation policies and practices of Volcanoes National Park. In Uganda, I encountered fear as a political tool of intimidation to keep sensitive, geostrategic information about Mgahinga Gorilla National Park under control.

Accounting for reciprocal fears in the field further raised uncomfortable questions about 'white, Western' traditions of fieldwork and 'knowledge production' in the global South for me: how can sending 'white' foreigners to point at other countries' challenges lose its colonial character of perceived hierarchical power relationships? And if at all, how can researchers alleviate such reciprocal fear dynamics in the conservation-conflict contexts within countries of sub-Sahara Africa and elsewhere? A true decolonialization of fieldwork as an act of academic knowledge production and methodologies (Tuhiwai Smith 1999) would then also imply efforts to reduce fears' harmful repercussions in the form of psychological stress or trauma for both researchers and informants in the field. As one way to achieve this I encourage future fieldworkers to engage with what I have called an 'emotional ethnography': a practice of critical, emotional reflexivity that can inform awareness and ethical choices to avoid unintended, negative and even traumatizing effects on researcher and interlocutors in conflict-affected contexts. Acknowledging individual fears can lead to collective resonances with others who do not dare to share and as such can provide acknowledgment, understanding and support. 


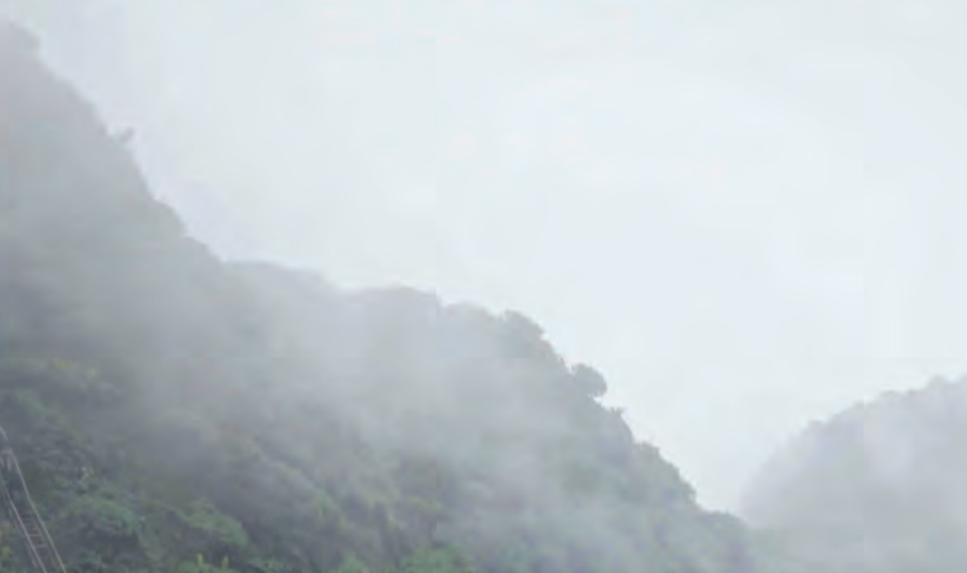

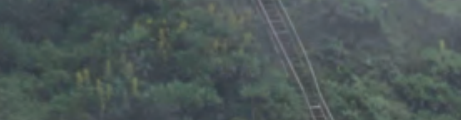

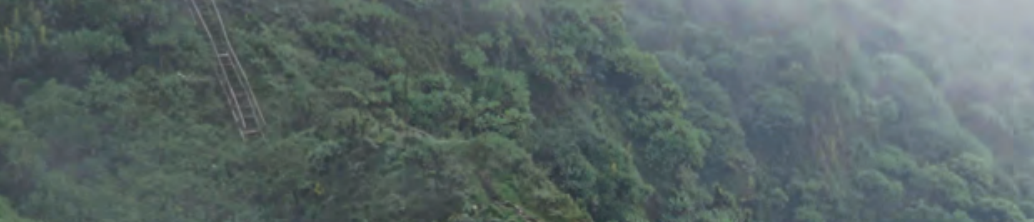

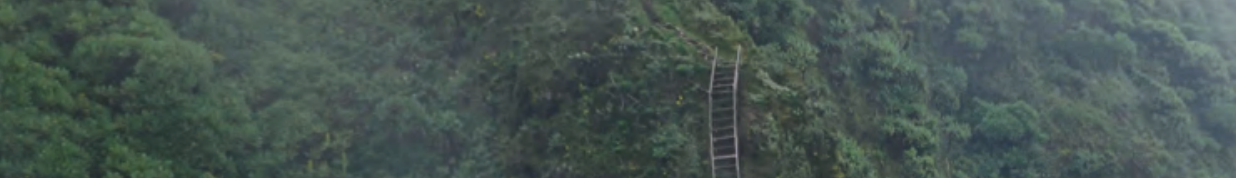

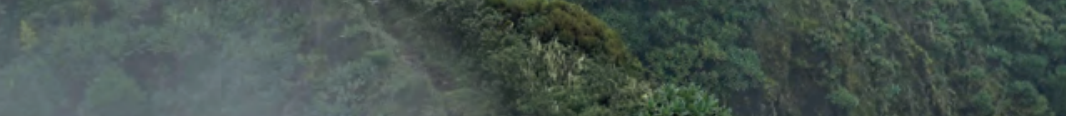

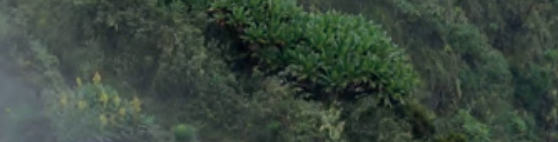

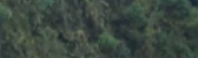
(4) 230 $x+4=\frac{1}{2}$

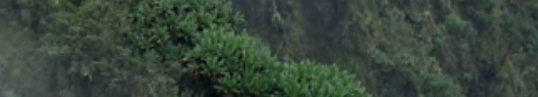

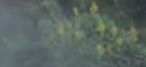

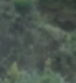

Whas:

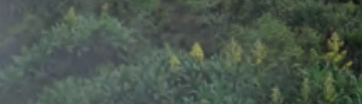

Q450 the

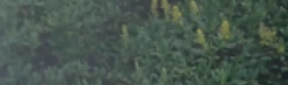

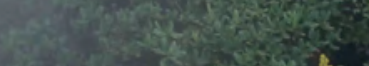<smiles>C1=C2C=C12</smiles>

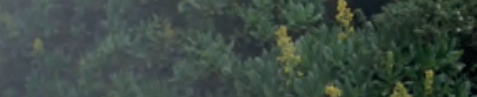
of $x^{3}$

Bistion?

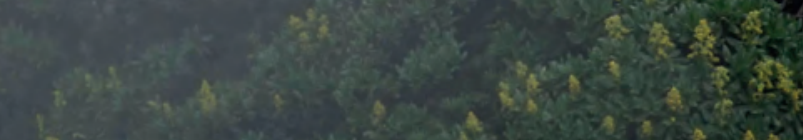

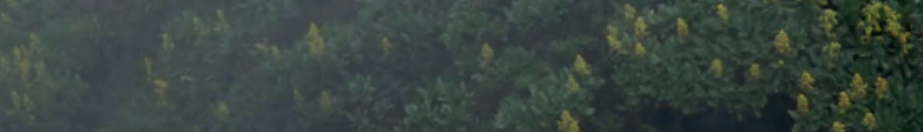

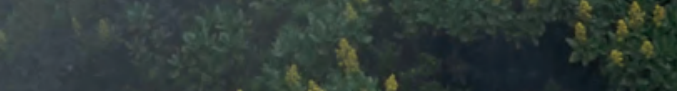




\section{Chapter VI}

Conclusion and discussion

< Fig. 6.1 "Cutting a pathway through the Virungas" 


\section{Introduction}

This thesis has explored the role of fear in undermining the efforts for an intended transboundary protected area (TBPA) straddling the Virunga volcanoes composed of Virunga National Park (PNVi) in the DRC, Volcanoes National Park (VNP) in Rwanda and Mgahinga Gorilla National Park (MGNP) in Uganda.

Grounded in theoretical presuppositions from human geography, my research approached this planned transboundary Virunga Conservation Area as a topographically and institutionally confined landscape comprising multiple - social, political, economic - geographies constituting both the condition for and the consequence of human action. Bringing the insights from my fieldwork and analyses together, I found that this reciprocal influence between landscape and people was strongly characterized by the emotion of fear. With fear I refer to people's emotional response to perceived threats that informed their performances of cognitive and behavioural coping strategies. The systematic analyses of different fears indicated the paramount impact of historical and ongoing regional conflicts weaving through all aspects of everyday life in the present, including conservation-related policies and practices. Fear thus pointed to the convergence of conservation and conflict in the borderland essentially determining the absence of the intended TBPA as one jointly managed, unified geography. Instead, fear shaped how people perceived and performed the multiple geographies of the borderland. To gain an understanding of this emotional condition and consequence of the conservation-conflict context undermining the TBPA efforts in the Virungas, the overall question of my research was: How is fear employed, experienced, and responded to in the conservation-conflict dynamics of the intended Virunga Conservation Area among the DRC, Rwanda and Uganda?

In the iterative sensemaking process of my empirical research and analysis throughout my $\mathrm{PhD}$ trajectory, this principal question was answered through four sub-questions that examined the entanglements of fears across scales in relation to tourism, conservation practices, livelihood strategies and the transboundary collaboration efforts that mutually affected one another. In the understanding of the TBPA institutionalization as a geopolitical process on a transnational scale that affected everyday realities on the local scale, the sub-questions were explored in four chapters following a logic of scaling down from the transnational, to the national, to the local, to the individual level. While each sub-question addressed my three field sites of PNVi in the DRC, VNP in Rwanda and MGNP in Uganda, certain sub-questions were answered throughout multiple chapters highlighting the entanglements of fear across scales and countries. My findings illustrated the stark contrast between conservation practices of PNVi, operating solitarily without and against a predatory Congolese government embedded in a society scarred by active, open conflict, versus the state-led conservation practices of VNP and MGNP in the so-called 'postconflict' societies within Rwanda and Uganda. These differences pointed to the incomparability of the three conservation-conflict contexts and highlighted the impracticality of a one-size-fits-all TBPA model. The regional distinctions further required me to devote more analytical attention to one specific field site or another within certain chapters in order to dismantle the locationdependent conservation and conflict dynamics within and among the three states. 
By addressing the four sub-questions, my research shed light onto the two puzzles introduced in chapter I through exploring the interrelation between fear and the undermining of the TBPA attempts. Therefore, my study engaged with current debates on TBPAs in relation to 'green' violence and militarization, tourism, and livelihood strategies in conservation-conflict contexts conducted predominantly within the field of political ecology.

Yet, to grasp the prominent impact of fear, an emotio-spatial hermeneutic based on emotional geographies and critical geopolitics allowed a shift in perspective to focus on multiple and overlapping geographies. The productive capacity of employing emotions into thinking geographies was substantiated through my research on fear in relation to conservation (in) conflicts, yet applicable to other contexts beyond the conservation sphere. Considering emotions beyond fear will strengthen and enrich political ecology debates as an interdisciplinary practice of knowledge production on the relationship between human and nature. Giving room to people's emotions allows one to see the world from different perspectives, including the reciprocal relationship between people and places. Because emotions are central to human (inter)action in and of geographies, I contend that they should be taken more seriously in human geography and inspire new questions and dialogues on the multiplicity of spaces, places and societies more generally. My use of an 'emotional ethnography' seeks to methodologically infuse such questions and dialogues with emotions to listen to, describe and translate other, different stories into theoretical and practical insights. Storytelling with emotions can offer authentic accounts of the subjectivity, complexity and diversity in human awareness and agency.

This points my own thinking into the future of emotion research on natural environments bringing up new questions: how is labour emotionally instrumentalized for the second economy of natural resource exploitations in the global South? How is such emotional instrumentalization linked to international demands on the world market? And how do such spaces of exploitation and production affect the emotional being of the labourers? This thesis only touches on these lines of inquiry by pointing to the highly political nature of fear and the interests in maintaining it. Fear 'works' to sustain conflict, insecurity and unpredictability to keep labour cheap and working conditions untransparent. Instrumentalizing fear then creates a circular relationship with violence begetting and multiplying one other and sheds light on the conditions of violent conflicts across the globe. As long as the international economy flourishes on products consumed daily in the global North, it thrives on daily fears in the global South. I contend it is upon future research to sense and listen to these fears and other emotions in order to unravel such complex entanglements and take action for change, in theory and practice.

To make a step in this direction, I discuss below how explorations of fear through my innovative theoretical framework can contribute to and advance critical conservation studies within political ecology. This is followed by a critical reflection on methodologies in such critical conservation studies, after which I explore how a practice of 'emotional ethnography' can benefit theory and methods in political ecology and the wider discipline of human geography. Subsequently, I address the social and political relevance of fear research by demonstrating its potential to provide alternative understandings of violence and livelihood strategies that yields practical recommendations for conservation-related policies and practices working with and for the people in and around (transboundary) protected areas. Finally, I advocate an academic institutionalization of emotional engagement for researchers before, during and after fieldwork 
and illustrate an alternative vision for a more self-critical and empathetic future of social scientific knowledge production.

\section{Emotional, geographical, political - ecology}

Based on my findings presented in the four analytical chapters, this thesis pursues three major theoretical contributions.

First, my research seeks to advance an emerging scholarship of emotional political ecology through a novel theoretical framework around geographies of fear that combines perspectives from critical geopolitics, emotional geographies and critical conservation studies. While the few emotion-focussed studies in political ecology concentrate on resource struggles and marginalized groups embedded in unequal power hierarchies based on feminist scholarship (Escobar 2014; Nyantakyi-Frimpong 2021; Singh 2013; Sultana 2015), a critical geopolitical approach provides guidance for a multi-scalar examination of emotions in political analyses and thus allows a hierarchy-transcending study of people and their livelihoods.

Critical geopolitics breaks down traditional understandings of geopolitics as solely a subject of International Relations to assert the original meaning of a geo(graphical)-politics. As such, it studies the reciprocal relationship between physical geography and politics shaping and shaped by people (Dalby 1994; Hyndman 2007; Ó Tuathail 2010). Through this focus on human agency, critical geopolitics acknowledges and engages with the paramount impact of emotions on human behaviour. My theoretical framework relies on the anthology on the geopolitics of fear edited by Pain and Smith (2009) to unravel the fear interactions between (geo)political and (geo)economic processes and everyday lives of local residents in and around the intended TBPA of the Virungas. I thus contend that theory informed by critical geopolitics is of particular merit for critical conservation studies on TBPAs in the context of postcolonial societies as these transboundary geographies are geopolitical arenas per se. As such, they are often characterized by a violent colonial history of arbitrary border-drawing charged with geostrategic meaning for the respective states, and commonly involving international stakeholders for promoting and implementing TBPA treaties. Researching how such geostrategic meanings of borderlands become instrumentalized in the politics of fear has proven to yield decisive insights for my study of the intended Virunga Conservation Area by pointing to the predominant impact of historical and ongoing, open, concealed and simmering warfare between the DRC, Rwanda and Uganda rendering (transboundary) conservation ambitions and practices secondary. In this regard, critical geopolitics can benefit critical conservation studies in exploring the interrelation between geopolitical conservation and conflict dynamics, on the one hand, and the everyday lives of the people perceiving, reacting, responding to and (re)creating social, political and economic geographies, on the other.

Given the significance of the spatial dimension in TBPA efforts, I complemented the critical geopolitics approach with insights from emotional geographies, which offers an analytical entry point into the emotional entanglements between people and landscapes. Inspired by Tulumello's analytical framework on 'fearscapes' and Tuan's discussion of 'landscapes of fear', this thesis demonstrated how politics of fear play a central role in the enclosure of conservation areas transforming landscapes into controlled spaces of exclusion and seclusion. Engaging with this 
emotio-spatial relationship reveals the political interests behind conservation policies and practices. In addition, I examined how people's fears have spatial attachments based on memories linking back to historical and imaginary threats. This thesis has shown how this spatiality of fears informs people's mental coping as well as physical movements to navigate within and around perceived spaces of danger (chapter III, IV), even across borders (chapter V). Moreover, connecting people's fears to space - like (transboundary) protected areas - enables an understanding of the personal and political reasons for violent and militarized conservation practices grounded in histories of violence and conflict engrained into the landscape. This emotio-spatial interrelation ultimately creates a link to the geopolitics of fear in instrumentalizing historical legacies, events, and warfare. This discursive strategy legitimizes governmental measures such as violence or militarization beyond conservation practices.

One specific benefit of an approach informed by emotional geographies and critical geopolitics is the analytical focus on scrutinizing public and governmental discourses of fear that governs people's emotional perception of threats. As I have shown in fear discourses common among park rangers, they re-narrated depictions of a geography of fear, 'Othering' against 'the Congo' and scapegoating resulting in ostensible compliance for political decisions in the transboundary conservation-conflict context. These fear narratives shed light on rangers' understanding, enactment and sense-making of their militaristic and violent conservation duties, mobilizing their sense of responsibility to protect both national park and borders. At the same time, this analysis highlighted park rangers' personal fears of social exclusion and inherent dilemma of being a source of fear for their own communities in their day-to-day life. Hence, analysing the politics of fear in discourses of, for example, Othering and scapegoating, further shows their conditional socio-historical structures, culture and policies. This can benefit the analyses of conservation policies practices generating new explanations for legitimization of increasing violence and militarization in the conservation context worldwide.

Research on emotional instrumentalization through discourses can further aid critical studies on wildlife and nature-based tourism. This thesis pointed to the commercialisation of fear for tourism to conflict-affected regions when security becomes a luxury good for the visitor, sold on the basis of fear characterizing the life of the host. I found that more critical examination of the emotio-spatial instrumentalization of human geographies is needed to dismantle, for example, the underlying interests of the manufacturing industry behind this 'security' consumption. My research already indicated such interests in the provision of armed convoys and personal 'body' guards for tourists, and the infrastructure of inclusion, exclusion and segregation between highend tourists and locals in the same place. Related debates on tourism as a conservation and development strategy became even more pressing since the COVID-19 pandemic accentuated the extreme volatility of the industry with devastating impacts on both local people's livelihoods and biodiversity protection. An emotional political ecology can advance these debates, not solely entailing an academic mission for empirical and theoretical engagement but also practical implications to raise awareness among tourists as the consumers, and thus implicitly ourselves.

Hence, relating approaches from emotional geographies with critical geopolitics yields deeper understandings as well as new questions in the important debates on increasingly problematic measures of 'green' securitisation, territorialisation, violence and militarisation 
including measures of surveillance, patrolling, punishments, imprisonment and shoot-on-sight policies scrutinized by a wide range of critical conservation scholars (see e.g. Adams et al. 2018; Neumann 2004; Lunstrum 2014; Lunstrum and Ybarra 2018; Marijnen and Verweijen 2016).

Based on this novel theoretical framework for a more emotional political ecology, the second theoretical advancement of this thesis refers to research on the different forms of violence in critical conservation studies. I contend that approaching the ambiguous concept of violence through a lens of fear can generate novel understandings of the conditions of and for violence in conservation-conflict contexts. As I have demonstrated in this thesis, an analysis informed by emotional geographies and critical geopolitics sheds light on the circular relationship between fear and violence: fear fuels practices of 'green' violence and militarisation in conservation practices that subsequently refuel fear of the people in and around conservation areas responding with further violence. Based on findings from neurobiological studies that fear is a universal emotional response lowering thresholds for violent behaviour (Meloy 2006; Siever 2008), this thesis has probed the role of fear in mobilizing conservation-related violence through analysing personal perceptions and sense-making of actors 'on the ground'. Accounting for the triggers of this psychological leverage induced by fear offers explanations for actors' diverse understandings and enactments of violence that are neither solely a result of conservation practices nor of violent conflict per se.

Hence, the examination of different fears by different people in the conservation-conflict context can transcend dichotomous legal versus illegal as well as 'green', structural, direct, or other categorizations of violence and thus complicate an analysis along victim-perpetrator lines. In order to understand these complex entanglements and potentially overcome dichotomies in violence studies, chapter III on park rangers represented a dialogue with chapter IV on Congolese women demonstrating the overlapping identities as well as the compliances, collaborations and conflicts of people within the park-adjacent communities. I contend that an analytical angle of fear allows an examination of violence without reducing the analysis to it. It can thus offer nuanced understandings of the reciprocal, discursive and embodied causes and effects of violence in relation to both, conservation and conflict. Approximating violence through the lens of those who fear and those who are feared can further provide the basis for new approaches how reconciliation of park-versus-people conflicts and nature conservation on a par with secure local livelihoods could be developed in the future.

As the third theoretical contribution to political ecology, I propose a shift in the dominant analytical focus from the concept of 'resistance' to 'coping'. Since a wide range of critical conservation scholars adapted James Scott's 'everyday resistance' $(1985 ; 1990)$ to analyse people's oppositional behaviours directed against conservation authorities and areas (Matose 2014; Poudel 2019; Verweijen 2018), I argued in this thesis that a focus on 'resistance' forecloses a more nuanced account of people's overlapping roles and identities, utilizations, interactions, collaborations, compliances and symbiosis with conservation actors and areas. Listening to people's fears enables to explore their fear-responsive coping understood as the individually developed emotional, cognitive and behavioural strategies for reducing or eliminating perceived 
threats and lowering (chronic) feelings of fear in conflict-affected settings (Johnson and Chronister 2010). A fear-focused coping analysis is thus particularly useful to unravel the complex entanglements of threats emanating from the coalescence of inter-and intrastate conflict with conservation measures.

Moreover, accounting for coping is an attempt to learn about people's self-created livelihood strategies of 'staying with the fear' - adapting Donna Haraways' 'staying with the trouble' (2016) - that can illuminate difficult, different and creative ways of living and surviving with(in) conservation-conflict contexts. By moving beyond resistance, a systematic analysis of fearinformed coping further foregrounds people's agency, self-determination and self-representation in proactive engaging with threats. This can dismantle victimizing accounts of certain marginalized groups, particularly women, in critical conservation studies. In this light, an engagement with coping in response to fear - but also other emotions - can benefit studies in human geography more generally by generating new perspectives on the reciprocal 'making' between humans and geographies.

Ultimately, an interdisciplinary, theoretical framework focused on geographies of fear merging insights from critical geopolitics, emotional geographies and political ecology proved to be productive for analyses and interpretation of people's everyday perceptions and performances in and of geographies. Such forthright engagement and research concerning the role of fear and other emotions further allows one to ground critical discussions of conservation practices in the emotional realities of those who experience (and enact) these practices in their everyday lives. I have shown how accounting for their experiences and sensemaking of fears aids in dismantling the triggers of and responses to perceived threats. This understanding can shed light on the politics of fear pervading conservation measures and conflict dynamics within and between states.

This highly political nature of fear demands a more emotional political ecology as it opens up new lines of inquiry on the means - such as fear discourses, intimidation tactics and (threats of) violence - and ends behind creating, disseminating and maintaining fear. This thesis only touches on these topics in exploring how fear 'works' through silencing the maintenance of conflict, insecurity and structural inequality that multiplies fear - pointing my own research interests into the future. Silence borne of fear disables open exchange, understanding, the expression of preferences, critical or alternative possibilities and thus deprives people living in fear from openly advocating for change. Silences also deprive the researcher of the academic strength we have in aiding to foster that change, namely through shedding light onto things kept in the dark. In this sense, an emotio-spatial framework conceptualizing geographies of fear can aid future studies to illuminate and expose the politics of fear as a way to speak up against enforced silences and permeating cultures of fear restricting people's lives in and beyond conservationconflict settings. This thesis sought to propose ways to make silences heard by facilitating and encouraging systematic attention and active listening to those who fear and those who are feared in critical conservation studies. Therefore, I next elaborate how an emotional, geographical, political ecology framework can be enriched by a methodological shift towards an 'emotional ethnography'. 


\section{Towards an emotional ethnography}

As I have demonstrated throughout this thesis, research in conflict-affected conservation contexts requires a considerate, ethical and sensitive methodology in fieldwork. While a wide range of studies related to political ecology have long engaged with geographies scarred by violence and/or conflict via fieldwork as the pivotal methodological approach (Bryant 2015, Büscher 2013; Marijnen and Verweijen 2016; Nyantakyi-Frimpong 2021), there has been surprisingly little reflection on and recommendations for fieldwork in such settings in the political ecology literature. This thesis seeks to contribute to filling this void by proposing a practice of 'emotional geographies'. I developed this practice throughout my fieldwork in the DRC, Rwanda and Uganda by engaging with the rich anthropological literature on conflict (Diphoorn 2012; Fujii 2010; Green 1994; Lee 1995; Kovats-Bernat 2002; Rodgers 2007; Taussig 1992; Wood 2006).

Emotional ethnography comprises practices of observing emotions, using them as a compass to navigate the field and incorporating the observations that are coloured by these emotions into our knowledge production. The approach is based on the constructivist notion that we, in our role as researchers, act as the 'research instrument' and that data collection, interpretation and analyses are influenced by our own emotions during and after fieldwork (Bondi 2005; Coffey 1999; Davidson and Milligan 2004; Rosaldo 1989; Thomson et al. 2013; van Maanen 2010). The balancing act between confessional navel-gazing and meaningful, reflexive analysis lies in the forthright engagement with emotions as 'meta-data' ranging from silences to open expressions informed by people's thoughts and feelings that reveal important structural features of the social and political context (Fujii 2010). Methodologies in critical conservation studies working with people in contexts of 'green' violence, militarization and warfare related to (transboundary) protected areas could benefit from 'emotional ethnography' in two ways.

First, tracking the 'meta-data' of our own and people's emotional (re-)actions in conflictaffected contexts in particular can yield methodological adaptations based on ethical considerations and empathy on the part of the researcher. Emotional ethnography allows one to account for people's feelings in light of sensitive topics and context, traumatizing experiences as well as the danger of harmful repercussions through the researcher's presence and questions. In this thesis, I have demonstrated how my awareness and systematic exploration of fear informed a range of methodological adjustments such as the utilization of 'photovoice' (chapter IV), the participatory approach working with park rangers (chapter III), and the change of locations (chapter V). These adjustments enabled me to account for rapidly changing political contexts, country-specific regimes, restrictions by surveillance and volatile security situations. Given the conflict-affected context of my three field sites, emotional awareness pointed me to a number of ethical challenges such as in the question for documented 'informed consent' that conveyed a threat to people's safety and generated suspicion and fear towards me. In order to address people's fears, I was constrained to develop mitigating, comforting strategies. One example presented in chapter IV was to guarantee people autonomy and ownership in conducting the photo diaries without guidelines or my own involvement, which afforded disassociation between people and task with my role as a white, Western researcher. 
Secondly, since particularly strong emotions in the researcher can enable deeper insights into otherwise unnoticed aspects of social life (Fujii 2014; Trigger et al. 2012; Koot 2016), emotional ethnography can generate unexpected, novel understandings of often invisible, systemic features of violence, oppression and inequality in the conservation-conflict context. In this thesis, I have shown that fear, although commonly considered a negative emotion to be avoided, also comprises inherently positive qualities that can function as a compass. I have exemplified how empathetic sensing of fear of and with the people sheds light on how structural and systemic as well as direct forms of violence affect local livelihoods (chapter III, IV, V). Therewith, I do not presume to make complacent assumptions about people's emotional worlds in face of their hardships, but to encourage listening to their fears - and other emotions - in order to understand their individual sensemaking and everyday survival strategies. This further can and should inform and advance conservation-related policies and practices, as I elaborate on below. Yet, my insights as a white, foreign researchers are limited to the situations I witnessed, and the stories people shared with me - a limitation that precludes me from truly feeling (with) the extent of their fears, horrors and trauma in the conservation-conflict context.

In the aim for understanding, I propose to infuse methodological approaches in critical conservation studies with empathy. One way would be to enhance fieldwork preparations and practices with aspects of emotional ethnography in order to encourage a more open, honest academic acknowledgment and expression of fear and other emotions during and after fieldwork. In this regards, emotional ethnography can aid researchers in a meaningful, reflexive and critical way to generate deeper academic and personal knowledge through a range of question that I developed to make sense of encountered emotions, for example:

- How do we experience spaces emotionally - and which emotions do spaces entail for others? What can the similarities and differences in these emotio-spatial perceptions point us to?

- How do people react on us when meeting the first time? How does this reaction change over time?

- Which methods can help us to identify and track changes in the emotional landscape of ourselves and our interlocutors throughout the research process?

- How do these changes impact our research and interpretation?

- How can we map, interpret and categorize other people's emotions while accounting for their cultural embedment?

- Which scenes or moments do we memorize consciously, and which unconsciously, after returning from fieldwork - and why?

- What do these defining moments reveal about our research topic or case study?

\section{Of social, political and ecological relevance}

In order to contribute to the 'emotional turn' in political ecology and wider human geography studies, I have shown the added value of an emotional ethnography approach for critical conservation studies in accounting for and incorporating the dominant impact of emotions on human behaviour into knowledge practices. Acknowledging and making sense of emotions such as fear generates novel understandings on how humans 'make' geographies through emotional perceptions and responding performances. What can this emotion-infused scientific knowledge, 
and in particular the examination of fear, contribute practically to the discussed socio-political problems in the transboundary conservation-conflict context?

As the main outcome of my research on fear in undermining the TBPA attempts in the Virungas, I found that conservation institutions promoting the imaginary of a 'peace park' for the conflict-affected region between the DRC, Rwanda and Uganda lacked understanding of the geostrategic meaning of the borderland. This led to an ignorance of the (geo)political implications that complicate an intergovernmental agreement. In order to bring the three governments to one table, appropriate TBPA planning would require an assessment of threats posed by the TBPA as perceived by the nation-states to address concomitant fears in written agreements at the outset. I found that in the intended TBPA of the Virungas these fears comprised losing: i) political sovereignty to an intergovernmental body such as the GVTC with neo-imperial connotations though the influence from Western donors; ii) territorial integrity through the repeal of political borders for transboundary purposes claimed by non-governmental conservation institutions; and iii) comparative economic advantage over self-determined fees, rules and regulations for mountain gorilla tourism.

Including these concerns in the negotiations of terms and conditions of a planned TBPA requires further involvement of all relevant stakeholders claiming authority in the regional context, including national, official, local and 'unofficial' representatives. Throughout my research, I witnessed mistrust to outright rejection of the GVTC by a wide range of people in governmental positions due to the lack of involvement and information-sharing leading to the erosion of planned TBPA measures and projects. The politics of fear I unravelled in this thesis are a response to missed opportunities for an inclusive planning process such as the direct undermining of TBPA-tourism agreements (chapter II). These pitfalls point to the 'weak spots' in the GVTC treaty (2015) and to the potential for developing more effective, inclusive alignments with relevant stakeholders in the future. Hence, researching the politics of fear can enable policymakers and practitioners in the sectors of conservation, development and conflict in the TBPA planning and establishment to address root causes of fear that hinder collaboration on the transnational to the local scale, applicable to other countries within and beyond sub-Saharan Africa.

Besides political recommendations on the transnational level, my research also yields practical relevance for national conservation practices and livelihoods on the local level. Following the fears of women like Pauline and Mama Sifa living with Virunga National Park in the DRC (chapter IV), of Ugandan park rangers on patrol along the political borders within the contiguous forest of the Virungas (chapter III), or of daily border-commuters escaping the lifethreatening restrictions and regulations around Volcanoes National Park in Rwanda (chapter V) provided an empirical account of the different, yet entangled threats emanating from conservation and the regional conflict simultaneously. Dismantling those threats aids understandings of the different needs of the different people ultimately experiencing, responding to and thus 'making' the conservation-conflict context of the Virungas. In practice, this should begin by accounting for the overlapping roles and inherent dilemmas of parastatal and paramilitary conservation actors and civilian community members. This would allow practitioners and policymakers to include and join their voices into designing more collaborative 
community-conservation practices that have proven to reduce violent conflicts between park and people in other conservation-conflict contexts such as Kahuzi-Biega National Park (Milburn 2014) or Garamba National Park (Titeca et al. 2020) in the DRC.

In addition, I have demonstrated in chapter III, IV and V that understanding conservation actors' personal perceptions of the entanglement between their fears and different forms of violence can explain reasoning, causes, conditions, and justifications for criminalizing, militaristic and violent conservation policies and practices. Without the intention to justify such violent conservation measures, I have sought to show in this thesis how meaningful engagement with the fears of 'those of whom we are critical' puts another face on the matter of compliance in violence and conflict. This avoids prejudgments and disabling categories in critical conservation studies and instead inspires practical solutions. Through my research, I learnt that park rangers perceive their own 'green' militarization in the conflict-affected borderland context of the Virungas as a form of protection facing threats to their lives on a daily base when conducting patrols. Yet, these threats do not emanate from unauthorized hunting activities by community members but the movements of armed actors inside the contiguous forest (chapter III, IV, V). Hence, a first step towards decreasing rangers' personal 'need' and sense of necessity for paramilitary training, armament and assemblage with the national army would be to address the root causes of the interstate warfare carried out through the contiguous forest and hence implies a high level of diplomatic round tables between the national governments of the DRC, Rwanda and Uganda.

This thesis thus holds political relevance for a different conservation approach in regional conflict contexts. At the same time, my research was accompanied by the question what I as a foreign researcher can meaningfully offer for the people 'on the ground' that I engaged with and relied on in these conflict-affected settings while I can (and did) just leave the place and the people at any time ${ }^{61}$ This question depicting an inherent, moral dilemma has been raised by many scholars in conflict areas, yet I realized that one can only find an individual answer for oneself. While I have altered events and lives of the people who worked with me, I sought to always be open about myself and engage with people's fears, sorrows, and needs in a mutual devotion of time. Particularly engaging with the different fears of people from the park-adjacent communities gave me an insight into their personal understandings of different threats from conservation and/or conflict dismantling some of my preconceived ideas of what beneficial conservation and development interventions would entail. In chapter II, for example, local tourism operators in the DRC expressed their fears of being 'squeezed out' of the tourism market as a result of the tourist kidnapping leading to high-level security demands for driving tourists to and from Virunga National Park. As fears can point to concomitant needs, one potential solution for Congolese tourism operators would be a contracted partnership with the management of Virunga National Park to share secured road access that would secure their source of income. In addition, I have demonstrated in chapter IV and V how an examination of the relationship between the emotion of fear and coping strategies affords identification of people's self-created and prioritized solutions for livelihood struggles. In this regard, I want to emphasize that it is not for this thesis to judge whether certain coping strategies born out of fear, such as unauthorized park activities that do

\footnotetext{
${ }^{61}$ In reference to Bourgois (1990)
} 
not align with general understandings in policy and practice, are 'right' or 'wrong'. Yet, I do argue that those activities denigrated as 'illegal' might open up room for alternative and more community-inclusive conservation approaches such as granting regulated access to the forest for traditional cultural and spiritual practices or collection of limited numbers of certain resources such as medical plants.

So, what is my contribution as a foreign researcher for the people apart from listening to their fears? I found that understanding and translating fears and coping can inform practical approaches for policy-makers and practitioners such as GVTC to seek out and include the perspective of different people across ethnicity, age, race and gender affected by (transboundary) protected area projects. Such a scientifically inspired approach would account for people's ideas and needs in the establishment and management of conservation areas and related development projects to benefit both, people and nature.

Finally, I highlight the practical relevance of an emotional engagement for academic institutions in establishing healthy, scientific environments beyond the publication realm. After I returned with minor traumatic repercussions from fieldwork, I had a conversation with an experienced researcher engaged in the DRC and Rwanda who criticized how current academic practices discourage an honest and open discussion about the emotionality of research and its long-lasting, potentially harmful imprint on the people who work with us and the researcher. Her awareness and courage to articulate what many doctoral researchers I spoke with - including myself - felt, exemplified that sharing vulnerability, challenges, dilemmas, guilt, discomfort and fear will resonate in others and open up dialogue, foster critical awareness and also advance theory building and scientific knowledge production. In practice, I envision an institutionalization of emotional awareness, engagement and open reflection that is encouraged and systemically incorporated into academic institutions. Such an institutionalization could comprise psychological counselling for researchers before and after fieldwork enabling mental and methodologically appropriate preparations that could reduce ethical and moral ambiguities as well as traumatic repercussions for both, researchers and the people who work with us in the 'field'. In light of current university structures, an institutional change towards a healthier academic culture would allow and appreciate emotional engagements in, for example, compulsory pre- and de-briefings of students and staff to acknowledge, understand, make use of and cope with (their) emotions. This thesis aims to encourage such honest engagement with emotions such as fear by making explicit the emotional labour of fieldwork (ref. Hochschild 1983) and its significance for the productive outcomes from fieldwork encounters as well as for healthy scientists and scientific environments beyond publications.

\section{On fears of whiteness}

In concluding, I want to draw attention towards the necessity for critical reflections on the emotional impact of interactions between white Western researchers like myself and the people who work with us. Emotional awareness can advance understandings of the colonial legacies inherent in foreign-led fieldwork practices in postcolonial societies of sub-Saharan Africa. In this thesis I have shared the reciprocal dynamics of fear between myself and the people in the field 
that partially resulted from my appearance as a $\mathrm{W}^{3}$ - a white, Western woman - carrying strong negative colonial attributes (chapter V). In the attempt to contribute to ongoing efforts of advancing the decolonization of academic practices (Marchais et al. 2020; Mills 2007; Toomey 2016; Tuhiwai Smith 1999), I have striven to make sense of and mitigate the fear partially evoked by my whiteness in others and myself to find answers to the uncomfortable question to what extent I am perpetuating such colonial legacies of scientific exploitation that were attributed to me? In other words, is my research automatically reproducing realities of a dominant white group because I am white (Mills 2007: 34)?

As I have discussed in this thesis, my research on the intended TBPA among the DRC, Rwanda and Uganda implied the white legacy of inherited violence from colonizers and conservationists claiming power over the region for decades. In chapter $\mathrm{V}$, the contempt of the security officer explicitly expressed that Western academic knowledge production by sending white people to point with their finger at other countries is neither appreciated nor perceived as beneficial for Uganda. In acknowledging these experiences, I want to scrutinize the impression that white, Western researchers are commonly welcome in countries with a colonial history to animate discussion about preconceptions, attitudes and methodologies for future fieldworkers with a similar background and appearance as me. At the same time, expressing these thoughts as a white European can come across as an indulgence system for a guilty conscious of 'white privilege' and yet just again centring whiteness. Indeed, in academic practices there is a trend in publications and self-representation to acknowledge and convey a sense of shame about white privilege and the need to correct for it, that so far has barely created changes in the status quo of white academic knowledge production. How can a white, Western academic meaningfully engage with and challenge this problematic issue of white privilege?

On the one hand, understanding the dynamics of (neo-)colonial attributes to research/fieldwork through critical self-reflection is the first step to disrupt inherent and often subconscious behaviours of 'white supremacy' such as the ignorance of racial situatedness and supposedly egalitarian and inclusive relationships in research practices. In addition, the implicit legacies of whiteness should become more prioritized and engrained in academic curricula of Western universities, in particular when implying potential first-hand research in foreign countries, to augment critical awareness in fieldwork and knowledge production practices. Part of reconsidering white-dominated knowledge production on postcolonial societies in sub-Saharan Africa in particular could further entail to relinquish more contributions in the respective academic journals to local scholars.

On the other hand, despite the best intentions and strongest moral compasses, we can only aim to accommodate the inconvenient truth of asymmetric research practices by using our privilege to support and empower those who lack it. I found that gratitude (and appropriate, respectful, financial compensations) for hospitality and participation might appear flawed in the undeniable difference between my role of a Western researcher and the local people in the rural areas adjacent to the Virungas. Even if we cannot adequately pay it back to the people who were sharing information, opinions, tea and time with us, I plead for paying it forward to create change. In this sense, my intention is and always has been to establish connections between the tales I was told and my Western sense-making, to tell it further and stir critical minds and new understandings in the curious who cannot go and listen themselves. My personal privilege as well 
as my possible contribution was - and is - to listen to the people trying to understand how they experience what my Western informed concepts call 'fear', 'violence', 'conservation', 'conflict' and translate their knowledge to a Western audience. The contribution then is not to fuel shame, guilt and fear of being white but to raise recognition of white privileges and therewith inspire systemic rethinking and action.

This thesis is thus an attempt towards exploring new directions in the decolonization of academic practices. In this sense, an emotional ethnography of honest engagement and empathy can advance necessary critical reflections on one's own ambiguous role and awareness of the inherent asymmetries in knowledge production practices. As such, letting emotions come closer so that we can listen to what they try to tell us may become a key element of study and research in the social sciences of Western academia, holding the potential to reimagine values of knowledge practices as "a humble and humbling activity" (Smith 1999: 5). 


\section{Bibliography}

Adams, W. M. 2019: "Geographies of conservation II: Technology, surveillance and conservation by algorithm", Progress in Human Geography 43(2): 337-350.

Abonga, F., Kerali, R., Porter, H., Tapscott, R. 2020: "Naked bodies and collective action: repertoires of protest in Uganda's militarised, authoritarian regime”, Civil Wars 22(2-3): 198223.

Adams, W. M., Infield, M. 2003: "Who is on the gorilla's payroll? Claims on tourist revenue from a Ugandan national park", World Development 31(1): 177-190.

Ahebwa, W.M., van der Duim, R., Sanbrook, C. 2012: "Tourism revenue sharing policy at Bwindi Impenetrable National Park, Uganda: a policy arrangements approach”, Journal of Sustainable Tourism 20(3): 377-394.

Ahmed, S. 2020: “'I am my own person,' women's agency inside and outside the home in rural Pakistan”, Gender, Place $\mathcal{E}$ Culture 27(8): 1176-1194.

African Rights. 1998: Rwanda: The insurgency in the Northwest. African Rights, London.

African Wildlife Foundation (AWF). 2014: https://www.awf.org/blog/remembering-heroicgorilla-guardian, accessed 9-8-2019.

African Wildlife Foundation (AWF). 2017: "Volcanoes National Park: a success story for Rwanda's communities and conservation", https://www.awf.org/blog/volcanoes-nationalpark-success-story-rwandas-communities-and-conservation, accessed 20-1-2021.

African Wildlife Foundation (AWF). 2018: "AWF donates land to Rwanda to protect mountain gorilla habitat", https://www.awf.org/news/awf-donates-land-rwanda-protectmountain-gorilla-habitat, accessed 28-12-2020.

African Wildlife Foundation (AWF). 2020: https://www.awf.org/blog/endangered-mountaingorillas-find-safe-haven-africas-oldest-park, accessed 20-2-2020.

Agnew, R. 2001: "Building on the foundation of general strain theory: specifying the types of strain most likely to lead to crime and delinquency", Journal of Research in Crime and Delinquency 38(4): 319-336.

Ali, S H. 2007: Peace Parks: conservation and conflict resolution, Cambridge: MIT Press.

Aljazeera. 2017: https://www.aljazeera.com/news/africa/2013/12/children-among-grouphacked-death-drc-20131216192151681961.html, accessed 17-9-2019.

Allen, Q. 2013: "Photographs and stories: ethics, benefits and dilemmas of using participant photography with Black middle-class male youth”, Qualitative Research 12(4): 443-458.

Alluri, R. M. 2009: The role of tourism in post-conflict peacebuilding in Rwanda. Working Paper, Bern: Swiss Peace Foundation.

Ammann, C. 2020: Women, agency, and the state in Guinea: silent politics, London: Routledge.

Ammann, C., Staudacher, S. 2020: "Masculinities in Africa beyond crisis: complexity, fluidity, and intersectionality", Gender, Place $\mathcal{E}$ Culture, (ahead-of-print).

Ampumuza, C., Driessen, C. 2020: "Gorilla habituation and the role of animal agency in conservation and tourism development at Bwindi, South Western Uganda”, Environment and Planning E: Nature and Space 1: 1-21. 
Anderson, K., Smith, S.J. 2001: "Editorial: emotional geographies”, Transactions of the Institute of British Geographers NS 26: 7-10.

Anderson, L. 2006: “Analytic autoethnography”, Journal of Contemporary Ethnography 35(4): 373-395.

Andersson, J.A., de Garine-Wichatitsky, M., Cumming, D.H.M., Dzingirai, V., Giller, K.E. 2013: Transfrontier conservation areas: people living on the edge, London and New York: Routledge.

Ancrenaz, M., Dabek, L., O’Neil, S. 2007: "The costs of exclusion: recognizing a role for local communities in biodiversity conservation”, PLoS Biol 5(11): 2443-2448.

Ansoms, A. 2009: "Re-engineering rural society: the visions and ambitions of the Rwandan elite”, African Affairs 108(431): 289-309.

Ansoms, A. 2013: "Large-scale land deals and local livelihoods in Rwanda: the bitter fruit of a new agrarian model", African Studies Review 56(3): 1-23.

Ansoms, A., Hilhorst, T. 2014: Losing your land - dispossession in the Great Lakes Region, Suffolk and New York: James Currey.

Appadurai, A. 1996: Modernity at large: cultural dimensions of globalization, Minneapolis, MN: University of Minnesota Press.

Ashaba, I. 2020: "Historical roots of militarised conservation: the case of Uganda", Review of African Political Economy, forthcoming.

Autessere, S. 2012: "Dangerous tales: Dominant narratives on the Congo and their unintended consequences”, African Affairs 111(443): 202-222.

Avraham, E. and Ketter, E. 2016: Tourism marketing for developing countries: battling stereotypes and crises in Asia, Africa and the Middle East, London: Palgrave Macmillan.

Baral, N., Heinen, J.T. 2006: “The Maoist people's war and conservation in Nepal”, Polit Life Sci 24: 2-11.

Barquet, K., Lujala, P., Ketil, J. 2014: "Transboundary conservation and militarized interstate disputes", Political Geography 42:1-11.

BBC. 1999: "Uganda tourists 'butchered”", http://news.bbc.co.uk/2/hi/africa/289196.stm, accessed 8-4-2019.

BBC. 2000: "Heavy fighting resuming in Kisangani", http://news.bbc.co.uk/2/hi/africa/785089.stm, accessed 27-11-2020.

BBC. 2018: "DR Congo troops killed 'in Virunga park' by Rwandan army“, https://www.bbc.com/news/world-africa-43085587, accessed 9-8-2019.

BBC. 2019: "Rwanda genocide: 100 days of slaughter", https://www.bbc.com/news/worldafrica-26875506, accessed 15-12-2020.

Bentrovato, D. 2015: "Rwanda, twenty years on: assessing the RPF's legacy through the views of the Great Lakes Region's new generation”, Cahiers d'Études Africaines 55(218): 231-254.

Berger, P., Luckmann, T. 1966: The social construction of reality. London: Allen Lane, Penguin. Bernhard, K., Smith, T., Sabuhoro, E., Nyandwi, E., Munanura, I. 2020: "Effects of integrated conservation-development projects on unauthorized resource use in Volcanoes National Park, Rwanda: A mixed-methods spatio-temporal approach”, Oryx, (ahead-of-print). 
Biswas, A.K., Tortajada-Quiroz, H.C. 1996: "Environmental impacts of the Rwandan refugees on Zaire”, Ambio 25(6): 403-408.

Blanchard, L. and Higgins-Desbiolles, F. 2013: Peace through tourism: promoting human security through international citizenship, London: Routledge.

Blomley, T. 2003: "Natural resource conflict management: the case of Bwindi Impenetrable and Mgahinga Gorilla National Parks, southwestern Uganda”, in: A. Peter Castro and Erik Nielsen: Natural resource conflict management case studies: an analysis of power, participation and protected areas, Rome: Food and Agriculture Organization of the United Nations, pp. 231250.

Bocajero, D., Ojeda, D. 2016: "Violence and conservation: beyond unintended consequences and unfortunate coincidences", Geoforum 69: 176-183.

Bondi, L., Davidson, J., Smith, M. 2005: Emotional geographies, London and New York: Routledge.

Bondi, L. 2005: "Making connections and thinking through emotions: between geography and psychotherapy", Transactions of the Institute of British Geographers 30(4): 433-48.

Boscoboinik, A., Horáková, H. 2014: The anthropology of fear, Zürich and Berlin: LIT Verlag. Bourdieu, P., Loïc J.D. W. 1992: An invitation to reflexive sociology, Chicago: The University of Chicago Press.

Bourgois, P. 1990: "Confronting anthropological ethics: Ethnographic lessons from Central America”, Journal of Peace Research 27(1): 43-54.

Bourke, J. 2006: Fear: A cultural history, Emeryville, CA: Shoemaker and Hoard.

Brockington, D. 2002: Fortress Conservation: the preservation of the Mkomazi Game Reserve, Tanzania, Oxford: James Currey.

Brockington, D., Duffy, R., Igoe, J. 2008: Nature unbound. Conservation, capitalism and the future of protected areas, London and New York: Earthscan.

Brosius, J. P., Russell, D. 2003: “Conservation from above: An anthropological perspective ontransboundary protected areas and ecoregional planning”, Journal of Sustainable Forestry 17(1-2): 39-65.

Bryant, R.L. 2015: International handbook of political ecology, Cheltenham, UK : Edward Elgar Publishing.

Buckley-Zistel, S. 2006: "Remembering to forget: chosen amnesia as a strategy for local coexistence in post-genocide Rwanda", African Studies Quarterly 76: 2: 131-149.

Büscher, B. 2013: Transforming the frontier. Peace parks and the politics of neoliberal conservation in southern Africa, Durham and London: Duke University Press.

Büscher, B., Fletcher, R. 2017: "Destructive creation: capital accumulation and the structural violence of tourism”, Journal of Sustainable Tourism 24(4): 1832-1858.

Büscher, B., Ramutsindela, M. 2016: "Green violence: Rhino poaching and the war to save Southern Africa's peace parks", African Affairs 115(458): 1-22.

Bush, G. K., Ikirezi, M., Daconto, G., Gray, M., Fawcett, K. 2010: Assessing impacts from community conservation interventions around Parc National des Volcans, Rwanda, Technical Report.

Butynski, T.M., Kalina, J. 1993: “Three new mountain parks for Uganda”, Oryx 27(4): 214-224. 
Cavanagh, C., Benjaminsen T.A. 2014: "Virtual nature, violent accumulation: the 'spectacular failure' of carbon offsetting at a Ugandan National Park", Geoforum 56: 55-65.

CGIS/DFGI (Georgia Tech Center for GIS and the Dian Fossey Gorilla Fund International) 2018: Poaching in Rwanda's Volcanoes National Park, http://hub.arcgis.com/datasets/6a9e68db05704b119adb5fc3e4708291, accessed 17-1-2020.

Clark, A. 2005: Situational analysis: grounded theory after the postmodern turn, Thousand Oaks, CA: Sage.

Clay, N. 2019: "Fixing the ecosystem: Conservation, crisis and capital in Rwanda's Gishwati Forest", Environment and Planning E: Nature and Space 2(1): 23-46.

Cloke, P., Philo, C., Sadler, D.1991: Approaching Human Geography, Chapman, London.

Coffey, A. 1999: The ethnographic self: fieldwork and the representation of identity, London; Thousand Oaks, CA: Sage.

Collier, P., Hoeffler, A. 2000: Greed and grievance in civil war, World Bank: Policy Research Working Paper 2355.

Cowen, D., Gilbert, E. 2008: "Fear and the familial in the US war on terror", in: R.Pain and S.J.Smith: Fear: Critical Geopolitics and everyday life, Hampshire: Ashgate Publishing, pp. 49. 58.

Creswell, J., Plano Clark, V.L. 2011: Designing and conducting mixed methods research, Los Angeles, CA: Sage Publications.

Dalby, S. 1994: "Gender and critical geopolitics; reading security discourse in the new world disorder", Environment and Planning D: Society and Space 12(5), 595-612.

D'Amore, L. 2009: "Peace through tourism: the birthing of a new socio-economic order", Journal of Business Ethics 89(4): 559-568.

Davidson, J., Milligan, C. 2004: "Embodying emotion, sensing space: introducing emotional geographies", Social and Cultural Geography 5: 523-532.

DCAF (Geneva Centre for Democratic Control of Armed Forces). 2002: Intelligence services and democracy, Working Paper Series No.13. Geneva.

De Bont, R. 2017: “A world laboratory: framing the Albert National Park”, Environmental History 22(3): 404-432.

De Merode E., Smith K. H., Homewood K. 2007: “The impact of armed conflict on protected area efficacy in Central Africa”, Biol Lett 3: 299-301.

Denike, M. 2015: "Scapegoat racism and the sacrificial politics of 'security", Journal of International Political Theory 11(1): 111-127.

Derrida, J. 1973: Speech and phenomena: and other essays on Husserl's theory of signs, Allison Evanston: Northwestern University Press.

Derrida, J. 2001: "What is a "relevant" translation?", Critical Inquiry 27: 174-200.

De Vries, L.A. 2012: Facing frontiers : everyday practice of state-building in South Sudan, PhD thesis, Wageningen University.

De Walt, K.M., De Walt, B.R. 2002: Participant observation: a guide for fieldworkers, Oxford: Rowman Altamira. 
Dian Fossey Gorilla Fund International. 2018: "Mountain gorilla population still increasing: Census results released”, https://gorillafund.org/mountain-gorilla-population-still-increasingcensus-results-released/, accessed 23-11-2020.

Dian Fossey Fund International. 2019: https://gorillafund.org/world-ranger-day/, accessed 9-82019.

Diphoorn, T. 2012: "The "emotionality of participation": various modes of participation in ethnographic fieldwork on private policing in South Africa", Journal of Contemporary Ethnography 42(2): 201-225.

Doevenspeck, M. 2011: "Constructing the border from below: narratives from the CongoleseRwandan state boundary", Political Geography 30: 129-142.

Doyle, M. W. 2005: "Three pillars of the liberal peace", The American Political Science Review 99(3): 463-466.

Driver, F. 2001: Geography militant: cultures of exploration and empire, Malden, MA: Blackwell.

Duffy, R. 2006: "The potential and pitfalls of global environmental governance: The politics of transfrontier conservation areas in Southern Africa”, Political Geography 25(1): 89-112.

Duffy, R. 2014: "Waging a war to save biodiversity: The rise of militarised conservation", International Affairs 4: 819-384.

Duffy, R. 2015: "Nature-based tourism and neoliberalism: concealing contradictions", Tourism Geographies: An International Journal of Tourism Space, Place and Environment 17(4): 529-543.

Duffy, R. 2016: "War, by conservation”, Geoforum 69: 238-248.

East, R. 1999: African antelope database 1998, IUCN/SSC Antelope Specialist Group, Switzerland and Cambridge: IUCN Gland.

Epstein, H. C. 2017: Another fine mess: America, Uganda and the war on terror, New York: Columbia Global Reports.

Fairhead, J. 2005: "Transnational dimensions to environmental resource dynamics: Modes of governance and local resource management in eastern DRC”, In: Q. Gausset, M.A. Whyte, and T. Birch-Thomsen, Sweden: Beyond territory and scarcity: Exploring conflicts over natural resource management, Nordiska Afrikainstitutet, pp. 195-215.

Fairhead, J., Leach, M., Scoones, I. 2012: “Green grabbing: a new appropriation of nature?”, Journal of Peasant Studies 39 (2): 237-261.

Fletcher, R. 2011: “'The only risk is wanting to stay': mediating risk in Colombian tourism development", Recreation and Society in Africa, Asia and Latin America 1(2): 7-30.

Fletcher, R., Büscher, B., Massarella, K., Koot, S. 2020: "Ecotourism and conservation under COVID-19 and beyond", ATLAS Tourism and Leisure Review 2: 42-50.

Fujii, L. A. 2009: Killing neighbors: webs of violence in Rwanda, London and Ithaca: Cornell University Press.

Fujii, L. A. 2010: "Shades of truth and lies: interpreting testimonies of war and violence", Journal of Peace Research 47(2): 231-241.

Fujii, L. A. 2014: "Five stories of accidental R ethnography: turning unplanned moments in the field into data", Qualitative Research 12: 528-539.

Furedi, F. 1997: The culture of fear: risk-taking and the morality of low expectation, London and New York: Continuum International Publishing Group. 
Gachago, D., Ivala, E., Chigona, A., Condy, J., 2015: “Owning your emotions or sentimental navel-gazing: digital storytelling with South African pre-service student educators", Cultural Science Journal 8(2): 22-42.

Galtung, J. 1969: "Violence, peace and peace research", Journal of Peace Research 6(3): 167-191.

Galtung, J. 1996: Peace by peaceful means: Peace and conflict, development and civilization, London: Sage Publications.

Galtung, J. 1990: “Cultural violence”, Journal of Peace Research 27: 291-305.

Gaynor, K. M., Brown, J. S., Middleton, A. D., Power, Brashares, J. S. 2019: "Landscapes of fear: spatial patterns of risk perception and response", Trends in Ecology $\mathcal{E}$ Evolution 34(4): 355-368.

Girard, R. 1979: Violence and the sacred, Baltimore, MD: Johns Hopkins University Press.

Global Witness. 2009: Natural resource exploitation and human rights in the Democratic Republic of Congo, 1993 to 2003, https://www.globalwitness.org/en/archive/natural-resourceexploitation-and-human-rights-drc-1993-2003/, accessed 16-6-2020.

Global Witness. 2018: Total systems failure. Exposing the global secrecy destroying forests in the Democratic Republic of the Congo, Report, London, https://www.globalwitness.org/en/campaigns/forests/total-systems-failure/, 3-3-2021.

González-Hidalgo, M., Zografos, C. 2020: "Emotions, power, and environmental conflict: expanding the "emotional turn" in political ecology", Progress in Human Geography 44(2): 235-55.

Goodwin, H., Santilli, R. 2009: "Community-based tourism: a success?" ICRT Occasional Paper 11: $1-37$.

Gourevitch, P. 1998: We wish to inform you that tomorrow we will be killed with our families: stories from Rwanda, New York: Farrar, Straus and Giroux.

Gray, E., Jackson, J., Farrall, S. 2011: "Feelings and functions in the fear of crime: applying a new approach to victimisation insecurity”, British Journal of Criminology 51 (1): 75-94.

Greater Virunga Transboundary Collaboration. 2005: Ministerial Tripartite Declaration of Goma.

Greater Virunga Transboundary Collaboration. 2006 [2015]: Ten Year Strategic Plan, Rubavu.

Green, L. 2004: “Living in a state of fear", Cultural Anthropology 9(2): 227-256.

Gregory, D., Johnston, R., Pratt, G., Watts, M., Whatmore, S. 2009: The dictionary of human geography, 5th edition. London: Wiley-Blackwell Publishing.

Gregory, D., Pred, A. 2007: Violent geographies: Fear, terror and political violence, New York: Routledge.

Grosspietsch, M. 2006: "Perceived and projected image of Rwanda: visitor and international tour operator perspectives”, Tourism Management 27(2): 225-234.

Haan, N. 1977: Coping and defending. Processes of self-environment organization, New York and London: Academic Press.

Haessly, J. 2010: “Tourism and a culture of peace”, In: O. Moufakkir and I. Kelly: Tourism, progress, and peace, Cambridge, MA: CABI Publisher, pp.1-16.

Hall, M. C., Dallen, T. J., Duval, T. D. 2004: "Security and tourism”, Journal of Travel and Tourism Marketing 15(2-3): 1-18. 
Haldrup, M., Koefoed, L., Simonson, K. 2009: "Practising fear: encountering O/other bodies", In: R. Pain and S.J. Smith: Fear: critical geopolitics and everyday life, Hampshire: Ashgate Publishing, pp. 117-128.

Hanks, J. 2003: "Transfrontier Conservation Areas (TFCAs) in Southern Africa: their role in conserving biodiversity, socioeconomic development and promoting a culture of peace", Journal of Sustainable Forestry 17(1-2): 127-148.

Hardin, G. 1968: "The tragedy of the commons”, Science 162(3859): 1243-1248.

Harding, A. 2020: "The loyalty oath keeping Rwandans abroad in check", https://www.bbc.com/news/world-africa-54801979, accessed 5-2-2021.

Harré , R. 1986: The social construction of emotions, Oxford and New York: Basil Blackwell.

Haq, M. 1999: Reflections on human development, New York and New Delhi: Oxford University Press.

Hickey, J. R., Basabose, A., Gilardi, K. V., Greer, D., Nampindo, S., Robbins, M. M., Stoinski, T. S. 2018: "Gorilla beringei ssp. beringei", IUCN Red List of Threatened Species, IUCN.

Hilborn R., Arcese P., Borner M., Hando J., Hopcraft G., Loibooki M., Mduma S., Sinclair, A.R. 2006: "Effective enforcement in a conservation area", Science 1266 (5803): 1266.

Hochleithner, S. 2017: "Beyond contesting limits: Land, access, and resistance at the Virunga National Park", Conservation $\mathcal{E}$ Society 15(1): 100-110.

Hochschild, A. R. 1983: The managed heart - commercialization of human feeling, Berkeley and Los Angeles: University of California Press.

Holden, A. 2008: Environment and tourism, London and New York: Routledge.

Homer. [8BC] 1999: Iliad, 2nd volume, revised and translated by William F. Wyatt, Harvard University Press.

Honey, M., Gilpin, R. 2009: Special report on 'Tourism in the developing world: promoting peace and reducing poverty', Washington DC: United State Institute of Peace.

Hsaio, E.C. 2018: Protecting places for nature, people, and peace : a critical socio-legal review of transboundary conservation areas, $\mathrm{PhD}$ dissertation, University of British Columbia.

Human Rights Watch. 1999: Uganda. Human Rights Developments, https://www.hrw.org/legacy/wr2k/Africa-12.htm, accessed 20-11-2020.

Human Rights Watch. 2005: https://www.hrw.org/reports/2005/drc0505/12.htm, accessed 15-12-2019.

Human Rights Watch. 2019: https://www.hrw.org/world-report/2019/countrychapters/democratic-republic-congo, accessed 15-12-2019.

Hume, M. 2007: "Unpicking the threads: Emotion as central to the theory and practice of researching violence”, Women's Studies International Forum (30):147-157.

Humle, T., Duffy, R., Roberts, D.L., Sandbrook, C., John, F.A.V, Smith, R.J. 2014: “Biology's drones: Undermined by fear", Science 344: 1351.

Humphrey, C. 2013 : "Fear as a property and an entitlement", Social Anthropology 21(3): 285 304.

Huysmans, J. 2006: The politics of insecurity: fear, migration and asylum in the EU, London: Routledge. 
Hyndman, J. 2007: "The securitization of fear in post-tsunami Sri Lanka", Annals of the Association of American Geographers 97(2): 361-372.

Ingelaere, B. 2016: Inside Rwanda's gacaca courts: seeking justice after genocide, Madison: University of Wisconsin Press.

Iñiguez de Heredia, M. 2017: Everyday resistance, peacebuilding and state-making. Insights from 'Africa's World War', Manchester: Manchester University Press.

Institute for Economics and Peace (IEP). 2017: Global Peace Index 2017, IEP Report 48.

International Alert. 2010: "The role of the exploitation of natural resources in fuelling and prolonging crises in the Eastern DRC”, https://www.internationalalert.org/sites/default/files/publications/Natural_Resources_Jan_10.pdf, accessed 3-3-2021.

International Crisis Group. 2020: "Averting Proxy Wars in the Eastern DR Congo and Great Lakes”, https://www.crisisgroup.org/africa/central-africa/democratic-republic-congo/b150averting-proxy-wars-eastern-dr-congo-and-great-lakes, accessed 27-11-2020.

International Gorilla Conservation Program (IGCP). 2010a: http://www.igcp.org/wpcontent/uploads/VirungaMountainGorillaCensus2010_final-report.pdf, accessed 10-112017.

International Institute of Peace through Tourism (IIPT). 2017: http://www.iipt.org/AboutUs.html, accessed 25/10/2017.

International Union for the Conservation of Nature (IUCN). 2016: "Community based approaches to sustainable use: reality or myth?”, IUCN WCC Knowledge Café, Honolulu, Hawai'i.

International Union for the Conservation of Nature (IUCN). 2020: https://www.iucn.org/theme/protected-areas/about/protected-areas-categories/category-iinational-park, accessed 10-5-2020.

Jenkins, M. 2008: "Who murdered the Virunga Gorillas?", http://ngm.nationalgeographic.com/2008/07/virunga/jenkins-text, accessed 18/8/2017.

Johnson, A., Zalik, A., Mollett, S., Sultana, F., Havice, E., Osborne, T., Valdivia, G., Lu, F, Billo, E. 2020: "Extraction, entanglements, and (im)materialities: reflections on the methods and methodologies of natural resource industries fieldwork", Environment and Planning E: Nature and Space, (ahead-of-print).

Johnson, E., Chronister, J. 2010: "Psychosocial adjustment and coping in the post-conflict setting”, in: E. Martz (ed.): Trauma rehabilitation after war and conflict, New York: Springer, pp. 256-290.

Joras, U., Palme, K., Alluri, R., Leicher, M. 2011: Tourismus, Frieden und Konflikt: Effekte, Strategien und das privatwirtschaftliche Engagement in der Friedensförderung, Cologne: Deutsche Stiftung Friedensforschung.

Kalulu, R., Tushabe, E., Nsabimana, E. 2016: "Local community attitude and perceptions towards tourism conservation policies in Rwanda case of Volcanoes National Park", Asian Journal of Science and Technology 7(11): 3811-3819.

Kankwenda, M. J. 2005: L'économie politique de la prédation au Congo Kinshasa: Des origines à nous jours 1885-2003, Kinshasa, Montréal and Washington: Icredes. 
Kanyamibwa, S. 1998: "Impact of war on conservation: Rwandan environment and wildlife in agony", Biodiversity and conservation 7(11): 1399-1406.

Kelly, I. 2006: "Introduction to peace through tourism”, IIPT Occasional Paper No.1, Global Educators Network.

Kelly, A. B. 2015: „The crumbling fortress: territory, access, and subjectivity production in Waza National Park, Northern Cameroon“, Antipode 47(3): 730-747.

Kekes, J. 2013: "Fear and reason”, Philosophy 88(346): 555-574.

Kivu Security Tracker. 2020: "Foreign incursion and clashes", https://kivusecurity.nyc3.digitaloceanspaces.com/reports/34/KST-monthly-Report-n30April20.pdf, accessed 3-3-2021.

Kivu Security Tracker. 2020: https://kivusecurity.org/, accessed 15-11-2020.

Kivu Security Tracker. 2021: The landscape of armed groups in Eastern Congo, Report, February 2021.

Kook, R.B., Harel-Shalev, A. 2020: "Patriarchal norms, practices and changing gendered power relations - narratives of Ultra-Orthodox women in Israel”, Gender, Place $\mathbb{E}$ Culture (ahead-of print): 1-25.

Koot, S. 2016: "Perpetuating power through autoethnography: my research unawareness and memories of paternalism among the indigenous Hai//om in Namibia”, Critical Arts 30(6): 840-854.

Koskela, H. 1997: “‘ Bold walk and breakings': women's spatial confidence versus fear of violence", Gender, Place Eु Culture 4: 301-19.

Kovats-Bernat, J.C. 2002: "Negotiating dangerous fields: pragmatic strategies for fieldwork amid violence and terror", American Anthropologist (104)1: 208-222.

Kujirakwinja, D., P. Shamavu, A. Hammill, A. Crawford, A. Bamba, Plumptre, A.J. 2010: Healing the rift: Peacebuilding in and around the protected areas in the Democratic Republic of Congo's Albertine Rift. Unpublished report to USAID.

Kumar, Ranjit. 2011: Research methodology, London: Sage.

Kwapis, J.L., Wood, M.A. 2014: "Epigenetic mechanisms in fear conditioning: implications for treating post-traumatic stress disorder", Trends in Neurosciences 37(12): 706-720.

Laurie, E.W. and Shaw, I.G.R. 2018: "Violent conditions: the injustices of being", Political Geography 65: 8-16.

Lazarus, R. S., Folkman, S. 1984: Stress, appraisal, and coping, New York: Springer.

Le Billon, P. 2001: "The political ecology of war: natural resources and armed conflicts", Political Geography 20(5): 561-584.

Lee, R. M. 1995: Dangerous fieldwork, Thousand Oaks, CA, London, New Delhi: Sage Publications.

Le Guen, O. 2009: “The ethnography of emotions: A field worker's guide”, in: A. Majid: Field manual volume 12, Nijmegen: Max Planck Institute for Psycholinguistics, pp. 31-34.

Lemarchand, R. 2012: The dynamics of violence in Central Africa, Pennsylvania: University of Pennsylvania Press.

Levebre, H. [1974] 1991: The production of space, translated by Donald Nicholson-Smith, Oxford: Basil Blackwell. 
Levy, S. E. and Hawkins, D. E. 2010: "Peace through tourism: Commerce-based principles and practices", Journal of Business Ethics 89: 569-585.

Liebal, K., Lubrich, O., Stodulka, T. 2019: Emotionen im Feld. Gespräche zur Ethnografie, Primatografie und Reiseliteratur, Bielefeld: Transcript Verlag.

Lisle, D. 2016: Holidays in the danger zone: entanglements of war and tourism, Minneapolis: University of Minnesota Press.

Litvin, S. 1998: “Tourism: The world's peace industry?", Journal of Travel Research 37(1): 63-66.

Lo Bue, V., Kim, E., Delgado, M. 2019: "Fear in development”, in: V. LoBue, K. Pérez-Edgar, K. A. Buss: Handbook of emotional development, New York: Springer, pp. 257-282.

Lombard, L. 2016: "Threat economies and armed conservation in northeastern Central African Republic”, Geoforum 69: 218-226.

Lombard, L., Tubiana, J. 2020: "Bringing the tracker guards back in: Arms-carrying markets and quests for status in conservation at war”, Political Geography 79: 1-11.

Longman, T. 2004: "Placing genocide in context: research priorities for the Rwandan genocide", Journal of Genocide Research 6(1): 29-46.

Lopez, E., Awawi, A., Salcedo-Albarán, E. 2017: "Trafficking of coltan in the Democratic Republic of the Congo", The Global Observatory of Transnational Criminal Networks, Research Paper No.6.

Lunstrum, E. 2014: "Green militarization: anti-poaching efforts and the spatial contours of Kruger National Park", Annals of the Association of American Geographers 4(104): 816-832.

Lutz, C. A., Abu-Lughod, L. 1990: Language and the politics of emotion, Cambridge: Cambridge University Press.

Maekawa, M., Lanjouw, A., Rutagarama, E., Sharp, D. 2013: "Mountain gorilla tourism generating wealth and peace in post-conflict Rwanda”, Natural Resources Forum 37.

Mamdani, M. 1996: Citizen and subject: contemporary Africa and the legacy of late colonialism. Princeton, NJ: Princeton University Press.

Mamdani, M. 2001: When victims become killers: colonialism, nativism, and the genocide in Rwanda, Princeton: Princeton University.

Marchais, G., Bazuzi, P., Amani Lameke, A. 2020: "'The data is gold, and we are the golddiggers': whiteness, race and contemporary academic research in eastern DRC”, Critical African Studies 12(3): 372-394.

Maréchal, G. 2010: “Autoethnography”, in: A.J. Mills, G. Durepos, E. Wiebe: Encyclopedia of case study research, Thousand Oaks: Sage, pp.44-48.

Marijnen, E. 2017: “The 'green militarisation' of development aid: the European Commission and the Virunga National Park, DR Congo", Third World Quarterly 38(7): 1566-1582.

Marijnen, E. 2018: "Public authority and conservation in areas of armed conflict: Virunga National Park as a 'state within a state' in Eastern Congo”, Development and Change 49(3): 790-814.

Marijnen, E., Verweijen, J. 2016: "Selling green militarization: The discursive (re)production of militarized conservation in the Virunga National Park, Democratic Republic of the Congo", Geoforum 75: 274-285. 
Marijnen, E., Verweijen, J. 2020: "Pluralising political forests : unpacking 'the state' by tracing Virunga's charcoal chain”, Antipode 52(4): 996-1017.

Marijnen, E., de Vries, L., Duffy, R. 2021: “Conservation in violent environments: Introduction to a special issue on the political ecology of conservation amidst violent conflict", Political Geography 87: 102253.

Martz, E. 2010: Trauma rehabilitation after war and conflict, New York: Springer.

Massé, F. 2017: "Researching in/on/with the frontline of anti-poaching: research proximity and the importance of getting close to those of whom we are critical”, unpublished paper, BIOSEC workshop: Conservation in conflict and militarised areas political ecology research towards violence and conflict, The University of Sheffield, Politics Department, Mohan Library, 7-8 November 2017.

Massé, F. 2018: "Topographies of security and the multiple spatialities of (conservation) T power: verticality, surveillance, and space-time compression in the bush”, Political Geography 67: $56-64$.

Mathys, G. 2017: "Bringing history back in: past, present, and conflict in Rwanda and the Eastern Democratic Republic of Congo", Journal of African History 58(3): 465-487.

Matose, F., 2014: "Nature, villagers, and the state: resistance politics from protected areas in Zimbabwe”, in: B. Büscher, W. Dressler, R. Fletcher: Nature ${ }^{T M}$ Inc.: The new frontiers of environmental conservation, Tucson: The University of Arizona Press, pp. 66-83.

Max Planck Gesellschaft 2018: "Number of wild mountain gorillas exceeds 1000", https://www.mpg.de/12057180/number-of-wild-mountain-gorillas-exceeds-1-0001, accessed 23-11-2020.

Mbaiwa, J. E. 2005: "Enclave tourism and its socio-economic impacts in the Okavango Delta, Botswana”, Tourism Management 26: 157-172.

Meadows, D.H, Meadows, D.L., Randers, J., Behrens III, W.W. 1972: The limits to growth, New York: Universe Books.

Mearns, K. 2012: "Community-based tourism and peace parks benefit local communities through conservation in Southern Africa", Acta Academica 44: 70-87.

Mehta, A. 1999: "Embodied discourse: On gender and fear of violence", Gender, Place $\mathbb{E}$ Culture 6(1): 67-84.

Meloy, J.R. 2006: "Empirical basis and forensic application of affective and predatory violence", Australian Journal of Psychiatry 40: 539-547.

Mertens, C., Pardy, M. 2016: “'Sexurity' and its effects in eastern Democratic Republic of Congo", Third World Quarterly 38(4): 956-979.

Miller, K.E., Rasmussen, A. 2010: "War exposure, daily stressors, and mental health in conflict and post-conflict settings: Bridging the divide between trauma-focused and psychosocial frameworks", Social Science and Medicine 70: 7-16.

Mills, C. 2007: "White ignorance", in: S.Sullivan and N.Tuana: Race and epistemologies of ignorance, Albany: State University of New York Press, pp.13-38.

Milner-Gulland, E.J., Mace, R. 1998: Conservation of biological resources, Oxford: Blackwell Science Ltd. 
Minarchek, M. 2020: "Creating environmental subjects: Conservation as counter-insurgency in Aceh, Indonesia, 1925-1940”, Political Geography 81: 102189.

Mollica, R.F. 2000: "Invisible wounds", Scientific American 282(6): 54-57.

Moufakkir, O., Kelly, I. 2010: Tourism, progress, and peace, Cambridge, MA: CABI Publisher.

Mountz, A. 2009: "The Other”, in: C.Gallaher, C.T. Dahlman, M. Gilmartin, A. Mountz, P. Shirlow: Key concepts in Human Geography: key concepts in Political Geography, London and Los Angeles: Sage, pp. 328-338.

Munanura, I. E., Backman, K. F., Hallo, J. C., Powell R. B. 2016: "Perceptions of tourism revenue sharing impacts on Volcanoes National Park, Rwanda: a Sustainable Livelihoods framework", Journal of Sustainable Tourism 24(12): 1709-1726.

Muresherwa, G., Amony, I., Iwu, G.C.,Dube, C.N. 2020: "The impact of mountain gorilla tourism: a residents' perspective”, African Journal of Hospitality, Tourism and Leisure 9(2): 1-18.

Mushonga, T., Matose, F. 2020: "Dimensions and corollaries of violence in Zimbabwe's protected forests", Geoforum 117: 216-224.

Mwambari, D. 2019: "Local positionality in the production of knowledge in Northern Uganda", International Journal of Qualitative Methods 18: 1-12.

Nassani, A. A., Zaman, K., Aldakhil, A. M, Qazi A. M. 2017: "War economy and pleasure: assessing the effects of military expenditure on tourism growth”, Qual Quant 51:1733-1754.

National Geographic. 2016: https://www.nationalgeographic.com/magazine/2016/07/virunganational-parks-africa-congo-rangers/, accessed 20-2-2020.

Neumann, R. 1998: Imposing wilderness: struggles of livelihood and nature preservation in Africa, Berkeley, California, USA: University of California Press.

Neumann, R. 2004: "Moral and discursive geographies in the war for biodiversity in Africa", Political Geography 23: 813-837.

Neumayer, E. 2004: "The impact of political violence on tourism", Journal of Conflict Resolution 48(2): 259-281.

Newbury, C. 1998: "Ethnicity and the politics of history in Rwanda", Africa Today 45(1): 7-24.

Nielsen, H., Spenceley, A. 2010: "The success of tourism in Rwanda. Gorillas and more", Background Paper for the African Success Stories Study, Washington D.C., World Bank.

Nightingale, A.J. 2013: "Fishing for nature: The politics of subjectivity and emotion in Scottish inshore fisheries management", Environment and Planning A 45(10): 2362-2378.

Nixon, R. 2011: Slow violence and the environmentalism of the poor, Cambridge, MA: Harvard University Press.

Nkurunungi, J. B., Ampumuza, C. 2013: Assessment of the impacts of mountain gorilla habituation and tourism on their sustainable conservation. Consultancy Report for the International Gorilla Conservation Programme.

Nordstrom, C. 1997: A different kind of war story, Philadelphia, PA: University of Pennsylvania Press.

Nunkoo, R., Ramkissoon, H. 2016: “Stakeholders' views of enclave tourism: a grounded theory approach", Journal of Hospitality and Tourism Research 40(5): 557-588.

Nyantakyi-Frimpong, H. 2021: "How identity enriches and complicates the research process: reflections from political ecology fieldwork", The Professional Geographer 73(1): 38-47. 
Nymeth Brehm, H., Fox, N. 2017: "Narrating genocide: time, memory and blame”, Sociological Forum 32(1): 116-137.

Nzabandora, N.M.J. 2006: "Plantations europeennes, parc national et mouvements des populations dans le territoire de Rutshuru au Nord-Kivu (1920-1996)" ['European Plantations, a National Park and Population Movements in the Territory of Rutshuru in NorthKivu (1920-1996)'], Goma: Pole Institute, https://www.poleinstitute.org/sites/default/files/regards16.pdf, accessed 18-8-2019.

Nzongola, G. 2002: The Congo: from Leopold to Kabila. A people's history, London: Zed Books.

Office of the High Commissioner for Human Rights (OHCHR). 2020: Report on violations of human rights and international humanitarian law by the Allied Democratic Forces armed group and by members of the defense and security forces in Beni territory, North Kivu provinceand Irumu and Mambasa territories, Ituri province, between 1 January 2019 and 31 January 2020.

Olsoy, P.J., Forbey, J.S., Rachlow, J.L, Nobler, J.D., Glenn, N.F., Shipley, L.A. 2015: "Fearscapes: Mapping functional properties of cover for prey with terrestrial LiDAR", BioScience 65(1): 74-80.

Okosun, T.Y., Kibiswa, N. 2013: "Human rights violations and genocide in the Democratic Republic of the Congo”, Contemporary Justice Review 16(4): 482-493.

Ortner, S. 2006: Anthropology and social theory: culture, power, and the acting subject, New York: Duke University Press.

Ó Tuathail, G. 1996: Critical geopolitics: The politics of writing global space, Minneapolis: University of Minnesota Press.

Ó Tuathail, G. 2010: "Localizing geopolitics: disaggregating violence and return in conflict regions”, Political Geography 29(5): 256-265.

Pain, R. 2009: "Globalised fear? Towards an emotional geopolitics”, Progress in Human Geography 33(4): 466-486.

Pain, R., Smith, S. J. 2008: Fear: critical geopolitics and everyday life, Hampshire: Ashgate Publishing.

Parpart, J.L., Parashwar, S. 2019: Rethinking silence, voice and agency in contested gendered terrains, Milton Park and New York: Routledge.

Peet, R., Watts, M. 1996: Liberation ecologies: environment, development, social movements, London and New York: Routledge.

Peluso, N.L., Watts, M. 2001: Violent environments, Ithaca, NY: Cornell University Press.

Pemunta, N.V. 2019: "Fortress conservation, wildlife legislation and the Baka Pygmies of southeast Cameroon", GeoJournal 84: 1035-1055.

Pennaz, K. A., Ahmadou, M., Moritz, M., Scholte, P. 2018: "Not seeing the cattle for the elephants: The implications of discursive linkages between Boko Haram and wildlife poaching in Waza National Park, Cameroon”, Conservation and Society 16(2): 125.

Pennisi, A., Falzone, A. 2020: The extended theory of cognitive creativity. Perspectives in pragmatics, philosophy and psychology, Switzerland: Springer.

Perreault, T., Bridge, G., McCarthy, J. 2015: The Routledge handbook of political ecology, New York and London: Routledge. 
Pizam, A. 1996: "Does tourism promote peace and understanding between unfriendly nations?", in: A. Pizam and Y. Mansfeld: Tourism, crime, and international security issues, West Sussex: John Wiley \& Sons.

Poudel, D.P. 2019: „Migration, forest management and traditional institutions: Acceptance of and resistance to community forestry models in Nepal“, Geoforum 106: 275-286.

Prunier, G. 2011: Africa's world war: Congo, the Rwandan genocide, and the making of a continental catastrophe, Oxford: Oxford University Press.

Purdeková, A., Reyntjens, F., Wilén, N. 2018: "Militarisation of governance after conflict: beyond the rebel-to-ruler frame - the case of Rwanda", Third World Quarterly 39(1): 158-174.

Refisch, J., Jenson, J. 2016: "Transboundary collaboration in the Greater Virunga Landscape: From gorilla conservation to conflict-sensitive transboundary landscape management", in: C. Bruch, C. Muffett, S.S. Nichols: Governance, natural resources, and post-conflict peacebuilding, London: Earthscan, pp. 825-841.

Reuss, A. 2020: "Forever vanguards of the revolution: the Uganda People's Defence Forces' liberation legacy, 30 years on", Journal of Eastern African Studies 14(6): 250-269.

Reuters. 2012: https://www.reuters.com/article/us-congo-democratic-rwandaminerals/exclusive-mineral-traders-in-rwanda-helping-fund-congo-rebels-u-n-panelidUSBRE89F1M320121016, accessed 28-4-2020.

Reuters. 2017: https://www.reuters.com/article/us-uganda-war/uganda-holds-dozens-of-fleeingm23-rebels-after-congo-clashes-idUSKBN16227T, accessed 23-12-2020.

Reuters. 2018: "Congo says soldiers killed in border skirmish with Rwanda”, https://www.reuters.com/article/us-congo-rwanda-violence-idUSKCN1FZ26H, accessed 27. 11-2020.

Reuters. 2019: "Uganda accuses Rwanda of imposing trade embargo", https://www.reuters.com/article/us-uganda-rwanda-idUSKCN1QU2IC, accessed 27-11. 2020.

Reuters. 2020: "Eastern Congo militia ambush kills 16, including 12 park rangers", https://www.reuters.com/article/uk-congo-violence/eastern-congo-militia-ambush-kills-16including-12-park-rangers-idUKKCN2262BA, accessed 27-11-2020.

Reyntjens, F. 2013: Political governance in post-genocide Rwanda, Cambridge: Cambridge University Press.

Ricardo, D. 1817 [1992]: The principles of political economy and taxation, London: Rutland.

Richards, P. 2005: No peace, no war: An anthropology of contemporary armed conflicts, Athens, $\mathrm{OH}$ : Ohio University Press.

Robbins, M. 2014: Gorilla Journal 48, June, Berggorilla \& Regenwald Direkthilfe, www.berggorilla.org/fileadmin/gorilla-journal/gorillajournal-48-english.pdf, accessed 12-22020.

Robin, A. 2004: Fear: the history of a political idea, Oxford: Oxford University Press.

Rosaldo, M. 1980: "The use and abuse of anthropology: Reflections on feminism and crosscultural understanding", Signs (5): 389-417.

Rosaldo, R. 1989: Culture and truth: The remaking of social analysis, London: Taylor and Francis. 
Rothschild, Z. K., Landau, M. J., Sullivan, D., Keefer, L. A. 2012: "A dual-motive model of scapegoating: Ddsplacing blame to reduce guilt or increase control”, Journal of Personality and Social Psychology 102(6): 1148-1163.

Ruzibiza, A. J. 2005: Rwanda: L'histoire secrète, Paris: Editions du Panama.

Rwanda Development Board (RDB). 2018: https://rdb.rw/rwanda-development-board-receivesland-donation-from-africa-wildlife-foundation-increasing-mountain-gorilla-habitat-involcanoes-national-park/, accessed 30-12-2020.

Rwanda Development Board (RDB). 2020: https://rdb.rw/rwanda-wins-emerging-destinationaward-as-top-30-place-to-travel-in-2020-and-top-overall-in-africa/, accessed 17-1-2020.

Sabuhoro, E., Wright, B.A., Powell, R.B. 2020: "Perceptions and behaviors of indigenous populations regarding illegal use of protected area resources in East Africa's mountain gorilla landscape", Environmental Management 65: 410-419.

Sandbrook, C. 2010: "Putting leakage in its place: the significance of retained tourism revenue in the local context in rural Uganda”, Journal of International Development 22(1): 124-136.

Sandwith, T., Shine, C., Hamilton, L. S., Sheppard, D. 2001: Transboundary Protected Areas for peace and co-operation, Best Practice Protected Area Guideline Series No. 7. Gland: IUCN.

Scheper-Hughes, N. 1992: Death without weeping: The violence of everyday life in Brazil, Berkeley: University of California Press.

Scheper-Hughes, N. 1995: "The primacy of the ethical: propositions for a militant anthropology”, Current Anthropology 36(3): 409-440.

Scheyvens, R., Hughes, E. 2019: "Can tourism help to 'end poverty in all its forms everywhere'? The challenge of tourism addressing SDG1”, Journal of Sustainable Tourism 27(7): 1061-1079.

Searle, J. 1979: Expression and meaning: Studies in the theory of speech acts, Cambridge: Cambridge University Press.

Selye, H. 1976: The stress of life, New York: McGraw-Hill.

Sharp, J. 2009: "Geography and gender: what belongs to feminist geography? Emotion, power and change", Progress in Human Geography 33(1): 74-80.

Shiva, V. 1990: The violence of the green revolution, Chicago: The University of Chicago Press.

Siever, L.J. 2008: "Neurobiology of aggression and violence", American Journal of Psychiatry 165(4): 429-442.

Sönmez, S. F. 1998: "Tourism, terrorism, and political instability", Annals of Tourism Research 25(2): 416-456.

Sparke, M. 2007: "Geopolitical fears, geoeconomic hopes and the responsibility of geography", Annals of the Association of American Geographers 97(2): 338-349.

Spenceley, A., Habyalimana, S., Tusabe, R., Mariza, D. 2010: "Benefits to the poor from gorilla tourism in Rwanda”, Development Southern Africa 27 (5): 647-662.

Spencer, J.P., Rurangwa, M. 2012: "Tourism as a route for the economic development of rural areas of Rwanda: Vibrant hope or impossible dreams?" African Journal for Physical, Health Education, Recreation and Dance 18 (4:2): 1023-1042.

Springer, S., Le Billion, P. 2016: "Violence and space: an introduction to the geographies of violence", Political Geography 52: 1-3. 
Stearns, J. 2012: Dancing in the glory of monsters. The collapse of the Congo and the great war of Africa, New York: Public Affairs.

Stearns, J. K. 2013: "Helping Congo help itself: what it will take to end Africa's worst war", Foreign Affairs: 99-112.

Straus, S. 2004: "How many perpetrators were there in the Rwandan Patriotic Front? An estimate", Journal of Genocide Research 6 (1): 85-98.

Strauss, A., Corbin, J. M. 1997: Grounded theory in practice, London: Sage.

Sultana, F. 2015: "Emotional political ecology", in: R.L. Bryant: The international handbook of political ecology, Cheltenham: Edward Elgar, pp.633-645.

Taussig, M. 1992: The nervous system, New York and London: Routledge.

Taussig, M. 1999: Defacement: public secrecy and the labor of the negative, Stanford: Stanford University Press.

Taussig, M. 2009: "What do drawings want?" Culture, Theory and Critique 50(2-3): 263-274.

The New Times. 2012: "Rwanda: DRC soldiers enter Rwanda, two killed in shoot out", https://allafrica.com/stories/201211050032.html, accessed 3-3-2021.

The New Times. 2018: "President Kagame reacts to attack by suspected FDLR and RNC", https://www.newtimes.co.rw/timestv/president-kagame-reacts-attack-suspected-fdlr-and-rnc, accessed 3-3-2021.

The Independent. 1999: https://www.independent.co.uk/news/the-jungle-massacre-touristsraped-and-butchered-in-horrific-act-of-revenge-on-britain-1077923.html, accessed 8-4-2019.

Thomson, S., Ansoms, A.; Murison, J. 2013: Emotional and ethical challenges for field research in Africa - the story behind the findings, Hampshire and New York: Palgrave Macmillan.

Titeca, K., Edmond, P., Marchais, G., Marijnen, E. 2020: "Conservation as a social contract in a violent frontier: The case of (Anti-) poaching in Garamba National Park, eastern DR Congo”, Political Geography 78: 1-9.

Toomey, A.H. 2016: "What happens at the gap between knowledge and practice? Spaces of encounter and misencounter between environmental scientists and local people", Ecology and Society 21(2): 28 .

Tripp, A. M. 2010: Museveni's Uganda: paradoxes of power in a hybrid regime, London: Lynne Rienner Publishers.

Tripp, A.M. 2015: Women and power in postconflict Africa, Cambridge: Cambridge University Press.

Trigger, D., Forsey, M., Meurk, C. 2012: "Revelatory moments in fieldwork" Qualitative Research 12: 513-527.

Trogisch, L. 2021: “Geographies of fear: the everyday (geo)politics of 'green' violence and militarization in the intended transboundary Virunga Conservation Area”, Geoforum 122: 92-102.

Trogisch, L., Fletcher, R. 2020: "Fortress tourism: exploring dynamics of tourism, security and peace around the Virunga transboundary conservation area”, Journal of Sustainable Tourism, (ahead-of-print).

Tuan, Y. 1976: Humanistic Geography, University of Minnesota, Minneapolis.

Tuan, Y. 1979: Landscapes of fear, New York: Pantheon Books. 
Tulumello S. 2015: "From 'spaces of fear' to 'fearscapes': Mapping for re-framing theories about the spatialization of fear in urban space", Space and Culture 18(3): 257-272.

Tulumello, S. 2017: Fear, space and urban planning: a critical perspective from Southern Europe, Switzerland: Springer.

Twinamatsiko, M., Baker, J., Harrison, M., Shirkhorshidi, M., Bitariho, R., Wieland, M., Asuma, S., Milner-Gulland E.J., Franks, P., Roe, D. 2014: Linking conservation, equity and poverty alleviation: understanding profiles and motivations of resource users and local perceptions of governance at Bwindi Impenetrable National Park, Uganda. IIED Research Report, London.

Tyner, J., Inwood, J. 2014: "Violence as fetish: Geography, Marxism, and dialectics", Progress in Human Geography 38(6): 771-784.

Uganda Wildlife Authority (UWA). 2020: https://www.ugandawildlife.org/wildlife-aconservation-2/conservation/communities-a-conservation, accessed 24-2-2020.

Uganda Wildlife Authority. 2018: Corporate annual report, https://www.ugandawildlife.org/download/category/12-annual-reports, accessed 9-8-2019

Uganda Wildlife Authority. 2020: "Poachers arrested for killing gorilla", https://www.ugandawildlife.org/news-events/news/poachers-arrested-for-killing-gorilla, ., accessed 3-3-2021.

UNEP. 2008: Agreement on the conservation of gorillas and their habitat, Action Plan Gorilla beringei beringei, First Meeting of Parties to the Agreement Rome, Italy, 29 November 2008.

UNEP. 2009: From conflict to peacebuilding. The role of natural resources and environment, Kenya: UNEP.

UNEP. 2016: Environmental cooperation for peacebuilding programme, Final Report 2016. Nairobi: UNEP.

UNEP. 2018: Number of Mountain Gorillas Rise in Virunga Massif, https://www.unep.org/news-and-stories/press-release/number-mountain-gorillas-rise-virungamassif, accessed 23/11/2020.

UNEP-MONUSCO-OSESG. 2015: Experts' background report on illegal exploitation and trade in natural resources benefitting organized criminal groups and recommendations on MONUSCO's role in fostering stability and peace in eastern DR Congo. Final report. April $15^{\text {th }} 2015$, accessed under www.unep.org, 12-12-2019.

UNESCO. 2007: "Virunga National Park: 4 more gorillas slaughtered", https://whc.unesco.org/en/news/367, accessed 3-3-2021.

UN Group of Experts 2012: Report S/2012/843. 12 November 2012.

UN Group of Experts 2013: Report S/2013/433. 19 July 2013.

UNHCR. 2000: "The Rwandan Genocide and Its Aftermath", in: The State if the World's Refugees 2000: Fifty Years of Humanitarian Action. UN Report, pp.245-275.

UNHCHR, OHCHR. 2010: Report of the mapping exercise documenting the most serious violations of human rights and international humanitarian law committed within the territory of the Democratic Republic of the Congo between March 1993 and June 2003, http://www.ohchr.org/EN/Countries/AfricaRegion/Pages/RDCProjetMap-ping.aspx, accessed 11-8-2019. 
UN Security Council (UNSC). 2014: Final report of the Group of Experts on the Democratic Republic of the Congo (S/2014/42).

UN Security Council Presidential Statement (S/PRST/2000/20), June 2, 2000.

UN Security Council Resolution 1457 (S/RES/1457/2003), January 24, 2003.

US National Counterterrorism Center (USNCC). 2009: Report on Terrorism. Office of the Director of National Intelligence, April 30, 2010.

UN Security Council (UNSC). 2010. Final report of the Group of Experts on the Democratic Republic of Congo. S/2010/ 596.

UN Security Council (UNSC). 2020: Midterm report of the Group of Experts on the Democratic Republic of the Congo. S/2020/1283.

UNWTO (United Nations World Tourism Organization). 2015: "Towards measuring the economic value of wildlife watching tourism in Africa". Briefing Paper, Madrid: UNWTO.

UNWTO. 2016: "Tourism, a catalyst for peace and development”, http://media.unwto.org/press-release/2016-07-14/tourism-catalyst-peace-and-development, accessed 2/3/2017.

Urry, J. 1994: Consuming places, London: Routledge.

Uvin, P. 1998: Aiding violence: the development enterprise in Rwanda, West Hartford, CT: Kumarian Press.

Van der Duim, R., Ampumuza, C., Ahebwa, W. M. 2014: "Gorilla tourism in Bwindi Impenetrable National Park, Uganda: an actor-network perspective”, Society and Natural Resources 27(6): 588-601.

Van Maanen, J. 2011: Tales of the field: on writing ethnography, Chicago and London: The University of Chicago Press.

Vedder, A., Weber, B. 1990: "The Mountain Gorilla Project," in: A. Kiss: Living with wildlife: wildlife resource management with local participation in Africa. World Bank, Washington, D.C.

Vikanza, P. K. 2011: Aires protégées, espaces disputes et développement au Nord-est de la RD Congo. Louvain: Presses universitaires de Louvain.

Virunga Alliance. 2020: The Virunga rangers, https://virunga.org/alliance/virunga-rangers/, accessed 3-3-2021.

Virunga National Park (PNVi). 2020: https://virunga.org/alliance, accessed 20-2-2020.

Vlassenroot, K. 2006: "War and social research", Civilisations 54: 191-198.

Vlassenroot, K., van Acker, F. 2001: "War as exit from exclusion? The formation of Mayi-Mayi militias in Eastern Congo", Afrika Focus 17(1-2): 51-77.

Vogel, C., Raeymaekers, T. 2016: "Terr(it)or(ies) of peace? The Congolese mining frontier and the fight against 'conflict minerals", Antipode 49(4): 1102-1121.

Volcanoes National Park (VNP). 2018: https://www.volcanoesnationalparkrwanda.com/rwanda/24-years-rwanda-aftergenocide.html, accessed 17-1-2020.

Volcanoes National Park (VNP). 2020: https://www.volcanoesnationalparkrwanda.com/blog/relief-rwanda-cuts-permit-fees.html, accessed 24-2-2020. 
Wang, C.C. 1999: "Photovoice: a participatory action research strategy applied to women's health", Journal of Women's Health 8(2): 185-192.

Watson, P. 1978: War on the mind: The military uses and abuses of psychology, New York: Basic Books Inc.

Weaver, A. 2011: "Tourism and the military: pleasure and the war economy", Annals of Tourism Research 38: 672-689.

Weber, M. 1919 [1992]: Politik als Beruf, Stuttgart: Reclam.

Williamson, J. 1989: "What Washington means by policy reform", in: J. Williamson: Latin American readjustment: how much has happened, Washington: Peterson Institute for International Economics, chapter 2.

Wolmer, W. 2003: Transboundary protected area governance: Tensions and paradoxes, Paper presented at the Transboundary Protected Areas in the Governance Stream of the 5thWorld Parks Congress, 12-13 September, in Durban, South Africa.

World Bank. 2013: https://www.worldbank.org/en/news/feature/2013/12/09/addressingviolence-against-women-in-war-torn-regions, accessed 20-2-2020.

World Health Organization. 2002: World report on violence and health, Geneva.

World Travel and Tourism Council. 2016: Tourism as a driver of peace, Policy Paper.

Wouters, C. 1989: "The sociology of emotions and flight attendants", Theory, Culture $\mathcal{E}$ Society 6(1): 95-123.

Yadav, P. 2020: “Can women benefit from war? Women's agency in conflict and post-conflict societies", Journal of Peace Research, (ahead-of-print).

Ybarra, M. 2016: ''Blind passes' and the production of green security through violence on the Guatemalan border", Geoforum 69: 194-206.

Ybarra, M., Kelly, A. B. 2016: "Introduction to themed issue: green security in protected areas", Geoforum 69: 171-175. 


\section{Summary}

This thesis explores the role of fear in undermining efforts for an intended transboundary protected area (TBPA) straddling the Virunga volcanoes composed of Virunga National Park in the Democratic Republic of the Congo, Volcanoes National Park in Rwanda and Mgahinga Gorilla National Park in Uganda. Since the borderland - commonly referred to as 'the Virungas' - is world-renowned as the last habitat of endangered mountain gorillas as well as for longstanding intra- and interstate warfare, international organizations promoted a TBPA as a key strategy to simultaneously pursue and integrate nature conservation, economic development and regional peace. Based on fifteen months of fieldwork (2015-2018), this study examines the stark contrast between the compelling TBPA imaginary of a boundless nature overturning colonial borders and violent conflicts, on the one hand, and the complex local realities of fear in relation to persistent conflict informing all aspects of everyday life, on the other. Engaging with the diversity of fears points to the coalescence of conservation- and conflict-related threats, affecting how people perceive, perform, react, respond to and (re)create diverse - social, political and economic geographies. To explore these multiple geographies of fear in the Virungas, this thesis starts from the premise of emotional human geography that the creation and organization of natural landscapes are both condition for and consequence of human agency shaping and shaped by emotions.

Chapter I introduces the two puzzling empirical insights that prompted the research objective and questions. Firstly, militarization and segregation of the three National Parks revealed that the vision of transboundary conservation and collaboration was deemed secondary and hardly relevant for the political and economic interests of the three nation states. Secondly, the experience of various fears in people's everyday lives emanating from conservation and conflict dynamics constituted an omnipresent societal condition. These fears also highlighted the starkly different contexts of the Eastern DRC, characterized by an ostensibly absent government and active, open conflicts between various armed groups, and the so-called 'post-conflict' societies under the rule of the authoritarian regimes in Rwanda and Uganda.

In order to study the paradox between peace-promoting TBPA efforts juxtaposed by different forms of 'green' violence (Büscher and Ramutsindela 2016) including 'green' militarisation (Lunstrum 2014), the chapter builds on the political ecology literature for conceptual and theoretical guidance. Throughout the iterative sensemaking process of empirical research and analysis, a conceptualisation of fear gradually developed to encompass the multitude of threats emanating from conservation and conflict dynamics. This focus informed the overarching research question of this thesis: how is fear employed, experienced, and responded to in the conservation-conflict dynamics of the intended Virunga Conservation Area among the DRC, Rwanda and Uganda? 
To address this question, a novel theoretical framework on geographies of fear brings critical geopolitics (Pain and Smith 2008) and emotional geographies (Bondi et al. 2005) into dialogue with critical conservation studies of political ecology. I hold that this framework provides an emotio-spatial hermeneutic to analyse the interdependencies of fear between transnational dynamics and everyday lives. The methodological choices and location-specific adaptations comprise elements of participatory and visual ethnography and developed into a practice of 'emotional ethnography' that is further elaborated on in chapter V. Four sub-questions constitute the structure of the thesis along four chapters following a logic of scaling down the levels of analyses across the transnational, national, local to the individual level.

Chapter II concentrates on the promoted tourism rationale in the official TBPA treaty between the DRC, Rwanda and Uganda to gain a deeper understanding of the transnational conservation-conflict dynamics that undermined the intended TBPA. The findings demonstrate how mountain gorilla tourism was promoted to incentivize collaboration for 'peace', yet led to intensified competition and conflict among the three countries. The analysis further shows how parastatal conservation authorities sell 'feelings of security' by framing their neighbours as threats in order to attract visitors. This finding pointed to a dimension of fear in commercialising security for tourism to conflict-affected regions. Chapter II thus contributes to important debates on tourism as a conservation and development strategy and advocates critical engagement with the dominant conceptualizations of 'peace through tourism' interrogating what 'peace' means in the conservation-conflict context, and for whom.

Chapter III sheds light on the meaning of fear on the national scale by engaging with how park rangers' fears inform their perceptions and performances of conservation practices undermining the intended TBPA. The chapter presents how participatory ethnographic methods enabled a gaze from the perspectives of 'those of whom we are critical' in political ecology studies in order to offering new insights into 'green' violence, militarization and TBPA efforts in conflictaffected borderlands. The analysis of three dominant fear narratives offer insight into rangers' understanding, enactment and sense-making of their militaristic and violent conservation duties. The resultant mental and spatial segregation between the three National Parks exemplified how attempts to foster transboundary collaboration by the Greater Virunga Transboundary Collaboration became gradually undermined. The link between fear discourses and 'green' violence on the parastatal level further illuminates the complex and concealed entanglements between conservation and (geo)political interests on the transnational level. By focusing on park rangers who are national state actors and local community members at the same time, chapter III plays a central role in the thesis' objective to account for the variety of people in their different, sometimes overlapping, roles and identities within the conservation-conflict context.

Chapter IV scales further down to the local level to gain a deeper understanding how fear shapes and is shaped by landscape and non-state actors in their everyday lives with(in) the conservation-conflict dynamics of the Virungas. The chapter provides a comprehensive analysis of a visual ethnography approach concentrating on the photo diaries and narratives of two women living adjacent to PNVi in the DRC in particular. The examination points to the gendered impact of fear from the threatful amalgamation of active violent conflict and militarized conservation that informs women's emotional and behavioral coping responses with conservation 
areas and actors. Chapter IV thus emphasizes one of the major contributions of the thesis arguing for a shift from the analytical focus on 'everyday resistance' against conservation practices and other armed actors to instead examine fear-induced coping strategies to account for compliances and collaborations with landscape and actors.

Chapter $\mathrm{V}$ concentrates on the individual scale to critically reflect on the reciprocal interrelation of fear between me in my role as a white, Western researcher and the people with whom I lived and worked. The chapter illustrates how I merged methods of auto-ethnography, accidental ethnography and emotional reflexivity into a practice I call 'emotional ethnography' for ethical, considerate and empathetic adaptations of my methodology. This methodological innovation enabled key conceptual insights into ostensibly closed parts of societies in the three different conservation-conflict contexts of the DRC, Rwanda and Uganda. Since methodological reflections on and recommendations for fieldwork in conservation-conflict studies of political ecology are scarce, chapter $\mathrm{V}$ seeks to fill this gap by making a case for more forthright engagement with the multiple meanings and functions of fear and other emotions.

Chapter VI provides the discussion and conclusion to the thesis by weaving together the insights of fieldwork and analysis that ultimately inform the scientific, social, political and ecological relevance of the study. The chapter emphasizes three major theoretical contributions of the thesis, namely i) advancing an emotional political ecology through an innovative conceptual framework on fear, ii) offering a novel research approach to violence, and iii) proposing a shift from an analytical focus on 'resistance' to 'coping'. The synthesis underlines that engaging with fear - and other emotions - can open up new lines of inquiry, dialogues and understandings in wider human geography studies. Ultimately, grounding critical discussions of conservation practices in the emotional realities of those who experience and enact these practices in their everyday lives would aid to address the root causes of conservation (in) conflict borderlands. Finally, the chapter advocates to institutionalize emotional awareness and engagement in universities to create a healthier academic culture for researchers and the people who work with us. This can advance critical reflections on the colonial legacies in foreign-led fieldwork practices and contribute to news pathways in the decolonialization of academic practices. 


\section{Funding statement}

The research described in this thesis was financially supported by a doctoral scholarship of the Studienstiftung des Deutschen Volkes, and further the Wageningen School of Social Sciences (WASS) and the chair group of Sociology of Development and Change. Financial support from Wageningen University for printing this thesis is gratefully acknowledged. 
$1-1=-2 \leq$ $\frac{2 x+2}{2+2}=32$

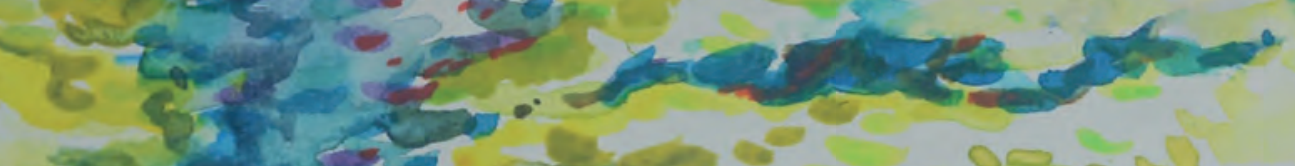
Gory

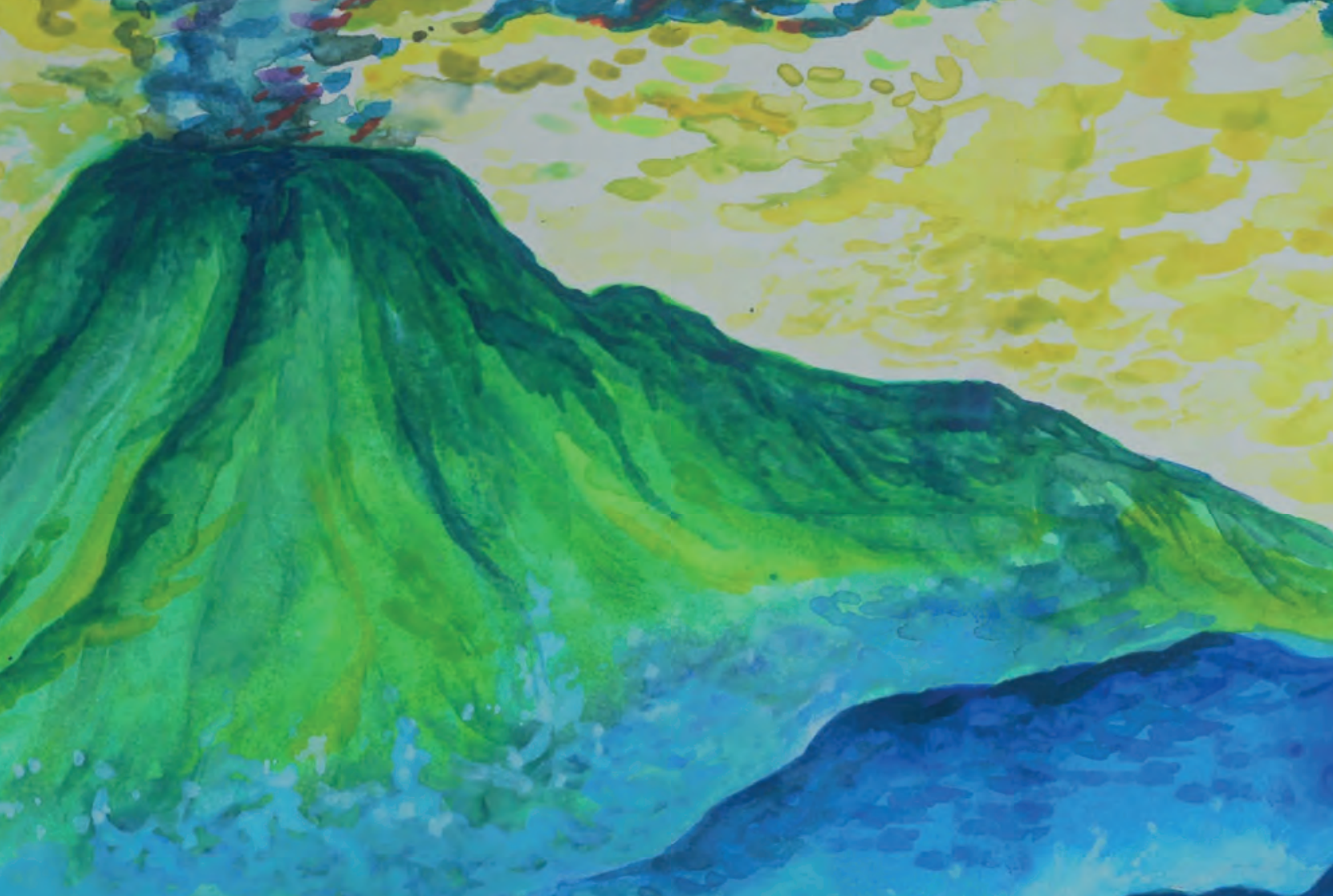

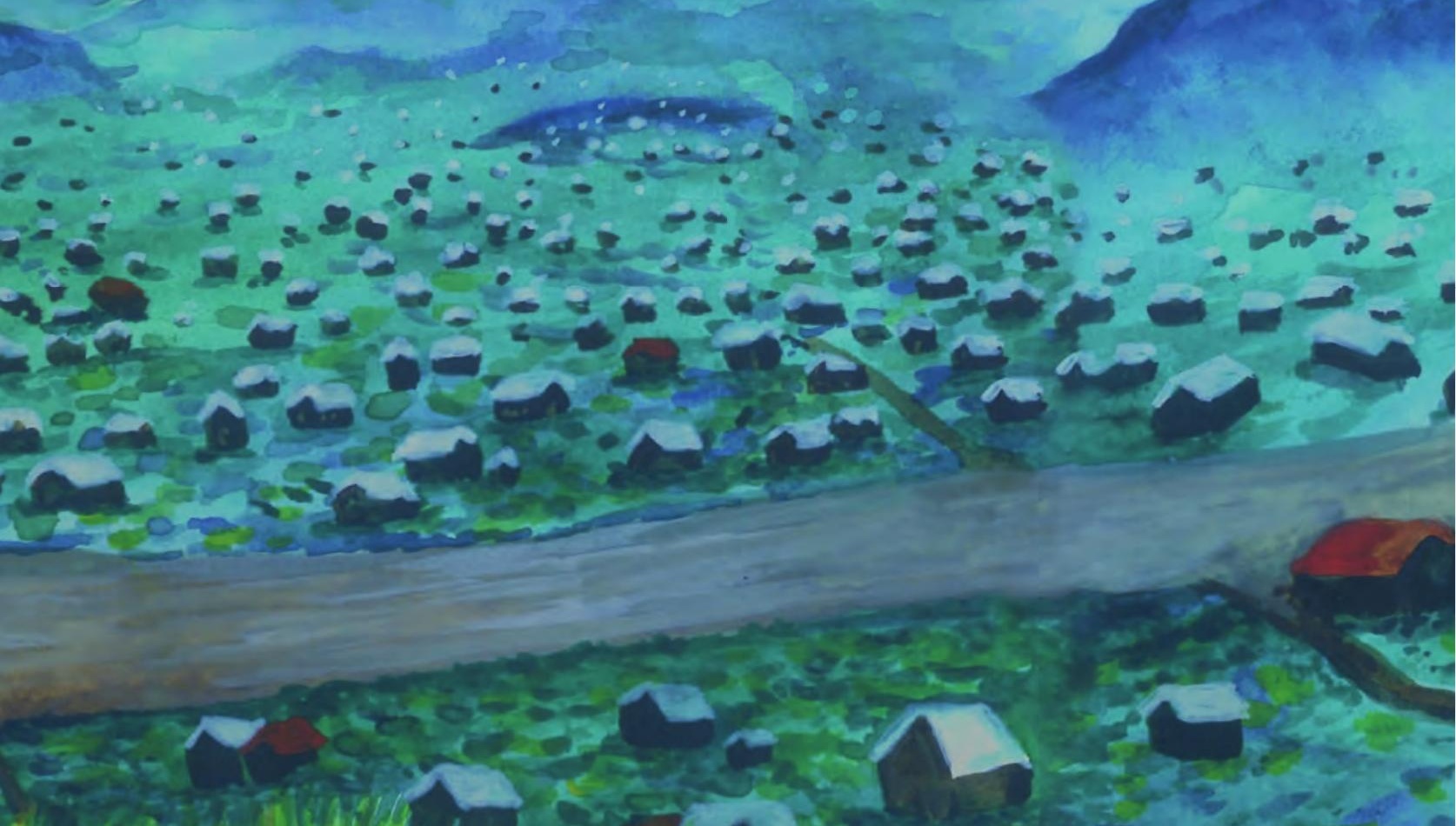

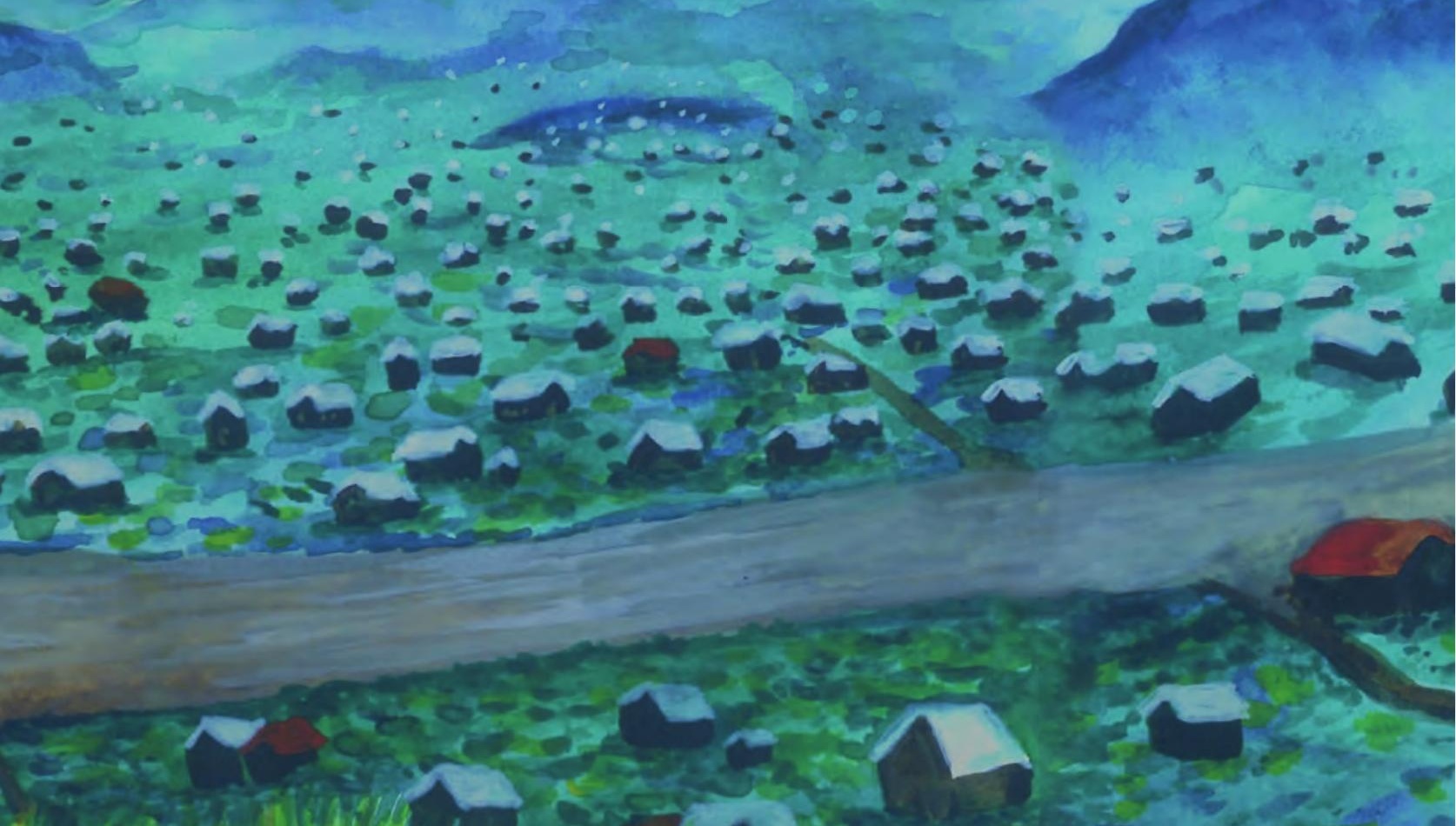

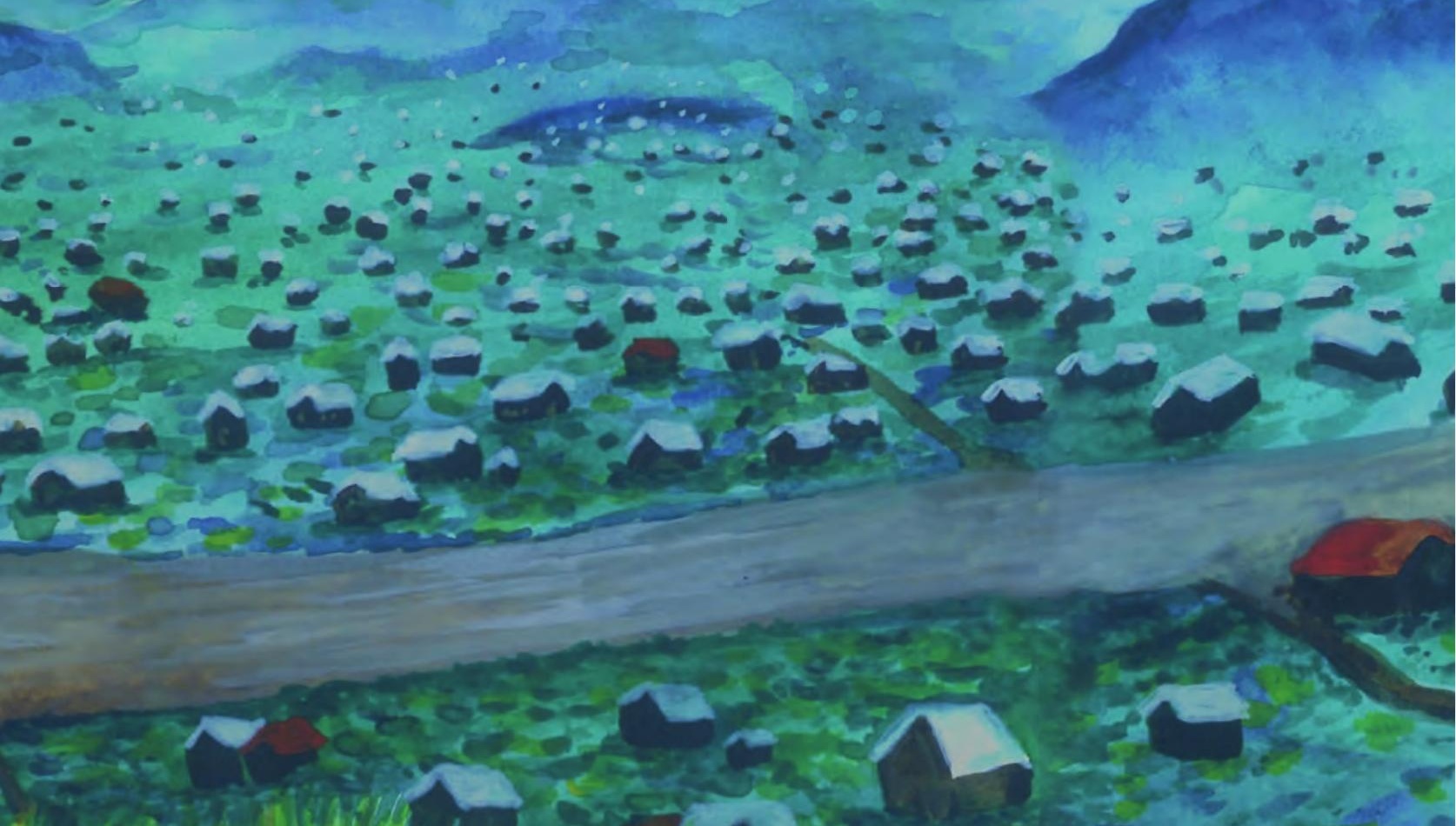

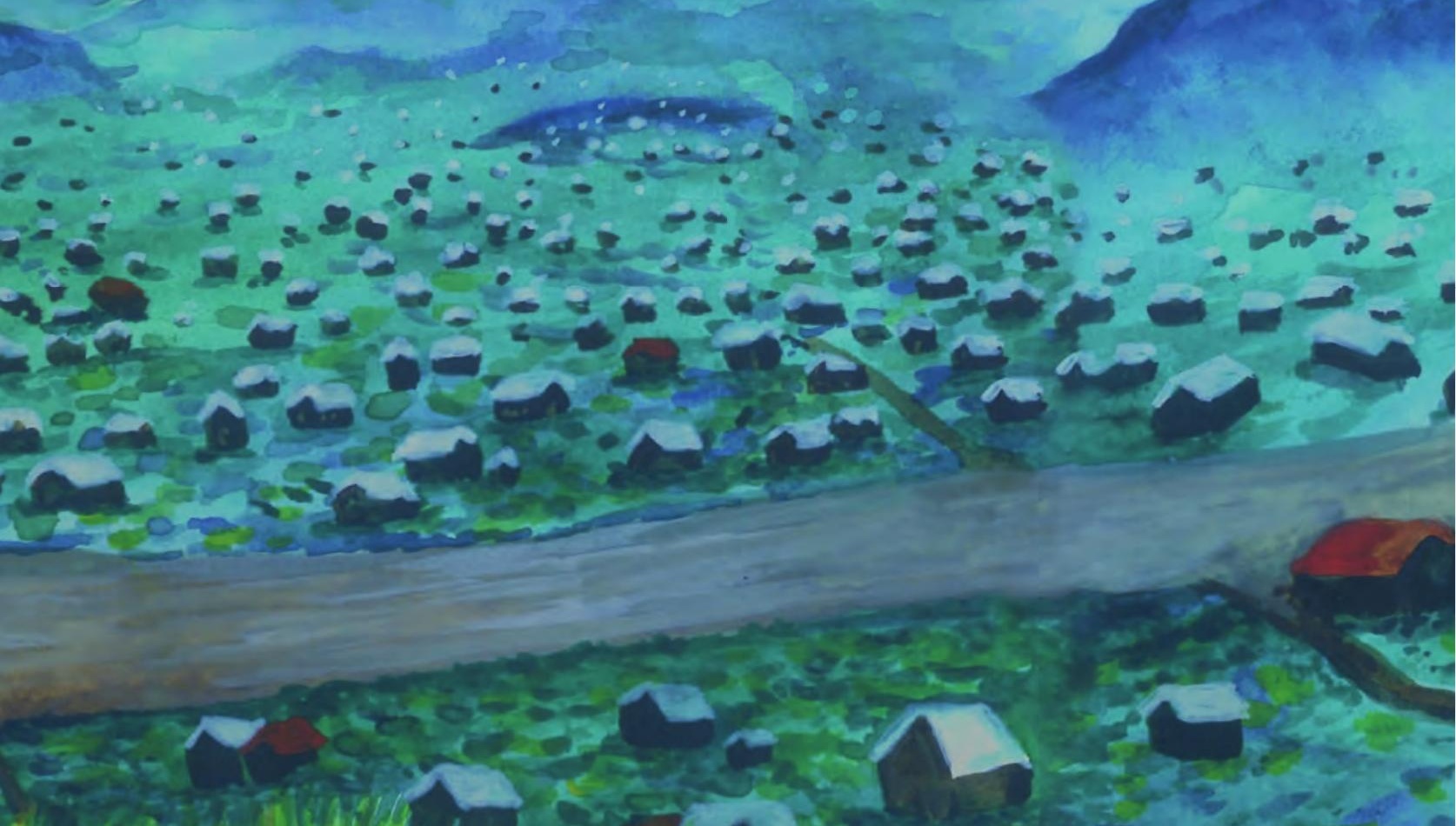

$-f$ ade ort 